\title{
The relevance of institutions and people's preferences for social protection
}

Citation for published version (APA):

Vinci, V. (2018). The relevance of institutions and people's preferences for social protection. [Doctoral Thesis, Maastricht University]. Boekenplan Maastricht. https://doi.org/10.26481/dis.20181122vv

Document status and date:

Published: 01/01/2018

DOI:

10.26481/dis.20181122vv

Document Version:

Publisher's PDF, also known as Version of record

\section{Please check the document version of this publication:}

- A submitted manuscript is the version of the article upon submission and before peer-review. There can be important differences between the submitted version and the official published version of record.

People interested in the research are advised to contact the author for the final version of the publication, or visit the DOI to the publisher's website.

- The final author version and the galley proof are versions of the publication after peer review.

- The final published version features the final layout of the paper including the volume, issue and page numbers.

Link to publication

\footnotetext{
General rights rights.

- You may freely distribute the URL identifying the publication in the public portal. please follow below link for the End User Agreement:

www.umlib.nl/taverne-license

Take down policy

If you believe that this document breaches copyright please contact us at:

repository@maastrichtuniversity.nl

providing details and we will investigate your claim.
}

Copyright and moral rights for the publications made accessible in the public portal are retained by the authors and/or other copyright owners and it is a condition of accessing publications that users recognise and abide by the legal requirements associated with these

- Users may download and print one copy of any publication from the public portal for the purpose of private study or research.

- You may not further distribute the material or use it for any profit-making activity or commercial gain

If the publication is distributed under the terms of Article $25 \mathrm{fa}$ of the Dutch Copyright Act, indicated by the "Taverne" license above, 


\section{The Relevance of Institutions}

and People's Preferences for

Social Protection

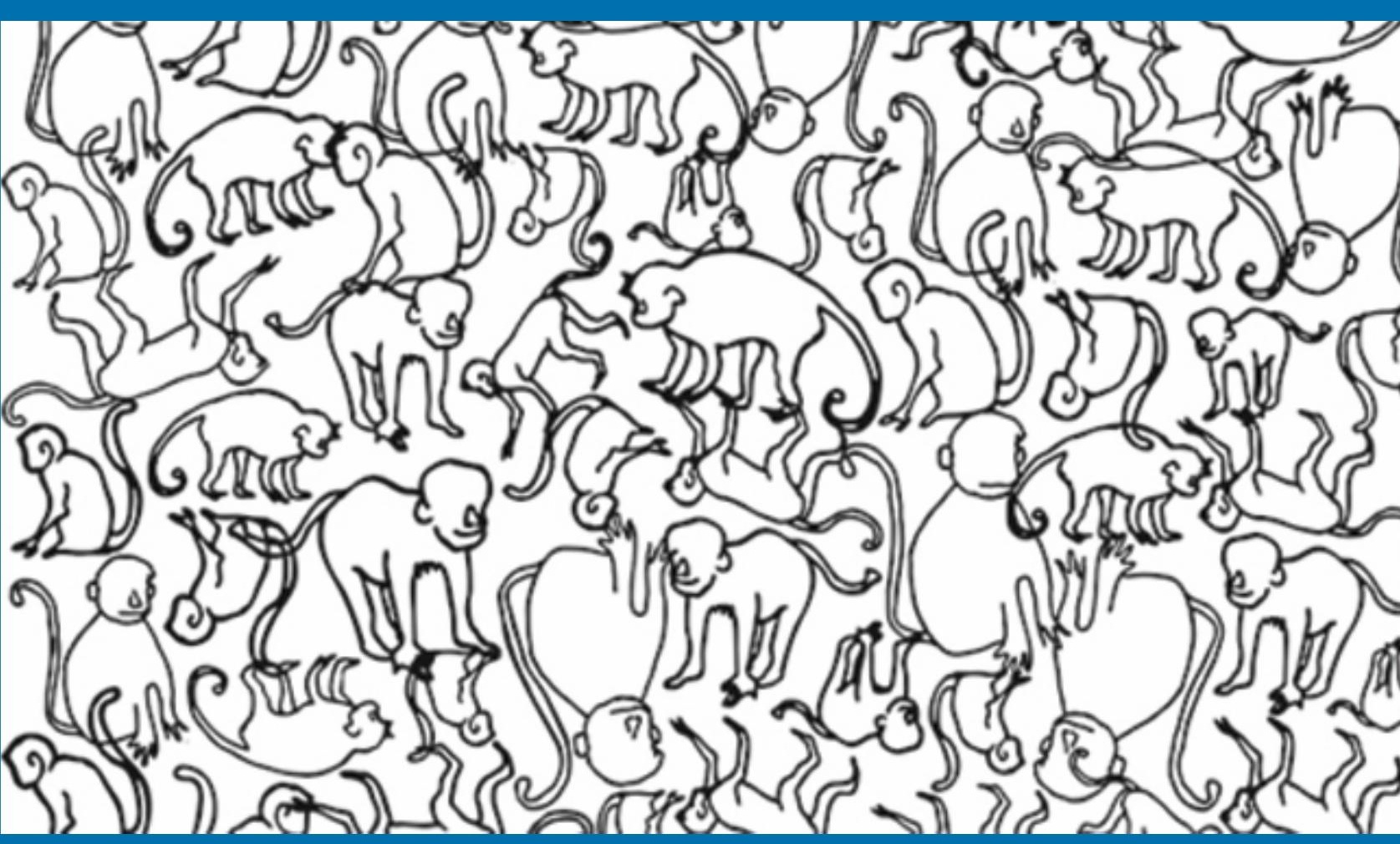

Vincenzo Vinci 

The Relevance of Institutions and People's Preferences for Social Protection 
(C) 2018 Vincenzo Vinci

\section{ISBN 9789086664610}

Cover illustration: Monkey Temple pattern @ 2018 Sarah Edmands Martin. All rights reserved.

Publisher: Boekenplan, Maastricht

www.boekenplan.nl

All rights reserved. No part of this publication may be reproduced, stored in a retrieval system, or transmitted in any form, or by any means, electronic, mechanical, photocopying, recording or otherwise, without the prior permission in writing, from the author. 


\title{
The Relevance of Institutions and People's Preferences for Social Protection
}

\author{
DISSERTATION
}

\begin{abstract}
To obtain the degree of Doctor at Maastricht University, on the authority of the Rector Magnificus Prof. Dr. Rianne M. Letschert in accordance with the decision of the Board of Deans, to be defended in public on Thursday, 22 November 2018, at 16:00 hours
\end{abstract}

by

Vincenzo Vinci 


\section{Promoters}

Prof. Dr. Franziska Gassmann

Prof. Dr. Pierre Mohnen

\section{Assessment Committee}

Prof. Dr. Shyama Ramani (chair)

Dr. Stephen Devereux, University of the Western Cape

Prof. Dr. Chris de Neubourg, Tilburg University

Dr. Nyasha Tirivayi 
To my wife Roselyn 



\section{Acknowledgements}

I am sincerely grateful and obliged to Prof. Franziska Gassmann and Prof. Pierre Mohnen and for their continuous support, mentoring, wisdom, empathy, friendship which made the research, our meeting and calls a real pleasure. They always read and listened with interest and attention what I had to say and asked stimulating questions which pushed to broaden my perspective. Having them as my advisers was probably the best decision I made during the $\mathrm{PhD}$.

I thank Prof. Chris de Neubourg for introducing me to the GPAC programme and for supporting with my GPAC application with Prof. Sudhanshu Handa. I thank Benjamin Davis and Wei Ha for the encouragement provided once I took the decision to pursue the PhD. I would like to thank the rest of my thesis committee, for their detailed review and careful recommendations.

This journey has been exciting, rewarding and I have enjoyed every moment, but it could not have been walked without companions. My sincere thanks go to the many people who enabled me to complete this research. My appreciation goes out to Mindel van de Laar and to her helpful support provided over this period. I was happy to see her welcoming me in Maastricht and I was always confident to receive her timely support. I am also thankful to Prof. Adam Szirmai, Richard Bluhm, Nyasha Tirivayi for providing me support in the early days of my $\mathrm{PhD}$ research. My appreciation and gratitude to Prof. Michael Cichon for sharing his knowledge, his advice and his time. Thanks to Keetie Roelen, for sharing interest, for joining me in part of this research conducted in Ethiopia and for her professionalism and her friendship.

These last years, allowed me to meet wonderful people and make friends: thanks Shea, Fernanda, Hana, Felipe, Abel, Mira, Jennifer and Bruno. A special note to Michael Kazimierczak who is very dear to me and for the countless dinners and discussions in Maastricht. I would also like to thank the GPAC coordination team (Charlotte, Shivani, Saba, Carlos, Cristina, Lukas and Kitti) for their support during the GPAC seminars. I would like also to thank UNICEF for providing me with the necessary flexibility to pursue this $\mathrm{PhD}$.

Thanks to Italo and Rosario for their friendship. Italo, we have walked and continue to walk together and you are like a brother to me. Many others have deeply contributed to make this experience unforgettable and, although not mentioned, I will be forever grateful for the support and difference you have made.

I was lucky to be born in Sicily, in a small town from a truly amazing family. My parents, my sister Valentina, my uncle Pippo have been always there for me. They are a true example of integrity, hard work, honesty and kindness. I will always be grateful to them.

Finally, I wish to thank my wife Roselyn for the unfailing and unending support and encouragement while travelling for our work in many countries and for her patience over the last years. Thank you for coming into my life and for the blessing of our two little ones, Alexander and Milo. 


\section{Contents}

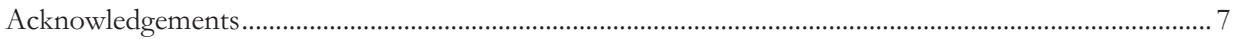

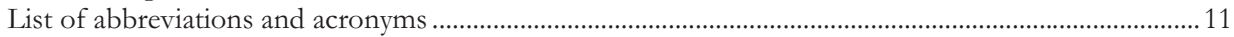

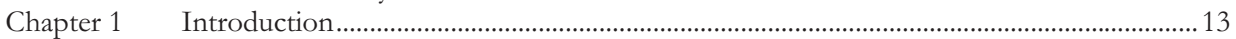

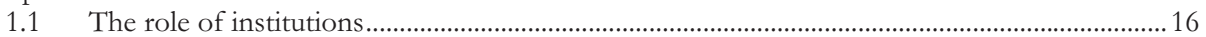

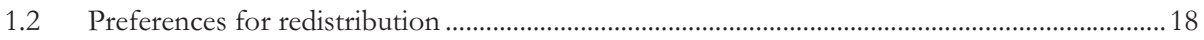

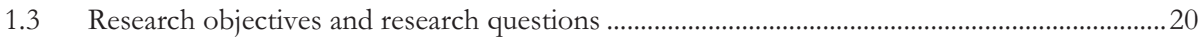

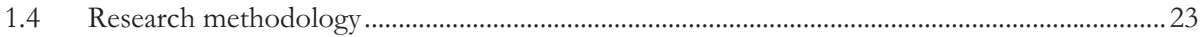

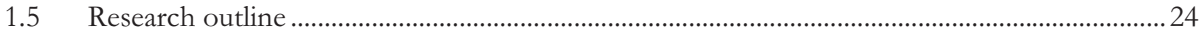

Chapter 2 Institutional factors and people's preferences and the extent of social protection:

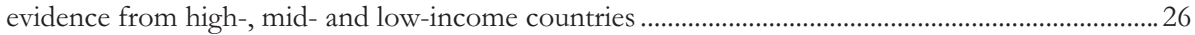

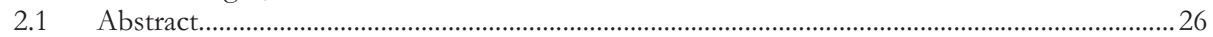

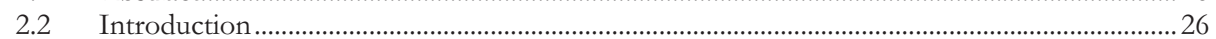

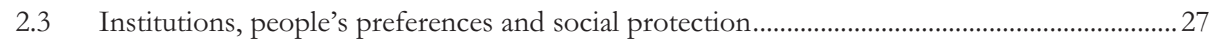

2.4 Social protection programmes: evidence and challenges...............................................................2.

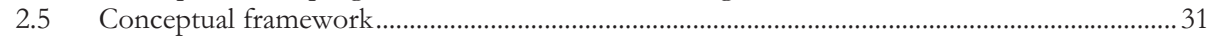

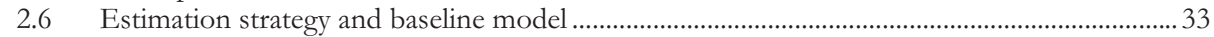

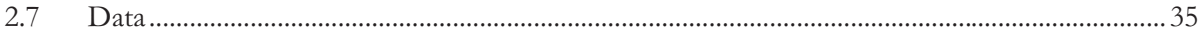

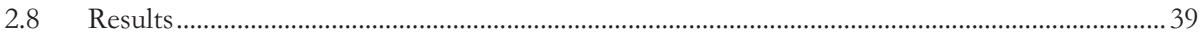

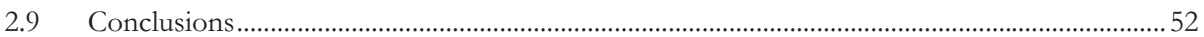

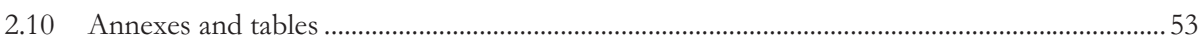

Chapter 3 Institutional Performance and People's Engagement in Social Protection in Nepal .....61

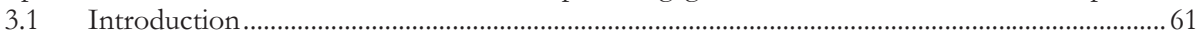

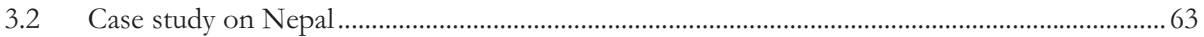

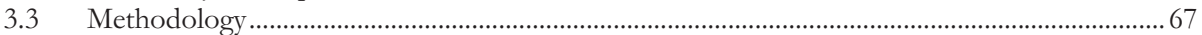

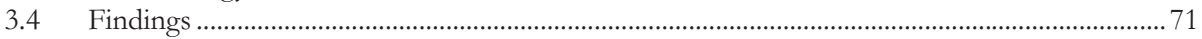

3.4.1 Quality of institutions........................................................................................................... 71

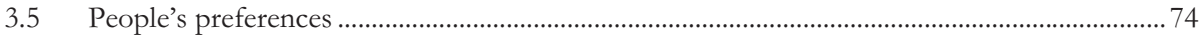

3.6 Implementation of development and social protection activities ................................................ 75

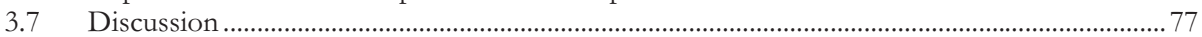

3.8 Quality of institutions and quality of provision of development and social protection activities

3.9 People's preferences and quality of provision of development and social protection activities

$10-60$

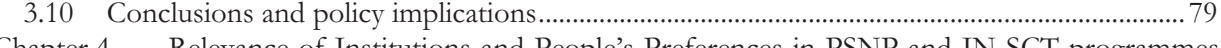

Chapter 4 Relevance of Institutions and People's Preferences in PSNP and IN-SCT programmes

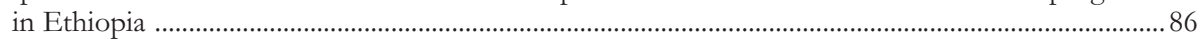

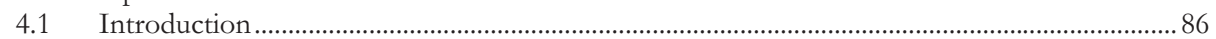

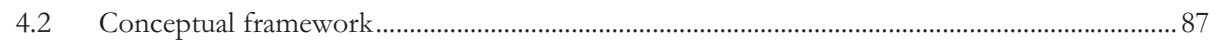

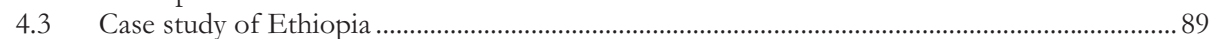

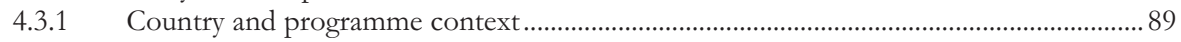

4.3.2 Operationalisation of conceptual framework ..................................................................... 91

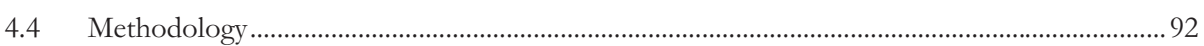

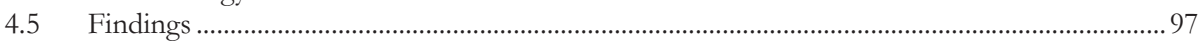

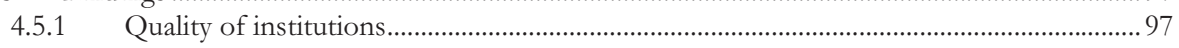

4.5.2 People's preferences ......................................................................................................100

4.5.3 Quality of implementation of social protection interventions ..........................................101

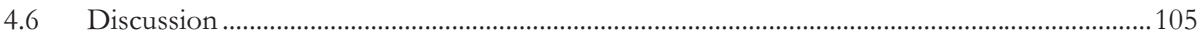

4.6.1 Quality of institutions and quality of implementation of social protection interventions. 
4.6.2 People's preferences and quality of implementation of social protection interventions.... 106

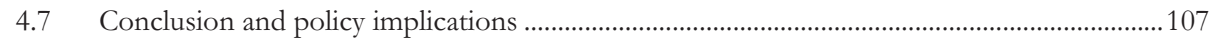

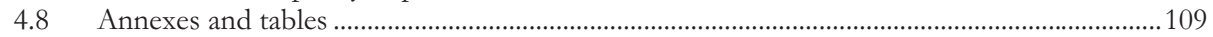

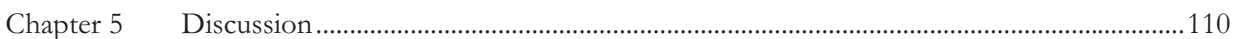

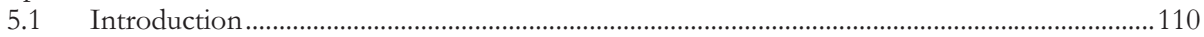

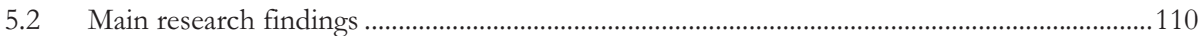

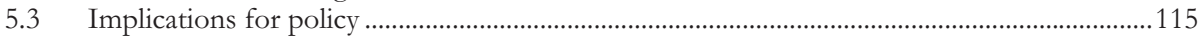

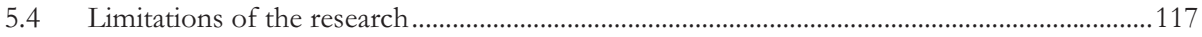

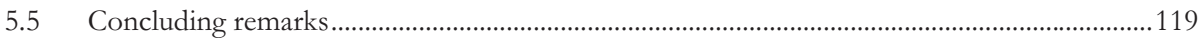

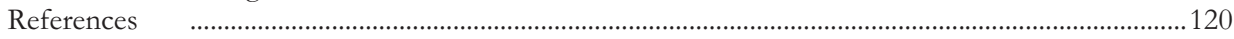

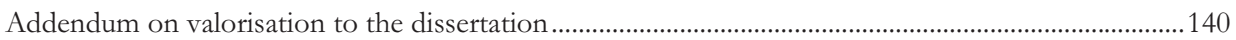

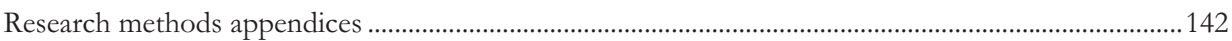

Appendix A.1 Study information sheet - Nepal .................................................................................142

Appendix A.2 Consent form for local officials - Nepal ....................................................................143

Appendix A.3 Interview guide for central level officials- Nepal........................................................144

Appendix A.4 Interview guide for local level officials - Nepal ......................................................149

Appendix A.5 Interview guide for civil society organisations - Nepal..............................................153

Appendix A.6 Consent form to be signed before the focus group discussions - Nepal................157

Appendix A.7 Interview guide for focus group discussions with community members - Nepal158

Appendix A.8 Timeframe of the interviews - Nepal ........................................................................163

Appendix B.1 Study information sheet - Ethiopia ……………......................................................... 164

Appendix B.2 Consent form for local officials - Ethiopia ................................................................165

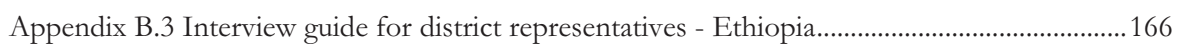

Appendix B.4 Interview guide for social workers - Ethiopia ............................................................. 168

Appendix B.5 Interview guide for development agents - Ethiopia ......................................................170

Appendix B.6 Interview guide for health extension workers - Ethiopia ...........................................172

Appendix B.7 Interview guide for focus group discussion with community care coalitions -

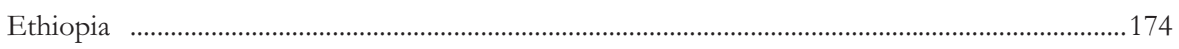

Appendix B.8 Interview guide for focus group discussions with permanent direct support clients -

Ethiopia

Appendix B.9 Interview guide for focus group discussions with temporary direct support clients -

Ethiopia 178

Appendix B.10 Interview guide for focus group discussions with PSNP Public Works clients -

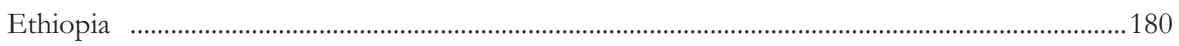

Appendix B.11 Consent form to be signed before focus group discussions - Ethiopia................182

Appendix B.12 Debriefing form for participation in the research study - Ethiopia........................183

Appendix B.13 Timeframe of the interviews - Ethiopia ......................................................................184

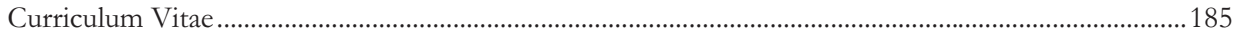




\section{List of Tables}

Table 2.1 Institutions, people's preferences and social protection (SP) expenditure ............................. 41

Table 2.2 Quality of institutions, people's preferences and SP expenditure: categorical analysis........... 42

Table 2.3 Different compositions of SP expenditure and quality of institutions ..................................... 44

Table 2.4 Different compositions of SP expenditure and quality of institutions (LICs and MICs).......45

Table 2.5 Different measures of SP expenditure (including health expenditure) ....................................46

Table 2.6 Different compositions of SP expenditure: controls for colonial and legal origins ................48

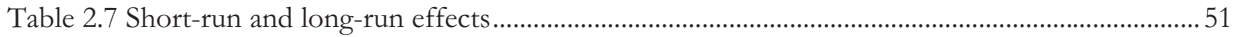

Table 3.1 Development, governance and poverty estimates in South Asia ...........................................64

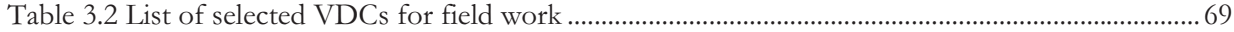

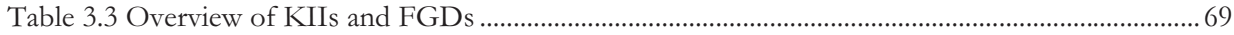

Table 3.4 Allocation of Block Grant at VDC level ................................................................................... 70

Table 3.5 Overview of quotes regarding Block Grant management and community structures.............72

Table 3.6 Overview of quotes regarding people's preferences .................................................................74

Table 3.7 Overview of activities and quotes on quality of provision of development and social protection

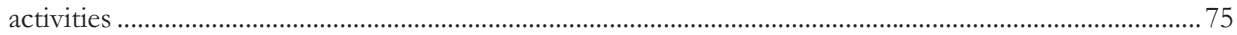

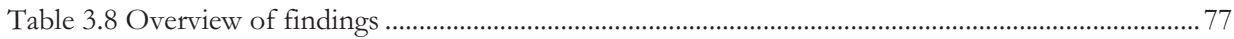

Table 4.1 List of selected kebeles for field work.................................................................................... 93

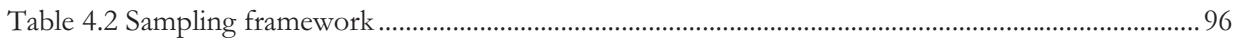

Table 4.3 Overview of quotes regarding service providers and community structures .........................97

Table 4.4 Overview of quotes regarding clients' preferences .................................................................. 100

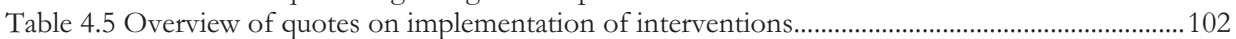

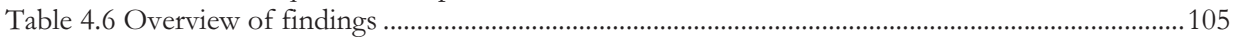

\section{List of Figures}

Figure 2.1 Conceptual framework ....................................................................................................... 32

Figure 2.2 Allocation of expenditure to SP (different compositions) by geographic regions, 2011.......36

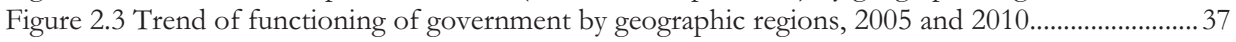

Figure 3.1 Social protection expenditure in South Asia countries, as \% of GDP...................................65

Figure 4.1 Administrative map of the selected woredas ............................................................................ 93

\section{List of Annexes}

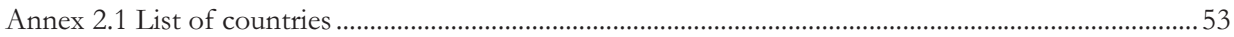

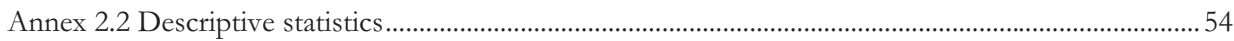

Annex 2.3 Correlation - 80 countries - 2011 dependent variable and 2009 control variables ...............56

Annex 2.4 Correlation - 52 countries - 2011 dependent variable and 2009 control variables ...............57

Annex 2.5 Correlation - 80 countries - 2011-2007 panel data ...................................................................5 58

Annex 2.6 Correlation - 52 countries - 2011-2007 panel data ................................................................59

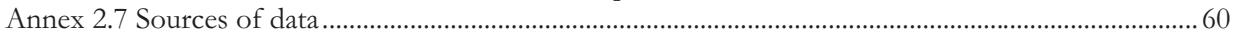

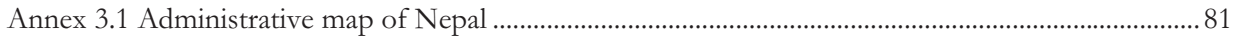

Annex 3.2 Summary of selected social protection measures in Nepal................................................. 82

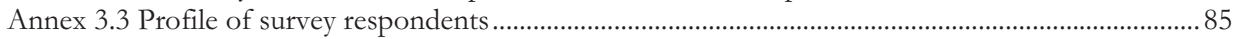

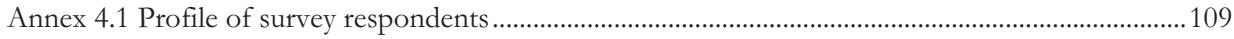




\section{List of abbreviations and acronyms}

\begin{tabular}{|c|c|}
\hline $\mathrm{AN}$ & Arsi Negele (Woreda) \\
\hline AT & Adami Tulu (Woreda) \\
\hline BCC & Behaviour change communication \\
\hline CACs & Citizen Awareness Centres \\
\hline $\mathrm{CBO}$ & Community Based Organisations \\
\hline CCC & Community Care Coalition \\
\hline CFSTF & Community Food Security Task Force \\
\hline DA & Development Agent \\
\hline DDC & District Development Committee \\
\hline DS & Direct Support \\
\hline ESAP & Ethiopia Social Accountability Programme \\
\hline FGD & Focus Group Discussion \\
\hline FPW & Female Public Work clients \\
\hline HEW & Health Extension Worker \\
\hline ILO & International Labour Organization \\
\hline IN-SCT & Improved Nutrition through Integrated Basic Social Services and Social Cash Transfer \\
\hline $\mathrm{KAC}$ & Kebele Appeals Committees \\
\hline $\mathrm{KC}$ & Kebele Chairman \\
\hline KFSTF & Kebele Food Security Task Force \\
\hline KII & Key Informant Interview \\
\hline KM & Kebele Manager \\
\hline LGCDP & Local Governance and Community Development Programme \\
\hline MCPM & Minimum Conditions Performance Measure \\
\hline $\mathrm{MoF}$ & Ministry of Finance \\
\hline MoFALD & Ministry of Federal Affairs and Local Development \\
\hline $\mathrm{MoHP}$ & Ministry of Health and Population \\
\hline MoIC & Ministry of Industry and Commerce \\
\hline MoLE & Ministry of Labour and Employment \\
\hline MoPR & Ministry of Peace and Reconstruction \\
\hline MoWCSW & Ministry of Women, Children and Social Welfare \\
\hline MPW & Male Public Work clients \\
\hline NPC & National Planning Commission \\
\hline OAA & Old Age Allowance \\
\hline
\end{tabular}




$\begin{array}{ll}\text { PDS } & \text { Permanent Direct Support } \\ \text { PLW } & \text { Pregnant and lactating women } \\ \text { PSNP } & \text { Productive Safety Net Programme } \\ \text { PW } & \text { Public Work } \\ \text { SW } & \text { Social Worker } \\ \text { TDS } & \text { Temporary Direct Support } \\ \text { UNDP } & \text { United Nations Development Programme } \\ \text { UNICEF } & \text { United Nations Children's Fund } \\ \text { VDC } & \text { Village Development Committees } \\ \text { WCFs } & \text { Ward Citizens' Forums } \\ \text { WGI } & \text { World Governance Indicators }\end{array}$




\section{Chapter 1 Introduction}

Compared to the beginning of the twentieth century, when a limited number of countries - mostly located in Europe - were starting to build social protection systems, today the majority of the countries in the world have social protection programmes covered by law (ILO, 2017), and have significantly increased and expanded their social protection systems over time (World Bank, 2018). Social protection policies are key elements of national development strategies to fight poverty, foster productivity and human capital, promote social justice, address vulnerability and prevent individuals from risks throughout the life cycle (García \& Gruat, 2003). Developed countries have acknowledged the importance of these programmes. In Europe and Central Asia, 84.1 per cent of the region's population have access to at least one cash social protection benefit (such as child and family benefits, maternity cash benefits, disability benefits and old-age benefits) with several countries reaching universal coverage (ILO, 2017). According to the World Bank, in 2018 the number of social protection programmes in Sub-Saharan Africa has doubled to 79 compared to 40 in 2015 (World Bank, 2018).

While progress has been made to increase the scope and improve the design of social protection programmes, the allocation of resources remains inadequate in developing countries. Most poor people in low- and middle-income countries are still not covered by any social protection programmes (World Bank, 2015b). Moreover, existing programmes are often ineffective, delivering poor outcomes due to inefficiencies in programme design and implementation (Bastagli et al., 2016).

The concept of social protection does not have a unique definition and has been traditionally associated with a range of public institutions, rules, and interventions aimed at protecting and preventing individuals and their households from poverty, vulnerability and deprivation (Barrientos, Hulme, \& Shepherd, 2005). Through income or in-kind support and programmes designed to increase access to services (such as health, education and nutrition), social protection supports the realization of the human right of individuals to social security as established in the article 22 of the Universal Declaration of Human Rights signed in 1948. Cichon et al. (2004, p. 11) define Social Protection as “... a set of measures that society employs to give its members some form of income security; these measures necessarily have a profound impact on income distribution in the country".

The various definitions agree that social protection should be considered as an investment (Morel, Palier, \& Palme, 2012; World Bank, 2011a) and that social protection programmes contribute to alleviate poverty, address vulnerabilities and inequities and are key to achieving pro-poor growth, economic development and an inclusive and just society (Barrientos \& Hulme, 2005, 2010; Ferrera, Hemerijck, \& Rhodes, 2001; Ocampo \& Stiglitz, 2018; OECD, 2009; Sabates-Wheeler \& Devereux, 2007; SDD, 2015; Weber, 2006).

One key difference in social protection programmes is between contributory and non-contributory schemes depending on how these interventions are financed. Contributory social protection programmes protect workers in the formal sector and are financed, at least in large part, through earnings-related 
contributions from employers and employees. Non-contributory social protection interventions are primarily aimed at protecting the poor and the most vulnerable groups and are mainly financed from general revenues and, in the case of some developing countries, from development aid.

Evidence on the effectiveness of social protection programmes in preventing risks, addressing vulnerability and poverty in high-, middle- and low-income countries abounds. In Europe, social protection programmes have helped reduce inequality until the first half of the 1980s and these programmes are still key in addressing poverty (Atkinson, 2013). Many examples of the positive impact of these programmes are from developing countries. Flagship programmes like Prospera (previously branded Oportunidades and then Progresa) and Seguro Popular in Mexico or Bolsa Familia in Brazil have contributed to reducing people's vulnerability. Prospera, one of the most studied social protection programmes in the world, has shown its positive impact of the programme on school enrolment rates, on child nutrition and education levels (Behrman \& Hoddinott, 2005; Handa, Huerta, Perez, \& Straffon, 2000). The public health insurance scheme Seguro Popular has supported the provision of health care to those without insurance and has reduced health inequities (Parker, Saenz, \& Wong, 2018). Bolsa Familia has contributed to decreasing income inequality in the country by 16 percent during the period 1999 and 2009 (Soares, Ribas, \& Osario, 2010). In Colombia, the health insurance scheme has greatly increased medical care utilization among the country's poor and uninsured (Trujillo, Portillo, \& Vernon, 2005). It has been estimated that social protection programmes in Latin America have reduced income inequality by 15 to 30 percent between 2002 and 2012 (Cornia, 2014). Moreover, evidence from the child, old age and invalidity grant system in South Africa (DSD, SASSA, \& UNICEF, 2012); the health insurance scheme in Rwanda (Lu et al., 2012), the cash transfer in Zambia (Handa, Natali, Seidenfeld, Tenbo, \& Davis, 2016), the child grant in Nepal (HagenZanker, Mallett, \& Ghimire, 2015) and the Productive Safety Net Programme in Ethiopia (Berhane et al., 2012) have shown the positive effects of social protection programmes on poverty and human capital outcomes for the poorest households.

The international community has recently stepped up efforts to support the expansion of social protection programmes and address the underlying factors that delay their implementation. The Social Protection Floors Recommendation (No. 202) was adopted in 2012 by the International Labour Conference (ILO, 2012) and endorsed by the G20, not least as a response to the effects of the global financial and economic crisis to promote, protect and maintain a minimum access to essential services and income security (Barrientos \& Hulme, 2010; Ortiz, Chai, \& Cummins, 2011; Ortiz, Cummins, Capaldo, \& Karunanethy, 2015) and expand social protection systems for all people across the life cycle when they need it most (Ocampo \& Stiglitz, 2018). In 2016, the International Labour Organization and the World Bank launched the Universal Social Protection initiative which affirms social protection as a primary development priority. This initiative advocates for increasing the number of countries that provide social protection for all (universal social protection) (ILO \& World Bank, 2016) in support of the Sustainable Development 
Goals agenda for social protection to tackle and contribute to eradicating poverty in all its forms by 2030 (United Nations, 2015).

If developing countries want to achieve their development objectives and address poverty, vulnerability and exclusion, they need to allocate more of their budget to social protection programmes. But why are countries not doing so? Why for example, does only 29 percent of the global population enjoy access to comprehensive social security, whereas 71 do not (ILO, 2017)?

The existing literature mainly focuses on issues related to definition, programme design, and impact, and deal more with the effects social protection programmes have on people's life once they are implemented, rather than with the factors, which influence the emergence and expansion of these programmes. Some scholars have recognised that the different determinants of social protection programmes relate to the demographic, the economic, the financing, the legal framework, the design, the political environment, and the governance of countries. In addition, they note that the main actors influencing social protection programmes are voters, politicians and bureaucrats (Alesina \& Tabellini, 2004; Avramov, 2003; Bastagli et al., 2016; Cichon et al., 2004; Snyder \& Yackovlev, 2000; Wilensky, 1975).

The International Labour Organization (2013) argues that changes in countries' demographic structure in the context of declining mortality and fertility and increased longevity requires adjustments in the establishment and in the type of social protection policies and programmes. Other scholars have also studied the influence of the international economy such as globalisation in influencing welfare systems (Cameron, 1978; Garrett, 1998; Rodrik, 1997; Scharpf, 2000). However, the conclusions are highly disputed (Huber \& Stephens, 2005). The bulk of the existing literature focuses on countries' financial resource availability as the main influencing factor for the shape and size of social protection programmes (Barrientos, 2007, 2013; Cichon, Hagemejer, \& Woodall, 2006; Haggard \& Kaufman, 2008). Financial affordability is a recurring issue in developing countries. These countries are often characterised by high poverty rates and financial constraints and are therefore concerned about the fiscal and political pressure these programmes might generate once they are established. Yet, several studies confirm the affordability of social protection programmes for developing countries and propose measures to identify fiscal space to accommodate such programmes (Behrendt, Cichon, Hagemejer, Léger, \& Pal, 2005; ILO, 2008; Ortiz, Cummins, \& Karunanethy, 2015b; Seekings, 2017).

Other studies investigate how different factors influence the implementation, the type and the outcomes of social protection programmes. Roelen at al. (2017), in a review of three cash transfers programmes in Africa, stress the importance of the establishment of legal frameworks and policies which can affect the delivery of social protection programmes. Bastagli et al. (2016), in a comprehensive review of programme impact of cash transfers in developing countries based on 201 studies, argue that the design and the implementation of social protection programmes influence social protection outcomes (Bastagli et al., 2016). Roelen et al. (2017), in a review of some of the main cash transfers programmes implemented in 
Latin America (the Chile Solidario in Chile) and Africa (the Improved Nutrition through Integrated Basic Social Services and Social Cash Transfer (IN-SCT) pilot programme in Ethiopia and the Livelihood Empowerment Against Poverty (LEAP) in Ghana), show how policy, programme and supply-side level factors are key in the overall implementation of social protection interventions.

With regards to the political environment, Hickey (2007) offers a conceptualisation of the politics of social protection with a particular focus on developing countries. The framework proposed by Hickey indicates among others the important role institutions, socioeconomic and global factors play in influencing the size, the type, the design and the implementation of social protection. Furthermore, Hickey (2011), in a study conducted in Botswana and South Africa, explores the role of politics in influencing the eligibility of social protection and analyses how the political ideology in a country (liberal vs. progressive) could result in either more targeted or universal social protection programmes. Kaltenborn et al. (2017), taking Ghana as case study, argue that policy and legal frameworks affect social protection systems affirming that while national policies can institutionalise social protection, legal framework can formalise the right to social protection and reduce extreme poverty (Kaltenborn, 2017).

Other authors have examined how the political environment influence redistribution policies based on research conducted in Latin America (Graham, 2002), in Southeast Asia (Haggard \& Birdsall, 2002; Haggard \& Kaufman, 2004), in India (de Waal, 2000) and in sub-Saharan Africa (de Waal, 1996, 1997; Hickey, 2009). The main findings from this stream of research recognise two main points. First, political attitudes affect not only the choice but also the design, allocation and the future directions of policies on social protection programmes. Second, the authors suggest to further investigate the role that the institutional environment might play in influencing social protection programmes. Ensuring adequate institutional capacity is essential for the realization of the right to social security (ISSA, 2013) and it can support and influence the implementation of social protection programmes. Human resources are part of overall organisational effectiveness and institutional performance, and are crucial to provide the necessary set of skills for the design, coordination among different levels of administration, management for the implementation of social policies and to ensure delivery of services to people (Kaufmann, Kraay, \& Mastruzzi, 2010).

It is acknowledged that the determinants mentioned so far play a role in affecting the establishment, type and implementation of social protection programmes. This research choses to focus particularly on two factors which have not been sufficiently studied and which are introduced in the following two sections: institutions and people's preferences for redistribution.

\subsection{The role of institutions}

Institutions and economic development are closely linked and influence the allocation of resources (Bluhm \& Szirmai, 2012). The term "institutions" can sometime be a "weasel-word” (Machlup, 1958). North (1990) refers to the term "institutions" as the rules of the game in society making reference to the set of formal legal frameworks such as the laws established in a country and the capacity of the government 
to enforce them. Acemoglu, Johnson and Robinson $(2002 ; 2001 ; 2005)$ allow for a wider perspective in the definition of institutions taking into account the fact the political interests determine the particular set of economic institutions which are eventually responsible to affect the allocation of resources. Easterly (2001) argues that, to contribute to the economic development, institutions should promote investments that respect the rights of the individuals. Again Easterly (2013) argues that good quality institutions should be able to deliver effective public services. In this thesis, the terms "quality of institutions" or "performance of institutions" are used to identify institutions' functioning and effectiveness (Rueschemeyer \& Evans, 1985).

The term "institutions" is sometimes used interchangeably with the term "organisations" (Abah, 2012) and scholars have viewed the organisations, their structures and procedures, as institutions which are responsible to exercise the governance over economic activities (Williamson, 1975, 1985). Institutions and organisations provide public services and support social protection programmes, influencing the design, the implementation and the management of these interventions (Coll-Black, Monchuk, \& Standford, 2018) both at central and decentralized level. It is also important to highlight that the level of decentralisation of a country may affect how institutions exercise their governance. For example, Faguet (2014) describes how decentralization processes may affect governance, responsiveness in the provision of public services and may improve public accountability. Furthermore, anti-poverty programmes depend on the performance of the different levels of institutions and administrations and on their personnel, which are responsible to deliver payments or in-kind benefits to selected beneficiaries.

A recent evaluation conducted in Ethiopia on the Improved Nutrition through Integrated Basic Social Services and Social Cash Transfer (IN-SCT), implemented by UNICEF under the umbrella of the PSNP 4 , hints to the importance of the capacity of local administration, service providers and people's involvement in community structures as key in the implementation of social protection interventions (Roelen, Devereux, Kebede, \& Ulrichs, 2017). The effective role local institutions and community structures play in contributing to a good governance and in improving social accountability is key in the a context of decentralisation and in the delivery of social services (Grindle, 2004; Jütting et al., 2005).

Institutions are also important as they serve to collect information on community members and social protection clients' needs for example by convening meetings through community structures where discussion on development issues and social protection programmes are discussed. Community structures established within the local administrations such the Community Care Coalition (CCC) and the Kebele Appeal Committee (KAC) ${ }^{1}$ in Ethiopia or the Ward Citizens Forum (WCF) in Nepal, are instrumental in

${ }^{1}$ The KAC was introduced into the PSNP in 2007 to address targeting appeals and other complaints. This system is different from that of targeting. Membership is supposed to consist of: an elected Kebele Council member; a Development Agent; one or two members of the Community Care Coalition (if existing in the kebele); a Health Extension Worker or Volunteer Community Health Worker; a Social Worker (if represented in the kebele); two elder representatives (of which one female). 
gathering data on community members and social protection clients' needs and supporting the targeting process and the type of social protection interventions implemented.

Moreover, institutions are responsible for articulating the planning and budgeting process through which, after taking into account people's needs and political considerations, resources are allocated to social protection (Caiden \& Wildavsky, 1974; Norton \& Elson, 2002). Institutions and their functioning is also key where the government needs to ensure a certain level of efficiency to collect taxes which may be used to support social protection interventions (Tanzi \& Zee, 2001). Therefore, constraints in institutional capacity such as fiscal, legal and human resources capacity, may generally result in challenges to implement welfare and deliver social protection programmes (Acemoglu \& Robinson, 2012; Besley \& Persson, 2013; Niño-Zarazúa, Barrientos, Hulme, \& Hickey, 2010).

Research has focused on the importance of the causal relationship between the quality of institutions and social protection. Delavallade (2006) examines the role of corruption, a proxy for the quality of institutions, showing how corruption can reduce expenditure in social protection. In a recent working paper, Murshed et al. (2017) finds positive relationship between institutions' fiscal capacity and social sector spending. However, these studies do not provide evidence on specific social protection programmes and different country contexts which may be useful in providing programmatic recommendations.

\subsection{Preferences for redistribution}

The other factor which could contribute to explaining the existence and variations of social protection programmes is related to people's preferences: how citizens and social protection clients express their demands for social protection systems, whether through voting mechanisms or through their direct involvement and engagement in community structures and interaction with local administrators and politicians.

Some of the existing research suggests that policy makers respond to changes in people's preferences over time (Jacobs, 1993; Stimson, Mackuen, \& Erikson, 1995; Wlezien, 1996). Alesina and La Ferrara (2005) argue that voting preferences and public perceptions can affect choices for the redistribution of resources. According to this view, reflecting people's preferences is politically more sustainable as they reflect people's values and beliefs about income redistribution (Alesina \& Angeletos, 2005). If poverty is considered to be the result of bad luck rather than as a lack of individual effort, this may increase government's support for redistribution and social spending (Alesina \& Angeletos, 2005; Fong, 2001). Therefore, the perception and attitude towards the poor are important factors in determining the redistribution of resources and the existence or changes of social protection programmes (van de Walle, 1998).

Brooks and Manza (2007) examine the extent to which mass policy preferences across countries around the world influence welfare policies through elections. The authors conclude that preferences are embedded in country's social structures, institutions and social factors such as religion, class, education and are linked 
to the social relations and contexts in which individuals are situated. Furthermore, governments tend to be responsive to general preferences about social policies programmes but also to specific policies, such as pension and employment programmes. Alesina and Giuliano (2009), using empirical evidence for the US, support the importance of historical experiences, cultural factors and personal history as determinants for preferences for redistribution while other studies found that the role of occupation status (Guillaud, 2013; Rehm, 2009) or the income of individuals (Dion \& Birchfield, 2010) affect their preferences.

A recent study shows how the preferences of most European populations for redistribution influence the delivery of welfare programmes (Reeskens \& van Oorschot, 2013). Ferry and Kaminska (2012) study how EU citizens support different types of welfare states. They stress the important role the governments should play in monitoring institutional developments and in using policy instruments to influence people's preferences. Recent studies conducted in Europe have also shown that preferences for redistribution can be affected by crises which may push the demand for social policies (Olivera, 2014), or by a deservingness culture supporting redistribution policies which are addressed to the needy groups (elderly people, sick and disabled people, unemployed people, etc.) (van Oorschot, 2006). Another study conducted in the UK reveals how the British public appears to notice and respond to changes in public spending and how British policymakers represent these preferences in spending (Soroka \& Wlezien, 2005).

Carbone (2011), in a study conducted in Ghana, explores how the democratisation process influences the country's health policy hinting to the fact that the demand expressed by citizens is important while studying the determinants of social policies. Hickey (Hickey, 2011) highlights the importance governments and citizens play in the bargaining of "social contracts", therefore confirming the importance of citizens in influencing social protection programmes through their demand and preferences expressed to the governments. Conway et al. (2001) state that "policy development should start from the needs, realities and priorities of the groups intended to benefit from social protection" (Conway et al., 2001, p. 65). The same authors reflect on the fact that while citizens and social protection clients have a significant role in the debate of social protection, the existing literature on social protection generally analyses their role in relation to the delivery of social protection rather than in relation to their capacity of influencing allocation of social protection programmes.

Therefore, people's preferences may lead to the establishment or the expansion of social protection programmes as governments could allocate funds to support these interventions. It is important to mention that preferences for redistribution are also channelled through citizens' involvement in community structures where development and social protection interventions are discussed. Therefore, people's engagement during the different phases of implementation of social protection interventions may influence the design (Donder \& Hindriks, 1998) and the implementation of social services and social protection programmes and the likelihood to achieve social protection outcomes (Bastagli et al., 2016; Grindle, 2004). 
It is likely that the different determinants of social protection so far mentioned are crucial to influence these programmes. While both the quality of institutions and people's preferences appear to be important in shaping social protection programmes, they have not been sufficiently studied in the context of social protection. However, if we leave quality of institutions and people's preferences aside for the debate and discussion of the determinants of social protection programmes, we will definitely miss out important aspects crucial for affecting both the allocation, design and the quality of implementation of social protection programmes. We would also discard important dimensions which contribute to the overall sustainability of social protection programmes.

What is currently lacking is an analysis on how these two factors are practically playing a role in countries and how they affect allocation, type and implementation of social protection programmes. What is not clear and is currently missing is to have concrete examples from the field that can relate and be used to explore these factors and contribute to the existing literature and the overall debate on the determinants of social protection.

\subsection{Research objectives and research questions}

The objective of this research is to examine how institutions and people's preferences affect social protection programmes. The research analyses to what extent institutions influence the level of expenditure in social protection. In addition, the two case studies explore the linkages between quality of institutions and people's preferences and the quality of implementation and type of social protection interventions.

The main research question is to what extent and how institutional factors and people's preferences affect the level of expenditure and the implementation and the type of social protection programmes in developing countries. This main question is further split into three sub-questions: (i) to assess the extent to which institutional factors and people's preferences for redistribution affect the level of expenditure in social protection in developing countries; (ii) to understand how institutional factors and people's preferences affect the type of social protection interventions and; (iii) to investigate how the quality of implementation of social protection interventions is the result of institutional factors and people's preferences.

Chapter 2 refers to the term institutions as the "rules of the game" defined by North (1990). These are rules which exist in a society, such as law and order, control of corruption, property rights, or the way in which public services are delivered. Because, the quality of institutions consists of many factors, it is preferred to use publicly data available which are as much as possible objectively assembled (Rabobank, 2016). In particular, the definition is operationalised in the chapter by using selected indicators which are proxies for good quality of institutions (Lehne, Mo, \& Plekhanov, 2014) and good government (La Porta, Lopez-de-Silanes, Shleifer, \& Vishny, 1998) such as the functioning of the government, government effectiveness, rule of law and property rights, used in the existing literature (Acemoglu et al., 2001) and part of the World Bank Worldwide Governance Indicators (WGI) (World Bank, 2011b) or part of the Quality of Governance Dataset (QOG) (Stefan, Holmberg, Rothstein, \& Hartmann, 2013). 
In Chapter 3 and Chapter 4 the term "institutions" is operationalised in light of the two case studies to assess the quality of local administrations such as the Village Development Committees (VDCs) in Nepal and the kebeles in Ethiopia where the social protection programmes (Block Grant in Nepal and PSNP and IN-SCT in Ethiopia) are delivered. In the case of Nepal, the performance of the VDC is measured by (i) VDC's clarity on how the Block Grant is allocated and managed and (ii) by the establishment and the level of functioning of community structures such as the citizen awareness centres and ward citizen forums. In the case of Ethiopia, the performance of the kebele is proxied by (i) the clarity of roles and responsibilities and efficiency of collaboration between main service providers in the kebeles, including social workers, development agents, health extension workers and kebele managers, and (ii) the establishment and the degree of functioning and regularity of meetings of community care coalitions and kebele appeal committees.

The definition of social protection expenditure applied in this research includes administrative costs and is the sum of all existing public social protection programmes (mainly formal social protection programmes) including health care expenditure. The scope of the indicator corresponds to the scope of the Social Security (Minimum Standards) Convention, 1952 (No.102) which established nine classes of benefits or social protection areas (branches): 1) medical care, 2) sickness benefit, 3) unemployment benefit, 4) old-age benefit, 5) employment injury benefit, 6) family benefit, 7) maternity benefit, 8) invalidity benefit and 9) survivors' benefit, plus other income support and assistance programmes, including conditional cash transfers, available to the poor and not included under the above classes (ILO, 2014). Data used to measure the level of expenditure in social protection across countries is borrowed from ILO and contains information for a vast number of countries. However, the dataset presents some limitations for this analysis as data on expenditures include all forms of social protection programmes, while data limited to social assistance interventions would have been preferred as these kinds of interventions are mainly implemented in low- and middle-income countries.

The first sub-question is answered though the use of regression analyses with a focus on 80 low- middleand high-income countries and aim at assessing the extent variables which proxy the quality of institutions and people's preferences may affect the level of expenditure of social protection programmes. The main explanatory variables are the quality of the institutions, proxied by different measures of institutions, and people's preferences which measure citizens' demand for redistribution and social protection programmes. Data on quality of institutions are from the Quality of Government Basic Dataset (QOG) (Stefan et al., 2013) which compiles country level data from individual researchers, from international organisations like the World Bank and the International Monetary Fund. People's preferences are instead measured using The World Values Surveys (WVS) as main source of data.

To answer the remaining research sub-questions, the dependent variable is measured by the quality of implementation and the type of selected social protection interventions through case studies implemented in Nepal and Ethiopia where the granularity of the respective country contexts and specific social protection programmes are considered. In the case of Nepal, the research investigates the type of social protection 
interventions implemented in the Village Development Committee (VDC) through the utilization of the Block Grants. The Block Grant are funds allocated to the VDC to support capital and social protection interventions and transferred by the central level via the district level of the administration. In the case of Ethiopia, the research adopts as dependent variable the quality of implementation of the Improved Nutrition through Integrated Basic Social Services and Social Cash Transfer (IN-SCT) vs. the Productive Safety Net Programme interventions implemented at the kebele (village) level. The Productive Safety Net Programme is one of the largest social protection programme implemented in Africa covering 8.5 percent of the country population. The explanatory variables used in the case studies consider measures for the quality of institutions related to the effective management and functioning of the local administration, such as Village Development Committees and kebeles, and the establishment and regular functioning of community structures and grievance mechanisms, such as Ward Citizens' Forums, Citizens Awareness Centres, Community Care Coalitions and Kebele Appeals Committees.

To measure people's preferences, the case studies focus on the capacity community members and social protection clients have to engage with community structures to influence the type of social protection activities. Both case studies offer an opportunity to explore how the establishment, variation of the performance and functioning of institutions, and people's preferences may affect the choice, the quality and the implementation of social protection programmes.

Based on the literature reviewed, the main hypothesis is formulated as follow:

The quality of institutions, expressed by stronger coordination among service providers and better performing community structures, and people's preferences reflected by how community members and social protection clients are able to express their needs and engage with community structures, influence the level of expenditure, the design and the quality of implementation of social protection programmes.

With the formulation of this hypothesis, this thesis seeks to help fill the existing knowledge gap in the literature and, by providing a conceptual framework for the analysis which focuses mainly on the role of institutors and people's preferences, using both quantitative and qualitative methods to provide evidence, which may help to disentangle how these factors could affect allocation, type and implementation of social protection programmes. The conceptual framework introduced in Chapter 2, summarizes the arguments so far presented, acknowledging the importance of countries' initial conditions (such as economic, demographic, legal, historical and geographical factors), but introduces and focuses particularly on the quality of institutions and on people's preferences as influencing factors for the investment in social protection programmes.

It is important, of course, to point out some disadvantages in the use of the data and some complexities while conducting the analysis. Studying the quality of institutions and people's preferences as factors influencing social protection programmes present some challenges. First, we know that quality of institutions, people's preferences and social protection programmes could influence each other and therefore this presents an element of complexity while undertaking the analysis. Second, the quality of 
institutions and people's preferences are path dependent and change very slowly over time (Acemoglu \& Robinson, 2012). Third, it is important to acknowledge that the analysis conducted in Chapter 2 is limited to formal institutions while it is acknowledged that informal institutions might play a role in developing countries (Bender, 2013). This could be a reason why existing studies on the determinants of social protection have focused on factors such as affordability where governments may have better control and where it is easier to make a case for governments to invest more in social protection programmes. Moreover, it is important to notice that the generalisation of the findings is limited in relation to the case studies because of the limited scope of the fieldwork and the country specificities.

In terms of the academic relevance, three main contributions are envisioned. The first one is that this thesis contributes to informing the conceptualisation provided by Hickey (2007) by suggesting a more explicit link to the quality of institutions and people's preference in the analysis of the politics of social protection. The second, is that this thesis expands on the work conducted by both Delavallade (2006) and Murshed et al. (2017), by considering in the analysis a measure for people's preferences jointly with the already used proxies for quality of institutions. Third, this thesis has practical implications and provides concrete examples, based on the case studies conducted in Nepal and Ethiopia, that can shed light on how local institutions and people's preferences are influencing the delivery of social protection programmes. From the analysis of the findings presented in the different chapters some patterns emerge that provide key insights on areas where the attention of development practitioners and policy makers should be oriented to continue promoting social protection interventions as part of the country development strategies to address poverty, income inequality and promote inclusive growth. In particular, attention is given to community structures and to the efficient administration and collaboration among service providers in delivering social protection interventions.

Therefore, findings from this research enrich the understanding of the determinants of social protection and provide additional elements to be taken into account in future research and analysis as they are crucial for the government to create the right foundations for the establishment and delivery of social protection contributing to the achievement of the first Sustainable Development Goal ("End poverty in all its forms everywhere").

\subsection{Research methodology}

In order to address the research questions, this thesis uses a mix of quantitative and qualitative methods. The quantitative approach is used in Chapter 2 to analyse whether and to what extent the level of social protection expenditure varies with institutional quality and people's preferences. Regression analysis is used to estimate the effects of the main independent variables, controlling for economic, demographic, legal, historical and geographical factors using cross-country panel data including high-, middle- and low-income countries. To implement the analysis, a comprehensive international dataset containing data on social protection expenditures is used and complemented with data on quality of governance and people's perception of the government's involvement in the provision of public services. 
Chapters 3 and 4 are qualitative in nature and investigate the dynamics at play at local level and explore how the quality of institutions and people's preferences may influence the quality of implementation of social protection programmes. Two case studies are conducted in Nepal and Ethiopia to allow for nuances, sequences and multiple perspectives of phenomena that are not clearly delineated and for an in depth analysis on the quality of institutions, people's preferences and provision of social protection programmes (Stake, 1995; Yin, 2014).

Two methods were used for primary data collection for the two case studies: (i) key informant interviews with local authorities, programme staff and service providers and (ii) focus group discussions with community members and social protection clients. A total of 16 key informant interviews and 22 focus group discussion were conducted in Nepal for a total of 200 participants. In Ethiopia, fieldwork included 17 key informant interviews and 20 focus group discussions covering 184 community members and social protection clients.

The approach followed in setting up the two case studies presents some similarities but also some points of divergence. Both case studies analyse the functioning of local institutions and the extent to which people express their need and engage with community structures. The main difference between the two case studies is that the one implemented in Nepal focuses more on changes in the type of social protection interventions while the case study implemented in Ethiopia explore the changes in the quality of implementation of social protection programmes.

It should be noted that the two case studies do not aim to be nationally or regionally representative but rather present an in-depth investigation into the interaction between the quality of institutions, people's preferences and the quality of implementation of social protection programmes. Therefore, findings and conclusions should be considered in light of the local contexts. The specific research methods and data are described in detail in the specific chapters.

\subsection{Research outline}

The research is articulated around three stand-alone papers which are presented in Chapter 2, 3 and 4. These chapters are all contributing to answer the overall research question and sub-questions as presented in Section 1.1 and therefore contain a certain degree of overlap in the literature review and in addressing the conceptual framework. Each chapter opens with an introduction which describes its specific contribution to the research questions and introduces the hypotheses. Furthermore, each chapter describes the methodology and data used and, after the presentation of the findings, concludes with general and specific remarks and policy implications in light of the specific country contexts.

Chapter 2 sets the scene and provides an understanding on the main issues building on the theoretical and empirical literature on the establishment and implementation of social protection programmes. The chapter examines the main factors which may explain why some countries are not investing enough in social protection systems and presents what can impede the achievement of social protection objectives. Finally, the chapter focuses on measures of quality of institutions and people's preferences to assess the extent to 
which these factors can affect the level of expenditure in social protection in high-, middle- and low-income countries.

Chapter 3 and Chapter 4 allow the study to shift the focus from the quantitative cross-country analysis to the national level by focusing on case studies on selected national social protection programmes in Nepal and Ethiopia. The case study implemented in Nepal assesses the variation in institutional quality and people's preferences considering high- and low-performing Village Development Committees (VDC) (recently named Gaunpalika - "village body" or "rural municipality"). In particular, the case study explores linkages between: (i) functioning of institutions, such as the efficient allocation and management of the Block Grant and the establishment and effective functioning of community structures as proxies for quality of institutions establishment; (ii) people's preferences, measured by the extent to which community members and social protection clients are able to express their preferences on the type of development and social protection activities and the dependent variable measured by the type of development and social protection activities implemented at Village Development Committee (VDC) level.

The case study implemented in Ethiopia investigates the variation of the quality of institutions and people's preferences based on slightly different social protection programmes' designs: the Productive Safety Net Programme (PSNP) and the Improved Nutrition through Integrated Basic Social Services and Social Cash Transfer (IN-SCT) pilot programme. The latter is assumed to have a better quality of institutions. The case study uses a similar approach compared to the previous case study, this time focusing more on the quality of implementation of social protection programmes. In particular, the case study explores linkages between: (i) quality of institutions, such as the collaboration of service providers and the establishment and functioning of community structures; (ii) people's preferences, measured by the extent to which social protection clients are able to voice out their preferences on social protection interventions and; (iii) the quality of implementation of PSNP and IN-SCT measured, among others, by the correct and effective implementation of transition of eligible clients from public work activities to temporary direct support and by the level of effective implementation of co-responsibilities ("soft" conditionalities).

Chapter $\mathbf{5}$ is a discussion chapter where research findings from the previous chapters are presented around statements. This allows the identification of promising practices and key points which can shed light on possible avenues to increase the shape and size of social protection programmes in developing countries. Moreover, the chapter elaborates on policy directions and new research questions and ends by providing concluding remarks. 


\section{Chapter 2 Institutional factors and people's preferences and the extent of social protection: evidence from high-, mid- and low- income countries}

\subsection{Abstract}

Social protection (SP) policies and institutions play multiple roles in the achievement of inclusive development. Over the last decade a paradigm shift took place whereby SP is no longer seen just as a cost for an economy, but instead as a social investment. Still, governments of low- and middle-income countries are reluctant to invest in nationally-owned SP systems. Developing countries redistribute only a small share of GDP to households in extreme or persistent poverty. This chapter analyses whether and to what extent the level of SP expenditure varies with institutional quality and people's preferences using cross-country panel data.

\subsection{Introduction}

Although developing countries have shown significant progress in investing in social protection, and the global recognition of the role these programmes play in fostering inclusive development has increased, most of the poor in low- and middle-income countries are not covered by any social protection programme (World Bank, 2015b). Given the existing evidence, ${ }^{2}$ which tends to confirm the positive effects of social protection programs on the reduction of poverty and inequality, the accumulation of human and physical capital and the local and regional spillover effects (SDD, 2015; World Bank, 2011a), to name just a few, the remaining gaps raise the question why countries are not increasing their investments in social protection in order to implement at scale social protection programs that effectively protect the poor and other vulnerable groups against shocks. The existing literature converges on mainly two reasons: the availability of financial resources and political commitment. There is a significant amount of research which focuses on the affordability and financing of social protection programmes in developing countries (Barrientos, 2013; Behrendt, Cichon, Hagemejer, Léger and Pal, 2005). In addition, it is also recognised that the level of social protection expenditure in a country depends, among other factors, its demography, its governance and the economic and political environment (Cichon et al., 2004; Wilensky, 1975).

This chapter, extending on the work conducted by Delavallade (Delavallade, 2006), provides new evidence on the role that institutions play in altering the budget allocation of social protection programmes across countries. In addition, inspired by the existing literature on how people's preferences influence government choices towards redistribution policies (Alesina \& La Ferrara, 2005; Duman, 2013), the chapter empirically tests the linkages between people's request to governments to provide for more services and its effect on the levels of expenditure in social protection.

\footnotetext{
2 Although social protection programmes can tackle the structural aspects of exclusion in various ways (Devereux \& Sabates-Wheeler, 2004), more research is needed to understand the strengths and limitations of social protection in tackling social exclusion and promoting inclusion (Babajanian, 2012).
} 
The hypothesis advanced is that well-functioning, freely elected and accountable governments tend to be more perceptive and responsive to their citizens' preferences on redistribution programmes. In addition, a well-performing government can better support the planning and budgeting process that determines the allocation of financial resources to social protection taking into account political and economic considerations. The findings presented in this chapter indicate that the functioning of institutions and people's preferences influence the level of social protection expenditure. The results are significant across different measures of social protection and quality of institutions. In addition, indicators for the maturity of social protection systems and the level of government revenues are positive and highly significant. This is in line with the existing literature, which affirms a degree of path dependency of social protection expenditure over time and the importance of examining tax policies in conjunction with the design of social protection programmes.

The chapter starts by presenting the main definitions used in this analysis and refers to the existing literature introducing a simple conceptual framework. Section 3 describes the specification strategy and the econometric methods and Section 4 the data. Section 5 is dedicated to present the empirical results. Then, Section 6 concludes and identifies policy implications.

\subsection{Institutions, people's preferences and social protection}

The existing literature does not converge to one single definition of the concept of social protection. The ultimate objective of social protection is to alleviate poverty and provide income security minimizing social risk (Barrientos \& Hulme, 2010; Barrientos et al., 2005; Conway, de Haan, \& Norton, 2000; Holzmann, Sherburne-Benz, Tesliuc, \& Unit, 2003) and addressing the causes of poverty and not simply its symptoms (World Bank, 2001). Traditionally, social protection is associated with a range of public institutions, rules, and interventions aimed at protecting and preventing individuals and their households from poverty and deprivation (Barrientos et al., 2005). In addition, social protection interventions have a profound impact on income distribution (Cichon et al., 2004) and through the provision of income, allow households smooth consumption and respond to vulnerabilities and contingencies (Kochar, 1999; Morduch, 1995). By providing income or in-kind support, social protection programmes facilitate access to services (such as health, education and nutrition among others), thereby contributing to the realization of the human right of individuals (UNICEF, 2011) to social protection as established in Article 22 of the Universal Declaration of Human Rights signed in 1948. In this context, the concept of social protection has considerably widened from a notion related to policies that attempt to target the poor to a more universal approach based on the concept of human rights (Samson, 2013).

In this chapter, the term social protection programmes indicates one or a combination of the following policy instruments that are typically provided by public institutions or mandated to private entities or nongovernmental organisations. The first one is social insurance such as pensions, health, or social transfers to individuals or households who are vulnerable to specific risks, for example unemployment, disabling injury or sickness. This policy instrument is mainly financed by compulsory contributions (or also defined 
as "contributory"), which are normally shared between employers and workers. The second instrument is social assistance (often called safety net), which consists of a minimum income guarantee, a cash or in-kind transfer, for example to remove financial and income related barriers to access social services or promote income generating activities (Dupper, 2013; Piachaud, 2013). This policy instrument is mainly but not only tax-financed ("non-contributory") and is typically designed to relieve poverty and targets a specific category of the population, for example income transfers to the elderly or to children.

The term "institutions" can be interpreted in many ways and is sometimes used interchangeably with the term "organisations" (Abah, 2012). This chapter refers to "institutions" as the rules of the game in society as defined by North (North, 1990), making reference to the set of formal legal frameworks such as the laws established in a country and the capacity of the government to enforce their respect. The term "performance of institutions" is used in this chapter to identify the quality of institutions, such as their functioning ${ }^{3}$ or effectiveness (Rueschemeyer \& Evans, 1985) and their interactions with the government in carrying out its activities to achieve a set of goals (McNamara, 1999).

People's preferences can affect and drive the support for income redistribution in the society. Individuals tend to support redistribution programmes either because their situation is better off after the implementation of the programme or because a redistribution programme conforms with their vision of what constitutes a good policy for society as a whole (Corneo \& Grüner, 2002) or matches their values and beliefs (Fong, 2001). In this chapter, people's preferences are defined as the degree of involvement that people would like the government to play in providing public services.

\subsection{Social protection programmes: evidence and challenges}

Over the last decade the important role that investments in social protection programmes have played to support economic development has been recognised (Morel et al., 2012). In 2015, most countries had social protection systems established by law, albeit in many cases only for a minority of their population (ILO, 2014). According to the World Bank (2015:1), “... every country of the world has at least one social safety net programme in place." Governments that decide to implement social protection programmes are called to make choices with respect to the mix and scope of programmes based on the country-specific contexts (World Bank, 2015b). Social protection programmes are implemented with different objectives and across different country typologies. In high-income countries, social protection programmes have contributed to reduce risks, poverty and income inequality redistributing resource largely to everybody (Atkinson, 2013). For example, they serve to guarantee access to health services, safe working conditions, provide income security measures and support people in the face of vulnerabilities and contingencies. In low- and middle-income countries social protection programme are key because of the large number of poor and vulnerable people which is exposed to covariate shocks be it socio-economic, political, or climaterelated shocks (Dercon, 2002; Shepherd et al., 2013).

\footnotetext{
${ }^{3}$ A critical and systematic discussion and review of concepts, evidence and measures of State Capacity can be found in (Cingolani, 2013).
} 
The question that has been asked most frequently in recent years is whether and to what extent social protection programmes are effective. The evidence generated in numerous studies across different countries shows the positive impact of these programmes in improving poverty indicators, schooling, and health thereby raising overall human capital in the future (Baez \& Camacho, 2011; DSD et al., 2012; The Kenya CT-OVC Evaluation Team, 2012), reducing inequality, improving social cohesion and effectively redistributing wealth among households (Debowicz \& Golan, 2014; Handa et al., 2000) and different categories of the population (Jutting \& Prizzon, 2013; OECD, 2009). In many countries, flagship programmes, like Prospera (previously branded Oportunidades) and Seguro Popular in Mexico, Bolsa Familia in Brazil, the subsidized health insurance scheme in Colombia, the child, old age and invalidity grant system in South Africa, the health insurance scheme in Rwanda (Shimeles, 2010) have shown the effects of social protection programmes on poverty and human capital outcomes. More recent studies measured the positive local and regional multiplier effects that each dollar transferred to a poor household can generate (K. Thome, Filipski, Kagin, Taylor, \& Davis, 2013; Karen Thome, Taylor, Mateusz, Davis, \& Handa, 2016), while others estimated the rates of return to investments in social protection (Mideros, Gassmann, \& Mohnen, 2015).

Following up on these positive experiences, many other developing countries have either initiated or expanded their investments in social protection. To accompany this process, the international community has recently stepped up to support the expansion of social protection programmes to address some underlying factors that delay their implementation. The Social Protection Floors Recommendation was adopted in 2012 by the International Labour Conference (ILO, 2012), not the least as a response to the effects of the global financial and economic crisis. The objective of the recommendation is to promote and strengthen national social protection systems and to protect a minimum access to essential services and income security for all people across the life cycle. Recently, the International Labour Organization (ILO) and the World Bank (ILO \& World Bank, 2016) have also called on world leaders to promote universal social protection, a step that further acknowledges and promotes the importance of these programmes.

In Africa alone, the number of cash transfer programmes has increased significantly over the last five years. In 2015, 40 out of 48 countries in the region had an unconditional cash transfer programme, which presents a doubling of the number in this short period. Conditional cash transfers have been introduced in 11 countries in Africa over the same period (World Bank, 2015b). Compared to the beginning of the 20th century, when a limited number of countries - mostly located in Europe - were starting to build social protection systems, today the majority of the countries in the world have social protection programmes covered by law. ${ }^{4}$ However, and mostly in developing countries, the benefits of these programmes do not necessarily reach the targeted population. Some countries in fact may have established the laws to regulate

\footnotetext{
${ }^{4}$ The terms "covered by law", "legal coverage" or "established by law" refer to the legal provision made by the Government to anchor one or a mix of social protection instruments to the national legislation. However, the fact that specific social protection interventions are covered by country laws does not necessarily mean that their benefits reach the targeted population immediately because that depends on the actual implementation of the interventions.
} 
the provision of social protection programmes but may delay their implementation due to lack of financial resources, complex procedures that deter participation or because of the weak institutional capacity to implement the delivery and administration of the interventions.

Although the benefits of having social protection programmes are evident and efforts to increase them in numbers and scope have been strengthened, the budgets allocated particularly to non-contributory social protection programmes are still relatively constrained especially in developing countries. The global average public investment in social protection was around 9\% of GDP in 2011,5 but ranged from about 4\% of GDP in sub-Saharan Africa to 27\% of GDP in Western Europe (ILO, 2014). Only an estimated 29\% of the global population enjoys access to comprehensive social protection, whereas $71 \%$ are covered partially or not at all (ILO, 2017).

The decision to establish or expand social protection programmes mainly depends on two elements: fiscal space ${ }^{6}$ and political will or government commitment to support social protection programmes (Barrientos \& Hulme, 2010). Despite the fact that social protection programmes constitute an "investment in people" (Cichon et al., 2006; World Bank, 2001, 2012), the identification of the resources to support their implementation represents a major challenge particularly for developing countries. governments in countries characterised by high poverty and financial constraints are concerned about the fiscal and political pressure these programmes might generate once they are established. Furthermore, the institutional capacity needed for the implementation and delivery of the interventions frequently poses an additional challenge (Barrientos, Hickey and Niño-Zarazúa, 2010).

Each government has to make its own choice and decide on the mix of domestic and external sources to support social protection programmes (ILO, 2001; Barrientos, 2007; Barrientos \& Hulme, 2010; Hall, 2010), for example, through macroeconomic policy, re-allocating public expenditures, increasing tax revenues, eliminating illicit financial flows, using fiscal and foreign exchange reserves, borrowing or restructuring existing debt, printing money or using international aid (Cichon et al., 2004; Durán-Valverde \& Pacheco, 2012; Heller, 2005; Ortiz, Cummins, \& Karunanethy, 2015b). Alternatively, in situations where the level of taxes is already prohibitive, a country could decide to increase tax revenues by improving the efficiency in tax collection or by fighting tax evasion (Ravallion, 2010; Warlters \& Auriol, 2005). Failure to improve institutions generally results in a failure to implement welfare improving policies (Jennings, 2013). However, improving efficiency may be a daunting task especially in developing countries. Establishing a functioning and efficient tax administration without a staff that has the appropriate skills, when money to pay good salaries to tax officers is scarce, (Evans \& Rauch, 1999; Tanzi \& Zee, 2001) or in presence of corruption (d'Agostino, Dunne, \& Pieroni, 2016) is not an easy task. While developing countries may struggle to find resources to support social protection programmes, rich or fast-growing countries are in

\footnotetext{
${ }^{5}$ The ILO (2014) estimate of global social protection expenditure includes expenditure for public health care, social protection for older persons, social protection for persons of active age and public social protection for children.

${ }^{6}$ Fiscal space defines "...the availability of budgetary room that allows a government to provide resources for a desired purpose without any prejudice to the sustainability of a government's financial position (Heller, 2005)".
} 
principle better equipped to find fiscal space to support social welfare and redistribution programmes. At the same time, unexpected events such as the 2008 economic crisis can limit the ability of governments to find or sustain the financial resources in support of social protection programmes and result in fiscal consolidation.

The second decisive element in the decision to allocate a budget to social protection is the political will, which can be defined as "the determination of an individual or a group of political actors to do and say things that will produce a desired outcome (Manor, 2004)." Even if fiscal space can be identified, without political commitment for reallocation within the executive, the available funds may be used for political or clientelist purposes (UNICEF \& ODI, 2009). Commitment can be stimulated and policy priorities guided by evidence identifying the benefits of the implementation of social protection programmes. Increasing the visibility of programmes, and engaging with non-state actors can embed social protection as a key part of policy, programming and resource allocation. Without political and civil consensus on how to implement rights to social protection, long-term commitments are difficult to obtain. Ethiopia and Nepal are examples of developing countries that have shown willingness to gradually increase - and not just replace - the scope of social protection interventions taking into account the available fiscal space. ${ }^{7}$

\subsection{Conceptual framework}

Although fiscal space and political will are key to explaining commitments to social protection, other factors may play a role as well. Institutional factors are expected to explain part of the variation in social protection spending. The functioning of institutions reflects, to a certain degree, the ability of governments to mobilize resources (Caiden \& Wildavsky, 1974). Better institutions are generally more efficient in tax collection, which is the main source of finance for social protection programmes. The functioning of institutions also exerts an influence through the planning and budgeting process (Wildavsky, 1992), which depends on the country context, fiscal conditions and political and economic considerations (Caiden \& Wildavsky, 1974; Thurmaier, 1995; Willoughby, 1993a). The planning and budget preparation in democracies consists of the following stages: i) assessment of overall resource availability and the adoption of aggregate expenditure and revenue targets; ii) disaggregation of aggregate targets into ministry ceilings; iii) preparation and distribution of budget guidelines and their distribution to spending ministries; iv) preparation of submissions by spending ministries and departments; v) review of submissions by the finance ministry; vi) preparation of draft estimates; vii) submission to and approval by parliament of draft estimates (World Bank, 1998). Although the steps appear to be sequential and distinct, in practice they can overlap. The main weaknesses in the budget preparation highlighted in the literature relate to the difficulties in making macro-economic projections, the lack of independence of the technocrats from the political control, the lack of accurate budget data and information on socio-economic trends (Diamond \& Potter, 1999). In a situation of well-functioning institutions, qualified personnel and sufficient capacity of ministries to carry

\footnotetext{
7 The Productive Safety Net Programme in Ethiopia was extended to selected urban areas in 2016/2017; the Old Age Allowance and the Child Grant in Nepal were both expanded in the fiscal year 2015-2016 and 2016-2017 respectively.
} 
out their own project management, the steps listed above can be executed more efficiently and effectively. Alesina and La Ferrara (2005) argued that the choice for more redistribution can be affected by voting preferences and public perceptions as to the extent of government involvement in the provision of public services. Public perceptions regarding whether the poor deserve social assistance or not also affect the support for social protection programmes. According to this view, government policies and interventions are politically more sustainable if they reflect the society's preferences. People's preferences may therefore explain the level of social protection expenditure and its allocation to programme beneficiaries (i.e. targeted or universal) because of the political consequences (Pritchett, 2005; Sen, 1995). Moene and Wallerstein (Moene \& Wallerstein, 2003) have argued that the degree of targeting of social protection programmes is determined prior to the political choice of the level of funding to be allocated. If the level of spending for social protection programmes is decided under a majority rule with voters who are self-interested and respond to targeting, a universal approach will result in a higher guaranteed income level for all. A shift towards a more targeted approach may compromise political support if the middle class does not benefit. The political economy models of targeting are based on the assumption that voters are self-interested. However, this may not be the case when people have a "prospect of upward mobility" (Bénabou \& Ok, 2001). The prevalence of self-interested voters is also contested in developing countries. Evidence from Zambia indicates that voters are altruistic and prefer targeted to universal approaches (Schüring \& Gassmann, 2012). The more a government is subject to fiscal constraints, which is the case in most developing countries, the more likely the decision about a specific social protection programme will depend on the political attitude concerning those who deserve support (Graham, 2002; Hickey, 2010).

This chapter argues that, in addition to a country's demographic, economic, legal, political and historical initial conditions, the quality of institutions plays a role in influencing the allocation of social protection expenditure via the planning and budgeting process. More efficient governments that are accountable to their citizens are better able to reflect and translate the preferences of their citizens into actual policies and related fiscal allocations. Figure 2.1 summarizes the arguments outlined above and also use elements provided by (Hickey, 2007) in its conceptualisation of the politics of social protection.

Figure 2.1 Conceptual framework

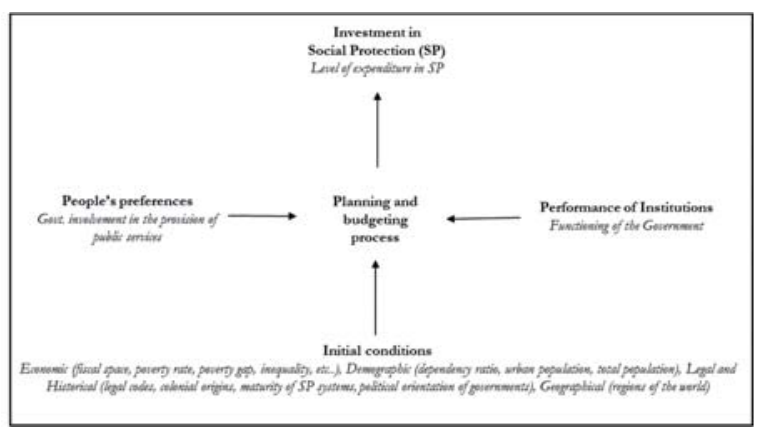


Changes in the public budget are not merely incremental (Wildavsky, 1964) but show a strong degree of path dependency compared to budget allocations in previous years. In particular, the social protection expenditure reflects people's preferences towards social policies and government's involvement in the provision of public services and income distribution through more or less well functioning institutions.

Finally, it is important to recognise that international actors such as donors and development partners may influence the design of social protection interventions especially in those low- and middle-income countries and fragile states where social protection programmes are mainly funded with donor funding (McCord, 2012). This chapter, without dismissing the importance of donors in the process of selection, design and allocation of social protection programmes, focuses on the assumption that social protection programmes respond to a domestic demand acknowledging that the argument donors versus government is only one aspect of the politics of social protection (Niño-Zarazúa et al., 2010).

\subsection{Estimation strategy and baseline model}

Regression analysis is used to estimate the effects of the main independent variables, controlling for different economic, demographic, legal, historical and geographical factors. The dependent variable and its different measures refer to the year 2011 while the independent and control variables have been lagged by two years for the following reasons. The budget outcome, that is the actual spending in a given year, depends on budgetary decisions made in the previous year, after completion of the planning and budget process. The latter is informed by social and economic indicators that may reflect the situation at the beginning of the budget process. Moreover, the room for budgetary reallocations is generally very limited and new financial resources may not be found quickly. Lagging the independent and control variables does also reduce simultaneity bias. In addition, while in almost all countries government budgets are prepared following an annual cycle, governments often take into account events outside the annual cycle (Wildavsky, 1986) because "[t]he time span of an annual budget is therefore too short for the purpose of adjusting expenditure priorities while uncertainties become too great over the longer term" (Allen \& Tommasi, 2001, p. 143). Therefore, the choice of lagging all explanatory variables with two years gives indicators time to produce their effect but also tries to limit interferences with former planning and budgeting processes.

The following reduced form equation (1) is estimated:

$$
S P_{i t}=\beta_{0}+\beta_{1} Q I_{i t-2}+\beta_{2} P P_{i t-2}+\boldsymbol{\gamma}^{\prime} \boldsymbol{E}_{i t-2}+\boldsymbol{\delta}^{\prime} \boldsymbol{D}_{i t-2}+\boldsymbol{\theta}^{\prime} \boldsymbol{L} \boldsymbol{H}_{i t-2}+\varepsilon_{i t}
$$

The variable $S P_{i t}$ measures the level of investment in social protection in country $i$ in year $t$, which in this case is the year 2011. $Q I_{i t-2}$ stands for the quality of institutions and $P P_{i t 2}$ measures people's preferences, both at time $t-2 . \boldsymbol{E}_{i t-2}, \boldsymbol{D}_{i t-2}$ and $\boldsymbol{L H}_{i t-2}$ are vectors of control variables for past economic performance, demographic characteristics, legal and historical factors respectively, while $\mathcal{E}_{i t}$ is the usual error term representing random variations across observations. 
GDP per capita (in logarithm) and the level of government revenues (as a percentage of GDP), which serves as a proxy for fiscal space, are expected to have a positive effect on the allocation of resources to social protection (Ortiz, Cummins, \& Karunanethy, 2015a). According to Wagner's law ${ }^{8}$, expenditures tend to rise as a country becomes richer (CIAT, ECLAC, OECD, \& IDB, 2015; Mauro, 1997, 1998; Tanzi \& Davoodi, 1997). The effect of the share of natural resource rents as a percentage of GDP on the level of social protection expenditure could go either way (Bastagli, 2015; Ross, 2012): the richer a country is in natural resources, the more it can in principle spend on social protection. Yet, a too high dependence on natural resources can lead to Dutch disease and a subsequent difficulty of funding social protection expenditure. An important factor in the rise of social protection programmes in developing countries is poverty (Barrientos, 2010). In particular, the level of poverty in a country, measured by the poverty rate and the average poverty gap before taxes and transfers, reflects the need for social protection: the higher the extent and depth of poverty, the larger the demand for public support. Yet, high poverty rates are more prevalent in countries with limited economic potential and constrained financial resources. The level of inequality is expected to play a role in affecting social spending; however, predicting the sign of the coefficient of the Gini index is not straightforward given that the level of social protection spending could be influenced by the inequality between classes (Schwabish, Smeeding, \& Osberg, 2003).

The demographic dependency ratio is expected to contribute positively to the allocation of social protection because the bulk of benefits is in most countries reserved for children and the elderly (Gupta, Davoodi, \& Tiongson, 2000; ILO, 2013). However, the impact of this variable on total social protection expenditure varies in conjunction with the specific social protection programmes implemented at the country level, the employment rates and the demographic dynamics of the population in the country. ${ }^{9}$ The share of the urban population in a country is expected to positively influence total social protection expenditure, particularly because access to health care services is often concentrated in urban areas, especially in developing countries (Scheil-Adlung, 2015). Finally, the maturity of social protection systems allows to control for path dependency and is expected to contribute positively to the level of social protection expenditure (Cichon et al., 2004).

Correlation matrices for both cross-sectional and panel-data are reported in Annex 2.3 to Annex 2.6. Using cross-sectional data, the proxies for quality of institutions and people's preferences are positively correlated with the total level of expenditure of social protection in the selected 80 countries $(0.61$ and 0.10 respectively) and in the 52 low- and middle-income countries ( 0.14 and 0.46 respectively). Similar levels of correlation are also observed for the panel data covering the period 2007-2011. Overall, the correlation

\footnotetext{
${ }^{8}$ Easterly and Rebelo (1993) provide a literature review on Wagner's law and show that, in a panel of countries, several components of public spending rise (as a ratio to GDP) as income per capita rises.

${ }^{9}$ In particular, social protection expenditure is expected to be relatively higher in countries with a larger proportion of pension recipients compared to the number of working-age adults. In countries with social protection programmes that target children or youth, the expenditure on social protection can be affected by fertility, child mortality rates or the overall demographic dynamics.
} 
among the independent variables and between the control variables and dependent variable is in line with the literature and overall moderate in intensity.

Because of the likely endogeneity of institutions and levels of social protection expenditure, the estimates based on the ordinary least squares (OLS) method could be biased. Using an instrumental variable approach could address the issue of endogeneity. We have decided to use trade freedom (or globalization) as an appropriate instrument for the quality of institutions. ${ }^{10}$ Besides running two-stage-least-squares (2SLS) we also attempt to partially remove the endogeneity by assuming it to be time invariant and estimating the model on panel data with fixed effects.

\subsection{Data}

The data used in this chapter draw on different sources (see Annex 2.7). Data on the level of expenditure in social protection are taken from the ILO social protection database, which covers the years 1990-2011.11 The expenditure data are available for every five years between 1990 and 2005 and yearly for the years 2007 to 2011. In this chapter, we use the year 2011 for the dependent variable. Data on institutional and governance variables are taken from the Quality of Government Basic Dataset (QOG) (Stefan et al., 2013) which compiles country level data from individual researchers, international organisations like the World Bank, the International Monetary Fund and the International Social Security Agency (ISSA), and from private sources like the Freedom House and the Heritage Foundation. Information on people's preferences is taken from the World Values Surveys (WVS), which collect information through interviewing representative national samples of individuals about changing values and their impact on social and political life..$^{12}$ The independent and control variables reflect information pertaining to the year $2009^{13}$ (or the closest year available).

Because of the unavailability of data for the dependent and some independent variables (mainly on people's preferences), the estimates presented in this chapter are conducted using data from 80 countries: 28 high income countries (HICs) and 52 low- and middle-income countries (LICs and MICs), which have been divided in six geographical zones (see Annex 2.1). Total social protection expenditure (including administrative costs) is the sum of all existing public social protection programmes (mainly formal social

\footnotetext{
${ }^{10}$ The existing literature on institutions and economic growth (Bluhm \& Szirmai, 2012) suggests different instruments for the quality of institutions. In particular, Mauro (Mauro, 1995) uses ethnolinguistic fractionalization to instrument bureaucratic efficiency, Hall and Jones (1999) use the distance from the equator as instrument of social infrastructure, and Acemoglu et al. (2001) adopt the settler mortality to instrument institutions. These choices have been criticised by other authors. For example Acemoglu, Johnson and Robinson (2001) argue that ethnolinguistic fractionalization is influenced by economic performance and therefore is not suited as an instrument. Gallup, Sachs and Mellinger (1999) argue that the latitude can affect institutions through climate change and geography, and Glaeser et al. (2004) argue that the instrument proposed by Acemoglu et al. (2001) is correlated with current disease environment and human capital, which could influence economic performance directly rather than through institutions. The proxy for human capital proposed by Glaeser, La Porta, Lopez-de-Silanes and Shleifer(2004) (average of years of schooling) has been tested and rejected as a valid instrument by Acemoglu, Gallego and Robinson (2014). Measures of openness to trade (Chan, 2002; Frankel, 2004) and human capital have been used as instrumental variable for institutions.

${ }^{11}$ Data on social protection expenditure are published in table B.12 of the World Social Protection Report 2014-15.

12 The proxy for people's preferences is collected from different waves of the WVS conducted during the period $1990-1994$ (wave two - 17 observations); 1995-1999 (wave three - 32 observations); 2000-2004 (wave four - 31 observations); 2005-2009 (wave five - 28 observations); and 2010-2014 (wave six - 52 observations).

13 Regarding the year from which we have picked the data in the cross-sectional dataset, our first choice was 2009 . If data for 2009 were not available, data for 2010 was used. If those for 2010 were not available, we used those for 2008, and if 2008 was lacking, 2011 was used and so forth.
} 
protection programmes) including health care expenditure. ${ }^{14}$ For the analysis, total social protection expenditure is expressed as a percentage of GDP. Alternatively, we exclude health from total social protection expenditure. ${ }^{15}$ In the sensitivity analysis, the two indicators are expressed either as a percentage of total government expenditure or as social protection expenditure per capita in international dollars. Figure 2.2 shows the levels of total social protection expenditure as a percentage of GDP across geographic regions in 2011. As expected, the highest level of expenditure on social protection is registered in Western Europe and North America. The lowest levels are measured for Sub-Saharan Africa and South-East Asia.

A note deserves to be made regarding the limitation of using expenditure as a measure for the dependent variable. The level of total expenditure as such says nothing about the quality of the spending, nor its efficiency. Therefore, by using expenditure it is assumed that social protection expenditure across countries are of equal quality.

\section{Figure 2.2 Allocation of expenditure to SP (different compositions) by geographic regions, 2011}

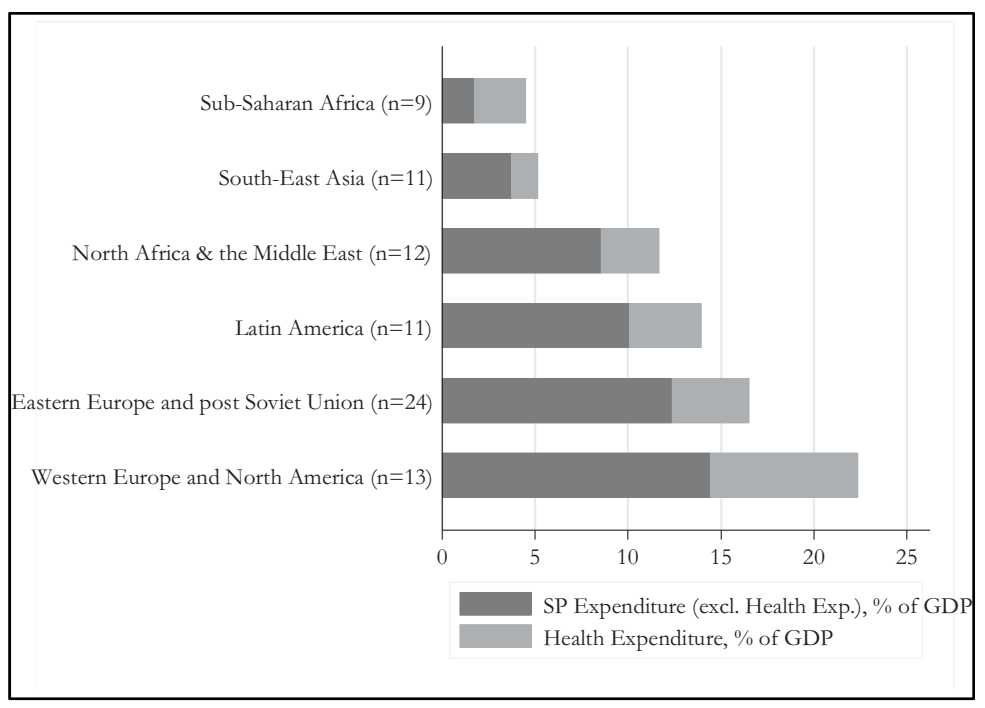

Source: Author's own calculation based on ILO social protection. Population weighted average per region; 80 countries in total.

The variable functioning of the government 16 is used as a proxy for the quality of institutions and is available for the period 2005-2012. The variable examines the extent to which the freely elected head of government

\footnotetext{
${ }^{14}$ The scope of the indicator corresponds to the scope of the Social Security (Minimum Standards) Convention, 1952 (No.102) which established nine classes of benefits or social protection areas (branches): 1) medical care, 2) sickness benefit, 3) unemployment benefit, 4) old-age benefit, 5) employment injury benefit, 6) family benefit, 7) maternity benefit, 8) invalidity benefit and 9) survivors' benefit, plus other income support and assistance programmes, including conditional cash transfers, available to the poor and not included under the above classes (ILO, 2014).

${ }^{15}$ The ILO dataset contains the following indicators: social protection expenditure, health expenditure and total social protection expenditure. Public social protection spending includes all expenditures financed with resources controlled by the government (different levels of government and social security funds); such as, among others, social insurance and social assistance payments (OECD, 2007).

${ }_{16}$ Other studies use similar measures for quality of institutions such as alternative measures of quality and coherence of political institutions, and bureaucratic/administrative capacity, see Hendrix (2010).
} 
and a national legislative representative determine the policies of the government, whether the government is free from pervasive corruption, accountable to the electorate between elections and operates with openness and transparency: countries are graded between 0 (worst) and 12 (best). ${ }^{17}$

Figure 2.3 shows the average values of the index which measures the functioning of government across six geographic regions. While geographic disparities are evident, the values for 2010 are almost at the same level as in 2005. This is explained by the fact that changes in institutions are path dependent and evolve slowly over time, with the exception of unexpected events such as revolutions or natural events, which may affect substantially the overall status and performance of institutions (Acemoglu \& Robinson, 2001).

Figure 2.3 Trend of functioning of government by geographic regions, 2005 and 2010

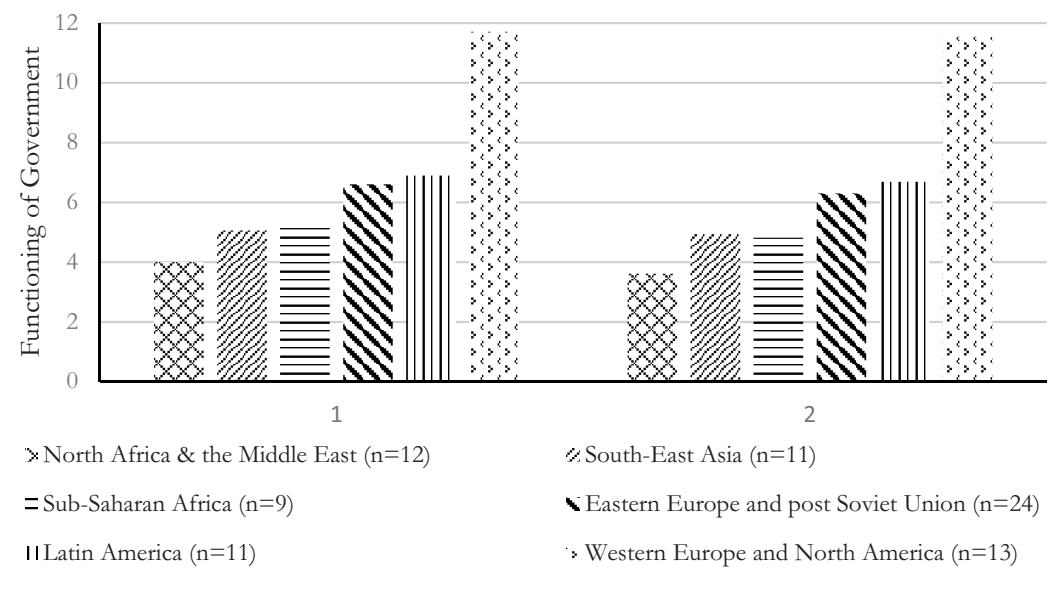

Source: Author's own calculation based on Quality of Government Basic Dataset (QOG) (Stefan et al., 2013); 80 countries in total.

Alternative indicators used in the literature to measure the quality of institutions ${ }^{18}$ (Adsera, Boix, \& Payne, 2003; La Porta et al., 1998) are taken from the QOG dataset and used to test the robustness of the findings. In particular, the variable government effectiveness, which is borrowed from the Worldwide Governance Indicators (WGI), is available for the period 1996-2011 and combines responses on the quality of public service provision, the quality of the bureaucracy, the competence of civil servants and ranges from 0 (weak governance) to 5 (strong governance). Data for the variable rule of law, which is also part of the WGI, is available for the period 1996-2011. The values of this indicator also range from 0 (weak) to 5

\footnotetext{
${ }_{17}$ The ratings are based on the subjective assessment of foreign investors and business experts in the respective countries.

${ }^{18}$ The variables used in this paper to measure the performance of institutions are composed indices and have been widely used in the literature. Over the past, these measures have received quite some criticism with respect to their constructs, comparability and methodological shortcomings, thereby questioning their validity (Steven van de Walle, 2006; Thomas, 2010). However, these arguments have been refuted as the critics do not provide evidence of any practical consequences, alternative definitions or failure to meet the criteria of construct validity (Kaufmann, Kraay, \& Mastruzzi, 2007, 2010).
} 
(strong) and measure to what extent agents have confidence in and abide by the rules of society. ${ }^{19}$ The variable property rights, which is part of the Heritage Foundation dataset and covers the period 1994-2012, scores the degree to which the laws of a country protect private property rights and the degree to which the government enforces those laws. This indicator is a classic measure used in the literature on institutions and economic growth (Brunetti, Kisunko and Weder, 1998; Brunetti \& Weder, 1998; Mauro, 1995) and is also used to measure the quality of government (La Porta et al., 1999). The scores of this indicator range from 0 to 100 , where 100 represents the maximum degree of protection of property. The variable polity 2 is a proxy for quality and coherence of political institutions. The scores of this indicator range from -10 to 10 , where 10 represents highly stable and democratic institutions (Marshall, Monty, \& Keith Jaggers, 2009).

The indicator for people's preferences measures the extent to which a society wants government to be involved in the provision of public services, redistribution or the provision of social welfare. The variable has values between 1 and 10 whereby a lower value is associated with the people's preference for less government involvement. ${ }^{20}$ For this variable, the available data closest to the year 2009 have been used.

Control variables account for economic, demographic, legal and historical and geographical factors and have been selected according to economic and statistical criteria in relation to the variable analysed. The control variables are compiled from different sources which have been listed above. The measure for the maturity of the social protection systems has been established using data provided by the International Social Security Association (ISSA). The variable is constructed by counting the number of years since when the oldest law (legal coverage) on social protection was approved in a country. The term "legal coverage" represents the extent to which social security areas are addressed by the national legislation while the term "effective coverage" represents the extent to which social security areas are actually covered (actual implementation). The control variables are grouped in Economic factors: a) GDP per capita based on purchasing power parity (PPP) converted to constant 2005 international dollars; b) government revenue as percentage of total GDP; c) total natural resources rents as percentage of total GDP; d) income inequality (pre-taxes and pre-transfers) measured by the Gini coefficient; e) poverty rate and poverty gap according to the international standard (below 1.90 USD PPP per capita per day in constant 2011 international dollars derived from the latest available World Bank PovCal ${ }^{21}$ data and limited to low- and middle-income countries). Demographic factors: a) total age dependency ratio (younger than 15 and older than 65 to the population aged 15-64); b) proportion of the urban population; c) total population. Legal and historical factors: a) Country's legal systems; b) Colonial origin c) maturity of social protection system in the country. The descriptive statistics for these variables are reported in Annex 2.2.

\footnotetext{
${ }^{19}$ The variable government effectiveness and Rule of law have been transformed from the original range from -2.5 (weak) to 2.5 (strong) to a range which goes from 0 to 5 in order to facilitate the interpretation of the estimation results.

${ }^{20}$ World Values Survey, latest available data. Question: Now I'd like you to tell me your views on various issues. How would you place your views on this scale? 10 means you agree completely with the statement on the left; 1 means you agree completely with the statement on the right; and if your views fall somewhere in between, you can choose any number in between. Higher scale: The government should take more responsibility to ensure that everyone is provided for. Lower Scale: People should take more responsibility to provide for themselves. For easier interpretation, the variable has been transformed and reversed compared to the original one.

${ }^{21}$ The latest PovCal data are based on estimates of global poverty from 1981 to 2012 based on 2011 purchasing power parity (PPP).
} 
A note has to be made in relation to data availability for the dependent and selected independent variables. Ideally, the analysis would have used data on the expenditures for social assistance programmes, which are primarily funded from general government revenues and which are prevalent in developing countries. However, data at this level of detail was not available at the time the research was undertaken. Given these data limitations, several robustness checks have been conducted to test the validity of our findings.

\subsection{Results}

Table 2.1 presents the results of estimating equation (1) for all 80 countries and for the subset of 52 low- and middle-income countries by using successively OLS with robust standard errors and 2SLS on cross-sectional and panel data. The variable which captures people's preferences is omitted from models 3 , 4, 7 and 8 based on panel data because it is observed only once during the period 2007-2011. In the 2SLS approach we instrument the variable functioning of the government ${ }^{22}$ with trade freedom to address the potential endogeneity of the quality of institutions due to reverse causality, common dependency with respect to a third variable or measurement error between social protection expenditure and the quality of institutions. While trade freedom could reflect the vulnerability of a country to international economic fluctuations and may therefore increase the necessity for social protection expenditure (Dreher, 2006), it is not correlated over a period of 10 years (1999-2009) with either the variation in exchange rates or the trade deficits, ${ }^{23}$ which are alternative measures of vulnerability. Hence, the choice of trade freedom ${ }^{24}$ is considered as an appropriate instrument for the variable functioning of government used in models 2, 4, 6 and 8 . It also seems to be a valid instrument on the basis of its significance in the first-stage estimation conditional on all other explanatory variables. With trade freedom as instrumental variable, the functioning of government is positive and significant using panel data in model 7 and 8 for the 52 low-and middle-income countries. The coefficient of people's preference is positive and significant in the models 5 and 6 for lowand middle-income countries.

The estimates show that the proxies for quality of institutions and people's preferences influence the level of expenditure in social protection in low- and middle-income countries. In all the model specifications for developing countries both variables are significant and positive with the exception of functioning of the government in the model specification 6 . An increase in the functioning of the government index by one unit is associated with a change in the level of social protection expenditure of 0.41 percent of GDP for the 52 low- and middle-income countries using cross sectional data and of 1.3 percent using panel data (see columns (5) and (8) of Table 2.1). A unit increase in the people's preferences index changes the level of

\footnotetext{
${ }^{22}$ Functioning of the government is the variable that is instrumented by trade freedom in models 2, 4, 6 and $8:$ F statistics are used to test the weak identification. According to Staiger \& Stock (1997) if the F-statistic is higher than 10 weak identification is not a matter of concern.

${ }^{23}$ Exchange rate defined as local currency units (LCU) per US\$, with values prior to the currency's introduction presented in the new currency's terms and trade deficit is defined as net trade in goods (BoP, current US\$), data from the World Development Indicators - World Bank.

${ }^{24}$ The trade freedom score is based on two inputs: the trade-weighted average tariff rate and non-tariff barriers (NTBs). Weighted average tariffs is a purely quantitative measure and accounts for the basic calculation of the score. The presence of NTBs in a country affects its trade freedom score by incurring a penalty of up to 20 percentage points, or one-fifth of the maximum score. The country's trade freedom ranges between 0 and 100, where 100 represents the maximum degree of trade freedom (Stefan, Holmberg, Rothstein, \& Hartmann, 2014).
} 
expenditure of social protection by as much as 1.4 percent of GDP in low- and middle-income countries (see columns (5) and (6)).

Holding all other variables constant, one additional year of maturity of the social protection system increases by about 0.1 percentage points the level of expenditure in social protection over GDP in the total list of countries which include high-income countries. This is in line with the existing literature on path dependency and maturity of social protection systems (Cichon et al., 2004). A significant and positive effect is also associated with the level of government revenues that serves as a proxy for fiscal space. The fact that this variable is significant confirms that the level of social protection spending cannot be considered separately from tax policies (Bastagli, 2015). The wealth effect, measured by the logarithm of per capita GDP, contributes positively to the level of expenditure in models 3, 4, 5 and 6 . The share of natural resources rents does not seem to be related to the level of social protection expenditure in developing countries, while its coefficient is negative and significant across the model specifications conducted on all countries. The poverty rate is negatively correlated with social protection expenditure, but an increasing poverty gap is associated with higher social protection expenditure in models 1 and 4 and a lower one in model 3.

The Gini index captures the inequality in income distribution before taxes and transfers. It affects negatively the level of social protection expenditure among high-, low- and middle-income countries. While this result may seem counterintuitive, its interpretation can be found in the political economy theories of budget allocations to social protection. Schwabish et al. (Schwabish et al., 2003) found that while inequality between the middle class and the poor has a small positive impact on the level of social spending, inequality between the rich and the middle class has a large and negative impact on social spending. As the "rich" become more distant from the middle and lower classes, they find it easier to opt out of public programs and to buy substitutes for social insurance in the private market. Among the demographic control variables, the share of urban population contributes positively to the level of expenditure in social protection in lowand middle-income countries.

It is difficult to predict the direction of the bias of our estimates given the potential endogeneity of the quality of institutions, the omitted variable bias and the measurement error in the selected variables. Similar studies assessing the linkages between quality of institutions and public spending find significant effects. Murshed et al. (2017) assess the linkages between fiscal capacity and the level of spending on social protection. After instrumenting the proxy for fiscal capacity, the effect of this variable on the level of public spending reduces. Delavallade (2006) instead finds that instrumenting the proxy for corruption increase the effect of the variable on the level of public spending. 


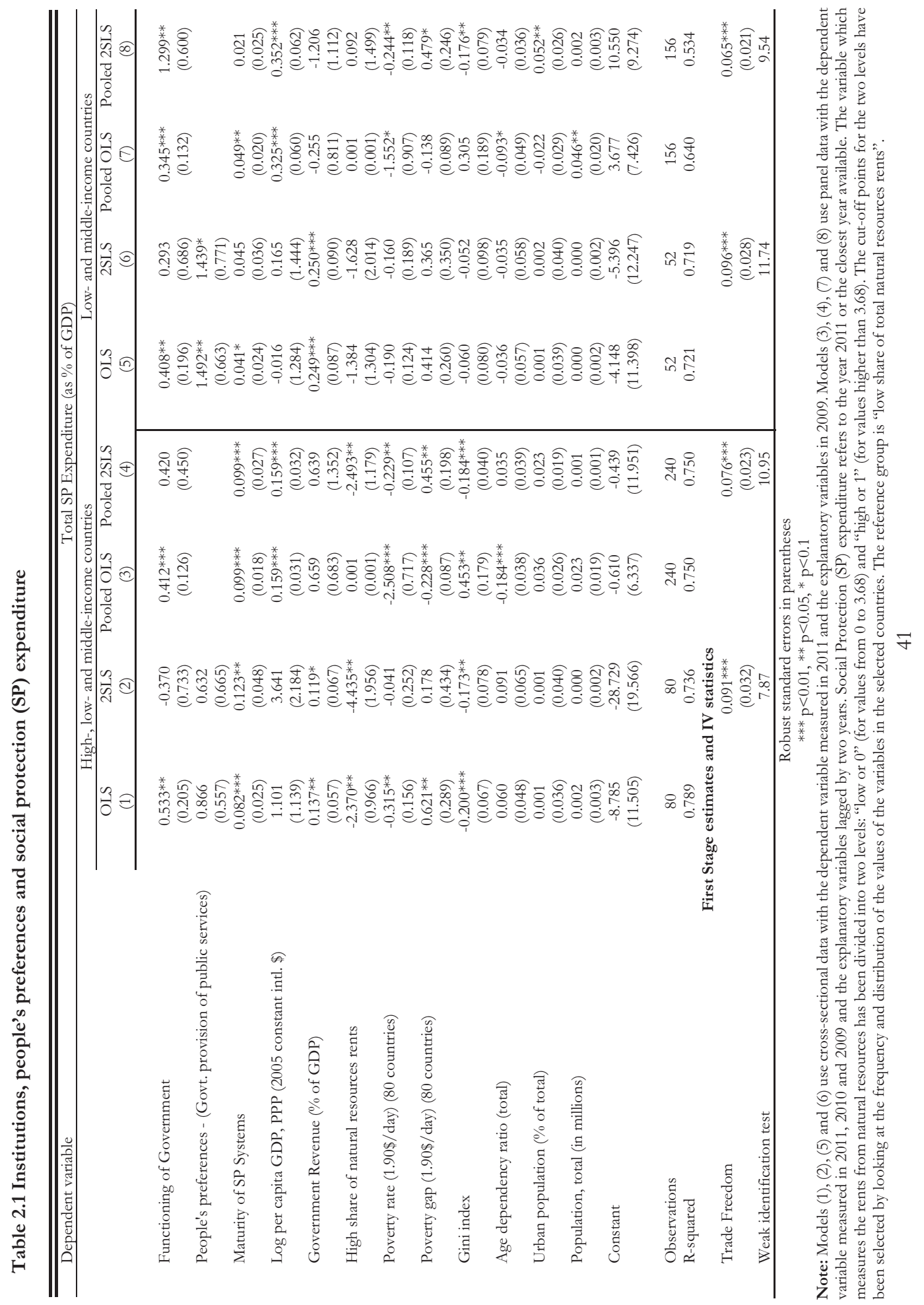


We tested whether there is a synergy between the quality of institutions and people's preferences (see Table 2.2). The measures for quality of institutions and people's preferences are transformed into binary variables in order to uncover potential synergy effects.

Table 2.2 Quality of institutions, people's preferences and SP expenditure: categorical analysis

\begin{tabular}{|c|c|c|}
\hline \multirow[t]{4}{*}{ Dependent variable } & \multicolumn{2}{|c|}{ Total SP Expenditure (as \% of GDP) } \\
\hline & $\begin{array}{l}\text { High-, low- and } \\
\text { middle-income } \\
\text { countries }\end{array}$ & $\begin{array}{l}\text { Low- and middle- } \\
\text { income countries }\end{array}$ \\
\hline & \multicolumn{2}{|c|}{ OLS } \\
\hline & (1) & $(2)$ \\
\hline Maturity of SP Systems & $\begin{array}{c}0.088^{* * *} \\
(0.028)\end{array}$ & $\begin{array}{c}0.027 \\
(0.023)\end{array}$ \\
\hline Government Revenue ( $\%$ of GDP) & $\begin{array}{c}0.135^{* *} \\
(0.057)\end{array}$ & $\begin{array}{c}0.291 * * * \\
(0.086)\end{array}$ \\
\hline High share of total natural resources rents & $\begin{array}{c}-2.744^{* *} \\
(1.091)\end{array}$ & $\begin{array}{l}-0.883 \\
(1.303)\end{array}$ \\
\hline Log per capita GDP, PPP (2005 constant intl. \$) & $\begin{array}{c}1.553 \\
(1.061)\end{array}$ & $\begin{array}{l}-0.937 \\
(1.355)\end{array}$ \\
\hline Poverty rate (1.90\$/day) (80 countries) & $\begin{array}{l}-0.237 \\
(0.157)\end{array}$ & $\begin{array}{l}-0.216^{*} \\
(0.126)\end{array}$ \\
\hline Poverty gap (1.90\$/day) (80 countries) & $\begin{array}{c}0.488 \\
(0.313)\end{array}$ & $\begin{array}{c}0.462 \\
(0.298)\end{array}$ \\
\hline Gini index & $\begin{array}{c}-0.212 * * * \\
(0.066)\end{array}$ & $\begin{array}{l}-0.072 \\
(0.084)\end{array}$ \\
\hline Age dependency ratio (total) & $\begin{array}{c}0.072 \\
(0.049)\end{array}$ & $\begin{array}{l}-0.031 \\
(0.050)\end{array}$ \\
\hline Urban population ( $\%$ of total) & $\begin{array}{l}0.009 \\
(0.042)\end{array}$ & $\begin{array}{c}0.021 \\
(0.040)\end{array}$ \\
\hline Population, total (in millions) & $\begin{array}{c}0.002 \\
(0.003)\end{array}$ & $\begin{array}{l}-0.000 \\
(0.003)\end{array}$ \\
\hline Baseline: O.Functioning of Govt.\#0.People's preferences & & \\
\hline 0.Functioning of Govt.\#1.People's preferences & $\begin{array}{c}1.749 \\
(1.491)\end{array}$ & $\begin{array}{c}1.596 \\
(1.673)\end{array}$ \\
\hline 1.Functioning of Govt.\#0.People's preferences & $\begin{array}{l}3.274 * \\
(1.841)\end{array}$ & $\begin{array}{c}2.649 \\
(1.612)\end{array}$ \\
\hline 1.Functioning of Govt.\#1.People's preferences & $\begin{array}{l}3.586^{*} \\
(1.957)\end{array}$ & $\begin{array}{l}5.444 * * \\
(2.156)\end{array}$ \\
\hline Constant & $\begin{array}{l}-6.955 \\
(9.898)\end{array}$ & $\begin{array}{c}12.315 \\
(12.298)\end{array}$ \\
\hline Observations & 80 & 52 \\
\hline R-squared & 0.782 & 0.735 \\
\hline
\end{tabular}

\section{Robust standard errors in parentheses}

*** $\mathrm{p}<0.01,{ }^{* *} \mathrm{p}<0.05,{ }^{*} \mathrm{p}<0.1$

Note: Models presented in the table use cross-sectional data with dependent variable measured in 2011 and explanatory variables in 2009. The variable which measures the functioning of the Government has been divided into two levels: "low or 0 " (for values from 0 to 6 ) and "high or 1" (for values from 7 to 12). The proxy for people's preferences has also been divided in two categories: "low or 0" (for values from 1 to 6.4) and "high or 1" (for values from 6.4 to 10 ) values. The variable which measures the rents from natural resources has been divided into two levels: "low or 0" (for values from 0 to 3.68) and "high or 1" (for values higher than 3.68). The cut-off points for the levels have been selected by looking at the frequency and distribution of the values of the variables in the selected countries. The reference group is "low share of total natural resources rents".

The variable functioning of the Government takes the value $Q I=0$ (low functioning) for values from zero to six, and $Q I=1$ (high functioning) for values from seven to twelve. Similarly, the variable people's preference has been recoded with $P P=0$ for values from 1 to 6.4 , and $P P=1$ for values higher than 6.4. It is expected that the interaction of better functioning institutions and stronger preferences of the society for Government 
involvement in the provision of public services is associated with higher levels of social protection expenditure.

The results show that a high level of functioning of the government increases significantly the intensity of social protection by 3.3 percentage points for all 80 countries selected. In addition, the simultaneous occurrence of high levels for both variables significantly increases the level of social protection expenditure over GDP by 3.6 percentage points on average for all countries and by 5.4 percentage points in low- and middle-income countries. Hence for the full sample, , we cannot conclude that there is complementarity in the sense of super-modularity between the two variables, as the simultaneous presence of people's preferences and quality of institutions is lower than the sum of the individual presence of each, compared to the reference scenario of the absence of both (Milgrom \& Roberts, 1990). However, for low- and middleincome countries, there is at least pointwise an indication of supermodularity, although in statistical terms the simultaneous presence of both is not strictly greater than the sum of the individual effects (the confidence intervals of 5.444 and of $1.596+2.649$ do intersect).

We have conducted a number of robustness checks. In table 2.3 we report the results obtained using two definitions of social protection expenditure (with and without health expenditure) and four alternative measures of the quality of institutions in addition to functioning of the government (government effectiveness, the rule of law, an index of property rights and a measure of stability of institutions). Quality of institutions is significant and positive in 6 out of the 10 model specifications and for 3 out of the 5 measures of the quality of institutions. The variable which captures people's preferences is always significant and positive in all model specifications for low- and middle-income countries. The maturity of the systems and the level of government revenues are also highly significant throughout the different models confirming the relevance of long-established social protection systems and the availability of fiscal space. The Gini index continues to have negative and significant coefficients in all model specifications. The poverty rate is negative and significant in 2 out of the 8 model specifications. While the Gini index continues to have negative and significant coefficients, the poverty gap continues to have positive and significant marginal effect on SP expenditure in 5 out of the 8 model specifications.

Similar but weaker results are presented in Table 2.4 for the low- and middle-income countries. The signs of the marginal effects remain the same with the exception of model 7 but many coefficients are no longer significant, partly because of the lower number of degrees of freedom. Table 2.5 summarizes additional tests conducted to assess the robustness of the analysis using two alternative measures of social protection expenditure (SP expenditure as a percentage of total government expenditure and the log of SP expenditure per capita). The estimates confirm the positive signs and significance of the variables for the functioning of the Government and people's preferences irrespective of the different definitions of the dependent variable, exception made for model 3 and 4 where the proxy for the quality of institution is not significant. To conclude, the results presented in Tables 2.3 and 2.4 are robust to changes in definitions of the dependent variable and to different measures of the quality of institutions. 


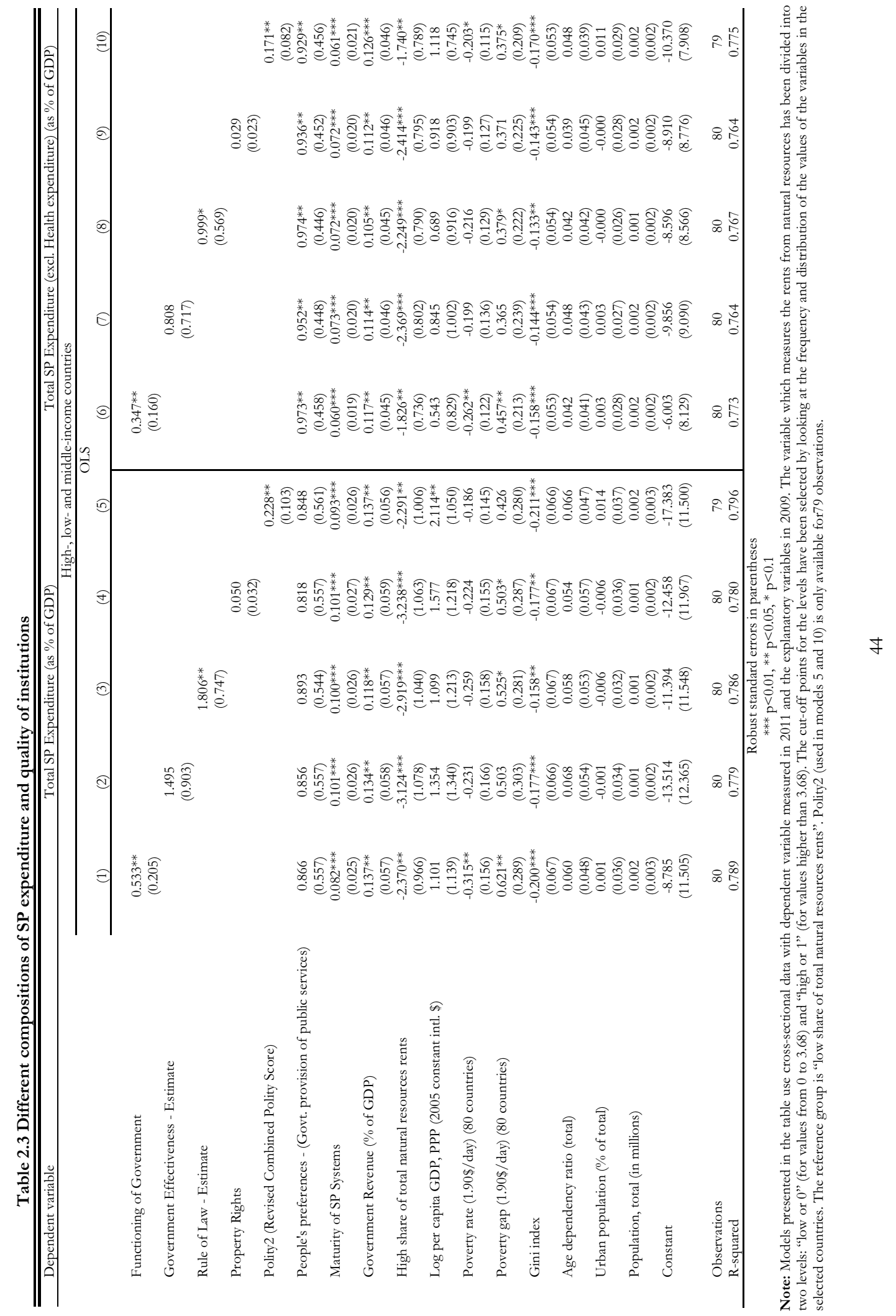




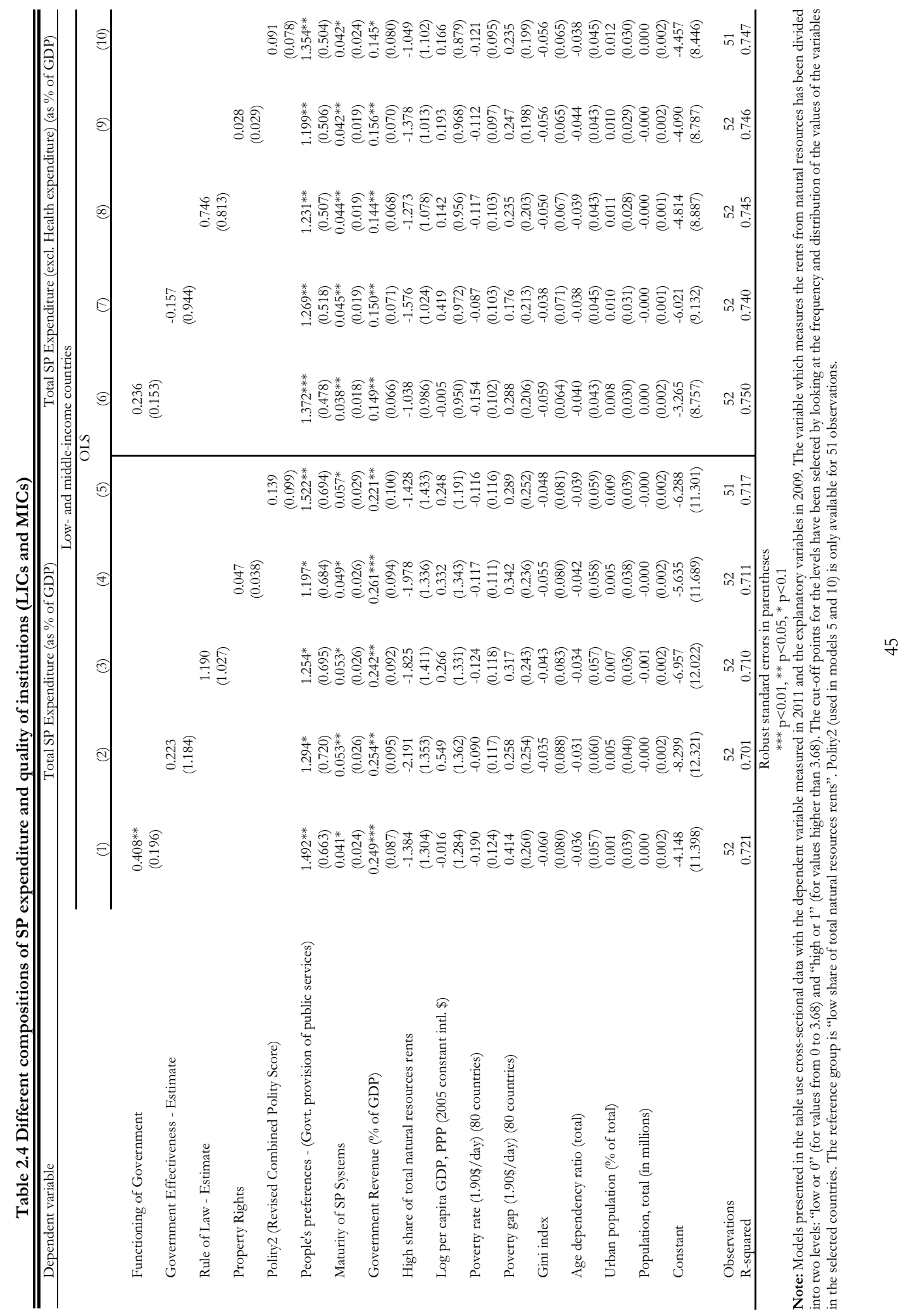


Table 2.5 Different measures of SP expenditure (including health expenditure)

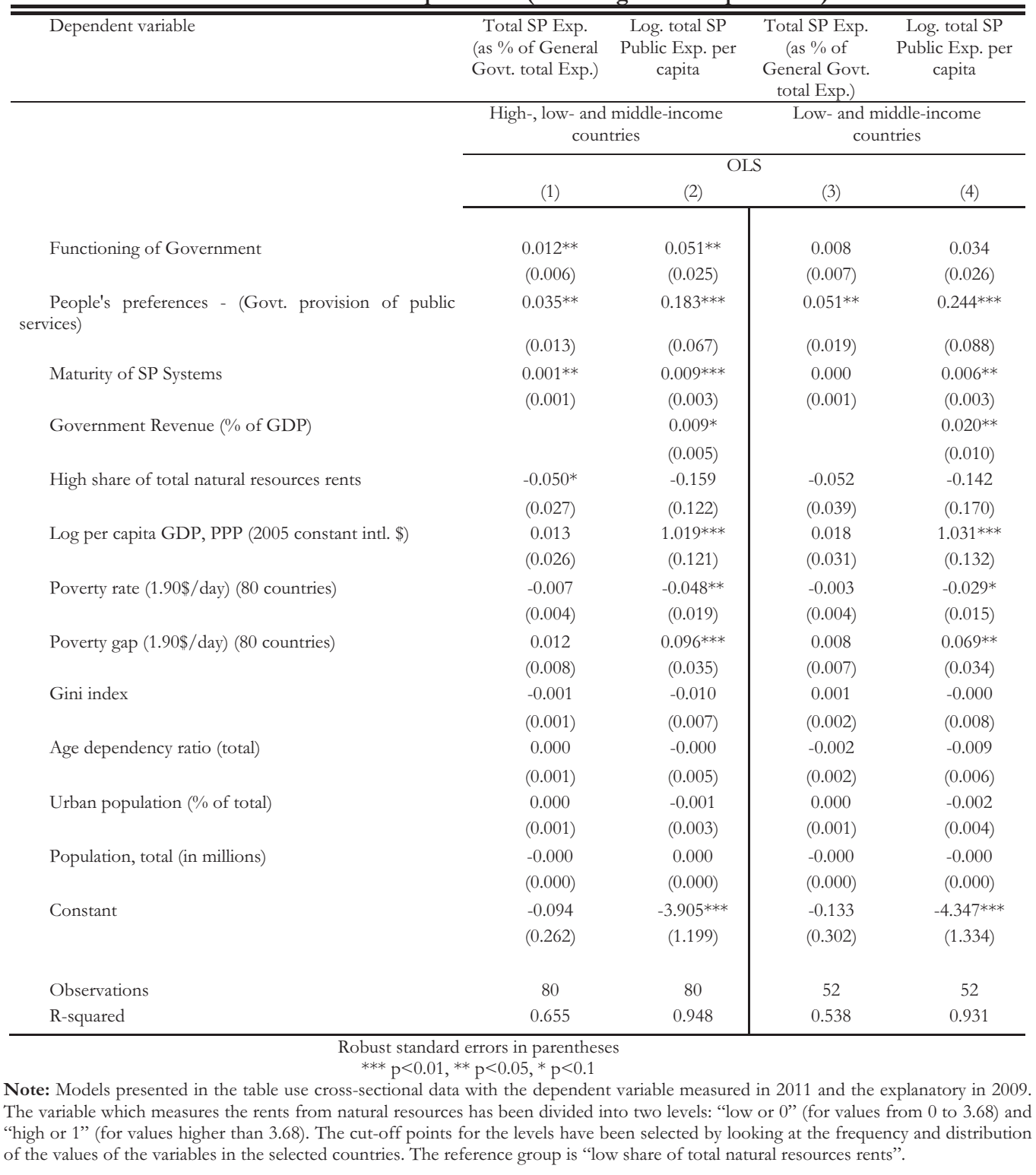


A further extension of the baseline model controls for colonial and legal origins. The countries which have never been colonized show positive and significant coefficients. The hypothesis advanced by (Bailey, 2004) that countries with French colonial origins tend to be more generous in terms of social protection compared to those that were former British colonies is not supported by the data, models (1) and (2) in Table 2.6. The results are robust to the inclusion or not of health expenditure in social protection expenditure for the 52 low- and middle-income countries.

If legal origins are controlled for and the English Common Law system is used as a baseline, the French legal system and the socialist/ communist laws do not seem to influence the level of social protection expenditure. A significant and positive additional level of social protection expenditure can be attributed to legal systems based on the Scandinavian code (using 80 countries) and using social protection expenditure excluding health as the dependent variable in models (3) and (4). The finding may reflect the relative generosity of social democratic welfare states ${ }^{25}$ (Esping-Andersen, 1990). The estimates for the group of low- and middle-income countries show positive and weakly significant additional effects for countries that have inherited the French or socialist legal codes in models (5) and (6). Alternatively, controls for Government political orientation have also provided robust estimates for both main independent variables. ${ }^{26}$ Additional robustness checks have been conducted controlling for ethnic and linguistic fractionalization and level of democracy. The results are in line with the initial estimates and do not change our conclusions.

\footnotetext{
${ }^{25}$ In particular, three ideal types of regimes or welfare states are advanced by Esping Andersen: the Social Democratic (for example Sweden), the Corporatist (such as Germany) and the Liberal (such as the United States) model. The Social Democratic regime is characterized by a high level of benefits and a high guaranteed minimum provided to the population, and it is mainly funded on general taxation. The Corporatist regime shows instead relative high level of benefits, which are mainly funded though contributions. Finally, the Liberal regime shows levels of benefits reduced to a minimum funded by general taxation (Wildeboer Schut, Vrooman, \& Beer, 2001).

${ }^{26}$ Tables are not included in the paper but available from the author upon request.
} 


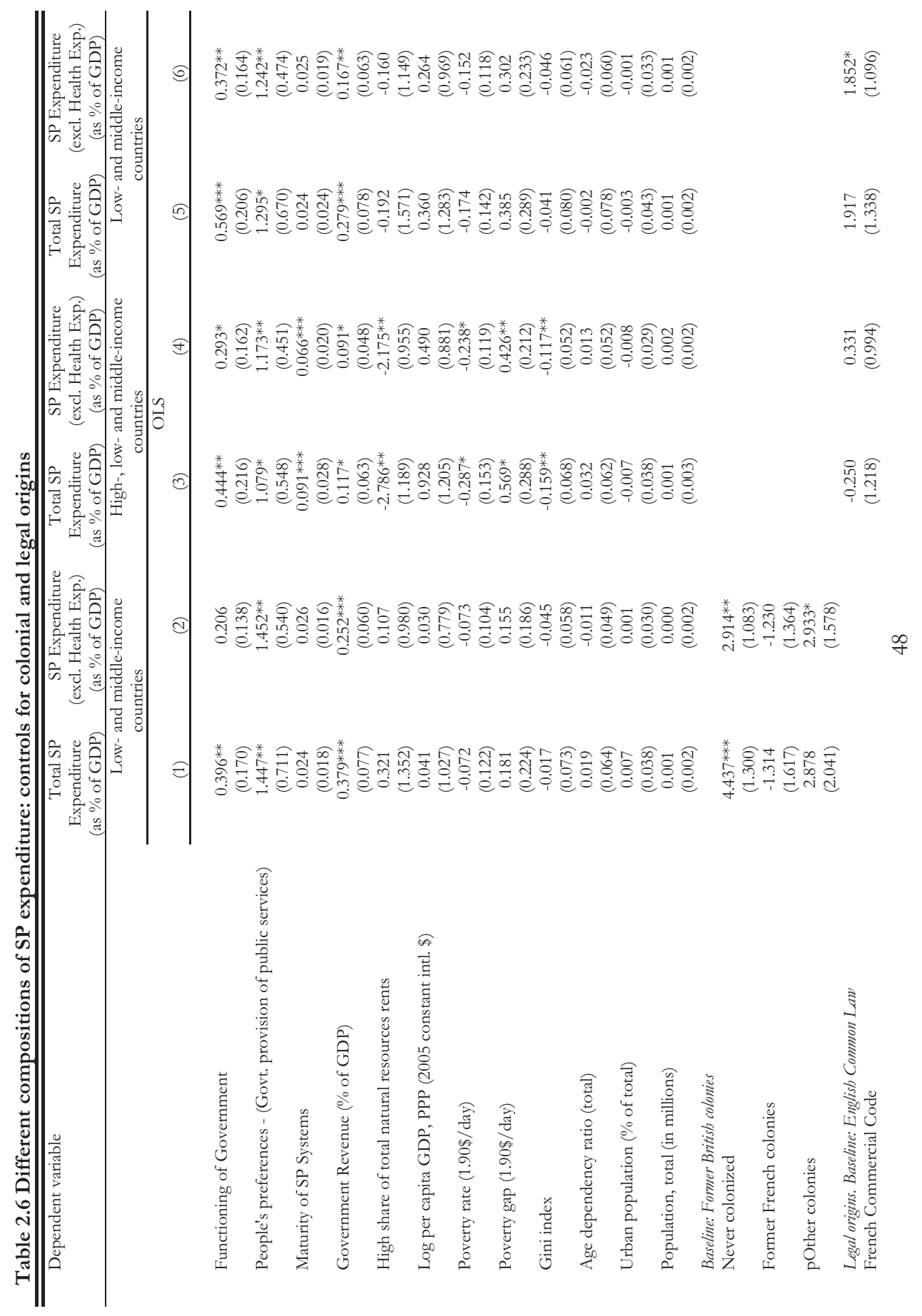




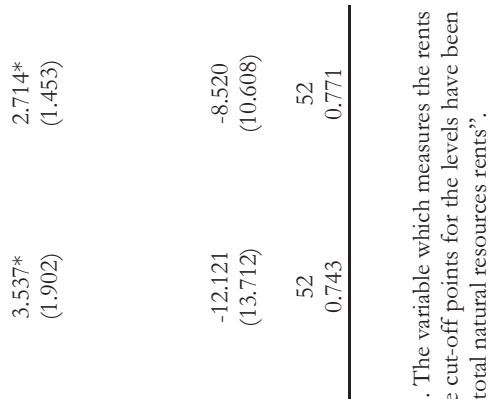

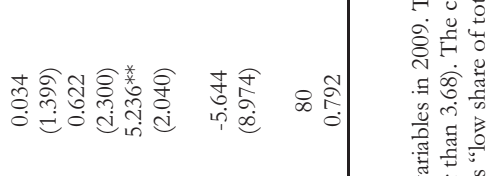

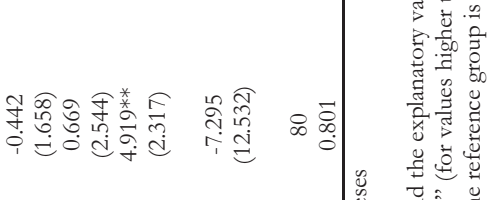

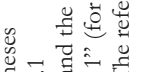

$$
\begin{aligned}
& \text { हैं है }
\end{aligned}
$$

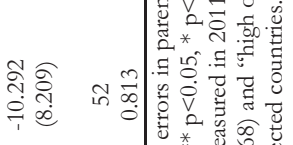

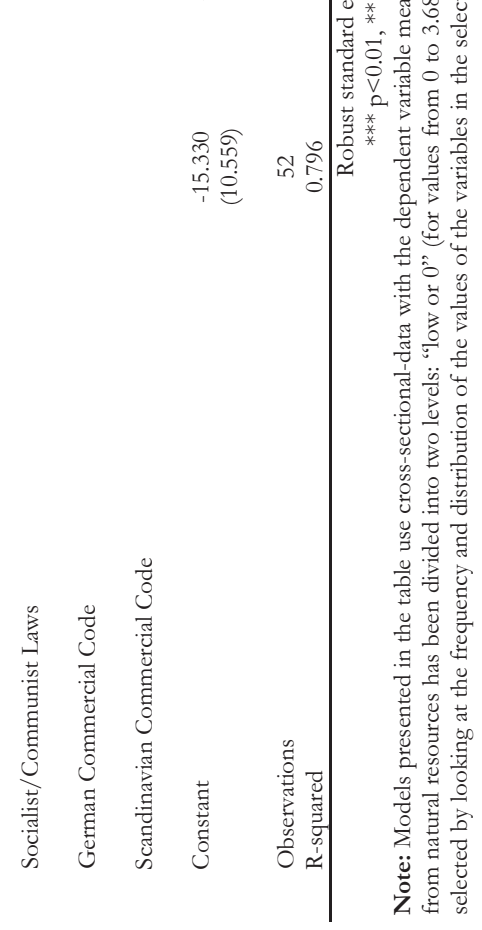


Finally, Table 2.7 reports the difference between short-run and long-run effects. We construct a panel data for 80 and 52 countries over 5 years (2007-2011). In columns 1 and 4 we report the pooled 2SLS estimates with panel data already reported in Table 1. The variable that captures people's preferences is no longer included because it is only observed in one year. The variable which measures the functioning of the government is positive and highly significant in the model specification 4 for low- and middle-income countries, while it is not significant in model specification 1 where estimates are conducted on all the 80 countries. We estimate the model using only the between variation of the data in columns (2) and (5) and only the within variation in columns (3) and (6). The former captures the long-run effects, the latter the short-run effects using trade freedom as instrument for the variable functioning of the government.

The strong persistence in SP expenditure explains the lack of significant explanatory variables in the fixed effects model. Because the quality of institutions does not vary much over time, a change in the functioning of the government is not significantly associated with a change in the total level of expenditure in social protection in the short-run. Only the maturity of the social protection systems is significantly and positively associated with an increase in the total level of SP expenditure as a percentage of the GDP in the estimates for all the 80 countries, while it is negative and significant in the fixed effects model for low- and middle-income countries. In the short- and long-term, the government revenue is positive and highly significant suggesting that fiscal capacity is important in explaining the level of expenditure in social protection. The level of expenditure in social protection as a proportion of GDP is also related to the level of income. A 1 percent increase in per capita GDP increases the level of expenditure in social protection by 8.3 and 11.7 percentage points in all 80 countries and in the low- and middle-income countries respectively. 


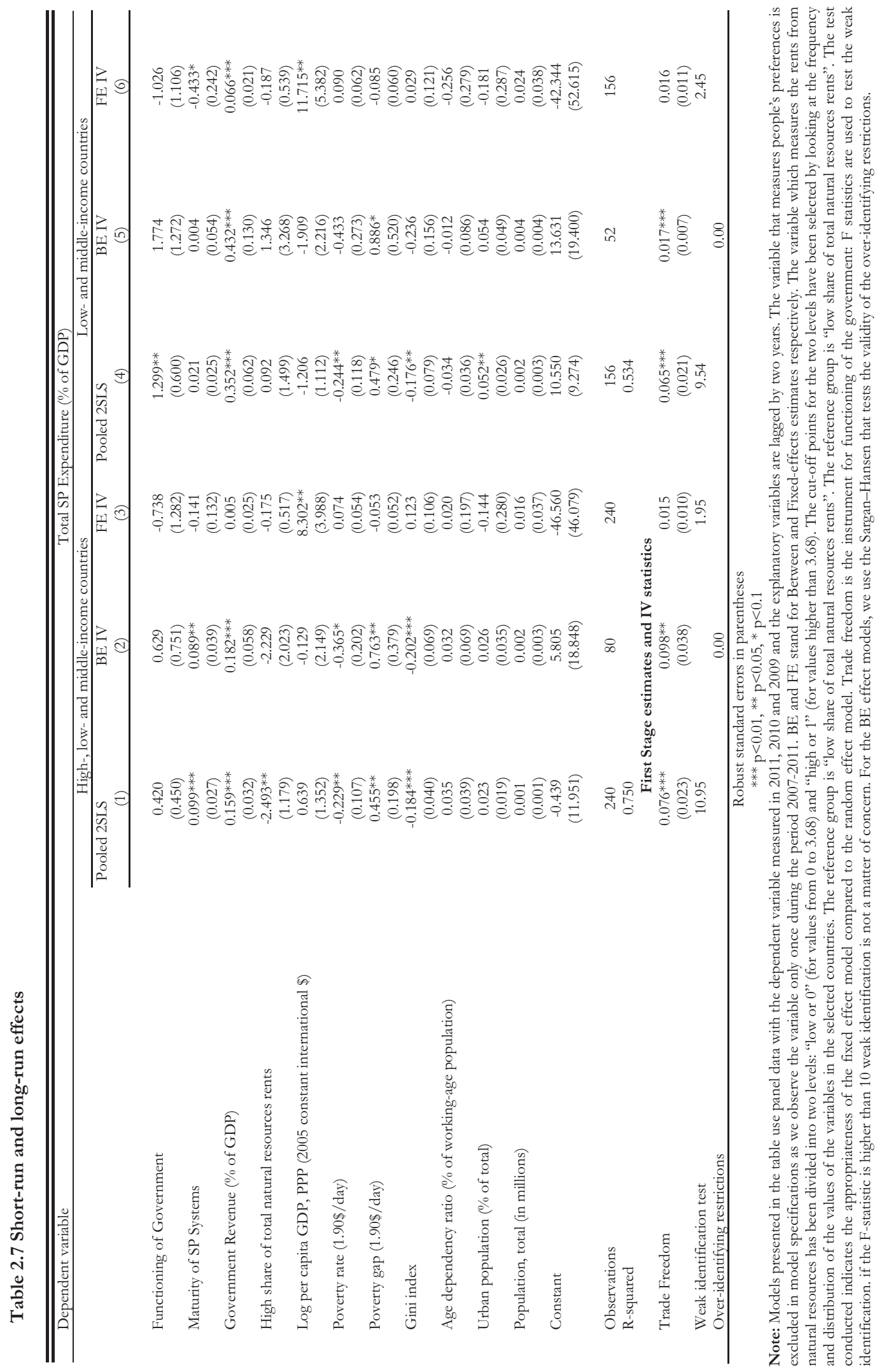




\subsection{Conclusions}

This chapter expands on the existing literature on the determinants of social protection by examining whether and to what extent the provision of social protection depends on the quality of institutions and people's preferences using panel data on 80 countries (52 low- and middle-income countries and 28 high income countries). The results show that both factors have an impact for all the countries in our sample but also for the group of low- and middle-income countries. The estimates are robust to the different definitions of the dependent variables and different measures for the quality of institutions.

These results have implications regarding social protection policies. First, our results suggest that it would be useful to continue enhancing the capacity of institutions and public authorities. This should not only be limited to the provision of technical support, for example to administrators who are expected to execute the social protection policies and to initiate reforms, but also to improve on existing legal frameworks, accountability, transparency, effectiveness, efficiency, equity, inclusiveness, participation and consensus. Some tools suggested by the ILO to guide countries are social budgeting, social protection expenditure and performance reviews (SPERs), which can also assist countries in improving their quantitative knowledge base on social protection. A recent report published by the Overseas Development Institute (Greenhill, Carter, Hoy, \& Manuel, 2015) shows that in order to reach the Sustainable Development Goals greater efforts should be put in investing in social contracts that include social protection, universal access to health and quality of education. While the best source for financing the social contract is domestic, rich countries still need to support the least developed countries and ensure long-term funding and fiscal commitments to those countries that have challenges in finding the resources needed to support, among others, social protection programmes.

The second area of focus is to ensure that people's preferences regarding the involvement of the Government in the provisions of public services are represented. Therefore, it is key to advocate for mechanisms and systems that allow people's preferences to be heard. This could also suggest, for example, a more effective role for the international organisations, academic institutions and think thanks in providing technical assistance to countries to ensure that well-functioning systems are in place that can capture and reflect people's preferences and influence social policies.

While supporting these two main areas might be beneficial to boost the level of expenditure in social protection programmes, the specific set of strategies and policy options to use will mainly depend on the specific national contexts. 


\subsection{Annexes and tables}

\section{Annex 2.1 List of countries}

\begin{tabular}{|c|c|c|c|}
\hline North Africa \& the Middle East & $\begin{array}{l}\text { Eastern Europe and post- } \\
\text { Soviet Union }\end{array}$ & $\begin{array}{l}\text { Western Europe and } \\
\text { North America }\end{array}$ & Latin America \\
\hline Algeria & Albania & Australia* & Argentina* \\
\hline Cyprus* & Armenia & Canada* & Brazil \\
\hline Egypt & Azerbaijan & Finland* & Chile* \\
\hline Iran & Belarus & Germany* & Colombia \\
\hline Israel* & Bosnia and Herzegovina & Italy* & Dominican Republic \\
\hline Jordan & Bulgaria & Netherlands* & Guatemala \\
\hline Kuwait* & Croatia* & New Zealand* & Mexico \\
\hline Morocco & Czech Republic* & Norway* & Peru \\
\hline Qatar* & Estonia* & Spain* & Trinidad and Tobago \\
\hline Tunisia & Georgia & Sweden* & Uruguay \\
\hline Turkey & Hungary* & Switzerland* & Venezuela \\
\hline \multirow[t]{2}{*}{ Yemen } & Kazakhstan & United Kingdom* & \\
\hline & Kyrgyzstan & United States* & \\
\hline South-East Asia & Latvia & & \\
\hline Bangladesh & Lithuania & Sub-Saharan Africa & \\
\hline China & Macedonia & Burkina Faso & \\
\hline India & Moldova & Ethiopia & \\
\hline Indonesia & Poland* & Ghana & \\
\hline Japan* & Romania & Mali & \\
\hline Korea, South* & Russia & Nigeria & \\
\hline Malaysia & Serbia & South Africa & \\
\hline Pakistan & Slovakia* & Tanzania & \\
\hline Philippines & Slovenia* & Uganda & \\
\hline Thailand & Ukraine & Zambia & \\
\hline Vietnam & & & \\
\hline
\end{tabular}

Source: World Bank Development Reports, 2012.

Note: Table listing the 80 selected countries, 28 of which are high income countries $\left(^{*}\right)$ and 52 are low- and middle-income countries, which are grouped in six geographical zones. 


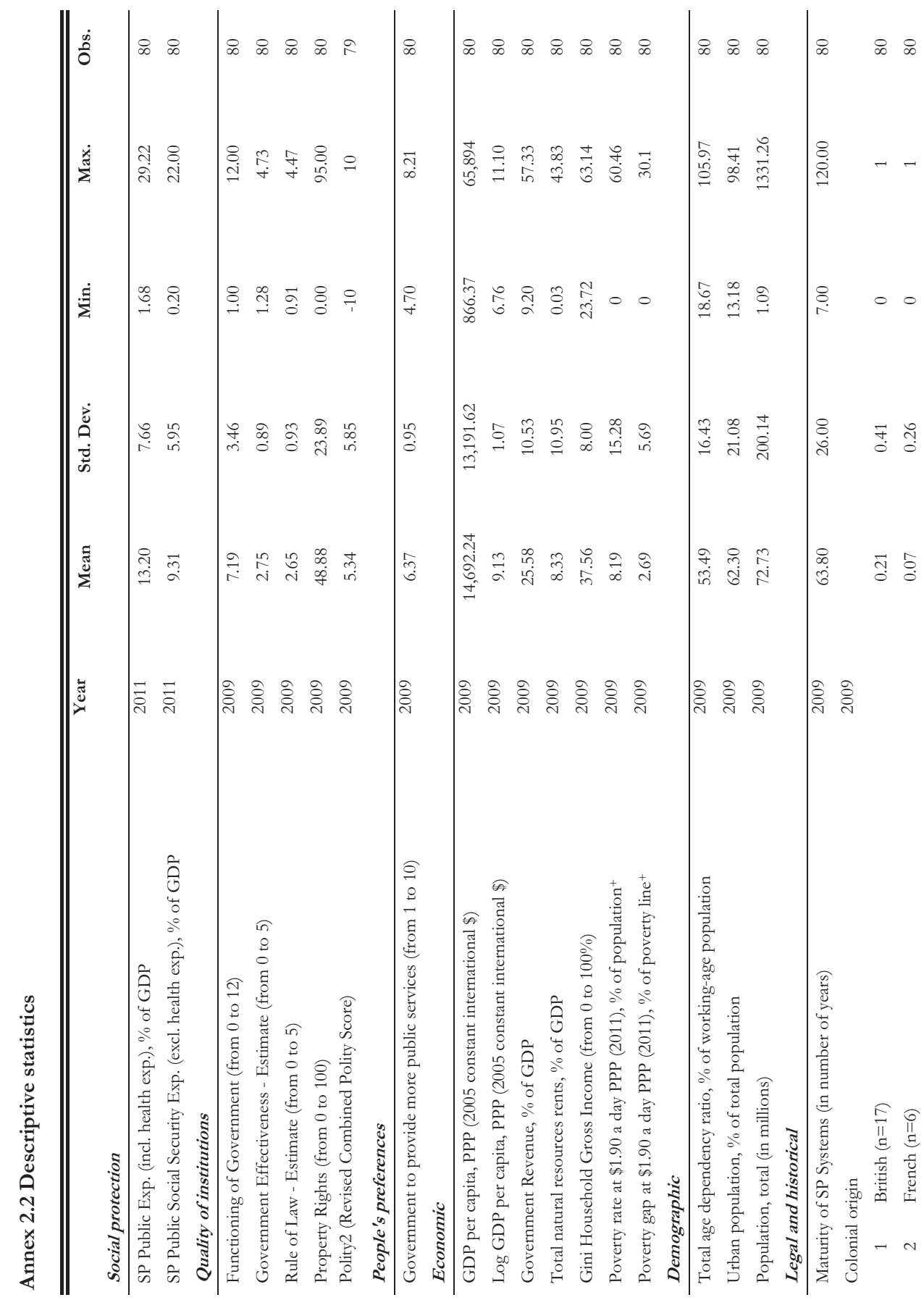




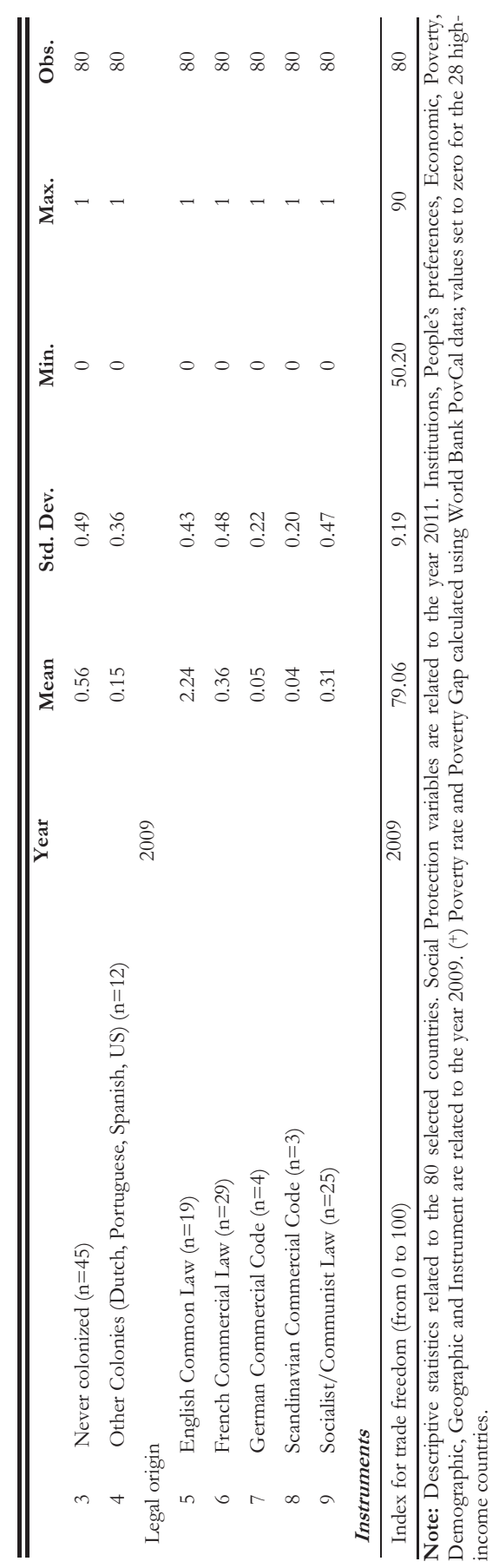




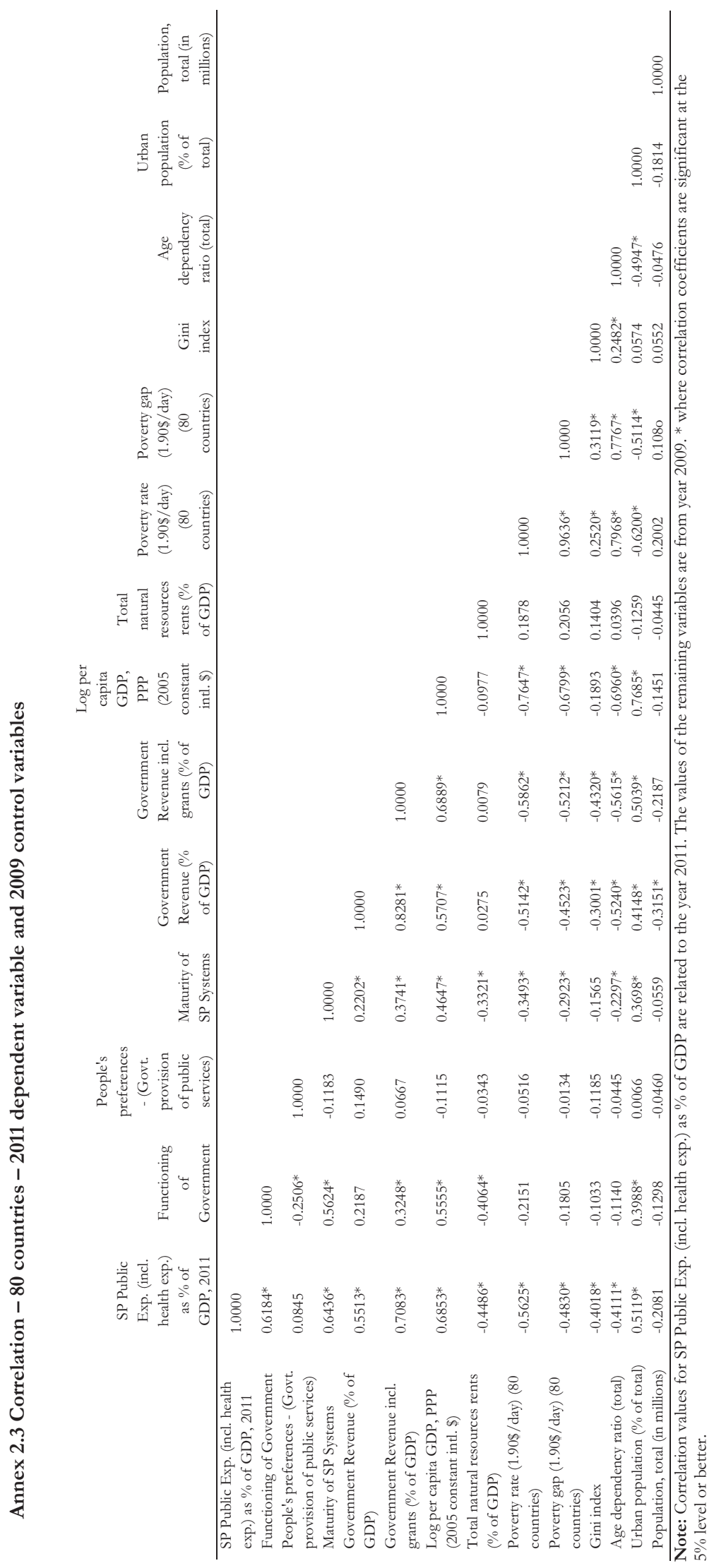




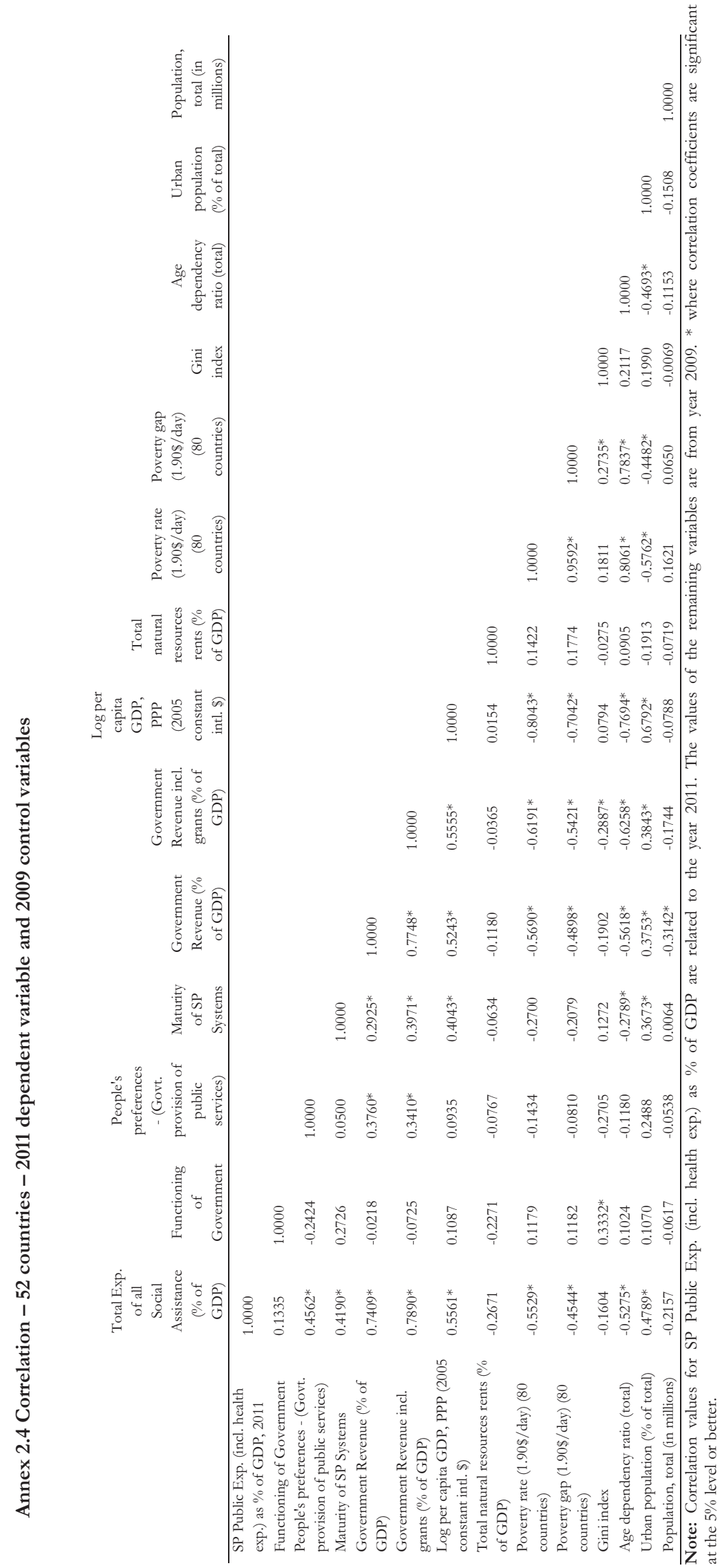




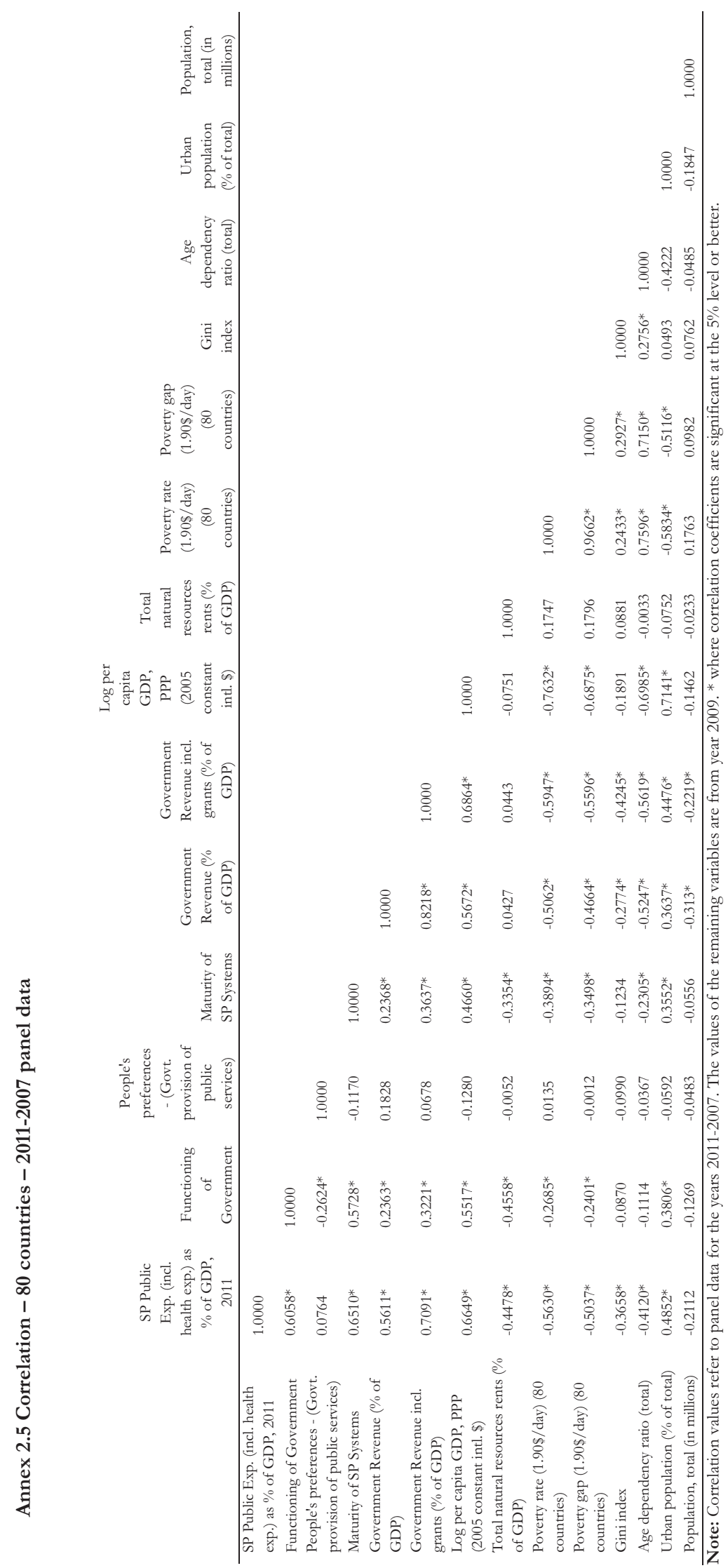




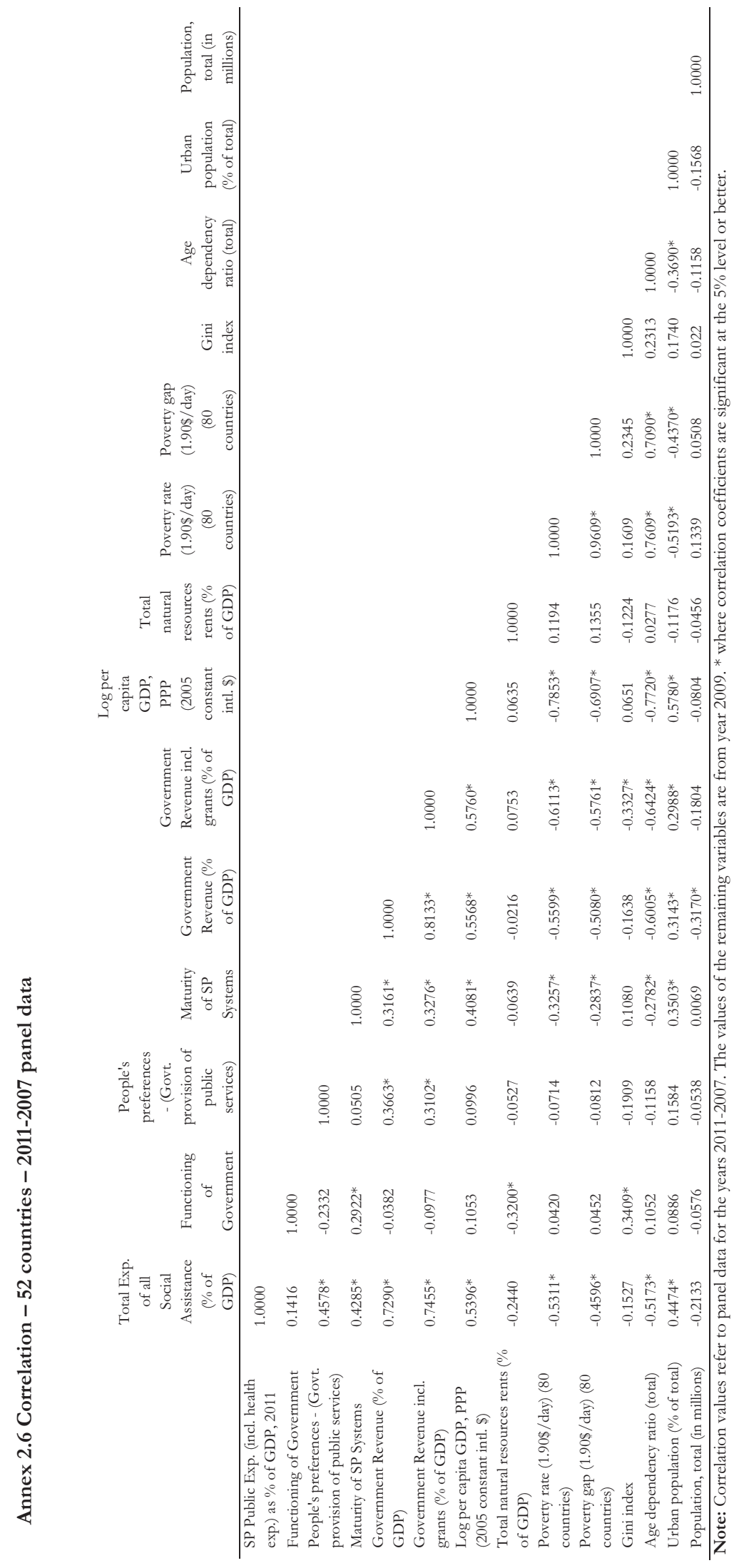




\section{Annex 2.7 Sources of data}

\begin{tabular}{|c|c|c|}
\hline Variable & Countries (Years) & Source \\
\hline \multicolumn{3}{|l|}{ Social protection } \\
\hline SP Public Exp. (incl. health exp.), \% of GDP & $188(1990-2011)^{*}$ & $\begin{array}{l}\text { ILO social protection database, (2014 World Social Protection } \\
\text { Report, Table B.12) }\end{array}$ \\
\hline $\begin{array}{l}\text { SP Public Social Security Exp. (excl. health exp.), \% } \\
\text { of GDP }\end{array}$ & $188(1990-2011)^{*}$ & $\begin{array}{l}\text { ILO social protection database, ( } 2014 \text { World Social Protection } \\
\text { Report, Table B.12) }\end{array}$ \\
\hline \multicolumn{3}{|l|}{ Quality of institutions } \\
\hline Functioning of Government & $196(2005-2012)$ & Quality of Government Basic Dataset (QOG). Freedom House \\
\hline Government Effectiveness - Estimate & $191(1996-2011)$ & $\begin{array}{l}\text { QOG dataset. World Bank, Worldwide Governance Indicators } \\
\text { (WGI) }\end{array}$ \\
\hline Rule of Law - Estimate & $193(1996-2011)$ & QOG dataset. World Bank - WGI \\
\hline Property Rights & $179(1994-2012)$ & QOG dataset. Heritage Foundation \\
\hline Polity2 (Revised Combined Polity Score) & $179(1946-2011)$ & QOG dataset. (Marshall \& Jaggers, 2009) \\
\hline \multicolumn{3}{|l|}{ People's preferences } \\
\hline Government to provide more public services & $98(1990-2014)$ & $\begin{array}{l}\text { World Values Surveys (WVSs). } \\
\text { Period 1990-1994 (wave two - } 17 \text { observations); 1995-1999 (wave } \\
\text { three - } 32 \text { observations); } 2000-2004 \text { (wave four - } 31 \text { observations); } \\
\text { 2005-2009 (wave five - } 28 \text { observations); and 2010-2014 (wave six } \\
\text { - } 52 \text { observations). }\end{array}$ \\
\hline \multicolumn{3}{|l|}{ Economic } \\
\hline GDP per capita, PPP (2005 constant international \$) & $181(1980-2011)$ & $\begin{array}{l}\text { QOG dataset. (World Bank, World Development Indicators } \\
\text { (WDI), 2013) }\end{array}$ \\
\hline Government Revenue, \% of GDP & $149(1990-2011)$ & QOG dataset. (World Bank, WDI 2013) \\
\hline Total natural resources rents, $\%$ of GDP & $220(1970-2014)$ & World Bank - (World Bank, WDI 2017) \\
\hline Gini Household Gross Income (from 0 to $100 \%$ ) & $152(1981-2012)$ & World Bank - PovCal \\
\hline $\begin{array}{l}\text { Poverty rate at } \$ 1.90 \text { a day PPP }(2011), \% \text { of } \\
\text { population }\end{array}$ & $152(1981-2012)$ & World Bank - PovCal \\
\hline $\begin{array}{l}\text { Poverty gap at } \$ 1.90 \text { a day PPP (2011), \% of poverty } \\
\text { line }\end{array}$ & $152(1981-2012)$ & World Bank - PovCal \\
\hline \multicolumn{3}{|l|}{ Demographic } \\
\hline $\begin{array}{l}\text { Total age dependency ratio, } \% \text { of working-age } \\
\text { population }\end{array}$ & $258(1961-2013)$ & World Bank - WDI (accessed on 22 July 2014) \\
\hline Urban population, $\%$ of total population & $258(1961-2013)$ & World Bank - WDI (accessed on 22 July 2014) \\
\hline Population, total & $258(1961-2013)$ & World Bank - WDI (accessed on 22 July 2014) \\
\hline \multicolumn{3}{|l|}{ Legal and historical } \\
\hline Maturity of SP Systems & $175(2009)$ & $\begin{array}{l}\text { Based on International Social Security Agency (ISSA) (Country } \\
\text { Profiles). Author's own calculation. }\end{array}$ \\
\hline Colonial origin & $211(1946-2012)$ & QOG dataset. (Hadenius \& Teorell, 2005) \\
\hline Legal origin & $211(1946-2012)$ & $\begin{array}{l}\text { QOG dataset. (La Porta, López-de-Silanes, Shleifer \& Vishny, } \\
2009 \text { ) }\end{array}$ \\
\hline \multicolumn{3}{|l|}{ Instruments } \\
\hline Index for trade freedom (from 0 to 100 ) & $180(1994-2012)$ & QOG dataset. Heritage Foundation \\
\hline Latitude (from 0 to 1 ) & $211(1946-2012)$ & $\begin{array}{l}\text { QOG dataset. (La Porta, López-de-Silanes, Shleifer \& Vishny, } \\
2009 \text { ) }\end{array}$ \\
\hline
\end{tabular}

Note: $\left.{ }^{*}\right)$ Data available every five years between 1990 and 2005 and yearly for the years 2007 to 2011 . For all the variables if data for the year 2009 is not available, the closest year available is chosen. 


\section{Chapter 3 Institutional Performance and People's Engagement in Social Protection in Nepal}

\subsection{Introduction}

Extended evidence is available on the key role social protection programmes play in contributing to poverty alleviation and in promoting social inclusion (Barrientos \& Hulme, 2010; Jutting \& Prizzon, 2013). Developing countries have established and expanded social protection systems over the past decades acknowledging the importance of these programmes in addressing the structural causes of poverty.

Among other factors, it is recognised that the level of social protection expenditure in a country depends on its demography, its governance, the economic and political environment (Cichon et al., 2004; Wilensky, 1975) and on the quality of the implementation of the social protection programmes (Bastagli et al., 2016). Preliminary estimates provided by Gassmann et al. (2016) on 80 low-, middle- and high-income countries show that the quality of institutions and people's preferences influence the level of expenditure in social protection. Similarly, it can be expected that institutional factors and people's preferences also affect the range of social protection interventions. By focusing on a developing country that has implemented social protection programmes, this study aims to shed light on how the design of social protection programmes can be improved with well-functioning institutions and people's engagement in influencing the quality of provision of social protection interventions.

Different factors determine the nature and scope of social protection programmes. Alesina and La Ferrara (2005) also found that political considerations are essential. The choice for more redistribution depends on voting preferences and public perceptions regarding the extent of government involvement in public services. In addition, social contracts between citizens and their respective governments facilitate the provision of social protection and the shape it takes (Hickey, 2011). Kaltenborn et al. (2017) have found that legal and policy frameworks act as a catalyst in the process of the development of social protection systems. Furthermore, the quality of institutions influence the way governments respond to citizens' demands and so therefore affecting the capacity of the system to deliver the services that satisfy people's preferences (Crouch \& Winkler, 2008). People's preferences may also influence the degree of targeting of social protection interventions (i.e. targeted or universal) which is linked to budget availability and government's political considerations (Pritchett, 2005). Finally, recent literature has highlighted the importance of the quality of implementation and design of social protection interventions in order to reach the desired social protection outcomes (Bastagli et al., 2016).

Following (McNamara, 1999), this chapter refers to the quality of institutions as the functioning, the efficiency and the effectiveness of the government in carrying out its activities to achieve a set of goals. The terms 'quality' and 'performance' of institutions are used interchangeably. Many definitions are provided in the literature on people's preferences (Engelen, 2017; Fisher, 2006; Hausman, 2005; Sen, 2007). They converge on the idea that people's preferences are "the subjective tastes, as measured by utility, of various 
bundles of goods. They permit the consumer to rank these bundles of goods according to the levels of utility they give the consumer"(Veres, Tarjan, \& Hamornik, 2014, p. 8). In this chapter, the notion of people's preferences refers to the extent to which community members are able to influence the choice of social protection interventions in the community through engagement with community structures.

The case of Nepal offers a unique opportunity to explore and examine how the efficient and effective functioning of institutions and people's engagement through community structures can affect the quality of provision of development and of social protection interventions at the local level. In addition, the case study offers an opportunity to understand how Nepal can improve the selection of social protection interventions by focusing on the quality of local institutions and by facilitating people's engagement to influence the choice of social protection interventions by establishing and strengthening the functioning of community structures.

During its history, Nepal has been affected by civil conflict and political instability and the quality of its institutions has reflected to a certain extent these volatile conditions. Yet, during the last decades, the country has showed an increasing commitment to invest in social protection programmes. Some of the main achievements in social protection have found their roots in people's mobilisation and demand for peace and a fair society ${ }^{27}$. The introduction of the social pension in 1995, the subsequent social assistance programmes and the government's commitment to social protection as evidenced by the scale-up of the Child Grant introduced in 2009 and expanded in 2016, are some examples of the attention the country has given to address the needs of the most vulnerable. Furthermore, the government has been allocating Block Grants to Village Development Committees (VDCs) (recently named as "rural municipalities" and representing the lowest administrative level) ${ }^{28}$, to address development and social protection needs, complementing and expanding the national social protection programmes already in place.

While the country has been expanding the scope and scale of social protection systems, challenges abound in the overall harmonization and delivery of social protection interventions. According to the United Nations Development Programme (UNDP), the country could manage its financial resources more effectively, build up institutional and policy capacity to better implement of strategic interventions (UNDP, 2011, 2014) and give greater support to the planning process (UNDP, 2013) and the capacity of the institutions. Several programmes such as the Local Governance and Community Development Programme (LGCDP) have been launched to improve the quality of its institutions and its accountability.

This chapter adopts a qualitative approach and explores the linkages between the quality of institutions and people's preferences in relation to the quality of provision of social protection interventions in Nepal. This chapter builds on the conceptual framework proposed by Gassmann et al. (2016) that summarises how, given a country's initial demographic, economic, legal, political and historical conditions, the quality of institutions and people's preferences can influence the provision of social protection. More specifically, this

\footnotetext{
27 The two People's Movements in 1991 and 2006 for restoring multiparty and federal democracy have contributed to raise the voice of mass demanding social security services especially to take care of the post conflict rehabilitation situation of the country (Mathema, 2012). In this period falls the introduction of the old age allowance in 1995.

${ }^{28}$ The Village Development Committee (VDC) was dissolved on March 10, 2017 by the "gaunpalika". According to the Ministry of Federal Affairs and Local Development the English translation to be used is "rural municipality".
} 
chapter analyses the extent to which the effective management of Block Grants and the establishment of community structures at the VDC level affect the quality of provision of development and social protection activities and how people's preferences influence the selection of development and social protection activities at the VDC level.

This chapter contributes to the literature in the following ways: (i) through primary data collection it investigates linkages between the quality of institutions, people's preferences and the provision of the Block Grant in Nepal with particular focus on social protection interventions; (ii) furthermore, this chapter represents the first study conducted in South Asia with the ultimate objective of exploring the functioning of the local administration, the community structures and the way community members and social protection clients engage with community structures and local administration to influence the range of social protection interventions implemented at the VDC level which reflect the needs of community members and social protection clients.

The remainder of this chapter is structured as follows: Section 2 presents the country and programme context and operationalises the different concepts and section 3 describes the study methodology. Section 4 presents the research findings and section 5 offers a discussion in relation to the main hypotheses. Section 6 concludes and identifies policy implications.

\subsection{Case study on Nepal}

Nepal is a landlocked country in South Asia with a population of 26 million according to the 2011 census, containing diverse ecological zones and is prone to natural disasters. In 2015 , the country was hit by a double earthquake. The country is divided into seven provinces and 77 districts including 753 local units ${ }^{29}$. The country has experienced important political changes in the last thirty years and it was a monarchy till 1990. With the latest constitution signed in 2015, Nepal has identified three organs of Government: the executive, the judicial and the legislative, formally moving to a bicameral parliament. The country has held successfully elections at the local, provincial and national levels in 2017.

Nepal is one of the poorest countries in the world. During the period 1990-1996, which followed the establishment of the multi-party democracy, the country had an average annual GDP growth rate of 6 percent. ${ }^{30}$ As a result of the civil conflict, the growth rate reduced to an average of 4.4 percent during the period 1996-2006 and remained around that level until 2014. Table 3.1, compares South Asian nations' social development and institutional performance indicators. With the exception of Sri Lanka and Maldives, the countries in this region show bottom scores among the 188 countries included in Human Development Index (UNDP, 2015). According to the index for government effectiveness - a measure of quality of institutions Nepal ranked 142 out of 215 countries in 1996 and just 173 out of 215 countries in 2016.

\footnotetext{
${ }^{29}$ There are 6 metropolises, 11 sub-metropolises, 276 municipal councils and 460 village councils for official works.

${ }^{30}$ Source: World Development Indicators, accessed on March 2016. Annual percentage growth rate of GDP at market prices based on constant local currency. Aggregates are based on constant 2005 U.S. dollars.
} 
Table 3.1 Development, governance and poverty estimates in South Asia

\begin{tabular}{|c|c|c|c|c|c|c|c|c|}
\hline & $\begin{array}{c}\text { Afghanista } \\
\mathrm{n}\end{array}$ & $\begin{array}{c}\text { Banglades } \\
\mathrm{h}\end{array}$ & $\begin{array}{c}\text { Bhuta } \\
\text { n }\end{array}$ & $\begin{array}{c}\text { Indi } \\
\text { a }\end{array}$ & $\begin{array}{c}\text { Maldive } \\
\mathrm{s}\end{array}$ & $\begin{array}{c}\text { Nepa } \\
1\end{array}$ & $\begin{array}{c}\text { Pakista } \\
\text { n }\end{array}$ & Sri Lanka \\
\hline HDI, 2015 & 171 & 142 & 132 & 130 & 104 & 145 & 147 & 73 \\
\hline SPFI $^{\mathrm{b}}$ & - & - & 3.0 & 3.7 & 1.2 & 3.8 & 3.5 & 3.9 \\
\hline CPI, $2015^{c}$ & 166 & 139 & 27 & 76 & $\mathrm{n} / \mathrm{a}$ & 130 & 117 & 83 \\
\hline $\begin{array}{l}\text { WGI, 2014d } \\
\text { 1. Government } \\
\text { effectiveness }\end{array}$ & 8.17 & 21.63 & 62.50 & 45.19 & 41.83 & 19.71 & 22.12 & 57.21 \\
\hline 2. Voice and accountability & 15.76 & 32.51 & 43.84 & 61.08 & 37.44 & 33.00 & 27.09 & 27.59 \\
\hline 3. Political stability & 2.91 & 17.96 & 82.52 & 13.59 & 78.64 & 22.33 & 3.40 & 34.95 \\
\hline 4. Regulatory quality & 11.54 & 18.27 & 15.38 & 34.62 & 39.90 & 20.67 & 27.88 & 50.00 \\
\hline 5. Rule of law & 2.40 & 25.96 & 67.79 & 54.33 & 36.54 & 28.37 & 23.56 & 51.92 \\
\hline $\begin{array}{l}\text { 6. Control of corruption } \\
\text { Poverty headcount ratio, }\end{array}$ & 6.25 & 18.75 & 88.46 & 38.94 & 54.81 & 36.06 & 21.63 & 46.63 \\
\hline$\$ 1.90$ per daye & $\mathrm{n} / \mathrm{a}$ & 73.65 & 2.20 & 21.25 & 5.59 & 14.95 & 8.30 & 1.69 \\
\hline
\end{tabular}

Source: Lowest and highest values are in bold. a Human Development Index (HDI). Ranking among 188 countries, Human Development Report UNDP, www.hdr.undp.org, accessed on 21 April, 2016. b SPFI country ranking based on relative minimum income criterion and income floor, 2012. ${ }^{c}$ Corruption Perception Index (CPI). Ranking among 167 countries, www.transparency.org, accessed 21 April, 2016. d Worldwide Governance Indicators (WGI), www.info.worldbank.org/governance/wgi//accessed 21 April,

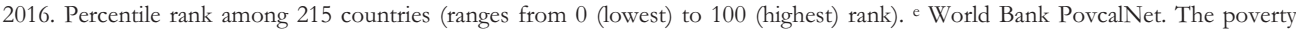
headcount measures the percentage of population living in households with consumption or income per person below the poverty line. Estimates based on the latest year available and based on 2011 PPP for all countries. Estimates for Bangladesh are based on 2005 PPP where the poverty headcount is 43.26 based on $\$ 1.25$ per day, www.iresearch.worldbank.org/PovcalNet/, accessed 21 April, 2016.

Over the past decades, the country has constantly invested in reducing disparities and discrepancies among the people, expanding progressively the scale and scope of social protection programmes (see Annex 2) supported by political party competition and of public pressure (Koehler, 2014). Although the poverty rate

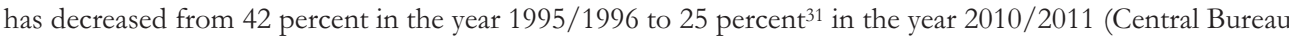
of Statistics, 2011), poverty is still far from being eradicated. This also due to the current level of economic growth which level that is insufficient to make a dent in the poverty rate (MoFALD, 2013).

According to ILO estimates ${ }^{32}$ (2014) the total amount of public social protection ${ }^{33}$ and health expenditure in Nepal is of 2.19 percent of the GDP compared to 1.5 percent of GDP in 2005. However, the country scores below South Asian countries' average in terms of expenditure allocated to social protection programmes of 5.20 percent of GDP (see Figure 3.1).

\footnotetext{
31 According to the 2010/2011 Living Standards Survey (Central Bureau of Statistics, 2011), 15.5 percent of the Nepali population living in urban areas were living below the poverty line compared to 27.4 percent in the rural areas.

${ }^{32}$ Latest year available for the following countries: Afghanistan (2011), Bangladesh (2011), Bhutan (2012), India (2012), Maldives (2012), Nepal (2013), Pakistan (2010), Sri Lanka (2012).

33 According to ILO's estimates (ILO, 2014), the average amount of public social protection expenditure in Nepal is of 0.66 percent of GDP (or 2.19 percent of GDP if health expenditure is included) which is lower than the average of the South Asian countries of 2.08 percent of GDP (or 3.62 percent of GDP including health expenditure). The scope of the ILO indicator corresponds to the scope of the Social Security (Minimum Standards) Convention, 1952 (No.102).
} 
Figure 3.1 Social protection expenditure in South Asia countries, as \% of GDP

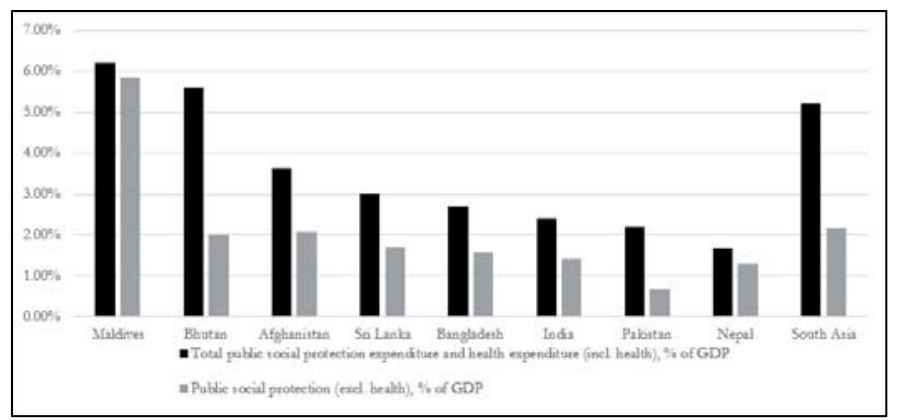

Source: Adapted from Table B.12. Public social protection expenditure, latest available year (\% of GDP) in "World Social Protection Report", by (ILO, 2014).

The proliferation of social protection interventions in Nepal in the previous years has created some questions over the overall effectiveness of the social protection system to achieve its full potential. These challenges stem from the fragmentation and lack of coordination among the existing social protection interventions (see Annex 3.2) which hamper efforts at poverty reduction and to address households' vulnerabilities. Effort has been made to address these issues by creating a social protection strategy that takes advantage of synergies across these interventions. However, the strategy has not yet been adopted yet by the Government.

After two decades of underinvestment in the area of social protection, Nepal has started increasing its budget commitment to allocate budget on social protection also as a way of promote peace after the 19962006 civil conflict and the peace agreement of 2007. The Old Age Allowance introduced in 1995 has been gradually expanded from NPR 100 in 1995 to NPR 2,000 in 201634. The Child Grant introduced in 2009 (Ministry of Finance, 2009) - a tax-financed, non-contributory and unconditional cash transfer to improve nutritional outcomes for vulnerable groups - was expanded in 2016 taking advantage of the political legitimacy and evidence produced on the positive impact of social protection interventions (Garde, Mathers, \& Dhakal, 2017). The Block Grant - a lump sum transfer provided by the government via the District Development Committees (DDC) to the VDCs ${ }^{35}$ - was introduced in $2006^{36}$ (NPC) to complement and support development and social protection interventions and has been recently expanded by the Government with an extra NPR 0.5 million, bridging the total amount transferred to the VDC to NPR 1 million (about USD $10,000)$.

\footnotetext{
${ }^{34}$ NRs 2,000 per month for citizens over 70 and NRs 1,000 for citizens over 60 in Karnali region or Dalits distributed three times in a year.

${ }^{35}$ Apart the Block Grant's lump sum transferred to all the VDCs, Block Grants are also transferred to DDCs and municipalities. The criteria used for the allocation of the Block Grant to DDC include: population size ( 20 percent), size of the territory (area) (10 percent), human development index (50 percent) and cost index (20 percent). The criteria instead used to transfer the Block Grants to municipalities is more complex and while propositions were made to include criteria similar to the ones used for the allocation of Block Grants to DDCs, the new formula has still not been applied by the government.

36 The Block Grant was introduced under the impulse of the National Planning Commission (NPC). The planning commission, changed names and compositions across the years. After the restoration of multiparty democracy in 1990, the newly elected government reconstituted the NPC again with the prime minister as chair, a full-time vice-chairman, seven members, and a member-secretary.
} 
The Block Grant is divided into the recurrent and capital amounts and sector and non-sector specific allocations ${ }^{37}$. In particular, there is a mandatory provision to support vulnerable segments of the community such as 10 percent for women, 10 percent for children and 15 percent for other disadvantaged groups. This 35 percent mainly reflects the social protection amount of the Block Grant. The VDC is in charge of allocating the Block Grant after consultations with the community either through general meetings or by using existing community structures such as the Citizen Awareness Centres (CACs) and Ward Citizens' Forums (WCFs) ${ }^{38}$.

The CACs and WCFs are key in channelling people's preferences and in providing a platform where community members and social protection clients can engage with VDC representatives or simply hold local representatives accountable for their choices (Lawoti, 2005). Therefore, these community structures can influence the allocation of the Block Grants to development and social protection interventions. However, the functioning of these community structures have been modest and there is a need to strengthen these mechanisms (Jones \& Bhatta, 2009; MoFALD, 2013). This means that in some instances people are not able to express their needs to local government because either community structures are not established or not functioning. Existing programmes such as the Local Governance and Community Development Programme have recognised the importance of strengthening the quality of these community mechanisms as a way to improve people's ability to express their preferences (MoFALD, 2013) but more still needs to be done.

This chapter focuses on the Block Grants which are allocated at VDC level and used to complement national social protection programmes implemented at VDC level by supporting local development and social protection activities. The analysis aims to understand the extent to which the effective and efficient management of the Block Grants can affect the provision of development and social protection interventions. Furthermore, this chapter investigates how the establishment and functioning of community structures and the extent to which people express their preferences through these community structures impact on the provision of development and social protection activities.

For the analysis, the different concepts have to be operationalised. Proxies need to be defined that reflect the quality of institutions, people's preferences and the quality of provision of social protection interventions.

The following dimensions are considered as proxies for quality of institutions:

\footnotetext{
37 The composition is: NRs 0.2 million for recurrent costs (such as salary and benefits of VDC staff members; annual salary of chairman and vice chairman; meeting allowance and stationary; grant for the teachers' who are recruited at a predetermined ratio of teachers to students; grant for health workers; and expenditures in human resource development). An amount of NPR 0.3 million is allocated for certain types of capital investments of which 0.15 million can also be spent as matching fund to carry activities to support women empowerment, projects involving benefits of children, mainstreaming of Dalits, uplifting of Indigenous groups and Janajatis and projects involving benefits of physically impaired and disabled. The top-up of NPR 0.5 million has been added to the capital grant component and can be spent on a range of capital investments (rural electrification, road, irrigation, bridge, drinking water, school building construction and health) only after the authorisation of the Local Development Officer (LDO) (Government of Nepal, 2008). This is the only part of the Block Grant that will be returned to the central level at the end of the fiscal year if not fully spent.

${ }^{38}$ Citizen Awareness Centres (CACs) and Ward Citizen Forums (WCFs) are community institutions at VDC level. According to the Local Governance and Community Development Programme (LGCDP). Each VDCs should have one CAC and nine WCFs. The major aim to form Citizen Awareness Centre is to empower community people for active engagement with local governments and strengthening downward accountability and capacity development to claim their rights. Each VDC has nine ward citizenship forums with 25 members. There are 225 members in each village who hold annual meeting to contribute to decide the budget and development programs.
} 
- VDC's clarity on how to allocate and efficiently manage the Block Grant at the VDC level as reported by VDC secretaries and community members.

- Establishment, efficient and regular functioning of community structures such as the community awareness centres and world citizen forums, as reported by the VDC secretaries and community members.

People's preferences are captured by:

- The extent to which community members and social protection clients are able to express their preferences on development and social protection activities through community awareness centres and world citizen forums, as reported by VDC secretaries and community members.

The quality of provision is assessed by:

- The range and the extent to which development and social protection activities implemented by the VDC reflect the needs of the community members and social protection clients. This includes the process of identification of development and social protection activities, as reported by VDC secretaries and by community members. Some examples of development and social protection activities are: road constructions, skill development and income generation training (such as beekeeping, and goat-keeping, tunnel farming, incense stick making), school meals programmes, scholarship programmes, women's awareness programmes on violence, women's empowerment training.

The underlying hypotheses are as follows: (i) village development committees with better institutions show a greater range of social protection interventions and; (ii) village development committees where community members and social protections clients' preferences are expressed through community structures have a greater range of social protection activities which reflect the needs of community members and social protection clients.

\subsection{Methodology}

This chapter is qualitative in nature because this approach provides and emphasises nuances, sequences and multiple perspectives (Bloomberg, Cooper, \& Schindler, 2008; Miles \& Huberman, 1994; Stake, 1995) and it is most suited to understand real-world context (Yin, 2014) and concepts such as the quality of institutions and people's preferences. It is important to note that the research is not aimed at national or local statistical representativeness and, in consultation with local counterparts and national experts, a purposeful sampling was used to select the VDC and the wards ${ }^{39}$ where the interviews were conducted.

A review of the available literature has been carried out largely on the basis of existing secondary resources available on current social protection programmes, research reports and publications by government agencies in Nepal. To complement the literature review, there have been a range of interviews with key stakeholders

${ }^{39}$ A ward in Nepal is a political division. Nine wards make up a village development committee (VDC); VDCs make districts; districts make zones; and zones (regions) make up the country. 
(KIIs) involved in the management and delivery of social protection interventions including government officials, selected international and civil society organisations, and VDC representatives (see Table 3) involved in the management and delivery of social protection interventions. Focus group discussions (FGDs) with beneficiaries and non-beneficiaries of social protection interventions were conducted at the VDC level, as well. Interviews conducted at the central and local level explored the functioning of the main ministries and local administration involved in the provision of social protection interventions and to gather perspectives about the role of social protection in the country and the extent to which people's engagement influences the range of development and social protection interventions.

Data collection was undertaken in six selected VDCs, five in Kaski district and one in the district of Kavrepalanchok. In this last district, interviews were conducted to pre-test the interview protocol ${ }^{40}$. Three VDCs were sampled with high level of institutional performance and three VDCs with a low level of performance. The selection of VDCs with a high and low levels of institutional performance was based on the Minimum Conditions Performance Measure score (MCPM). ${ }^{41}$ The choice of undertaking the study only in one district, while acknowledging that this decision might have limited the external validity of the findings, was motivated by the desire to have an in-depth understanding and variation of the different level of institutional performance of VDCs within the selected district. The district of Kaski covers an area of 2,017 square $\mathrm{km}$ and has a population of 492,098 according to 2011 census and its altitude ranges from 450 metres the lowest land to 8,091 metres at the highest point in the Himalaya range. The district consists of peoples with multiple languages, religions and cultures. There are also different cuisines, dresses and norms based on people's caste and religion. According to the last census, the district of Kaski has people from about 84 castes such as Gurung, Brahmin, Chhetri, Newar, Thakali, Kumal, with 44 languages and 11 religions.

The selection of the VDCs was conducted in three steps: firstly the effect of the MCPM on the final amount of the local grant allocated to the VDC was calculated for all the VDCs in the district of Kaski. Secondly, depending on the magnitude of the effect of the MCPM on the final amount of the local grant allocated to the VDCs, two groups of VDCs were created representing low (0-22 percent) and high (higher than 22 percent) level of VDC performance (based on accountability, transparency and responsiveness indicators ${ }^{42}$ ) (see Table 3.2). Thirdly, two VDCs were identified from each of the two identified groups based on their facility to be reached. The high-performing VDC in the district of Kavrepalanchok, the location of the pre-test, was added to the analysis as the district and the VDC present similar socio-economic conditions.

\footnotetext{
${ }^{40}$ Ethical Review Committee Inner City (ERCIC) of Maastricht University provided approval of the interview protocols.

${ }^{41}$ Minimum Conditions Performance Measure assesses the performance of local bodies based on a set of criteria and standards and tie up the block grants based on their performance results. In Rule no 273 (d) of Local Self-Governance Regulation, it is stated that MoFALD can evaluate the local bodies based on the MCPM indicators (i.e. accountability, transparency and responsiveness) and award them in the recommendation of Local Bodies Fiscal Commission. This on one hand encourages the local bodies to improve their performance and on the other helps to tie up grants with their capacity that will enable capable local bodies to acquire additional grants (http://lbfc.gov.np/manuals).

42 To assess VDCs, the MCPM includes a list of 13 indicators in which VDC should require 40 marks (over a total of 100 ) for the eligibility of full topping up grants: 1 Participatory Planning (15); 2 Budget Releases and Expenses (10); 3 Budget Allocation and expenses for Targeted Groups and Sectors (10); 4 Publicize the Revenues and Expenditures (10); 5 Implementation of Social Security Programme (5); 6 Record Keeping of Vital Registration (5); 7 Village Profile (5); 8 Citizen Charter (5); 9 Public Audit (5); 10 Inventory Management (5); 11 Internal Resource Management (10); 12 Public Hearing (5); 13 Advances and irregularities (10) (http://lbfc.gov.np/vdc).
} 
Table 3.2 List of selected VDCs for field work

\begin{tabular}{lllll} 
No. & VDC & District and (Zone)/ Capital & $\begin{array}{l}\text { VDC/Development } \\
\text { Region/Ecological }{ }^{43} \text { Region }\end{array}$ & VDC Population \\
\hline $\mathbf{1}$ Pre-test & VDC 1 (H) & Kavrepalanchok (Bagmati)/Dhulikhel & VDC 1/Central/Hill & 6,121 (2,935 M; 3,186 F) \\
$\mathbf{2}$ & VDC 2 (L) & Kaski (Gandaki)/Pokhara & VDC 2/Western/Hill & 3,880 (1,957 M; 2,135 F) \\
$\mathbf{3}$ & VDC 3 (L) & Kaski (Gandaki)/Pokhara & VDC 3/Western/Hill & $3,257(1,468 \mathrm{M} ; 1,789 \mathrm{~F})$ \\
$\mathbf{4}$ & VDC 4 (L) & Kaski (Gandaki)/Pokhara & VDC 4/Western/Hill & 5,892 (2,591 M; 3,301 F) \\
$\mathbf{5}$ & VDC 5 (H) & Kaski (Gandaki)/Pokhara & VDC 5/Western/Hill & $2,993(1,254 \mathrm{M}$; 1,739 F) \\
$\mathbf{6}$ & VDC 6 (H) & Kaski (Gandaki)/Pokhara & VDC 6/Western/Hill & 2,637 (1,151 M; 1,486 F) \\
\hline
\end{tabular}

Note: The column VDC lists the selected VDCs and their institutional performance based on the MCPM score where L indicates lowperforming VDCs (MCPM < 22 percent) and H indicates high-performing VDCs (MCPM $>$ than 22 percent). VDC/District population from Population Nepal Census, 2011. Total population in the district of Kaski is 480,952 (228,074 M; 252,878 F) and 375,221 (177,546 M; 197,675 F) in the district of Kavrepalanchok. All the selected districts belong to the Hill Ecological region.

The pre-testing of the interview protocol was conducted in one high-performing VDC in the district of Kavrepalanchok because of its vicinity to Kathmandu. The pre-testing had the following objectives: (i) testing the time needed to conduct the KIIs and FGDs; (ii) assessing whether the KIIs and FGDs questions were translated properly and were understandable and appropriate to the local context; (iii) determining whether revisions needed to be made or additional questions to be added. Interview protocols were translated into Nepali and translated back into English to ensure consistency of meaning of content between protocols using different languages. Field guidelines were developed to guide the data collection that was held during the period 26 May 2016 - 29 July 2016. The field work included 16 KIIs and 22 FGDs with a total of 210 participants (40 percent male and 60 percent female) with an average age of 54 years (see Table 3.3 and Annex 3.3). The choice to have separate FGDs with men and women of the Dalit group was justified in order to enable a free discussion without potential pressure stemming from the presence of higher cast members. In total, seven FGDs exclusively involved 71 Dalits (38 percent male and 62 percent female) representing 34 percent of the total number of people interviewed. All fieldwork was conducted in Nepali with exception made for the KIIs at central level, which were conducted in English.

Table 3.3 Overview of KIIs and FGDs

\begin{tabular}{|c|c|c|c|}
\hline Location & KIIs & & \\
\hline Kathmandu & \multicolumn{3}{|c|}{$\begin{array}{l}\text { Ministry of Federal Affairs and Local Development (MoFALD); Ministry of Finance (MoF); National Planning } \\
\text { Commission (NPC); Nepan; HelpAge; Ministry of Peace and Reconstruction (MoPR); Women for Human } \\
\text { Rights; - The World Bank; Save the Children - General Federation of Nepalese Trade Unions (GEFONT) }\end{array}$} \\
\hline Total & \multicolumn{3}{|c|}{10} \\
\hline Location & $\begin{array}{l}\text { KIIs } \\
\text { (VDC } \\
\text { representative) }\end{array}$ & $\begin{array}{l}\text { FGDs } \\
\text { (Male and Female } \\
\text { Dalits) }\end{array}$ & $\begin{array}{c}\text { FGDs } \\
\text { (Male and Female group -including senior citizens, single } \\
\text { women, disabled people, beneficiaries and non-beneficiaries } \\
\text { of social protection benefits-) }\end{array}$ \\
\hline VDC $1(\mathrm{H})$ & 1 & 0 & 3 \\
\hline VDC $2(\mathrm{~L})$ & 1 & 0 & 3 \\
\hline VDC 3 (L) & 1 & 1 & 2 \\
\hline VDC $4(\mathrm{H})$ & 1 & 2 & 2 \\
\hline VDC 5 (L) & 1 & 2 & 3 \\
\hline $\operatorname{VDC} 6(\mathrm{H})$ & 1 & 2 & 2 \\
\hline Total & 6 & 7 & 15 \\
\hline
\end{tabular}

\footnotetext{
${ }^{43}$ Development regions: Eastern, Central, Western, Mid-West and Far West. Ecological regions: Mountains, Hills and Tarai.
} 
Data collection was implemented by a local research team (composed of one FGD facilitator and one note taker) which was experienced and had previously implemented researches with similar design. Prior to the fieldwork, the researchers were trained on the topic and provided with operational definitions of key concepts such as Block Grant or the Planning and Budgeting process in Nepal. Data analysis involved the reading and re-reading of the responses collected using a process of categorization and identification of themes, trends and patterns across the different segments of respondents identifying coherent categories. Next, the responses were systematically translated and transcribed to English and analysed. The themes, such as empowerment, transparency, grievance, were identified using both word counting and line-by-line analysis to ensure, to the extent possible, consistency with the literature review and collected data. Furthermore, the analysis was aimed at ensuring validity of findings across different types of respondents through triangulation and observation.

Prior to the fieldwork, data was gathered on the amount of Block Grant (capital and recurrent) transferred to the selected low- and high-performing VDCs and on the estimated portion of funds earmarked for social protection interventions. The information in Table 4 and collected at the central level was the starting point to understand whether the Block Grants were transferred to the VDCs and estimate the amount of Block Grant earmarked for social protection interventions.

On average, the selected VDCs received an average of NPR 1.8 million (about USD 18,000) as a capital grant (including the top up provided in relation to previous year's VDC performance based on the MCPM score), estimated NPR 0.4 million (about USD 4,300) to cover recurrent costs and an estimated average of NPR 0.6 million (about USD 6,300) for discretionary allocation for social protection interventions (representing 35 percent of the capital grant assigned to the VDC) (see Table 3.4). The table reflects low variation of the different amounts of the Block Grants allocated among the selected VDCs. The utilization of the Block Grant was not available at the central level and the data related to the level of execution of the Block Grant was gathered during the interview with VDC representatives. However, VDC representatives interviewed were not able to provide precise figures due to the limited accounting process and recording of expenditure implemented in the VDCs. Instead, they rather reported that the social protection amount part of the Block Grant was fully spent with the exception of the VDC of Kaskikot ${ }^{44}$.

Table 3.4 Allocation of Block Grant at VDC level

\begin{tabular}{|c|c|c|c|c|c|c|}
\hline No. & VDC & $\begin{array}{l}\text { Capital } \\
\text { Amount }\end{array}$ & $\begin{array}{l}\text { Recurrent } \\
\text { Amount }\end{array}$ & $\begin{array}{l}\text { Social } \\
\text { Protection } \\
\text { Amount }\end{array}$ & $\begin{array}{c}\text { Final } \\
\text { Allocation }\end{array}$ & Population \\
\hline 1 - Pre-test & VDC $1(\mathrm{H})$ & $\begin{array}{r}2,090(672) \\
\text { USD } 20,409(6.562)\end{array}$ & $\begin{array}{r}453 \\
\text { USD } 4.424\end{array}$ & $\begin{array}{r}732 \\
\text { USD } 7.148\end{array}$ & $\begin{array}{r}2,543 \\
\text { USD } 24.833\end{array}$ & 6,121 \\
\hline 2 & VDC 2 (L) & $\begin{array}{r}1,845(533) \\
\text { USD } 18,017(5,205)\end{array}$ & $\begin{array}{r}434 \\
\text { USD } 4,238\end{array}$ & $\begin{array}{r}646 \\
\text { USD } 6,308\end{array}$ & $\begin{array}{r}2,279 \\
\text { USD } 22,255\end{array}$ & 3,880 \\
\hline 3 & VDC $3(\mathrm{~L})$ & $\begin{array}{r}1,778(486) \\
\text { USD } 17,362(4,746)\end{array}$ & $\begin{array}{r}434 \\
\text { USD } 4,238\end{array}$ & $\begin{array}{r}622 \\
\text { USD } 6,074\end{array}$ & $\begin{array}{r}2,212 \\
\text { USD } 21,601\end{array}$ & 3,257 \\
\hline 4 & VDC $4(\mathrm{~L})$ & $\begin{array}{r}1,869(781) \\
\text { USD } 18,251(7,627)\end{array}$ & $\begin{array}{r}453 \\
\text { USD } 4,424\end{array}$ & $\begin{array}{r}654 \\
\text { USD } 6,386\end{array}$ & $\begin{array}{r}2,322 \\
\text { USD } 22,675\end{array}$ & 5,892 \\
\hline 5 & $\operatorname{VDC} 5(\mathrm{H})$ & $1,747(420)$ & 434 & 611 & 2,181 & 2,993 \\
\hline
\end{tabular}

${ }^{44}$ Kaskikot VDC reported that only 20 percent of the amount earmarked for social protection interventions allocated to the VDC was spent in the year 2014/2015 because of lack of clarity in policies and insufficient time to implement social protection interventions. 


\begin{tabular}{|c|c|c|c|c|c|c|}
\hline No. & VDC & $\begin{array}{l}\text { Capital } \\
\text { Amount }\end{array}$ & $\begin{array}{l}\text { Recurrent } \\
\text { Amount }\end{array}$ & $\begin{array}{c}\text { Social } \\
\text { Protection } \\
\text { Amount }\end{array}$ & $\begin{array}{c}\text { Final } \\
\text { Allocation }\end{array}$ & Population \\
\hline 1 - Pre-test & VDC $1(\mathrm{H})$ & $\begin{array}{r}2,090(672) \\
\text { USD } 17,060(4,101)\end{array}$ & $\begin{array}{r}453 \\
\text { USD } 4,238\end{array}$ & $\begin{array}{r}732 \\
\text { USD 5,967 }\end{array}$ & $\begin{array}{r}2,543 \\
\text { USD } 21,298\end{array}$ & 6,121 \\
\hline 6 & $\operatorname{VDC} 6(\mathrm{H})$ & $\begin{array}{r}1,736(396) \\
\text { USD } 16,952(3,866)\end{array}$ & $\begin{array}{r}434 \\
\text { USD } 4,238\end{array}$ & $\begin{array}{r}608 \\
\text { USD } 5,937\end{array}$ & $\begin{array}{r}2,170 \\
\text { USD } 21,190\end{array}$ & 2,637 \\
\hline Average & & $\begin{array}{r}1,844(548) \\
\text { USD } 18,009(5,351) \\
\end{array}$ & $\begin{array}{r}440 \\
\text { USD } 4,300 \\
\end{array}$ & $\begin{array}{r}645 \\
\text { USD } 6,303 \\
\end{array}$ & $\begin{array}{r}2,285 \\
\text { USD } 22,317 \\
\end{array}$ & 4,130 \\
\hline
\end{tabular}

Source: Author's compilation. The column VDC lists the selected VDCs and their institutional performance based on the MCPM score where $\mathrm{L}$ indicates low-performing VDCs (MCPM $<22$ percent) and $\mathrm{H}$ indicates high-performing VDCs (MCPM $>$ than 22 percent). Columns Capital Amount (including the MCPM effect), Recurrent Amount, Social Protection Amount and Final Allocation report the different components of the Block Grant where Social Protection Amount has been estimated as 35\% of the Capital Amount allocated to the VDC. Data on Capital Grant, MCPM effect and Recurrent Amount borrowed by MoFALD. Values in Nepali Rupees (NPR) unless otherwise stated. Exchange rate applied (US\$ 1 = to NPR 102.405 in 2015), World Bank Indicators.

The interviews aimed at exploring how people were articulating their preferences and expressing their needs through community structures thereby influencing the planning and budgeting process and the allocation of the Block Grants to support development and social protection activities.

No major challenges were encountered during the fieldwork. The communication with the VDC representatives and community members was properly managed and the research team adjusted the field work schedule based on the availability of the VDC representatives. In terms of the availability of information, detailed documentation on budgets and expenditures were not available at the VDC level. In some cases, hand written notes were provided containing the list of social protection interventions implemented in the VDC. Yet, information on the actual execution of the Block Grant was most of the time not available and only communicated verbally. Only five VDCs were eventually covered in Kaski district out of the six VDCs initially selected because saturation was reached during the interview process. Availability of secondary data at VDC level was limited and it was difficult to find academic sources of information related to the selected VDCs regarding quality of institutions and people's preferences.

\subsection{Findings}

\subsubsection{Quality of institutions}

This section explores the quality of institutions at the VDC level. The quality of institutions is demonstrated by the following two factors: (i) VDC's clarity on how the Block Grant is allocated and managed and (ii) by the establishment and the level of functioning of community structures such as the citizen awareness centres and ward citizen forums.

VDCs with a high MCPM score are assumed to have better quality institutions and to be high-performing compared to the VDCs with low MCPM scores. Findings confirm that the selected high-performing VDCs are functioning better compared to those low-performing VDCs. Table 3.5 presents an overview of illustrative quotes followed by a discussion of findings for each of the proxies for quality of institutions. 
Table 3.5 Overview of quotes regarding Block Grant management and community structures

\begin{tabular}{|c|c|c|}
\hline & Low-performing VDCs & High-performing VDCs \\
\hline $\begin{array}{l}\text { Village development } \\
\text { committee's clarity on } \\
\text { how to allocate and } \\
\text { efficiently manage the } \\
\text { Block Grant at village } \\
\text { development } \\
\text { committee level }\end{array}$ & $\begin{array}{l}\text { "Nepal government provides the VDC with a } \\
\text { Block Grant and the VDC, following the } \\
\text { directives developed by the Government, } \\
\text { allocates the Block Grant for women, Dalits, } \\
\text { disadvantaged groups, Muslims, children, ethnic } \\
\text { groups and in different sectors." [VDC 2-KII 5] } \\
\text { "Once a year the VDC allocates the budget. } \\
\text { However, in our ward we do not get information } \\
\text { on how much budget is allocated and on what } \\
\text { headings... and we do not know the process } \\
\text { followed by the VDC to allocate the Block } \\
\text { Grant." [VDC 2-FGD 1] } \\
\text { "We usually do not have information on Block } \\
\text { Grant's allocation process, so it is not } \\
\text { transparent. Political leaders allocate the budget } \\
\text { for development activities but the work is not } \\
\text { done transparently." [VDC 3-FGD 1] }\end{array}$ & $\begin{array}{l}\text { "We use the Block Grant based on the directives } \\
\text { developed by MoFALD that describe how to } \\
\text { use capital grant, how to use the recurrent } \\
\text { grant } 45 \text { and how to use the grant given by NGOs } \\
\text { and INGOs." [VDC 5-KII 6] } \\
\text { "The Block Grant in the VDC is allocated to } \\
\text { implement development and social protection } \\
\text { activities such as road construction, provision of } \\
\text { training and allowances to women." [VDC 5- } \\
\text { FGD 3] } \\
\text { "We do not have any problems in implementing } \\
\text { and reporting the budget on time." [VDC 6-KII } \\
\text { 4] }\end{array}$ \\
\hline $\begin{array}{l}\text { Establishment, efficient } \\
\text { and regular } \\
\text { functioning of } \\
\text { community structures } \\
\text { such as the } \\
\text { community awareness } \\
\text { centres and the ward } \\
\text { citizen forums }\end{array}$ & $\begin{array}{l}\text { "Whenever there is a meeting (CAC and WCFs) } \\
\text { nobody goes to attend them. Then, how can we } \\
\text { get more grant? VDC allocates the budget for } \\
\text { our ward and whatever they give we just take } \\
\text { it...it is our weakness that we don't attend such } \\
\text { meeting but it is the duty of VDC to provide but } \\
\text { it even doesn't do that." [VDC 3-FGD 2] } \\
\text { "Community members are members of the } \\
\text { WCFs but only the name is there. If there is a } \\
\text { meeting, the WCF coordinator does not bother } \\
\text { inviting their members." [VDC 3-FGD 2] } \\
\text { "We have not attended these meeting (i.e. WCFs } \\
\text { and CAC) so far so we do not know." [VDC 4- } \\
\text { FGD 3] }\end{array}$ & $\begin{array}{l}\text { "In our VDC the CAC is used to identify most } \\
\text { disadvantaged groups and what kind of } \\
\text { awareness activities need to be conducted." } \\
\text { [VDC 5-KII 5] } \\
\text { "WCFs are active and provide community } \\
\text { members the right to select the ward plan and to } \\
\text { monitor its implementation." [VDC 6-KII 4] }\end{array}$ \\
\hline
\end{tabular}

Note: A total of six VDCs were selected in this study which have been numbered to preserve anonymity. A total of 22 FGDs and 6 KIIs were conducted in the selected VDCs.

\section{Quality of institutions: VDC's clarity on Block Grant's allocation and its efficient management}

Findings show that clarity and effective allocation and management of the Block Grant is greater in the selected high-performing VDCs compared to the selected low-performing VDCs which nonetheless are aware of how the Block Grants should be allocated and managed.

All selected high-performing VDCs have a clear understanding on the way funds should be allocated to development and social protection activities and to vulnerable groups. Furthermore, the same highperforming VDCs regularly inform community members about the allocations made on development and social protection activities. All VDC secretaries in the selected high-performing VDCs report that Block Grants are allocated according to the Local Self Governance Act, which identifies 14 steps to follow in budget planning and resource allocation. VDC secretaries are knowledgeable on the different dimensions and amounts of the Block Grant such as recurrent costs, capital costs, development and social protection activities meant to specifically target children, women and disadvantaged segments of the community such as Dalits.

\footnotetext{
${ }^{45}$ The Block Grant is divided into capital, recurrent amounts and sector and non-sector specific allocations.
} 
However, the management of the Block Grant also differs across high-performing VDCs as reported by the VDC secretaries. One high-performing VDC has increased the share of the budget allocated to children as part of the child friendly initiative, another one allocates the total portion of the Block Grant for social protection activities every year to a different ward to avoid dispersion of the limited funds among different wards. Overall, all selected high-performing VDCs are able to closely monitor the implementation of Block Grant's supported development and social protection activities through monitoring committees. Finally, all selected high-performing VDCs have reported that all the Block Grant funds transferred to the VDC have been spent.

All the VDC secretaries in the selected low-performing VDCs are aware on how the Block Grants should be apportioned between recurrent costs, development activities and benefits to disadvantaged groups. Furthermore, two out of the three selected low-performing VDCs have established monitoring committees which report annually and provide suggestions and recommendations to community members about the overall implementation of development and social protection activities. In one of the selected low-performing VDCs, the VDC secretary reports that because of delays in the transfer of the Block Grant from the central and district level, the VDC does not have enough time to spend the money received.

One main difference with high-performing VDCs is that the community members and social protection clients in low-performing VDCs are not aware on how the funds are allocated to different wards. They feel that the allocation process is not transparent and is driven by political interests.

All selected VDCs have reported a lack of staff and financial resources to implement development and social protection activities at the VDC level. Furthermore, all selected VDCs acknowledge that the current staff is overstretched and that financial resources are insufficient to meet the demands of the community.

\section{Quality of institutions: establishment, efficient and regular functioning of community structures}

In the selected high-performing VDCs, world citizen forums are established, meet regularly (every month) and discuss the implementation of development and social protection activities. Community members and social protection clients in one high-performing VDC report that although the community awareness centre and the world citizen forums meetings are held regularly, the committees also meet when needs arise. Furthermore, community members are regularly informed about the purpose of the community structures' meetings by their respective coordinators. Finally, all decisions taken during world citizen forums are communicated by the coordinators to the VDC secretary to inform the decision process and influence the choice of development and social protection activities to be implemented in the community.

In the selected low-performing VDCs, VDC secretaries report that although community awareness centres have not been established, there is a provision for the world citizen forum meeting to be held. Interviews conducted with community members and social protection clients in the same VDCs confirm that the world citizen forum meetings take place only when the needs arise but they are not regularly held. 
Furthermore, the community structures are not effectively organised and meetings are not previously announced to the community by the respective coordinators.

Overall the interviews conducted in the selected VDCs confirmed the MCPM scores are appropriate and confirm the variations in the quality of institutions among the selected low- and high-performing VDCs.

\subsection{People's preferences}

This section explores the extent to which community members and social protection clients are able to express their preferences on development and social protection activities and the extent to which development and social protection activities are the result of the preferences expressed by community members and social protection clients. Table 3.6 presents relevant key quotes from the interviews and FGDs.

Table 3.6 Overview of quotes regarding people's preferences

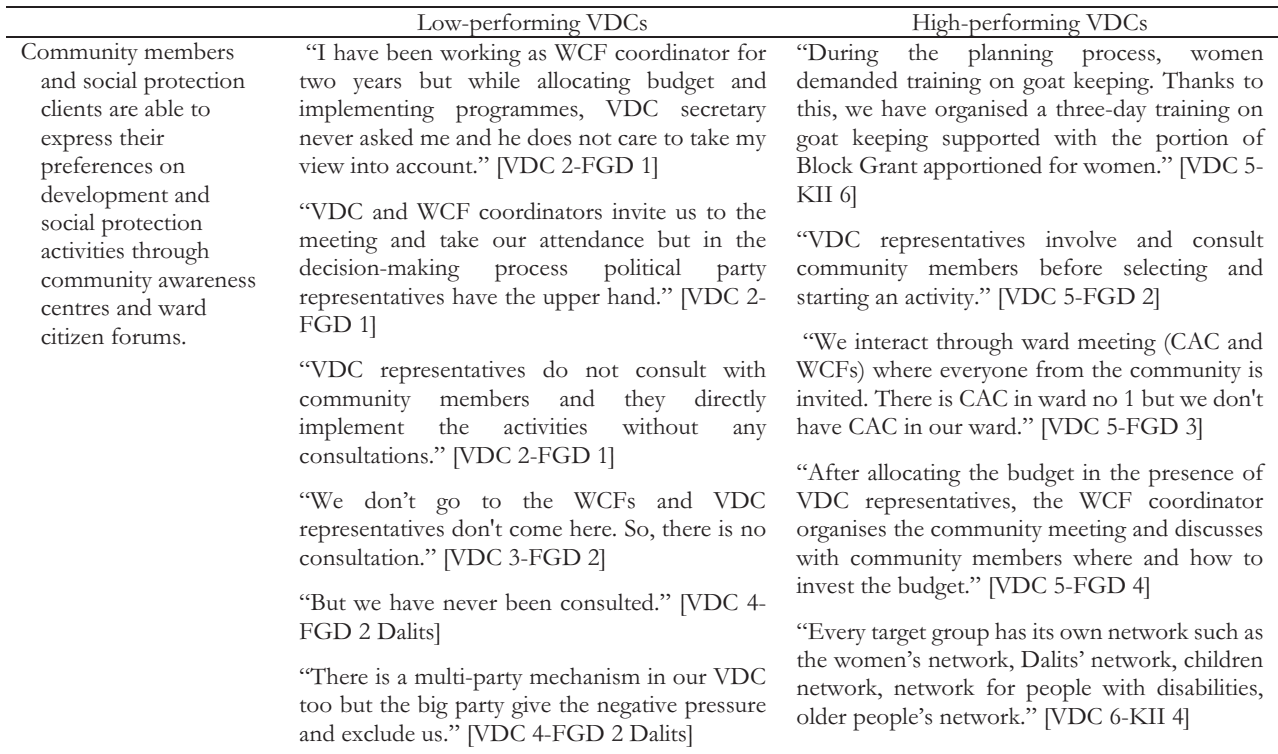

Note: A total of six VDCs were selected in this study which have been numbered to preserve anonymity. A total of 22 FGDs and 6 KIIs were conducted in the selected VDCs.

Findings show that community members and social protection clients in high-performing VDCs have better access to community structures such as community awareness centres and ward citizen forums where preferences on development and social protection activities can be expressed. Furthermore, high-performing VDCs better reflect people's preferences in how development and social protection activities are implemented compared to what observed in the selected low-performing VDCs. Overall, better quality of institutions allows for people's preferences to be better reflected when development and social protection activities are decided by the VDCs which contribute to the achievement of better outcomes.

Community members and social protection clients in high-performing VDCs are aware of their responsibilities to express their preferences and confirm the importance of participating in world citizen 
forums and community awareness centre meetings to influence the choice of development and social protection activities implemented in the VDC. In one selected high-performing VDC, network groups are established for target groups such as women, Dalits, children, people with disabilities and elderly to facilitate consultations and learn about the community's needs.

In low-performing VDCs, the engagement of community members and social protection clients is weak. Community members are not consulted by the VDC and community structures do not report to VDC representatives the preferences expressed by the members and social protection clients during the meetings. The development and social protection activities implemented in the VDC do not reflect members' preferences but political interests, as reported by the secretary of one low-performing VDC.

Overall, all VDCs report the lack of local election in the last years as a factor that has negatively affected the implementation of development and social protection activities in the selected VDCs. Community members find it challenging to hold VDC representatives accountable for the decisions taken. In all VDCs, elderly and people with disabilities have difficulties engaging or influencing the decision-making process in the wards, because they are not always able to attend community meetings. However, in some highperforming VDCs additional network meetings have been established, where different segments of the population, such as older persons, children, or people with disabilities are represented. This has helped these population groups to be heard in world citizen forums meetings, therefore assuring that their preferences are represented.

\subsection{Implementation of development and social protection activities}

The quality of provision of development and social protection interventions is assessed by observing whether the activities implemented by the VDC are expression of community members and social protection clients' preferences. This includes the process of identification of development and social protection activities as reported by the VDC secretaries and by community members.

Findings show that high-performing VDCs present a wider range of development and social protection activities compared to low-performing VDCs as presented in Table 7 below. Furthermore, the development and social protection activities implemented in high-performing VDCs reflect better the needs and preferences of community members and social protection clients. Table 3.7 presents an overview of quotes with respect to the development and social protection activities implemented in low- and high-performing VDCs.

Table 3.7 Overview of activities and quotes on quality of provision of development and social protection activities

\begin{tabular}{lll}
\hline & \multicolumn{1}{c}{ Low-performing VDCs } & \multicolumn{1}{c}{ High-performing VDCs } \\
\hline - The range of & Provision of children dresses, stationery, and school meals. & Mid-Day-Snack programmes for school children; \\
development and & "Dalit children are provided scholarships and, & Support child development centres and provide school \\
social protection & dresses. Dalits are also provided with different & equipment and Scholarships for Dalit students. "We \\
activities implemented & income generating training on beekeeping and & have allocated the amount of NPR 20,000 for \\
by the village & goat-keeping." [VDC 3-VDC secretary] & $\begin{array}{l}\text { Mid-Day-Snack programme for school children } \\
\text { development }\end{array}$ \\
committee, including & $\begin{array}{l}\text { Skill development and income generating training (such } \\
\text { as baskets making) forpeople living with disabilities and }\end{array}$ & \\
\hline
\end{tabular}




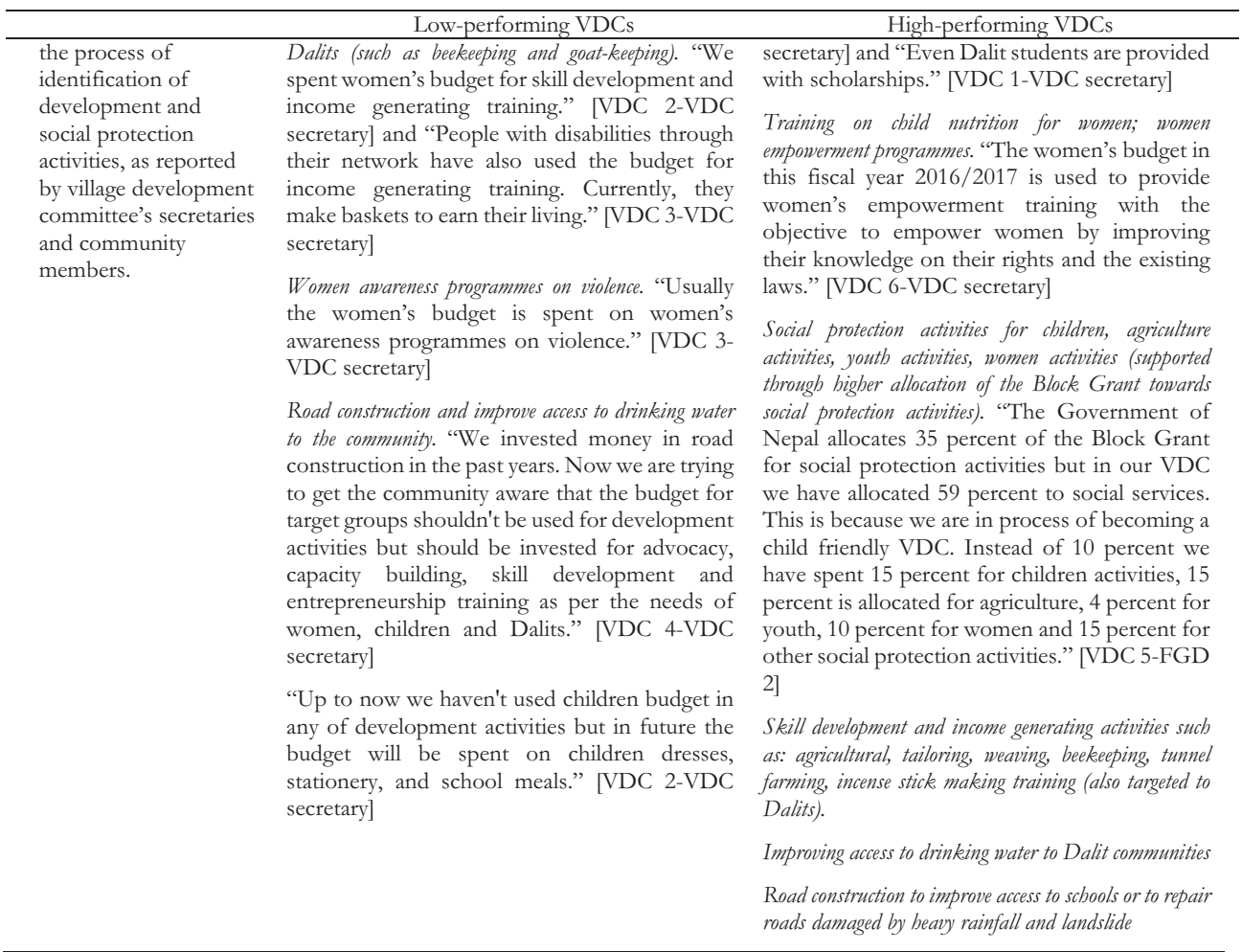

Note: A total of six VDCs were selected in this study which have been numbered to preserve anonymity. A total of 22 FGDs and 6 KIIs were conducted in the selected VDCs.

High-performing VDCs report that development and social protection activities are implemented using the allocated Block Grants. VDC secretaries report that the discretionary amount of Block Grants has been allocated for activities on children such as the provision of school meals to improve school enrolment. Furthermore, social protection interventions have been expanded targeting youth, women, and the agricultural sector. Community members and social protection clients in one of the selected high-performing VDCs report that women's empowerment programmes and training on child nutrition for women have been conducted in recent years. In another VDC, tailoring, weaving, women's empowerment programmes and income generating training (such as tunnel farming, incense stick making training) have been implemented together with activities are targeting Dalits and the most disadvantage segments of the community.

In one of the two selected low-performing VDC, social protection activities targeting children have not been prioritised in recent years while funds have been mainly spent on income generating activities for women. A VDC secretary, reports that the majority of the Block Grant received in past years was mainly allocated to development activities, leaving out social protection activities. Low-performing VDCs implement activities mainly directed to Dalits and people living with disabilities and have reported that funds for Dalits have been regularly allocated to support income generating activities. 


\subsection{Discussion}

The discussion is organised in two sections which aim at (i) investigating the linkages between the quality of institutions and the range of development and social protection activities implemented at the VDC level and; (ii) studying how people's preferences may influence the range of development and social protection activities implemented at the VDC level. Table 3.8 provides an overview of findings across the three main topics of study - quality of institutions, people's preferences and the quality of the provision of social protection activities for low- and high-performing VDCs.

\section{Table 3.8 Overview of findings}

\begin{tabular}{|c|c|c|}
\hline Quality of institutions & $\begin{array}{l}\text { Low-performing } \\
\text { VDCs }\end{array}$ & $\begin{array}{l}\text { High-performing } \\
\text { VDCs }\end{array}$ \\
\hline $\begin{array}{l}\text { Village development committee's clarity on how to allocate and efficiently } \\
\text { manage the Block Grant at village development committee level }\end{array}$ & $+/-$ & + \\
\hline $\begin{array}{l}\text { Establishment, efficient and regular functioning of community structures } \\
\text { such as the community awareness centres and ward citizen forums }\end{array}$ & $+/-$ & + \\
\hline \multicolumn{3}{|l|}{ People's preferences } \\
\hline $\begin{array}{l}\text { Community members and social protection clients are able to express their } \\
\text { preferences on development and social protection activities through } \\
\text { community awareness centres and ward citizen forums }\end{array}$ & - & + \\
\hline \multicolumn{3}{|l|}{ Quality of provision of social protection interventions } \\
\hline $\begin{array}{l}\text { The range of development and social protection activities implemented by } \\
\text { the village development committee, including the process of identification } \\
\text { of development and social protection activities, as reported by village } \\
\text { development committee secretaries and community members. }\end{array}$ & $+/-$ & + \\
\hline
\end{tabular}

\subsection{Quality of institutions and quality of provision of development and social protection activities}

Findings presented above confirm the hypothesis that better performing institutions - measured by VDC's efficiency in allocating and managing the Block Grants and by the establishment and better functioning of community structures - are associated with better quality provision of development and social protection activities implemented in the selected VDCs.

Findings show that both low- and high-performing VDCs are overall aware on how the Block Grant should be allocated between recurrent costs, development and social protection activities. However, three important differences emerged in terms of the Block Grant's management between high- and low performing VDCs. The first is that the selected high-performing VDCs are more effective in communicating how the Block Grant is allocated to community members and social protection beneficiaries compared to the selected low-performing VDCs. The second is that in the selected high-performing VDCs monitoring committees are established to track the allocation and the level of expenditure and the implementation of development and social protection activities. Finally, the selected high-performing VDCs better comply with the allocation criteria included in the directives provided by the central level compared to the selected low-performing VDCs that do not respect the level of the budget to be allocated across the different target groups.

In the selected high-performing VDCs, the community awareness centres and the world citizen forums are established and are well-functioning. They meet regularly and provide linkages between community 
members and VDC representatives. Community members in high-performing VDCs better engage with community structures expressing their concerns and with information related to the activities to be implemented at community level. In the selected low-performing VDCs, community structures are not always established and meet only when needs arise. This seems to have an impact on the activities implemented in the communities which do not reflect the needs and the preferences of the communities. Exception is made for Dalit community members as activities in all selected low- and high-performing VDCs are implemented to address the needs of this vulnerable segment of the population.

Two points are important to report. The first is that personnel in all VDCs such as the VDC secretary, social mobilisers and world citizen forums' coordinators report to be overstretched because they perform more tasks than the ones officially assigned to them due to limited availability of human and financial resources. Second, while the degree of functioning of the VDCs may affect the level of budget execution, in this case study it is difficult to observe such a linkage because of only a limited amount of the Block Grants transferred to the selected VDCs was fully utilised.

\subsection{People's preferences and quality of provision of development and social protection activities}

Findings support the hypothesis that people's preferences - measured by the extent to which community members and social protection clients are able to express their preferences on development and social protection activities through community structures - affect the quality of provision of social protection interventions at the VDC level.

All VDCs reported a certain degree of consultation with community members and social protection clients. However, in the selected high-performing VDCs, community members' interests and preferences were better represented by the kind of development and social protection activities implemented in the VDCs. Findings confirm that community structures (such as community awareness centres and world citizen forums) and network groups have a key role in channelling community members' needs to VDC representatives and decision bodies that are responsible to approve the development and social protection activities. Findings in the selected low-performing VDCs show that the decision-making process about the nature of development and social protection activities is highly politicised and community members have difficulties engaging with community structures and VDC representatives. This compromises the quality of development and social protection interventions in the sense that their design does not respond to the needs of the community.

The findings are consistent between responses received from Dalits and non-Dalits. While the country has showed increased commitment to address the needs of minorities over the last years, Dalits still report some level of discomfort in having their voice heard by the VDCs. Focus group discussions with Dalits in both low- and high-performing VDCs have unearthed feelings of discrimination and difficulties in articulating their preferences. In particular, Dalits report to be aware of their entitlements (i.e. child grant or endangered ethnicity allowance) and the process followed by the VDCs in allocating part of the Block Grant to their 
group. Yet, they are often excluded from the participation in community meetings and in the planning and budgeting process. The responses collected among Dalits are in line with the existing literature (Chhetri et al., 2013; Pandey, 1999) which suggests that people less educated or belonging to lower castes are likely to be disconnected from the VDCs and disempowered from engaging in community meetings where decisions are made.

Interestingly, none of the focus group discussions highlighted women's disempowerment issues regarding their participation in the community. In many of the sampled VDCs, women's groups promoting their preferences have been established, which most likely explains this outcome. Finally, because the elderly and people with disabilities have difficulty attending community meetings, the establishment of network groups helps these segments of the population to express their needs at community meetings through their assigned representatives.

\subsection{Conclusions and policy implications}

The study, adopting a qualitative approach, investigates the relationships between the quality of institutions and people's preferences and the range and the extent to which development and social protection activities implemented at community level in Nepal reflect these. The paper is based on an analysis which considers the allocation and management of the Block Grant at the VDC level and the establishment and functioning of community structures such as the community awareness centres and the world citizen forums as proxies for the quality of the institutions; people's ability to raise their voice and communicate their preferences on development and social protection activities is used as proxy for people's preferences. Finally, the paper assesses whether development and social protection activities implemented in the selected VDCs reflect the needs of community members and social protection clients as the indicator for the overall quality of the provision of development and social protection interventions.

The findings confirm the assumption of the existing variation in the quality of institutions and people's preferences between low- and high-performing VDCs. The allocation and management of the Block Grant seem to be more efficient in high-performing VDCs compared to the selected low-performing VDCs although the low-performing VDCs confirmed their awareness on how Block Grant should be allocated and managed. This is demonstrated by both the level of knowledge on how the resources should be distributed in the VDC, by the degree of compliance with the guidelines provided by the federal level and by the willingness to address the vulnerable segments of the community. Both factors related to institutional quality and people's preferences are linked with the choice of development and social protection activities implemented at the VDC level. Furthermore, in high-performing VDCs, community awareness centres and world citizen forums are established and meet regularly compared to low-performing VDCs.

The hypothesis that people's preferences influences the selection of social protection activities implemented at the VDC level is supported by the findings. In higher performing VDCs, community members and social protection clients are better able to engage with community awareness centres and ward 
citizen forums to channel their concerns and preferences on development and social protection activities compared to in lower performing VDCs.

Findings are slightly different for the interviews conducted with Dalits who acknowledge that although funds are allocated to them by the VDCs, their understanding on how decisions are taken by the VDCs and their involvement in the decision-making process continues to be limited.

This paper expands on the existing but limited literature on factors influencing the quality of provision of social protection programmes. In particular, the study provides evidence on the importance of the quality of institutions and people's participation in social protection which so far has been limited to the analysis of community empowerment in the agricultural sector (Chhetri, Johnsen, Konoshima, \& Yoshimoto, 2013; Giri \& Darnhofer, 2010; Lachapelle, Smith, \& McCool, 2004) and for selected education programmes (Khanal, 2013).

Findings indicate that the country should continue to invest in inclusive social protection systems and should strengthen in engagement and empower the community members (Søndergård Madsen \& eTriantafillou, 2016). Furthermore, VDCs should strengthen the functioning of the community structures during the planning and budgeting process where decisions are taken and resources allocated. Findings suggest that the establishment of network groups could be promoted in those VDCs where the participation of certain categories of people is challenged and in certain cases limited to the elites (Khanal, 2013). Current programmes implemented in Nepal such as the Local Governance and Community Development Programme improve the quality of institutions, empower society to exercise its rights, influence the planning process, and hold local Government actors accountable (MoFALD, 2013). Therefore, they should be continued and expanded. Finally, evidence on the effectiveness of social protection interventions should still be regularly produced in order to influence the scaling up of existing social protection intervention ones (Garde et al., 2017).

Although responses have highlighted that at the central level technical skills are in place among the different ministries to manage and implement social protection interventions, at the local level, staff is limited and insufficient to provide timely services to the communities. Social mobilisers and ward citizen forum coordinators, which are critical to mediate between VDC and community members and social protection clients, are overstretched and most of the time are not able to manage effectively the tasks assigned. Therefore, the Government should improve its effort to beef up the overall human resources structures at the local level.

Nepal has signed its Constitution which establishes federalism and the country has recently local elections after more than 20 years. These important changes represent an historical and unique opportunity to move toward more inclusive institutions and better administrative capacity, ensuring that the most vulnerable segments of the population can channel their preferences and influence the allocation of social protection interventions. 


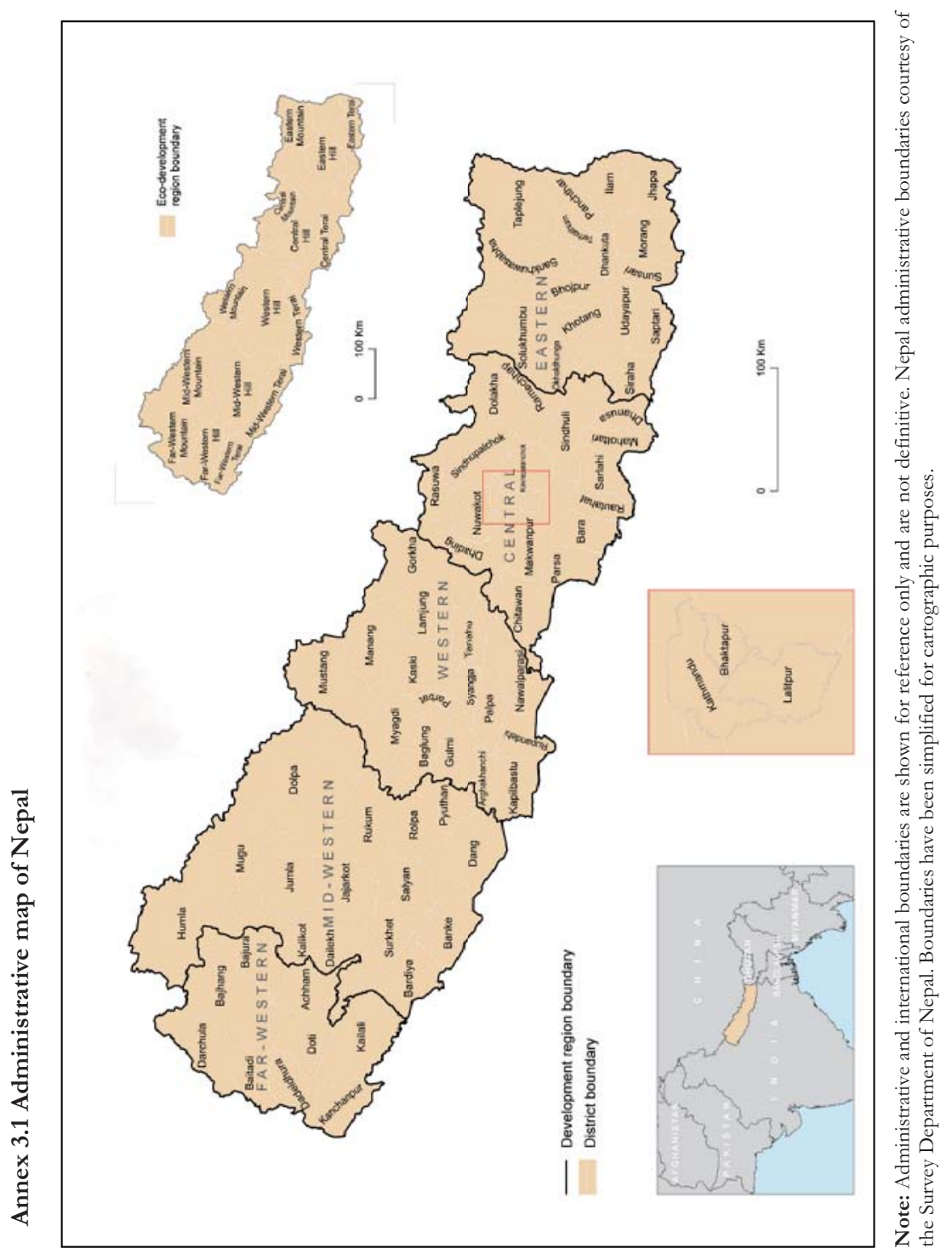




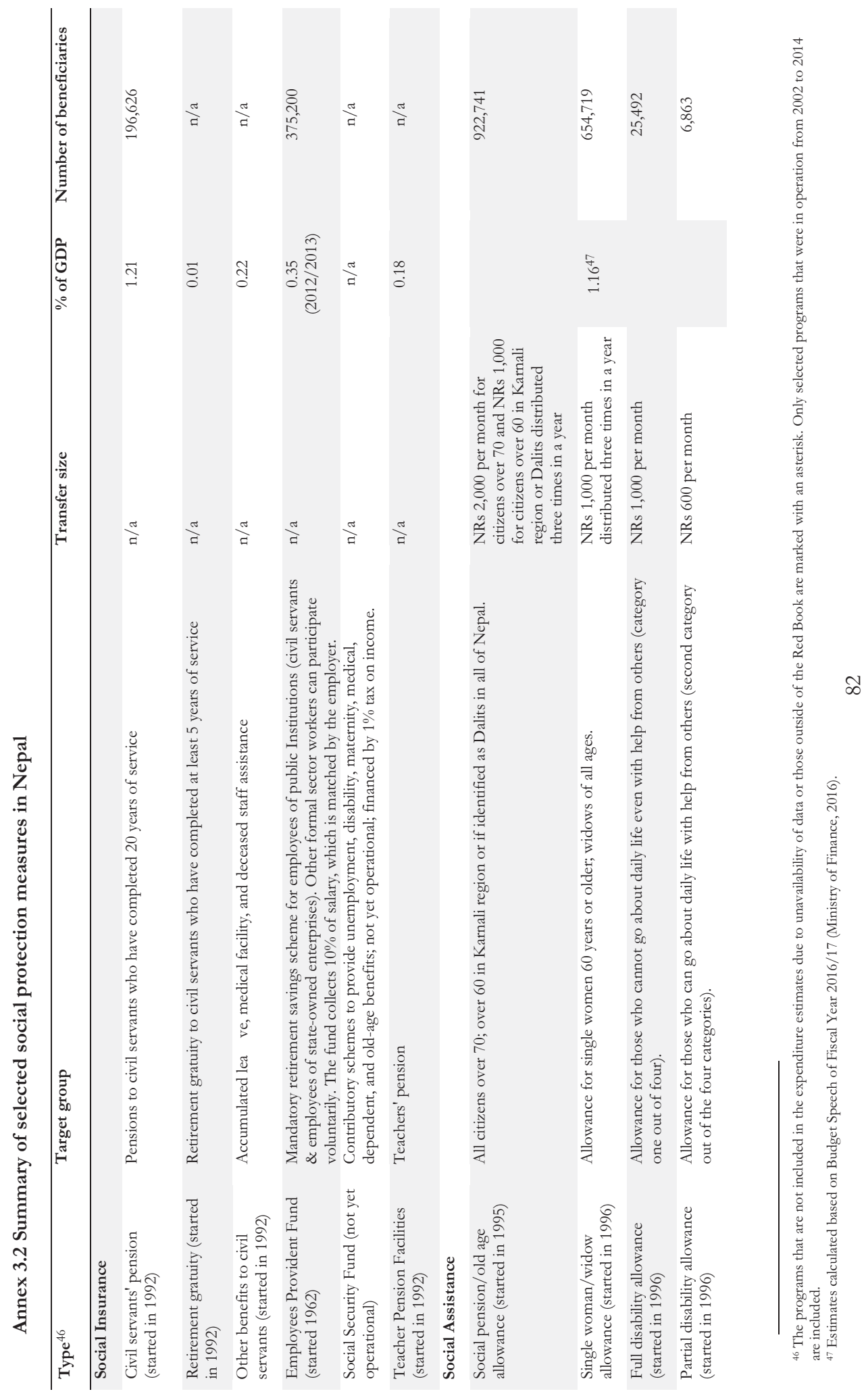




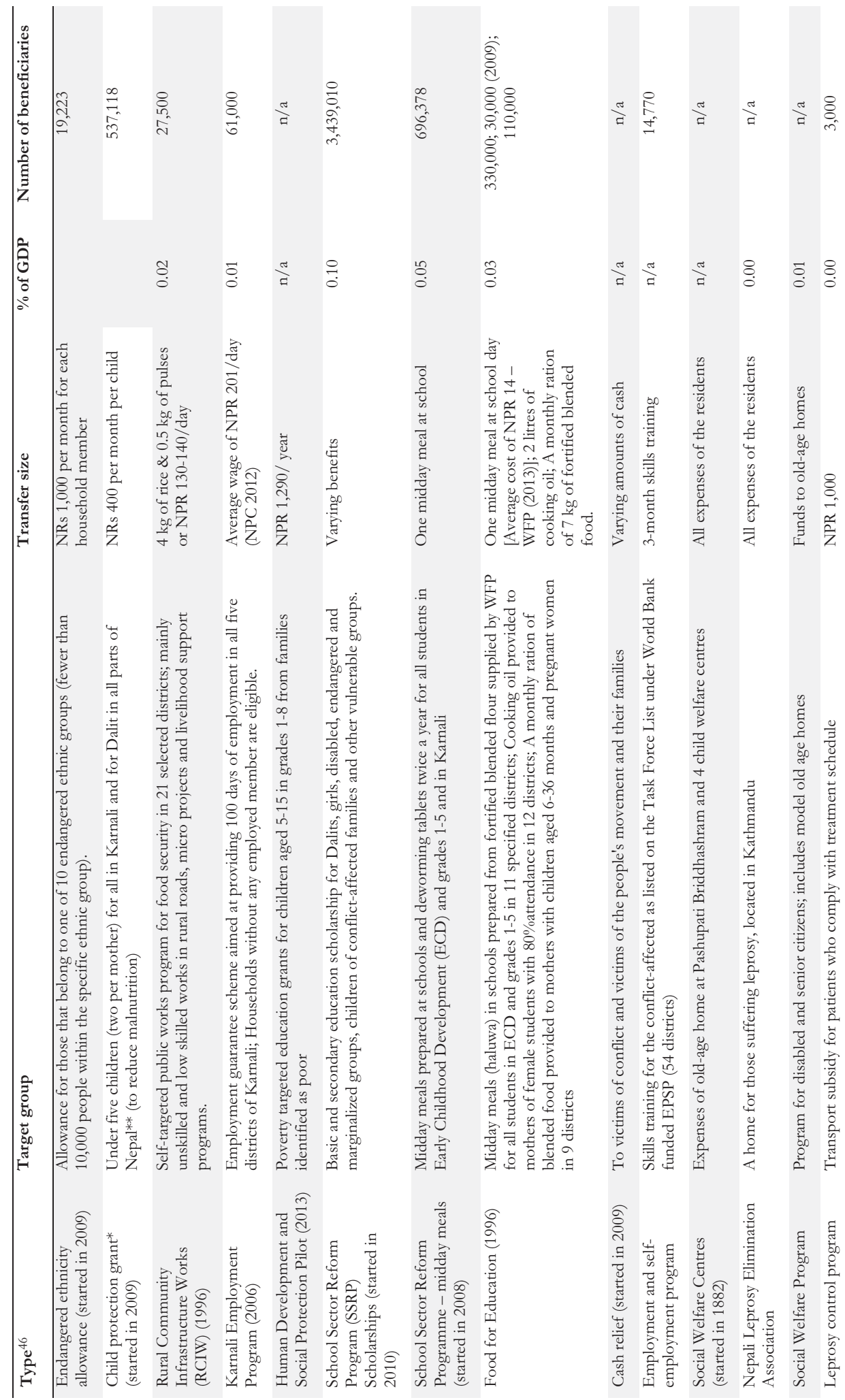




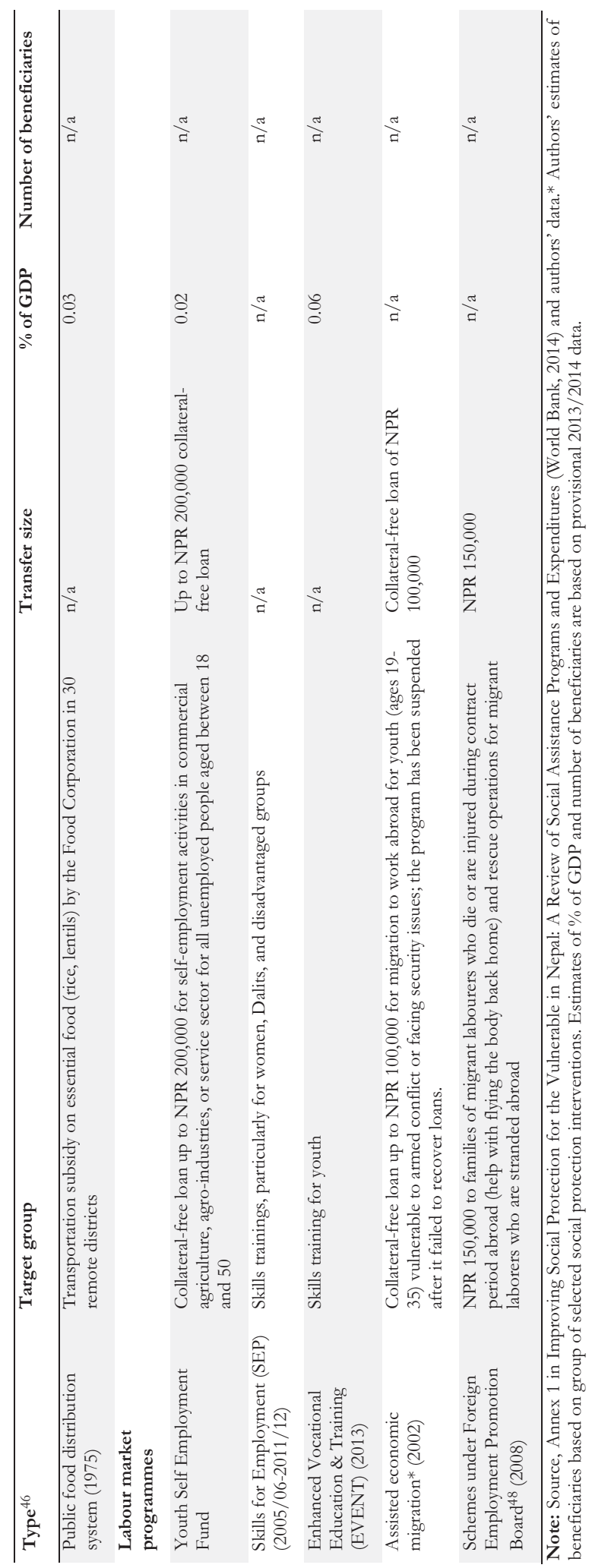




\section{Annex 3.3 Profile of survey respondents}

\begin{tabular}{|c|c|c|}
\hline Characteristics & Total & Percentage \\
\hline \multicolumn{3}{|l|}{ Gender } \\
\hline Female & 125 & $59.5 \%$ \\
\hline Male & 85 & $40.5 \%$ \\
\hline Not specified & 0 & \\
\hline \multicolumn{3}{|l|}{ Age } \\
\hline $19-29$ years & 22 & $10.5 \%$ \\
\hline $50-59$ years & 27 & $12.9 \%$ \\
\hline 60 and older & 84 & $40.0 \%$ \\
\hline Not specified & 22 & $10.5 \%$ \\
\hline \multicolumn{3}{|l|}{ Caste } \\
\hline Dalit & 71 & $33.8 \%$ \\
\hline
\end{tabular}

Source: Author's compilation, based on survey results. 


\section{Chapter 4 Relevance of Institutions and People's Preferences in PSNP and IN-SCT programmes in Ethiopia}

\subsection{Introduction}

In the last decades low- and middle-income countries have increasingly established and expanded their social protection systems, reaffirming the important role of social protection investments (Cichon et al., 2006, 2004; Morel et al., 2012; World Bank, 2012). Social protection is important for alleviating poverty (Barrientos \& Hulme, 2010; Barrientos et al., 2005), responding to its symptoms as well as addressing its causes (World Bank, 2001). There is now also widespread evidence regarding the effectiveness of social protection programmes in improving social cohesion and effectively redistributing wealth among different categories of the population (Jutting \& Prizzon, 2013; OECD, 2009).

Effective implementation of interventions is crucial for affecting change (Bastagli et al., 2016). Evaluations of cash transfer programme find that regular and consistent payments, and appropriate messaging about behaviour change constitute important mediating factors in achieving effects (Bastagli et al., 2016; Daidone, Davis, Handa, \& Winters, 2017). Evidence from comprehensive graduation programmes that combine a range of livelihood-oriented support indicates that the supply of appropriate assets and positive relationships between beneficiaries and programme staff are vital for positive impact (Banerjee et al., 2015; Devereux, Roelen, Sabates, Stoelinga, \& Dyevre, 2015). Research investigating factors that underpin the quality of implementation (or lack thereof) of individual programmes is limited however. A recent study across 80 high-, middle- and low-income countries shows that both quality of institutions and people's preferences for social protection have a positive impact on the level of expenditures in social protection (Gassmann et al., 2016). This research, using a qualitative approach, builds on these findings and studies the role of the quality of institutions and people's preferences in reference to implementation of social protection.

This chapter posits that, given a country's demographic, economic, legal, political and historical conditions, the quality of institutions and the extent to which people are able to voice their preferences influences the quality of implementation of social protection. In particular, the study investigates to what extent greater and more effective collaboration between programme staff and service providers at different levels of administration, effective functioning of community committees, and beneficiaries' abilities to have their preferences taken into account is associated with more effective implementation of programme components. It does so in the context of widespread poverty and relatively low levels of administrative capacity in Ethiopia. As such, this research aims to contribute to improving the effective implementation and thereby positive impact of social protection interventions in low-income countries, many of which are establishing, expanding or scaling up programmes in similar contexts.

Ethiopia implements one of the largest social protection programmes in Africa, namely the Productive Safety Net Programme (PSNP). It was established in 2005 in response to high levels of food insecurity and 
is currently in its fourth round of implementation (PSNP4). Although the programme is implemented within a framework that articulates the responsibilities and functions assigned to different levels of administration (MoARD, 2014), challenges abound with respect to implementation. This includes limited access to service providers (such as health extension workers) and irregularly functioning community committees such as the Community Care Coalitions (Berhane et al., 2012; Gilligan et al., 2016). This study is premised on qualitative analysis in sites that implement the 'standard' model of PSNP4 and sites where a more intensive version of this model is piloted, the so-called Improved Nutrition through Integrated Basic Social Services and Social Cash Transfer (IN-SCT) programme. This pilot model is implemented under the umbrella of PSNP4 and introduces elements that aim at strengthening the collaboration among service providers, such as the employment of social workers and establishment of cross-sectoral coordination committees (MoARD, 2016). Comparative analysis across both models allows for investigating factors underpinning the quality of implementation across sites with different levels of institutional quality.

The remainder of this chapter is structured as follows: Section 4.2 presents the conceptual framework. Section 4.3 introduces the country and programme context in Ethiopia as well as the operationalisation of the conceptual framework. Section 4.4 presents the study's methodology. Section 4.5 discusses research findings and Section 4.6 offers a discussion in relation to the main hypotheses. Finally, Section 4.7 concludes and elaborates on policy implications.

\subsection{Conceptual framework}

Existing evidence highlights the importance of the effective implementation of social protection programmes to achieve social protection outcomes. However, the knowledge about the factors which may undermine the quality of implementation of social protection programmes is not exhaustive. Hickey (2011) emphasises the role of the political economy and the importance of social contracts between governments and citizens in facilitating social protection. Alesina and La Ferrara (2005) argue that voting preferences and public perceptions can lead to more redistribution or greater government involvement in the provision of public services. Kaltenborn et al. (2017) explore the role of legal and policy frameworks in influencing social protection systems, finding that they can galvanise progress towards systems-building but are also subject to the very factors that may impede progress towards expansion and integration of social protection such as lack of ownership and lack of coordination. Indeed, recent evaluations find political will, vertical and horizontal coordination and stakeholders' alignment of objectives to be key factors in facilitating so-called 'cash plus' approaches (Roelen, Devereux, Abdulai, et al., 2017).

Beyond size and design of social protection systems and programmes within those systems, the quality of implementation is vital for achieving positive impact (Bastagli et al., 2016). Despite this acknowledgement, factors that ensure an effective programme implementation are not often explicitly studied. One exception is a study by Kardan et al. (2016) which concludes that the strained capacity of local administration and community structures that often implement social programmes with very limited resources and the lack of training against the backdrop of already high workloads matter for the 
implementation. This inevitably undermines the extent to which programmes can deliver on their promises in a timely and effective manner.

In order to advance the limited understandings of what drives the quality of implementation of social protection, this study draws on wider work regarding factors underpinning the size and design of social protection systems and interventions. We employ the conceptual framework by Gassmann et al. (2016) to consider the role of quality of institutions and people's preferences. The framework posits that, given a country's initial conditions such as demographic, economic, legal, political and historical factors, the quality of institutions and people's preferences can influence resource allocations towards social protection programmes. Firstly, the functioning of institutions reflects, to a certain degree, the ability of governments to mobilise resources (Caiden \& Wildavsky, 1974). Secondly, people's preferences may explain the level of social protection expenditures and its allocation to programme beneficiaries (i.e. targeted or universal) because of the political consequences (Pritchett, 2005; Sen, 1995). This study transposes this conceptual framework to the investigation of factors underpinning the effectiveness of implementation of social protection and considers the extent to which a greater quality of institutions and the ability for people to voice their preferences, and have them taken into account, are associated with a greater quality of implementation.

The underlying hypotheses are as follows: i) a higher quality of institutions is associated with a better implementation of social protection interventions and; ii) people's ability to express their preferences and have them taken into account improves the implementation of social protection interventions.

This case study employs a narrow definition of institutions, particularly focusing on the role of government. Following McNamara (1999), we refer to the "quality of institutions" as the way things are done in a society. Furthermore, this chapter considers effective public services as an integral element of high quality institutions (Easterly, 2013). We use the terms 'quality', 'effectiveness' and 'performance' of institutions interchangeably.

There are different definitions on the term people's preferences (Engelen, 2017; Fisher, 2006; Hausman, 2005; Sen, 2007) but they converge on "the subjective tastes, as measured by utility, of various bundles of good that permit the consumer to rank these bundles of goods according to the levels of utility they give the consumer"(Veres et al., 2014). In this case study, the notion of "people's preferences" refers to the extent to which social protection beneficiaries are able to influence the implementation of social protection through formal mechanisms such as the participation in community meetings and interactions with service providers.

The implementation of social protection interventions usually follows the policy design and the targeting process and consists of the delivery of the interventions and the regular programme monitoring and evaluation (World Bank, 2015b). It is recognised that the implementation of social protection interventions is affected by a mix of factors such as politics, social contracts between citizens and state authorities, institutions, actor interests, socio-cultural attitudes and fiscal constraints (Holmes \& Jones, 2010). This 
chapter explores how institutional quality and people's preference affect the quality of implementation of social protection interventions by focusing on the following aspects: effective monitoring, the effective implementation of social protection activities and whether social protection interventions are chosen to meet their clients' needs.

\subsection{Case study of Ethiopia}

\subsubsection{Country and programme context}

Ethiopia is one of the fastest growing economies in Africa and in the world. Annual GDP growth averaged 11 percent in the period between 2004 and 2014 (World Bank, 2016) and moved from being the $2^{\text {nd }}$ poorest country in the world in 2000 to being the $11^{\text {th }}$ poorest in 2014 (World Bank, 2016). Poverty has reduced concomitantly. In 2000, Ethiopia had one of the highest poverty rates with 56 percent of the population living below \$1.25 PPP per day. In 2011, this had reduced to 31 percent (World Bank, 2015a). According to the latest estimates, ${ }^{49}$ the headcount poverty rate declined from 29.6 percent in 2010/2011 to 23.5 percent in 2015/2016 (NPC, 2017). Notwithstanding these achievements, poverty remains widespread and particularly the most vulnerable and marginalised have not seen an improvement in their living conditions (NPC, 2017). Food insecurity has been and remains a strong component of vulnerability in Ethiopia, in part due to the country's geographical setting, its exposure to climatic shocks and traditional dependence on undiversified livelihoods (Devereux, 2000).

Ethiopia implements a myriad of social protection interventions including social insurance programmes (pensions), access to basic social services (fee waivers), national nutrition programme (supplementary feeding) and the Food Security Programme (Ministry of Labour and Social Affairs (MoLSA), 2012). The latter includes the PSNP, which is one of the largest social protection interventions in Sub-Saharan Africa (Slater \& McCord, 2013) and can be considered the cornerstone of social protection in Ethiopia (World Bank, 2015a).

The PSNP was first implemented in 2005. The programme was developed in response to widespread food insecurity and continued need for emergency food relief by providing food insecure households with a transfer in lean times to avoid asset depletion and protect livelihoods (Devereux et al., 2014). The two main components are a public works programme for households with labour capacity and a direct support element that provides direct cash or food transfers to households without labour capacity. Since its inception, the programme has widely expanded and now covers 8.5 percent of the country population. It is implemented in Afar, Amhara, Dire Dawa, Harari, Oromia, Somali, Southern Nations, Nationalities and Peoples' Region and Tigray (Hirvonen, Mascagni, \& Roelen, 2016). Over the years, it has been found to reduce household vulnerability, food insecurity, and distress sale of assets among others (Berhane et al.,

\footnotetext{
${ }^{49}$ Estimates based on Household Income Consumptions and Expenditures and Welfare Monitoring Surveys conducted by the Central Statistical Agency in 2015/2016. Poverty line based on the 2010/2011 Household Income and Consumptions Expenditure Survey using a basket of goods defined in 1995/1996 which provides 2,200 kilo calories valued at 2010/2011 national average prices in order to obtain food poverty line of $2010 / 2011$.
} 
2013). The programme is currently in its fourth round of implementation, also referred to as the PNSP450 which will cover a five -year period (June 2015-June 2020) and it is funded by the Government of Ethiopia (14 per cent) and nine donors (MoARD, 2014).

Programme design and implementation have undergone various changes from previous rounds, aiming to strengthen the programme and improve its outcomes (MoARD, 2016). Clients with a permanent lack of labour capacity in their household - Permanent Direct Support (PDS) clients - now receive payments over 12 months rather than just six months per year. Pregnant and lactating women and caregivers of malnourished children will move from Public Works (PW) to Temporary Direct Support (TDS) from four months of pregnancy until the child is 1 year old or for as long as the child is malnourished. PSNP4 also includes co-responsibilities ${ }^{51}$ for PDS and TDS clients, including the need for clients to take-up antenatal and postnatal care services and attendance of behaviour change communication (BCC) sessions. These coresponsibilities are not punitive; non-compliance does not lead to withdrawal from the programme or transfers being withheld.

The Improved Nutrition through Integrated Basic Social Services and Social Cash Transfer (IN-SCT) pilot programme falls under the umbrella of PSNP4. It is implemented by the Ministry of Labour and Social Affairs (MoLSA), with support from UNICEF and Irish Aid, in collaboration with the regional and woreda ${ }^{52}$ level representatives of the Ministry of Agriculture and Natural Resources (MoARD), the Ministry of Education (MoE), and the Ministry of Health (MoH). The pilot started in 2016 and is implemented in two PSNP woredas in Oromia region (Adami Tulu and Dodota) and two PSNP woredas of Southern Nations Nationalities and People (SNNP) Region (Halaba and Shashego). The pilot aims to improve the uptake of social services by direct support client households. It also seeks to improve the knowledge, attitudes and practices of direct support client households regarding nutritional, sanitary, health, child protection and educational behaviour, as well as contribute to a better understanding of the roles and responsibilities of actors such as social workers and community-based committees in achieving improved outcomes (Schubert, 2015). A key component of this pilot is the employment of social workers that operate at kebele level to undertake case management of direct support clients and collaborate with community care coalitions ${ }^{53}$ (CCCs) for purposes of monitoring and follow-up, particularly in relation to the newly introduced coresponsibilities.

CCCs are groups of individuals at community level that join together with the common purpose of facilitating people's involvement in community activities, and expanding and enhancing care and support for the most vulnerable groups of people, including children (UNICEF \& UNAIDS, 2004; World Vision International, 2010). CCCs typically include 10-15 members from across the community, mostly

\footnotetext{
${ }^{50}$ The PSNP4 will cost approximately USD 3 billion reaching an estimated 8.5 million people in Ethiopia.

51 The programme facilitates linkages with health and nutrition services, particularly for pregnant and lactating women who have antenatal care and nutrition-related co-responsibilities (soft conditionalities) as they transition to temporary direct support, but also for public works clients, whose participation in nutrition behavioural change communication (BCC) sessions counts towards their public works requirement (MoARD, 2014).

${ }_{52}$ Ethiopia is administratively divided into regional states and chartered cities, zones, woreda (districts) and kebele (wards) which are the smallest unit of local government.

53 Also known as Community-Based Social Protection Committee, the term CCCs was introduced in 2016 with the development of the PSNP4 Programme Implementation Manual.
} 
representing key community structures such as the kebele management, government sector bureaus, faith based organisations and women's development army ${ }^{54}$ (MOLSA, 2017). The community care coalitions' effectiveness in mobilising community involvement depends on how well it functions, its inclusiveness across the community and the effectiveness of initial mobilization efforts to promote the use of these community structures (Germann, Ngoma, Wamimbi, Claxton, \& Gaudrault, 2009). Specific programmes have also been established to support the expression of people's demands and concerns about the provision of basic services such as the Ethiopia Social Accountability Programme (ESAP) ${ }^{55}$ which has the main objective to hold service providers and local institutions accountable to citizens and delivery quality basic services to citizens in line with their preferences (ESAP, 2016) and social protection interventions (Ayliffe, 2018).

The expansion of PSNP interventions and its achievements with respect to poverty have not gone handin-hand with improved government effectiveness, as reflected by international indicators. ${ }^{56}$ Ethiopia has been ranked as a poor performing country over the last years (Kaufmann, Kraay, \& Mastruzzi, 2007), reflecting a low level of participation in political decision-making, limited ability to express preferences and overall weak effectiveness of institutions. This is further aggravated by episodes of political-motivated violence. In October 2016, the government imposed a state of emergency in response to protests by the Oromo and Amhara ethnic groups against the government. This was lifted in August 2017 but has resulted in restrictions in and access to information, while also affecting to a certain extent the functioning of institutions such as community care coalitions and community appeal committee at kebele level.

\subsubsection{Operationalisation of conceptual framework}

In order to explore the linkages between the broad concepts of quality of institutions, people's preferences and quality of implementation, we focus on specific components within the PSNP4 and the IN-SCT pilot.

In this case study, we consider the quality of institutions to be indicated, among other things, by the level of engagement and the strength of collaboration, coordination and interaction between the main service providers in the kebeles. These primarily include social workers, development agents, health extension workers and kebele managers. The degree of functioning and regularity of meetings of community committees such as the community care coalitions, and grievance redress mechanisms such as the kebele appeal committees also contributes to quality of institutions. As such, the following factors are taken into account as proxies for quality of institutions:

\footnotetext{
${ }^{54}$ Women's development army consists of female community members (one member for every six families) advocating and advising women for example to give birth in health facilities and communicate women's needs to community representatives.

55 The programme is operational in 223 woredas (around a quarter of the total) and it is part of the Promotion of Basic Services programme (PBS) led by the Ministry of Finance and Economic Cooperation (MoFEC). The project started in November 2011 and in its second phase (ESAP2) which started in January 2016.

56 Source: Kaufmann D., A. Kraay, and M. Mastruzzi (2010), The Worldwide Governance Indicators: Methodology and Analytical Issues www.govindicators.org. The index of government effectiveness - a proxy for institutional quality - ranked Ethiopia 125 out of 214 countries in 2010 and only 150 out of 214 countries in 2016. The index of voice and accountability - a proxy for people's preferences - ranked Ethiopia 189 out of 214 countries in 2010 and 186 out of 214 in 2016 . The index for political instability ${ }^{56}$ ranks Ethiopia 195 out of 214 countries in 2016.
} 
- Clarity about roles and responsibilities of service providers and efficiency of collaboration between service providers in the kebele, including health extension workers, social workers, development agents and kebele managers, as reported by service providers;

- Establishment and efficient functioning of community structures and grievance redress mechanisms such as community care coalitions or the kebele appeal committee, as reported by service providers and clients.

The ability for people to voice their preferences or complaints, and for those to be responded to, is crucial for social accountability. This case study chooses to focus on PSNP and IN-SCT clients, as well as offering a specific analysis on temporary direct support and public work clients as they are expected to interact with community structures and kebele representatives because of the nature of their work.

People's preferences are assessed based on the following:

- Extent to which public work clients are able to engage with community structures and share their preferences or concerns on the type of public work activities implemented at kebele level, as reported by clients and service providers.

Finally, the quality of implementation is assessed with two new programme components, namely the process of transitioning pregnant and lactating women from public works into temporary direct support, and the monitoring and follow-up of co-responsibilities assigned to temporary direct support clients, including attending growth monitoring and behaviour change communication sessions, amongst others. As such, the quality of implementation of social protection interventions is proxied by the following factors:

- Correct and effective implementation of transition of pregnant and lactating women or primary caregivers of malnourished children from public work activities into temporary direct support, including the processes of identification of pregnant and lactating women, confirmation of pregnancy, and transition from public work into temporary direct support, as reported by clients and service providers;

- Effective implementation of co-responsibilities ${ }^{57}$ for temporary and permanent direct support clients, including the extent of support and follow-up in case of non-compliance with coresponsibilities, as reported by clients and service providers.

- The type of social protection interventions implemented reflects people's needs, including the extent to which the choice of public work activities implemented reflects people's preferences.

\subsection{Methodology}

This chapter presents a qualitative investigation based on primary data. A qualitative approach allows for the assessment of and emphasises nuances, sequences and multiple perspectives of phenomena that are not clearly delineated (Stake, 1995), which holds true for the notions of quality of institutions, people's

\footnotetext{
${ }^{57}$ Co-responsibilities include: attend 4 antenatal care visits; obtain postnatal care; obtain vaccination of children; attend monthly growth monitoring for children; attend behavioural change communication sessions; complete birth registration; and for children aged 6-18 to go to school (for permanent direct support clients only).
} 
preferences and provision of social protection programmes. Primary qualitative data collection consisted of two components: (i) key informant interviews (KIIs) with programme staff and service providers at woreda and kebele level and, (ii) focus group discussions (FGDs) with PSNP and IN-SCT clients. The proposed methodology allows for obtaining different perspectives about the research questions in an effective manner and to complement and triangulate responses between categories of respondents. The research protocol included questions related to the proxies described above - functioning of the kebele institutions; 58 functioning of CCCs and grievance redress mechanisms such as the KACs; collaboration among service providers; quality of implementation and monitoring of transition of eligible clients from PW activities into TDS; overall accountability of kebeles to community members.

Data collection was undertaken in four kebeles in Oromia region, two kebeles implementing PSNP4 and two kebeles implementing the IN-SCT (see Table 4.1 and Figure 4.1).

Table 4.1 List of selected kebeles for field work

\begin{tabular}{lllll} 
No. & Programme & Woreda & Kebele & Kebele $^{59 / \text { Woreda Population }}$ \\
\hline $\mathbf{1}$ & IN-SCT & Adami Tulu & Kebele 1 & $6,498 / 141,405$ \\
$\mathbf{2}$ & IN-SCT & Adami Tulu & Kebele 2 & $2,579 / 141,405$ \\
$\mathbf{3}$ & PSNP & Arsi Negele & Kebele 1 & $2,524 / 260,129$ \\
$\mathbf{4}$ & PSNP & Arsi Negele & Kebele 2 & $3,858 / 260,129$ \\
\hline
\end{tabular}

Note: Population data from CSA Ethiopian Population Census, 2007.

Figure 4.1 Administrative map of the selected woredas

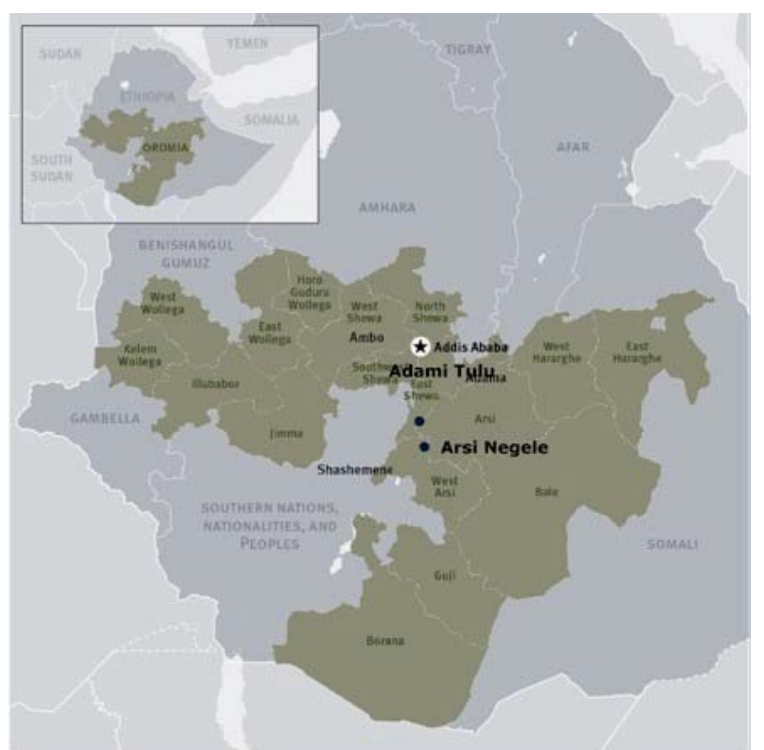

Source: Author's adaptation. Oromia region, Adami Tulu and Arsi Negele woredas.

${ }^{58}$ Kebele administration consists of an elected kebele council (in principle 100 members), a kebele cabinet (also referred as executive committee and comprised by a manager, chairperson, development agent, school director, representatives from the women association and youth association), a social court (three judges) and the development and security personnel assigned at the kebele. All the kebele cabinet members are members of the kebele council. Three kebele council members are supposed to represent the kebele in the woreda council (Yilmaz \& Venugopal, 2008).

${ }^{59}$ Census 2007, population projections based on 2.9 per cent population growth of Oromia region. 
In consultation with local counterparts, purposive sampling has been used to select the region, woredas and kebeles ${ }^{60}$ under study (see Table 4.2). The choice for undertaking fieldwork in only one region - Oromia - was driven by the desire to provide an in-depth analysis of the existing variance between kebeles in the selected woredas where the two different programme approaches were implemented. Oromia is one of the nine ethnically based regional states of Ethiopia, covering 284,538 square kilometres. It is bordered by the Somali Region to the east; the Amhara Region, the Afar Region and the Benishangul-Gumuz Region to the north; South Sudan, Gambela Region, and Southern Nations, Nationalities, and Peoples' Region to the west; and Kenya to the south. According to the 2007 census, Oromia Region has a population of 27 million, which makes the region the largest in population and area.

The selection of woredas and kebeles was conducted in three steps:

Firstly, two kebeles were selected with the PSNP4 interventions in place and two kebeles with the IN-SCT approach that, as described above, represents an extended version of PSNP4. Kebeles implementing the INSCT approach are assumed to have better quality institutions because the IN-SCT pilot aims at strengthening the integration of services and collaboration among service providers. This includes the employment of social workers and the establishment of coordination mechanisms at woreda level. The inclusion of both models in this study allows for insights across areas with variation in quality of institutions.

Secondly, within each of the selected woreda, two kebeles were identified as advised by the woreda representatives. One aspect of this advice included the choice for sites that were relatively unaffected by the civil unrest that took place in Oromia Region from late 2016 to August 2017. In some areas this resulted in the disruption of the regular functioning of the institutions and local administrations.

Finally, the selection of the kebeles was based on practical considerations such as ease of access and budget implications. Kebeles were selected on the basis of their access to main roads, availability of services and performance in PSNP/IN-SCT as advised by woreda representatives.

Pre-testing of interview protocols was conducted in Warja Washgula kebele in Adami Tulu Woreda with the following objectives: (i) testing the time needed to conduct the KIIs and FGDs; (ii) assessing whether the KIIs and FGDs questions were translated properly, understandable and appropriate to the local context; and (iii) determining whether revisions needed to be made or additional questions to be added. The actual fieldwork was conducted in April 2017. In total, fieldwork included 17 KIIs with government representatives, and representatives of service providers, and 20 FGDs that included a total of 184 community members and social protection clients (34 percent male and 66 percent female) with an average age of 40 (see Annex 4.1). FGDs were separated by gender to allow for free discussion. All fieldwork was conducted in Amharic. Interview protocols were therefore translated into Amharic during the training of the enumerators to ensure consistency of meaning of content between protocols using different languages ${ }^{61}$.

\footnotetext{
${ }^{60}$ Ethiopia consist of 9 regions which are further subdivided into 68 zones. Woreda or districts are smaller subdivisions. Kebeles are municipalities and are the smallest administrative division.

${ }^{61}$ Interview protocols were approved by the Ethical Review Committee Inner City (ERCIC) of Maastricht University.
} 
Data was collected by a team of four field researchers, working in teams of facilitators and notetakers respectively with experience in conducting research with similar design. The principal investigators supervised the team during the data collection process at the pre-testing phase and at two points in time during the implementation of the field work. The team was trained on each topic and provided with operational definitions of key concepts (for example PSNP, IN-SCT, responsibilities of service providers, etc.). All research protocols were then translated in English, and all interviews were transcribed into English. Data analysis and interpretation was undertaken manually by reading and re-reading the responses collected using a process of categorization and identification of themes, trends and patterns across the different segment of respondents identifying coherent categories. The identification of themes emerged after using techniques such word repetition and line-by-line analysis based on both the data and on the prior theoretical understanding of the phenomenon under study based on the review of the existing literature. Next, the responses were analysed and findings were corroborated using triangulation and observations to ensure, to the extent possible, validity of findings between different sources and different categories of respondents.

No major challenges were encountered during fieldwork, although the team had to overcome various logistical issues. Firstly, although communication and invitation were properly delivered, during fieldwok in the first kebele, different categories of respondents arrived at the same time creating some difficulties in managing the different groups. Priority was given to pregnant and lactating women and to permanent direct support clients (who are mostly elderly people). During fieldwork in subsequent kebeles, the research team organised the activities in a more structured manner having different groups attending their respective sessions at different times. Secondly, because permanent direct support clients are advanced in age, some of them conveyed difficulties to hear and understand questions. Extra time was allocated for FGDs conducted with this respondent category to gather the required data. Thirdly, kebele managers in two of the four selected kebeles were not available during data collection days. Interviews were rescheduled to take place at another time. Finally, in Arsi-Negele $W$ oreda, social workers were recently hired and not yet assigned to specific kebeles. This has compromised to a certain extent the depth of the answers received from their interviews.

A few notes about the methodology are in place. Firstly, this study does not aim to be nationally or regionally representative. The research represents an in-depth and localised study; findings and conclusions should be considered in light of Oromia's regional context. Secondly, this study aims to give insight into and reflect on beneficiaries and service providers' perceptions and experiences with respect to the linkages between quality of institutions and people's preferences and the quality of implementation of social protection interventions as opposed to identifying causal pathways. We report associations following respondents' suggestions and ideas. 
Table 4.2 Sampling framework

IN-SCT

Focus Group Discussions (FGDs)

\begin{tabular}{|c|c|c|c|c|c|}
\hline \multirow{3}{*}{ Location } & \multirow[b]{3}{*}{$\begin{array}{l}\text { Key Informant Interviews } \\
\text { (KIIs) }\end{array}$} & \\
\hline & & \multirow[b]{2}{*}{ Committees } & \multirow[b]{2}{*}{$\begin{array}{c}\text { Temporary Direct } \\
\text { Support (TDS) clients }\end{array}$} & \multirow{2}{*}{$\begin{array}{l}\text { Permanent } \\
\text { Direct } \\
\text { Support } \\
\text { (PDS) } \\
\text { clients }\end{array}$} & \multirow[b]{2}{*}{$\begin{array}{c}\text { Public } \\
\text { Work (PW) } \\
\text { clients }\end{array}$} \\
\hline & & & & & \\
\hline $\begin{array}{l}\text { Adami Tulu (woreda } \\
\text { level) }\end{array}$ & $\begin{array}{l}\text {-W oreda SCT coordinator \& } \\
\text { PSNP coordinator together }\end{array}$ & & & & \\
\hline Adami Tulu kebele 1 & $\begin{array}{l}\text { - Development Agent (DA) } \\
\text { - Health Extension Worker } \\
\quad \text { (HEW) } \\
\text { - Kebele Manager (KM) } \\
\text { - Social Worker (SW) }\end{array}$ & $\begin{array}{l}\text { CCC including Kebele } \\
\text { Administrator (KA) } \\
\text { (chairperson) }\end{array}$ & $\begin{array}{l}\text {-Female group [including } \\
\text { pregnant and lactating } \\
\text { women (PLW), and } \\
\text { primary caregivers of } \\
\text { malnourished child] }\end{array}$ & $\begin{array}{l}\text {-Female } \\
\text { group }\end{array}$ & $\begin{array}{l}\text {-Male group } \\
\text {-Female } \\
\text { group }\end{array}$ \\
\hline Adami Tulu kebele 2 & $\begin{array}{l}\text { - Development Agent (DA) } \\
\text { - Health Extension Worker } \\
\text { (HEW) } \\
\text { - Kebele Manager (KM) } \\
\text { - Social Worker (SW) }\end{array}$ & $\begin{array}{l}\text { CCC including Kebele } \\
\text { Administrator (KA) } \\
\text { (chairperson) }\end{array}$ & $\begin{array}{l}\text {-Female group [including } \\
\text { pregnant and lactating } \\
\text { women (PLW), and } \\
\text { primary caregivers of } \\
\text { malnourished child] }\end{array}$ & $\begin{array}{l}\text {-Female } \\
\text { group }\end{array}$ & $\begin{array}{l}\text {-Male group } \\
\text {-Female } \\
\text { group }\end{array}$ \\
\hline Total & 9 & 2 & 2 & 2 & 4 \\
\hline \multicolumn{6}{|c|}{$\Gamma \quad \rho_{1}$} \\
\hline Location & $\begin{array}{l}\text { Key Informant Interviews } \\
\text { (KIIs) }\end{array}$ & Committees & $\begin{array}{l}\text { Temporary Direct } \\
\text { Support clients }\end{array}$ & $\begin{array}{c}\text { Permanent } \\
\text { Direct } \\
\text { Support } \\
\text { clients }\end{array}$ & $\begin{array}{l}\text { Public } \\
\text { Work } \\
\text { clients }\end{array}$ \\
\hline $\begin{array}{l}\text { Arsi Negele (woreda } \\
\text { level) }\end{array}$ & $\begin{array}{l}\text {-Woreda BOLSA vice-head } \\
\text { and PSNP coordinator } \\
\text { together }\end{array}$ & & & & \\
\hline Arsi Negele kebele 1 & $\begin{array}{l}\text { - Development Agent (DA) } \\
\text { - Health Extension Worker } \\
\text { (HEW) } \\
\text { - Kebele Manager (KM) } \\
\text { - Social Worker (SW) (no } \\
\text { assigned SW) }\end{array}$ & $\begin{array}{l}\text { Kebele Food Security } \\
\text { Task Force (KFSTF) } \\
\text { rather than CCC } \\
\text { which are not } \\
\text { established in the } \\
\text { kebele. }\end{array}$ & $\begin{array}{l}\text {-Female group [including } \\
\text { pregnant and lactating } \\
\text { women (PLW), and } \\
\text { primary caregivers of } \\
\text { malnourished child] }\end{array}$ & $\begin{array}{l}\text {-Female } \\
\text { group }\end{array}$ & $\begin{array}{l}\text {-Male group } \\
\text {-Female } \\
\text { group }\end{array}$ \\
\hline Arsi Negele kebele 2 & $\begin{array}{l}\text { - Development Agent (DA) } \\
\text { - Health Extension Worker } \\
\text { (HEW) } \\
\text { - Kebele Manager (KM) } \\
\text { - Social Worker (SW) (no } \\
\text { assigned SW) }\end{array}$ & $\begin{array}{l}\text { Kebele Food Security } \\
\text { Task Force (KFSTF) } \\
\text { rather than CCC } \\
\text { which are not } \\
\text { established in the } \\
\text { kebele. }\end{array}$ & $\begin{array}{l}\text {-Female group [including } \\
\text { pregnant and lactating } \\
\text { women (PLW), and } \\
\text { primary caregivers of } \\
\text { malnourished child] }\end{array}$ & $\begin{array}{l}\text {-Female } \\
\text { group }\end{array}$ & $\begin{array}{l}\text {-Male group } \\
\text {-Female } \\
\text { group }\end{array}$ \\
\hline Total & 8 & 22 & 2 & 2 & 4 \\
\hline
\end{tabular}




\subsection{Findings}

This section presents the findings with respect to (i) the quality of institutions, (ii) people's preferences, and (iii) the quality of implementation of social protection interventions along the proxies defined above. It does so by drawing on the comparison between PSNP and IN-SCT sites.

\subsubsection{Quality of institutions}

This section explores the quality of institutions at kebele level. Proxies for the quality of institutions include (i) the clarity of roles and responsibilities and efficiency of collaboration between main service providers in the kebeles, including social workers, development agents, health extension workers and kebele managers, and (ii) the establishment and the degree of functioning and regularity of meetings of community care coalitions and kebele appeal committees.

Findings for these two proxies suggest that institutions in IN-SCT kebeles included in this research function more effectively in comparison to those in PSNP kebeles. Table 4.3 presents an overview of illustrative quotes followed by a discussion of findings for each of the proxies for quality of institutions.

Table 4.3 Overview of quotes regarding service providers and community structures

\begin{tabular}{|c|c|c|}
\hline & IN-SCT & PSNP \\
\hline $\begin{array}{l}\text { Clarity about roles and } \\
\text { responsibilities of } \\
\text { service providers and } \\
\text { efficiency of } \\
\text { collaboration between } \\
\text { service providers in } \\
\text { the kebele (i.e. } \\
\text { development agent, } \\
\text { health extension } \\
\text { worker, kebele manager } \\
\text { and social worker) }\end{array}$ & $\begin{array}{l}\text { "We are working and collaborating together. We } \\
\text { are especially working well with the social } \\
\text { worker, the kebele chairman and the kebele } \\
\text { manager." [AT-K1-HEW] } \\
\text { "The most important collaborations are those } \\
\text { between the social worker and development } \\
\text { agent and social worker with health extension } \\
\text { worker, even though all others are also } \\
\text { important for the program." [AT-K1-KM] }\end{array}$ & $\begin{array}{l}\text { "What kind of integration you are talking about. } \\
\text { We development agents are the only actors at } \\
\text { kebele level. With regards to woreda actors, I think } \\
\text { there is weak integration between woreda finance } \\
\text { and agriculture office." [AN-K1-DA] }\end{array}$ \\
\hline \multirow[t]{4}{*}{$\begin{array}{l}\text { Efficient and regular } \\
\text { functioning of } \\
\text { community structures } \\
\text { and grievance redress } \\
\text { mechanisms (such as } \\
\text { community care } \\
\text { coalitions and kebele } \\
\text { appeals committee) }\end{array}$} & $\begin{array}{l}\text { "The first community care coalition was } \\
\text { established in November } 2015 \text { but it was } \\
\text { dismantled following the country wide public } \\
\text { unrest which destroyed so many institutions. } \\
\text { The "renaissance" of government brought new } \\
\text { people to offices. The current community care } \\
\text { coalition was established in August 2016." [AT- } \\
\text { K1-CCC-FGD] }\end{array}$ & $\begin{array}{l}\text { "No, as far as I know community care coalition } \\
\text { and grievance mechanisms are not yet } \\
\text { established" [AN-K1-DA-KII] } \\
\text { "There is no one assigned in our kebele to } \\
\text { manage community care coalition and grievance } \\
\text { redress mechanisms." [AN-K1-FPW-FGD] }\end{array}$ \\
\hline & $\begin{array}{l}\text { "The community cate coalition was established } \\
\text { in February 2016." [AD-K2-CCC-FGD] }\end{array}$ & $\begin{array}{l}\text { community members about the PSNP activities } \\
\text { through meetings attended by most of the } \\
\text { community members." [AN-K1-FPW-FGD] }\end{array}$ \\
\hline & $\begin{array}{l}\text { "We are aware about social protection activities } \\
\text { which are presented at community meeting } \\
\text { where updates are shared. Information is also } \\
\text { provided and posted on a board at the centre of } \\
\text { the kebele...Transparency is ensured through } \\
\text { disclosing plans and reports at the general } \\
\text { meeting." [AT-K1-FPW-MPW-TDS-FGD] }\end{array}$ & \multirow[t]{2}{*}{$\begin{array}{l}\text { "The kebele administration usually informs the } \\
\text { community about the PSNP activities at the } \\
\text { general meeting." [AN-K1-FPW-FGD] }\end{array}$} \\
\hline & $\begin{array}{l}\text { "Transparency is ensured through disclosing } \\
\text { plans and reports at the general meeting. This is } \\
\text { mainly done to target PSNP beneficiaries. After } \\
\text { posting the results, three days are given to the } \\
\text { people to confirm whether the right people have } \\
\text { been shortlisted." [AT-K1-MPW-FGD] }\end{array}$ & \\
\hline
\end{tabular}

Note: a) Selected woredas and kebeles: Arsi Negele woreda (AN); Adami Tulu woreda (AT); Kebele 1 (K1); Kebele 2 (K2); b) Research method: Focus Group Discussion (FGD); Key Informant Interview (KII); c) Respondents: Community Care Coalition (CCC); 
Development Agent (DA); Female Public Worker clients (FPW); Health Extension Worker (HEW); Kebele Manager (KM); Male Public Workers clients (MPW); Social Worker (SW); Temporary Direct Support clients (TDS).

\section{Clarity about roles and responsibilities and collaboration among service providers}

Findings indicate that the clarity of roles and the relationship among service providers including development agents, health extension workers, kebele managers and social workers in IN-SCT kebeles is stronger compared to PSNP kebeles. The availability of social workers in IN-SCT kebeles is a key factor in greater collaboration between service providers in IN-SCT versus PSNP kebeles, and allows service providers to more effectively perform their tasks in IN-SCT kebeles compared to PSNP kebeles.

Service providers in IN-SCT kebeles in Adami Tulu report that collaboration among service providers and roles and responsibilities in terms of who should do what during the different phases of implementation of social protection interventions are clear. For example, the kebele manager in kebele 2 maintains contacts with service providers such as development agents and health extension workers and interacts regularly with school directors to monitor school attendance.

Social workers in IN-SCT kebeles support the organisation and running of meetings for different service providers and community groups. One of the social workers explained how they strengthen contacts between service providers and clients, particularly in terms of improving nutritional outcomes. Permanent direct support clients attested to the important role of social workers, pointing out their role in monitoring whether children attend school, following up in case that they do not, and advising direct support clients to use the cash transfer received for food and child education. The latter is an essential part of the implementation of the co-responsibilities for IN-SCT clients.

Notwithstanding the positive collaboration among service providers in IN-SCT kebeles, many service providers also reported to be overstretched. They struggle with the need to take care of their own personal responsibilities while accomplishing their professional assignments.

In the PSNP kebeles included in this research, service providers reported not to be entirely clear about their responsibilities in implementing PSNP interventions. Development agents and health extension workers reported lack of training and awareness to be important challenges. In both kebeles, development agents, health extension workers and kebele managers did not know that co-responsibilities include clients needing to send their children to school or pregnant and lactating women needing to attend antenatal care visits. Furthermore, the health extension workers conveyed a limited understanding of their role in monitoring co-responsibilities. For instance, one health extension worker was unaware that primary caregivers of malnourished children are eligible for temporary direct support.

The IN-SCT pilot employs social workers for the specific purpose of monitoring and following up on co-responsibilities as well as coordinating the cross-sectoral response to clients across service providers at kebele level. In PSNP kebeles, these tasks are to be undertaken by regular government social workers or to be shared among other service providers, including health extension workers and development agents. The 
PSNP kebeles included in this study do not have social workers, as confirmed by PSNP clients. This is an important explanation for lack of awareness and collaboration in these kebeles.

\section{Establishment and efficient functioning of community structures}

Community structures in the in the form of community care coalitions and kebele appeals committees are established and functioning in the IN-SCT kebeles included in this research, as reported by clients and service providers. Meetings do not take place on a regular basis but only when needs arise. Despite the lack of regular meetings, community care coalitions are reported to follow up on community members who are eligible for temporary direct support and cannot perform labour intensive public work or are chronically food insecure in the kebele. However, various coalition members indicated that the coalitions do not meet frequently enough to meet the demands expressed by the permanent and temporary direct support clients.

Findings suggest that the functioning of community coalitions is very sensitive to external shocks and their impact on individual members. The drought in 2016 and early 2017 as well as civil unrests in the region in late 2016 and early 2017 was found to have undermined community care coalitions' functioning to a certain extent. For example, community care coalition members in kebele 1 reported that they were less able to dedicate time to discuss public issues and that they had to prioritise their own livelihood activities.

The kebele appeals committees constitute the mechanisms through which clients and non-clients can complain or voice preferences about the programme. These committees are in place in both IN-SCT selected kebeles in Adami Tulu, as reported by the respective development agents. Members of the committee include the development agent and the health extension worker as well as the vice kebele chairman, a representative of women affairs, a representative of the community elders and religious leaders. Male public work clients reported that they are aware about the possibility to report their complaints to the kebele chairman, kebele manager, village leaders and development agent. Complaints get referred to the committee through the village leader, who acts as a gatekeeper to the committee. Once the village leader is informed, he brings specific cases to the attention of the committee. However, development agents in both IN-SCT kebeles reported that clients can also directly file their complaints with the committee as indicated in the PSNP implementation manual (MoARD, 2014). The appeals committees were found not to meet regularly, but rather when complaints are made. ${ }^{62}$

Community structures - including both community care coalitions and kebele appeals committees - were found not to be established or in place in the PSNP kebele included in this study. PSNP clients indicated to report their complaints directly to the village leader, kebele chairman and kebele manager, albeit with differences across the respondent groups. While female public work and temporary direct support clients reported that they are filing their complaints particularly to the kebele chairman, male public workers and permanent direct support clients file their complaints to village leaders, kebele chairman, development agent and kebele manager.

62. The kebele appeals committees is stipulated to meet quarterly according to the implementation guidelines. 


\subsubsection{People's preferences}

This section explores the extent to which social protection clients are able to express their preferences regarding implementation modalities, and whether those preferences are taken into account. We consider to what extent clients engage with community care coalitions and grievance committees for voicing their preferences and the extent to which such bodies subsequently channel people's requests into programme implementation of social protection interventions. This is different from what we considered in the previous section where the analysis was limited to the establishment and functioning of community structures. Table 4.4 presents an overview of illustrative quotes with respect to the extent to which clients' preferences are expressed when kebele public work activities are decided.

Table 4.4 Overview of quotes regarding clients' preferences

\begin{tabular}{|c|c|c|}
\hline & IN-SCT & PSNP \\
\hline \multirow{5}{*}{$\begin{array}{l}\text { Social protection clients } \\
\text { are able to express } \\
\text { their preferences on } \\
\text { social protection } \\
\text { interventions through } \\
\text { (community care } \\
\text { coalitions and kebele } \\
\text { appeals committee) }\end{array}$} & $\begin{array}{l}\text { "People decide what is to be done when there } \\
\text { is the general meeting at community level...and } \\
\text { people influence the choice of public work } \\
\text { activities through their representatives during } \\
\text { the kebele council." [AT-K1-MPW-FGD] }\end{array}$ & $\begin{array}{l}\text { "The development agent first plans the type of } \\
\text { public work activities and presents them to the } \\
\text { community. The community will add if there is } \\
\text { the need of any improvement to be made } \\
\text { otherwise agrees with development agent's } \\
\text { plan." [AN-K1-MPW-FGD] }\end{array}$ \\
\hline & $\begin{array}{l}\text { "The list of public work activities is proposed by } \\
\text { the development agents and presented at the } \\
\text { general meeting. Then the community with full } \\
\text { participation approves priority activities through } \\
\text { discussion." [AT-K1-TDS-FGD] }\end{array}$ & $\begin{array}{l}\text { "We do all what the development agent and } \\
\text { kebele management decided and people can't } \\
\text { influence the type of PW activities." [AN-K2- } \\
\text { MPW-FGD] }\end{array}$ \\
\hline & $\begin{array}{l}\text { "Since the public work activities approved at the } \\
\text { community general assembly, the community } \\
\text { members have opportunities to influence the } \\
\text { type of the public work to be done in the kebele } \\
\text { in each year." [AT-K2-MPW-FGD] }\end{array}$ & $\begin{array}{l}\text { "We are called to start the public work activities } \\
\text { and we do not know the exact mechanism of } \\
\text { decision making on the type of public work. We } \\
\text { think that development agent and kebel } \\
\text { management select types of public work and we } \\
\text { then participate in the implementation. They } \\
\text { inform and discuss with us just before the } \\
\text { starting of the implementation." [AN-K1-TDS- } \\
\text { FGD] }\end{array}$ \\
\hline & be changed." [AT-K2-FPW-FGD] & \multirow{2}{*}{$\begin{array}{l}\text { "Development agents prepare the proposal of } \\
\text { the list of activities then the whole community } \\
\text { decided at the general meeting...As the } \\
\text { community gave final decisions, they do have a } \\
\text { right to accept or reject the development agents } \\
\text { proposals." [AN-K2-FPW-FGD] }\end{array}$} \\
\hline & $\begin{array}{l}\text { "We do all what the development agent suggests } \\
\text { us to do; we can't influence the type of public } \\
\text { work activities." [AT-K1-FPW-FGD] }\end{array}$ & \\
\hline
\end{tabular}

Note: a) Selected woredas and kebeles: Arsi Negele woreda (AN); Adami Tulu woreda (AT); Kebele 1 (K1); Kebele 2 (K2); b) Research method: Focus Group Discussion (FGD); Key Informant Interview (KII); c) Respondents: Female Public Worker clients (FPW); Male Public Workers clients (MPW); Temporary Direct Support clients (TDS).

In the IN-SCT kebeles included in this study, findings point towards a gendered use of grievance mechanisms, suggesting that male public work clients are more likely to raise complaints and to have their preferences reflected in the choice of public work activities.

Few female public work and permanent direct support clients in IN-SCT kebeles reported having voiced complaints to the kebele chairman. They reported being aware about the opportunity to raise their issues to the development agent and to the kebele manager but usually did not to do this either out of fear of repercussions or because they do not want to bother kebele officials or service providers. The same groups 
of clients indicated to feel unable to influence the choice of the type of public work activities that are to be implemented at the community level and preferred following the development agents' decisions.

By contrast, male public work clients in both kebeles reported voicing their preferences during the general meeting ${ }^{63}$, to the kebele appeals committee, or filing their complaints directly to the kebele chairman or to the development agent. In case of the latter, they subsequently discuss the issues at the kebele council and after thorough discussions, approve and select public works activities. Similarly, temporary direct support clients (who are mostly women) reported filing complaints to the kebele appeals committee or directly to the kebele manager. Depending on the complexity of the issues raised, the kebele manager either responds immediately or refers the complaint to the grievance committee. In case of the latter, the issue is discussed in consultation with the other members of the committee.

The ability to voice preferences and have them taken into account is limited in PSNP kebeles included in this study. This is not surprising given the fact that community structures are not in place. In case of complaints, clients refer to the kebele chairman or to the kebele manager directly. One development agent indicated PSNP clients to be "silent recipients" who are subject to the decisions of woreda and kebele leaders. The leaders were said to inform community members more for reasons of formality or to manage political pressure rather than to promote a discussion with PSNP clients and consider their concerns. Male public work clients in both kebeles would prefer the redress mechanisms to be functional in order for them to contribute to overall levels of community engagement and to increase the involvement of community representatives.

Notwithstanding the absence of functioning community structures for making complaints, individual service providers and staff at community level act as focal points. While experiences with the kebele chairman and manager taking up this role is generally positive, experiences differ across kebeles in case of the development agent. Female public work clients reported that when they approach the development agent to communicate their preferences regarding the types of public work activities to be implemented at community level, the development agent rarely takes their voices into account in the final approval of activities. Male public work clients in kebele 2 reported that they generally follow the development agent's decisions without the possibility of influencing those decisions. However, male public work clients in kebele 1 explained that the development agent presents the list of public work activities to the community which is approved unless additional activities are suggested to be included.

\subsubsection{Quality of implementation of social protection interventions}

The quality of implementation of social protection interventions is assessed by observing (i) the process of transitioning pregnant and lactating women out of public work activities into temporary direct support, and (ii) the process of monitoring of compliance with co-responsibilities and support and follow-up in case of non-compliance with co-responsibilities for temporary direct support clients. Table 4.5 presents an

${ }^{63}$ General meeting which bring together social protection and community members as part of the targeting process. 
overview of quotes for each proxy with respect to the design and delivery of social protection interventions in IN-SCT and PSNP kebeles.

Table 4.5 Overview of quotes on implementation of interventions

\begin{tabular}{|c|c|c|}
\hline & IN-SCT & PSNP \\
\hline \multirow{3}{*}{$\begin{array}{l}\text { Correct and effective } \\
\text { implementation of } \\
\text { transition of pregnant } \\
\text { and lactating women } \\
\text { or primary caregivers } \\
\text { of malnourished child } \\
\text { from public work } \\
\text { activities into } \\
\text { temporary direct } \\
\text { support, including the } \\
\text { processes of } \\
\text { identification of } \\
\text { pregnant and lactating } \\
\text { women, confirmation } \\
\text { of pregnancy, and } \\
\text { transition from public } \\
\text { work activities into } \\
\text { temporary direct } \\
\text { support. }\end{array}$} & $\begin{array}{l}\text { "When at public work activities see a pregnant } \\
\text { woman, I tell her to stay at home and not to } \\
\text { attend public work activities or if a woman } \\
\text { brings confirmation about her pregnancy even } \\
\text { at one month I will transfer her to TDS until the } \\
\text { child gets } 1 \text { year old." [AT-K1-DA-KII] }\end{array}$ & $\begin{array}{l}\text { "We received a direction from the woreda PSNP } \\
\text { to transfer the pregnant women and lactating } \\
\text { mothers into temporary direct support for } 17 \\
\text { months. As per this direction we are } \\
\text { implementing it and no monitoring of the } \\
\text { activity is done." [AN-K1-DA-KII] }\end{array}$ \\
\hline & $\begin{array}{l}\text { "Pregnant and lactating women are being given } \\
\text { permission to stay at home when they disclose } \\
\text { their pregnancy. Some bring a test result to get } \\
\text { transferred to temporary direct support as early } \\
\text { as possible. When, malnourished children are } \\
\text { discovered they are also immediately transition } \\
\text { to temporary direct support until the child is } \\
\text { recovered." [AT-K2-CCC-FGD] }\end{array}$ & $\begin{array}{l}\text { "If a woman is found to be pregnant, she is } \\
\text { expected to inform her lowest level group } \\
\text { (called "Tokko-Shanee" means one-to-five } \\
\text { group leader) and the group leader informs the } \\
\text { health extension worker who will finally notify } \\
\text { me about the woman's pregnancy. Then I will } \\
\text { allow her to be free of PW until six months post- } \\
\text { delivery." [AN-K2-DA-KII] }\end{array}$ \\
\hline & $\begin{array}{l}\text { "There are conditions in which pregnant and } \\
\text { lactating women are found working. This } \\
\text { happens partly because of development agent"s } \\
\text { failure to comply with the guidelines and partly } \\
\text { when a woman fails to report her pregnancy due } \\
\text { to cultural influence and remain working until } \\
\text { her pregnancy is visible." [AT-K1-CCC-FGD] }\end{array}$ & $\begin{array}{l}\text { "There is no paper work involved in transferring } \\
\text { a pregnant woman into temporary direct } \\
\text { support apart from sending list of those with } \\
\text { similar rights to be excluded from public work } \\
\text { activities." [AN-K2-DA-KII] }\end{array}$ \\
\hline \multirow{5}{*}{$\begin{array}{l}\text { Effective } \\
\text { implementation of co- } \\
\text { responsibilities for } \\
\text { temporary direct } \\
\text { support clients, } \\
\text { including monitoring } \\
\text { of compliance with co- } \\
\text { responsibilities and } \\
\text { support and follow-up } \\
\text { in case of non- } \\
\text { compliance with co- } \\
\text { responsibilities). }\end{array}$} & $\begin{array}{l}\text { "We know that we are encouraged to meet some } \\
\text { responsibilities such as to have latrine and to use } \\
\text { it properly, to send our children to school, to } \\
\text { follow our antenatal visits at the health post }\end{array}$ & $\begin{array}{l}\text { "We don't know anything about co- } \\
\text { responsibilities. Even the word is new to me- } \\
\text { he said - I heard this word from you just now." } \\
\text { [AN-K1-DA-KII] }\end{array}$ \\
\hline & $\begin{array}{l}\text { pourtnatal visits (at least once after delivery), to } \\
\text { give birth at the health centre, to take } \\
\text { immunization for ourselves and our baby, and }\end{array}$ & $\begin{array}{l}\text { "We are not aware about any expectations while } \\
\text { on rest due to the temporary direct support } \\
\text { benefits." [AN-K1-TDS-FGD] }\end{array}$ \\
\hline & $\begin{array}{l}\text { to have proper feeding practices (exclusive } \\
\text { breast feeding up to } 6 \text { months of the child age)." } \\
\text { [AT-K1-TDS-FGD] }\end{array}$ & $\begin{array}{l}\text { "I do not know about co-responsibilities in this } \\
\text { kebele." [AN-K2-DA-KII] }\end{array}$ \\
\hline & $\begin{array}{l}\text { "The social worker comes to our houses and } \\
\text { asks whether we are sending our kids to school } \\
\text { or not. Additionally, fathers of the children } \\
\text { strictly follow on their education as most of us } \\
\text { are living with our grandchildren." [AT-K1- } \\
\text { PDS-FGD] }\end{array}$ & \multirow[t]{2}{*}{$\begin{array}{l}\text { "No co-responsibilities are given in relation to } \\
\text { PSNP." [AN-K2-TDS-FGD] }\end{array}$} \\
\hline & $\begin{array}{l}\text { "We are not asked to meet any co- } \\
\text { responsibilities by the health extension worker } \\
\text { or social worker, but the village leaders and the } \\
\text { health extension worker call us for a meeting } \\
\text { and advise us to deliver at health centre." [AT- } \\
\text { K2-TDS-FGD] }\end{array}$ & \\
\hline
\end{tabular}

Note: a) Selected woredas and kebeles: Arsi Negele woreda (AN); Adami Tulu woreda (AT); Kebele 1 (K1); Kebele 2 (K2); b) Research method: Focus Group Discussion (FGD); Key Informant Interview (KII); c) Respondents: Community Care Coalition (CCC); Development Agent (DA); Permanent Direct Support clients (PDS); Temporary Direct Support clients (TDS).

\section{Effective transitioning of pregnant and lactating women from public work activities into temporary direct support}

Findings show that IN-SCT kebeles are more effective in implementing the transition of eligible clients from public work activities into temporary direct support compared to the PSNP selected kebeles. Clients 
that are eligible for this transition include pregnant and lactating women and caregivers of malnourished children.

In IN-SCT kebeles, development agents, health extension workers and social workers reported that the transition of eligible temporary direct support clients out of public work activities is well implemented as all pregnant and lactating women transition out of public work and into temporary direct support. Social workers play a key role in facilitating this transition. They collect monthly reports from development agents and visit public work sites to check whether any pregnant and lactating women are working on the sites. In addition, social workers interact with development agents, who are main gatekeepers in terms of the transition as they provide information about this programme provision to public works clients and approve who can move from public work into temporary direct support.

Despite these positive findings, service providers indicated that the overall quality of the transition of clients from public work into temporary direct support could still be strengthened. Development agents in particular mentioned the need for further awareness raising among women to encourage those that are eligible to claim their rights.

In PSNP kebeles, the transition from public works into temporary direct support appeared to function relatively well, although not as effectively as in IN-SCT kebeles. Temporary direct support clients reported to have been provided with basic orientation about their rights to be transferred to temporary direct support by development agents and health extension workers. As no social workers operate in the PSNP kebeles, the process of transition of eligible temporary direct support clients out from public work activities is mainly supported by the development agents and the health extension workers. This leads to implementation issues. For example, development agents ask clients for a family member to replace them in public work activities when transitioning into temporary direct support. This is against PSNP policy and guidelines in the implementation manual.

Effective monitoring of compliance of and follow-up on co-responsibilities for temporary direct support clients

Findings show that IN-SCT kebeles are more effective in the implementation and monitoring of compliance of co-responsibilities compared to PSNP kebeles.

In IN-SCT kebeles included in this research, awareness of co-responsibilities for temporary direct support clients was high among those interviewed. Development agents, health extension workers and kebele managers reported co-responsibilities to be well implemented and communicated to clients by the development agents, health extension workers and social workers. This was confirmed by permanent direct support clients in both kebeles.

Implementation of co-responsibilities is not without challenges however. Social workers, who are primarily responsible for the effective implementation of co-responsibilities, were found to be overstretched. They cover multiple kebeles, leading to a high workload and little time to perform their duties in each kebele. The quality of implementation of co-responsibilities may also be improved by strengthening 
the monitoring on how co-responsibilities are observed by social protection clients. One kebele manager suggested the monitoring could be improved by establishing an independent body responsible for monitoring.

In the selected PSNP kebeles, the quality of implementation of co-responsibilities was generally low. The health extension workers, development agents and kebele managers in both kebeles were not aware of the concept of co-responsibilities. Female public work clients mentioned that behavioural change communication sessions are not held regularly and the development agent mainly provides clients with financial savings advice. Both male and female public work clients did report receiving information from the health extension worker on immunization, family planning, antenatal care and postnatal care followups, bed-nets utilization to prevent malaria and good hygiene practices. Equally, male public work clients reported that the school director encourages them to send their children to school. However, the advice provided by health extension workers and school directors is likely to be part of regular health and education outreach rather than a result from the implementation of PSNP co-responsibilities.

\section{The type of public work activities implemented is a reflection of people's preferences}

Findings show that public work clients in IN-SCT kebeles have greater access to community structures and are better able to communicate their preferences and concerns about the type of public work activities implemented in the community. In particular, the findings show that male public work clients engage in discussions held at community meetings and submit their list of activities to the development agent who presents them to general meeting and to the kebele council that is responsible for decision-making. Therefore, the discussions about public work activities held at community meetings support the decisionmaking process and help to identify public work activities which reflect people's needs and public work clients' preferences.

In the selected PSNP kebeles, male public work clients do not have access to community structures and therefore the level of discussion about public activities to be implemented is limited. The development agent proposes public work activities and activities are then decided after a limited discussion during the general meeting at the kebele. The choice of public work activities implemented does not necessarily reflect public work clients' preferences.

Findings show that in both IN-SCT and PSNP selected kebeles, female public workers do not engage effectively in the discussion of activities to be implemented because of fear or repercussion or because they feel that their concerns will not be represented and that the type of public work activities is decided by the kebele representatives.

Table 4.6 provides a comparative summary of the findings for the three main themes- the quality of institutions, people's preferences and the quality of implementation - for IN-SCT and PSNP kebeles. It can be observed that - based on the respective proxies - the quality of institutions is higher in IN-SCT compared to PSNP kebeles, the ability for clients to have their voices heard and incorporated to be slightly 
better in IN-SCT compared to PSNP kebeles, and the quality of implementation to be generally higher in IN-SCT kebeles compared to PSNP kebeles.

Table 4.6 Overview of findings

\begin{tabular}{|c|c|c|}
\hline Quality of institutions & IN-SCT & PSNP \\
\hline $\begin{array}{l}\text { Level of engagement, collaboration, coordination and interaction among } \\
\text { main service providers (i.e. development agent, health extension worker, } \\
\text { kebele manager and social worker) }\end{array}$ & + & - \\
\hline $\begin{array}{l}\text { Efficient and regular functioning of community structures and grievance } \\
\text { redress mechanisms (such as community care coalitions and kebele appeals } \\
\text { committee) }\end{array}$ & + & - \\
\hline \multicolumn{3}{|l|}{ People's preferences } \\
\hline $\begin{array}{l}\text { Social protection clients are able to express their preferences on social } \\
\text { protection interventions through (community care coalitions and kebele } \\
\text { appeals committee) }\end{array}$ & $+/-$ & - \\
\hline \multicolumn{3}{|l|}{ Quality of implementation of social protection interventions } \\
\hline $\begin{array}{l}\text { Correct and effective implementation of transition of pregnant and lactating } \\
\text { women or primary caregivers of malnourished child from public work } \\
\text { activities into temporary direct support, including the processes of } \\
\text { identification of pregnant and lactating women, confirmation of } \\
\text { pregnancy, and transition from public work activities into temporary } \\
\text { direct support. }\end{array}$ & + & $+/-$ \\
\hline $\begin{array}{l}\text { Effective implementation of co-responsibilities for temporary direct } \\
\text { support clients, including monitoring of compliance with co- } \\
\text { responsibilities and support and follow-up in case of non-compliance } \\
\text { with co-responsibilities). }\end{array}$ & $+/-$ & - \\
\hline $\begin{array}{l}\text { Type of social protection interventions implemented reflects people's needs, } \\
\text { including the extent to which the choice of public work activities } \\
\text { implemented reflects people's preferences. }\end{array}$ & $+/-$ & - \\
\hline
\end{tabular}

\subsection{Discussion}

This section reflects on the hypotheses underpinning this case study. The first section elaborates on the link between the quality of institutions and the effective implementation of social protection interventions. The second section discusses how people's preferences may influence the design and quality of implementation of social protection interventions.

\subsubsection{Quality of institutions and quality of implementation of social protection interventions}

Findings confirm the notion that a higher quality of institutions is associated with a greater quality of implementation of social protection interventions. Collaboration between service providers and the establishment and functioning of community structures is stronger in IN-SCT kebeles compared to PSNP kebeles. This is reflected by the more effective transitioning of pregnant and lactating women into temporary direct support and stronger monitoring and follow-up of co-responsibilities.

The fact that service providers in IN-SCT kebeles have continuous and regular interactions with clients contributes to better monitoring of co-responsibilities and a better understanding of clients' expectations and responsibilities upon receipt of the cash transfer. This has a positive impact on the clients' compliance with co-responsibilities. In addition, service providers in IN-SCT kebeles appear to have greater clarity about their roles and responsibilities with respect to who should do what in terms of supporting the transition 
out of public work into temporary direct support. In contrast, service providers in PSNP kebeles seem to be less clear about their role and responsibilities. This is partly due to the fact that training and information sessions on the overall PSNP approach and public work activities are not regularly provided.

One important contributing factor to the greater quality of implementation is the presence of assigned social workers in the IN-SCT kebeles. The social workers visit IN-SCT clients and inform them about the importance of implementing co-responsibilities and make referrals to kebele-level government structures (administration, development agent, and health extension worker). While social workers implement their tasks in IN-SCT fairly effectively, they do report being overstretched because of the high number of kebeles assigned to them. This undermines the quality of implementation.

Finally, IN-SCT kebeles have functioning community care coalitions and kebele appeals committees, and they appear to offer an important accountability mechanism that may contribute to more effective implementation. Yet findings also attest to the sensitivity of community structures to shocks. Particularly covariate shocks that affect all members of the committee (such as drought or civil unrest) in particular can cause the mechanism to break down.

\subsubsection{People's preferences and quality of implementation of social protection interventions}

Overall, findings show that clients in kebeles with greater collaboration among service providers and functioning community structures and grievance redress mechanisms - in this case in IN-SCT kebeles - are better able to file complaints and express their preferences to community care coalitions or grievance committee members. Findings suggest that in absence of strong community structures, the ability to raise complaints and have voices taken into account is highly dependent on the personal engagement of the individuals that act as focal points in absence of community committees.

Yet, the availability of community structures and grievance mechanisms is no guarantee for people's preferences to be factored into implementation of social protection interventions. Even though female public work and permanent direct support clients are aware of the possibility of filing complaints, they tend not to do so because of fear of repercussions. Some prefer not to bother the community care coalition and grievance committee members. Male public work clients often use community structures and are able to easily express their preferences with respect to the choice of public work activities. This is also reflected in the type of public work activities implemented in the selected IN-SCT kebeles, which is the results of discussion and people's engagement and participation compared to the PSNP kebeles where clients have limited access to community structures and public work activities are mainly decided by the kebele representatives.

This gender dynamic is not exclusive to IN-SCT kebeles where mechanisms are in place. In the PSNP kebeles, male public work clients reported that they propose changes to the development agents' plans when activities are presented to the community during general meeting. Female public work clients instead report 
that decisions regarding the type of public work activities to be implemented in the kebele is mainly driven by the development agent with limited public work clients' influence.

\subsection{Conclusion and policy implications}

This case study expands on the existing but limited literature on factors underpinning the quality of implementation of social protection programmes. Using a qualitative approach and using Ethiopia's PSNP and IN-SCT as a case study, this chapter explores the links between the quality of institutions and people's preferences in relation to the quality of implementation of social protection interventions. The case study considers the degree of collaboration between service providers and the establishment and the effective functioning of community structures as indications of the quality of the institution. The extent to which clients are able to express their preferences on public work activities are considered as manifestations of people's preferences. The correct and effective implementation of the transition of eligible clients from public work into temporary direct support, the effective implementation of co-responsibilities, and the extent to which the choice of public work activities reflects people's preferences are used as measures of the quality of implementation of social protection interventions.

Findings confirm the assumed variation in institutional functioning observed in IN-SCT kebeles versus regular PSNP kebeles. This is reflected by stronger relationships between service providers, including development agents, health extension workers, kebele managers and social workers, and a clearer understanding of roles and responsibilities on behalf of the service providers. In PSNP kebeles, the division of tasks and responsibilities among service providers is more blurred with comparatively weaker coordination and collaboration.

In IN-SCT kebeles, the access to community structures such as community care coalitions and kebele appeals committee is greater compared to PSNP kebeles were community structures are not established and show limited functioning. IN-SCT clients report greater access to community structures, allowing them to voice their preferences on social protection interventions. However, this finding is limited to male public work clients, pointing towards gender inequality in terms of translating preferences into outcomes.

Findings suggest that greater interaction among service providers and better functioning community structures allow for stronger implementation of social protection interventions. The implementation of coresponsibilities, a proxy for quality of implementation of social protection interventions, is more effective in IN-SCT kebeles with greater engagement among service providers and better functioning community structures. In PSNP kebeles, the implementation of co-responsibilities is observed to be weak, largely due to the fact that no social workers are assigned to these kebeles and limited functioning of community structures.

The research supports the notion that people's abilities to voice their preferences shapes the design or implementation of social protection interventions. The research particularly considered whether the availability and use of community structures and grievance mechanisms was reflected in the types of public work activities undertaken in the kebeles. Findings show public work activities implemented in IN-SCT kebeles reflect clients' need and their involvement in the decision process compared to PSNP kebeles where 
the activities are mainly decided by the kebele representatives. Across the board, female clients were less likely to voice their preferences or if they did, to have their voices taken into account.

In reference to the specific situation in Ethiopia, this research shows that continued investment in PSNP structures is crucial for the quality of its implementation at the local level. The inclusion of new components into the fourth round of PSNP - such as co-responsibilities and the shift from public work to temporary direct support for pregnant and lactating women - and the subsequent demands for implementing those components require a systems approach with linkages to and collaboration across service providers. Finally, the comparative analysis of quality of implementation across regular PSNP kebeles and kebeles with the INSCT model indicates that greater investment in services, including awareness creation for community members and social protection clients and investment in capacity-building of all service providers is imperative for making a systems approach work. The research also indicates that well-functioning grievance mechanisms are a necessary requirement for taking clients' preferences into account but also that they are not sufficient in the sense that social dynamics and gender inequalities affect the way some groups of clients feel able to voice their preferences and to have those voices heard. 


\subsection{Annexes and tables}

Annex 4.1 Profile of survey respondents

\begin{tabular}{lcc} 
Characteristics & Total & Percentage \\
\hline Gender & 121 & $63.8 \%$ \\
\hline Female & $34.2 \%$ \\
Male & \\
\hline Age & 61 & $33.2 \%$ \\
\hline $19-29$ years & 46 & $25 \%$ \\
$30-39$ years & 24 & $13 \%$ \\
$40-49$ years & 19 & $10.3 \%$ \\
$50-59$ years & 34 & $18.5 \%$ \\
60 and older & &
\end{tabular}

Source: Author's compilation, based on survey results. 


\section{Chapter 5 Discussion}

\subsection{Introduction}

The focus of this research is to assess how the quality of institutions and people's preferences affect the level of expenditure, the provision and the quality of implementation of social protection programmes with a particular focus on developing countries.

In the introduction chapter of this thesis three questions were formulated to be investigated(i) to assess the extent to which institutional factors and people's preferences for redistribution affect the level of expenditure in social protection in developing countries; (ii) to understand how institutional factors and people's preferences affect the type of social protection interventions and; (iii) to investigate how the quality of implementation of social protection interventions is the result of institutional factors and people's preferences.

In order to answer the research questions, three studies have been conducted. Chapter 2 analyses whether and to what extent the level of social protection expenditure varies with institutional quality and people's preferences using cross-country panel data on 80 high-, middle- and low-income countries. Chapter 3 explores how the variation in village development committee performance and people's engagement with local authorities through community structures in Nepal play a role in influencing the provision of social protection interventions implemented at the local level. Chapter 4 investigates and compares two different social protection programme designs, namely the PSNP and the IN-SCT, which represent different levels of institutional quality and people's engagement. The chapter explores how these two factors affect the quality of the implementation of social protection interventions in the kebeles (villages) in Ethiopia.

This chapter is structured as follows. Section 5.2 articulates the main research findings through statements and presents the academic contribution and areas for future research. Section 5.3 discusses research's implications for policy. Finally, Section 5.4 provides concluding remarks.

\subsection{Main research findings}

This section presents key findings from the various chapters of this dissertation. The findings are presented in the form of four statements, which are substantiated by the evidence gathered in this dissertation. It also includes the academic contribution and specific policy implications and suggestions for future research.

Statement 1: Well-functioning institutions and people's preferences for redistribution are related to higher levels of social protection expenditure in low and middle-income countries

Chapter 2, using a quantitative approach, assesses whether and to what extent social protection spending depends on the quality of a country's institutions and people's preferences for redistribution using panel data on 80 countries (52 low- and middle-income countries and 28 high-income countries). The results 
show that both factors have a positive impact on the level of social protection expenditure for all the countries in our sample but also for the group of low- and middle-income countries. In particular, an increase in the functioning of the government index by one unit is associated with a change in the level of social protection expenditure of 0.41 percent of GDP for the 52 low- and middle-income countries using cross sectional data and of 1.3 percent using panel data). A unit increase in the people's preferences index changes the level of expenditure of social protection by as much as 1.4 percent of GDP in low- and middleincome countries.

The chapter contributes to the existing literature in two ways. First, it suggests including institutions and preferences for redistribution in the analysis of the determinants of social protection which today are mainly focused on the politics and on the financing and affordability of social protection programmes (Cichon et al., 2004). Second, it expands on the work conducted by Delavallade (2006) and by Murshed et al (2017). It does so by jointly using proxies for quality of institutions and people's preferences to assess the extent to which these variables may affect the level of expenditure in social protection programmes.

Policy implications based on findings presented in Chapter 2 call for a more effective role played by the international organisations, academic institutions and think thanks to provide technical assistance to countries to ensure that well-functioning institutions are in place and are able to capture and reflect people's preferences to better influence social policies. Furthermore, governments should continue their efforts to provide citizens the opportunity to express their preferences though different mechanisms.

Measures of institutional quality and people's preferences could be included in future country specific quantitative analysis conducted on different social protection interventions to investigate how these factors interact with the quality of implementation of social protection programmes and influence the level of expenditure in social protection. A comparative analysis between similar social protection interventions across different developing countries would be informative. The selection of countries to be investigated could be based on the different degrees of autonomy of institutions at central and decentralized level to assess the extent to which different institutional and administrative models affect the implementation and the level of expenditure of social protection interventions.

Future research should aim at using disaggregated measures of expenditure in social protection expenditures reflecting contributory and non-contributory social protection interventions and considering different forms of basic social protection. This research focused on formal institutions and it would be equally important to complement the analysis by looking at the relevance of informal institutions in explaining resource allocations to social protection in developing countries. As of today, this type of data is not available and it would be important that international organisations, research centres and universities gather this data in collaboration with the respective countries.

This will help to disentangle the role institutional factors and people's preferences play in the context of contributory and non-contributory social protection programmes. Future analyses will benefit from longer 
time series compared to what is used in this dissertation, which is key due to path dependency of institutions, their quality and people's preferences.

Additional analyses should be conducted by testing the conceptual framework introduced in Chapter 2 with the use of regression analysis across different social protection programmes in different countries. In addition, future research could explore and examine the linkages and the extent to which changes at local level may influence policy decisions, quality of implementation and allocation of expenditure in social protection programmes at the central level.

Statement 2: Efficient allocation and management of financial resources and people's engagement with community structures positively affects the type of social protection interventions

Chapter 3, using a case study implemented in Nepal, adopts the efficient allocation and management of the Block Grant at the Village Development Committee level and the establishment of community structures as measures for the quality of institutions; people's ability to raise their voice and communicate their preferences to VDC representatives and community structures is used as proxy for people's preferences. Finally, the provision of development and social protection activities, analysed in terms of type of activities implemented in selected VDCs, is taken as an indicator for the overall quality of implementation of social protection interventions.

Findings suggest that the allocation and management of the Block Grant is more efficient in high performing VDCs for mainly two reasons. The first one is that high performing VDCs have a better knowledge on how the Block Grant should be allocated among different development and social protection activities. The second reason is that high performing VDCs, during the process of selection of programme interventions funded by the Block Grant, take into account the needs of the most vulnerable segments of the community.

High performing VDCs are also characterised by established and functioning community structures such as the community awareness centres (CACs) and the world citizen forums (WCFs) which meet regularly. These community mechanisms are found to be key in gathering people's demands and in discussing development and social protection issues among community members and social protection clients affecting the decision of the programme interventions. At the same time, community members and social protection clients in higher performing VDCs are better able to express their needs and to engage with community structures and politicians compared to lower performing VDCs as confirmed by interviews conducted with key informants and focused group discussions. This seems to influence the choice of social protection activities.

Chapter 3 provides and confirms elements to inform and expand the conceptual framework provided by Hickey (2007), for example, by emphasizing the role of community members and social protection clients in expressing their preferences through their engagement with community structures. Results from 
Chapter 3 confirm that countries should continue to invest in inclusive social protection systems and strengthen the engagement with community members (Søndergård Madsen \& Triantafillou, 2016). Current programmes implemented in Nepal such as the Local Governance and Community Development Programme can further improve the quality of local institutions and empower society in exercising their rights, influencing the planning process and holding local government actors accountable (MoFALD, 2013). Network groups should be established in those VDCs where the participation of certain categories of people is challenged and in certain cases limited to the elites (Khanal, 2013). Finally, the government can employ sufficient personnel at the local level as key staff, such as the social mobilizers and the ward citizen forum coordinators, are currently overstretched and most of the time incapable of managing effectively the tasks assigned.

Future analyses would benefit from data collected over time to explore more in depth why and how institutional performance differs among local administrations and how it influences the delivery of social protection programmes.

Statement 3: Collaboration among service providers and effective community structures have a positive impact on the provision and implementation of social protection interventions

The case study conducted in Ethiopia examines the relationships between institutional factors and people's preferences and how these two factors contribute to the quality of implementation of social protection interventions.

The degree of collaboration between service providers and the establishment of effective community structures are used as indications of the quality of local institutions; the extent to which clients are able to express their views on public works activities as manifestations of people's preferences. Finally, measures for quality of implementation of social protection interventions include the correct and effective transition of eligible clients from public work into temporary direct support, the effective implementation of coresponsibilities, and the extent to which the choice of public work activities reflect people's preferences.

Findings show that higher performing IN-SCT kebeles have stronger relationships and a better understanding of roles and responsibilities among service providers in the implementation of social protection programmes. They also have better access to community structures such as community care coalitions (CCCs) and kebele appeals committees (KACs) compared to the PSNP kebeles. Better collaboration among service providers and better organisations of the kebeles could contribute to better quality of implementation of social protection interventions. Investments in improving the governance of the kebeles in general could contribute to improve the capacity of the local institutions to respond and delivery according to citizens' needs (Grindle, 2004).

Results presented in Chapter 4 suggest that greater interaction among service providers, such as development agents, health extension works and social workers, and better functioning community structures allow for a more effective implementation of social protection interventions. Specifically, co- 
responsibilities - which relate to the attendance of basic health and nutrition services for Temporary Direct Support (TDS) clients of the PSNP - are better monitored in higher performing kebeles compared to lower performing kebeles.

The case study supports the hypothesis that better functioning institutions and people's abilities to voice their preferences shape the design and the implementation of social protection interventions. Public work activities implemented in IN-SCT kebeles reflect clients' needs and their involvement in the decision process. This is not the case for the PSNP kebeles where social protection activities are mainly decided by the kebele representatives without necessarily considering the needs of the community members. It is important to notice that findings from the field work conducted in both IN-SCT and PSNP kebeles highlighted that female clients were less likely to voice their preferences or if they did, to have their voices taken into account.

The implementation of social protection interventions requires a systems approach with linkages to and collaboration across service providers. Greater investment in services, including awareness creation for community members and social protection clients, and investment in capacity-building for all service providers, is imperative for making the systems approach work and influence the delivery of social protection programmes.

Findings from Chapter 4 reinforce the importance of considering the functioning of institutions and people's preference to expand the conceptual framework provided by Hickey (2007). In line with what found in Chapter 3, it underlines the key role of the community structures in articulating community members and social protection clients' preferences for social protection. Findings suggest that the collaboration among service providers who are expected to deliver social protection interventions can be improved by investing in the capacity of institutions and public administration at central and local level by providing technical support to the staff expected to initiate and implement policies. The other area of focus is to ensure people's preferences are represented regarding the involvement of the government in the provisions of public services. Therefore, findings advocate to establish and strengthen systems which allow people's preferences to be heard.

The research also indicates that well-functioning grievance mechanisms are a necessary requirement for taking clients' preferences into account, but also that they are not sufficient in the sense that social dynamics and gender inequalities affect the way some groups of clients feel able to voice their preferences and to have those voices heard. Chapter 4 highlights gender disparities in accessing community structures in the selected districts where the research was implemented. Future research could explore this aspect more in depth, therefore providing a more rigorous and systematic analysis on how gender disparities impact on engaging community structures across different districts and time (Agarwal, 1997) and on the extent to which preferences for social protection are expressed by community members and social protection clients.

A limitation of this case study is that the community structures were analysed at a point in time. Therefore, an interesting contribution to evidence could be provided by analysing over time the functioning 
of community structures, the degree of engagement of community structures in the planning and budgeting process and their linkages with the quality of the implementation of social protection programmes.

Finally, issues such as resilience of the community structures to natural and political shocks and their linkages with the quality of implementation of social protection would be of interest for developing countries.

Statement 4: Efficient and effective planning and budgeting processes improve the quality and spending of social protection programmes.

Chapter 2 introduces the conceptual framework where planning and budgeting processes play a key role in influencing the level of expenditure in social protection. Findings, particularly from Chapter 3 and Chapter 4 reinforce the importance of the participatory planning process and the involvement of community members and social protection clients in the decision process of the social protection programmes implemented at the decentralized level. Community structures were shown to be key in collecting preferences from community members and social protection clients and to improve the communication with the community leaders considering their preferences at the time when the planning process is conducted, the budget discussed and resource allocated.

Strengthening the planning and budgeting processes by making them more participatory and accessible to community members and social protection clients will eventually increase the quality of institutions will contribute to influence the level of expenditure for social protection programmes. This is particularly true for the most disadvantaged segments of the society, who often do not communicate their needs because they feel their voice is not heard by community leaders that often take decisions without considering their inputs, as found in both case studies. In addition, findings show that network groups could help vulnerable groups to convey messages to community representatives during the planning and budgeting process. Future research could further explore in more details the variation of the planning and budgeting process across different countries and interactions between stakeholders involved in the process.

\subsection{Implications for policy}

This research recognizes the important role that demographic, political, economic and governance factors play in influencing social protection programme decisions. The findings of this thesis reinforce this view, but also call for a renewed attention to the functioning of institutions and people's preferences for redistribution as important factors influencing national social protection systems. For instance, the thesis has shown in Chapter 2 that variations in functioning of the government and in people's preferences about redistribution policies are associated with changes in the level of public spending for social protection. The effect of institutions on public spending is confirmed in two different studies which analyse the effect of institutions on public spending (Delavallade, 2006; Murshed et al., 2017). Chapter 2 provides also new evidence on the role people's preferences have on social protection expenditure. 
This has societal implications, as social protection is an integral component of any country's strategic effort to eradicate poverty. Therefore, there is an interest from Governments, international organisations, civil societies and donors to understand the factors that influence their provision of such programmes. Governments, especially in developing countries, should reflect on the complexity of the provision of social protection programmes and their interlinkages with central and local institutions and people's preferences. Hence, these factors should be carefully considered, and preferences elicited in the elaboration of development plans, country strategies, and policies and in designing programmes on social protection.

This could be achieved in two ways. First, development plans, country strategies and policies should reflect an awareness of the possible impact of these two factors on the choice and on the quality of social protection programmes, and so include elements which articulate the role of institutions at different levels and the extent to which people will be able to express their preferences and be engaged in the decision process of social protection programmes. Second, Government directives, which translate laws into actions, need to provide clear guidelines to departments and to the different levels of administration so that actions can be taken at different levels. For example, planning and budgeting guidelines should identify steps to ensure people's engagement in the planning process where development interventions are shaped and through which resources are allocated.

At the same time, governments should continue to focus on strengthening the capacity of local institutions in order to achieve effective collaboration and coordination among service providers, ensuring the establishment and the functioning of community structures. This is even more important for those governments of developing countries that are in the process of political and fiscal devolution and decentralization as they need to provide the necessary technical support in the initial phases of the process and ensure that effort is sustained in the long term.

Findings from the two case studies provide evidence on the importance of having competent staff in place to deliver social protection programmes. In particular, the two case studies highlight that institutions are not only important for the delivery of social protection interventions, but they are also crucial to ensure that community members and social protection clients' demands are taken into account. To improve people's participation, governments can strengthen their planning and budgeting processes and improve the functioning of community structures as these processes and mechanisms provide essential moments for people to engage in community development, improve ownership and sustainability of the programmes and influence the choice and the implementation of social protection interventions. Findings from Chapter 4 point towards a gendered use of grievance mechanisms, suggesting that male social protection clients are more likely to raise complaints and to have their preferences reflected in the choice of social protection activities. Therefore, governments should ensure that institutions and policies continue to address inequalities between privileged and marginalised segments of society.

International organisations have the opportunity to provide technical and financial support to governments and ensure that the issues of good governance and preferences for redistribution are discussed 
and articulated in the country programme documents and strategies. International organisations and donors have been often instrumental in supporting the launch of social protection programmes in developing countries providing considerable technical support in the design of social protection systems. There are at least three main entry points where both the quality of institutions and people's preferences can be included in the analysis and discussion of social protection. The first one is at the time when international organisations and donors conduct their respective country situation analyses and develop, jointly with the government, their respective country strategies. The second one is through the acknowledgment and inclusion of these principles in their respective framework of analyses so that they can be appropriately integrated in programme interventions. The third one is related to the convening roles international organisations have to stimulate the debate and facilitate the technical discussion on these factors through conferences, technical workshops and the production of robust and solid evidence. Given the growing citizens' demand for open and accountable governments, international organisations and donors should continue to work with countries to propose new approaches to supporting transparency and promoting greater accountability. Support to governance and accountability should be specifically analysed with respect to the delivery of social protection programmes to better explain the different factors linked to the implementation of social protection interventions which is key to reach social protection outcomes (Bastagli et al., 2016).

Donors acknowledge the importance of supporting quality of institutions and governance and accountability to improve the provisions of development programmes. However, some donors may not be specialised in these areas and therefore it would be required that, depending on the different country contexts and implementation of social protection programmes, specific international organisations take the lead to address these specific factors. These changes will require donors' adjustments to their roles and forms of assistance, funding modalities and new approaches to risk and results management.

\subsection{Limitations of the research}

This research has some limitations which should be considered when interpreting the findings and conclusions. The choice of using both quantitative and qualitative methods is motivated by the interest in finding associations and in assessing how variations in the quality of institutions and people's preferences can affect the level of expenditure in social protection. At the same time, this research acknowledges that phenomena such as institutions and people's preferences are complex concepts that are often not clearly demarcated and that would benefit from country contextualisation and qualitative analyses. Therefore, the choice of using qualitative methods provides for nuances while exploring the main variables of interest and helps investigating the different dynamics at play across different programme and country contexts.

The analysis in Chapter 2 is limited by the currently available data. Hence, the results should be interpreted more in terms of associations between our independent variables of interest and the level of expenditure in social protection. The analysis conducted in Chapter 2 is based on the most comprehensive available dataset provided by the International Labour Organization. The ILO dataset on social protection 
expenditures aggregates different social protection programmes without providing a breakdown for social assistance programmes which are the core interest of this thesis. The availability of such specific data could offer interesting insights on how institutions and preferences influence the allocation of general government revenues to social assistance programmes aimed at poor and vulnerable households. At least, the chapter compares social protection expenditure with and without the inclusion of health expenditure. Currently, the Global Development Institute in Manchester is preparing a dataset which will include information on the expenditure specifically for social assistance programmes which could be further exploited in future research. Secondly, the analysis conducted in Chapter 2 could benefit from longer time series for the main variables of interests to establish causal relationships. However, even in this case, the analysis would face certain limitations, as the variables used to proxy the quality of institutions and people's preferences are only available for recent years. For example, the data for people's preferences are collected from different waves of the World Value Survey, which are only implemented every five years in selected countries. Therefore, for many countries only one value is available.

Chapter 3 and Chapter 4 are qualitative in nature and the generalizability of the findings is limited. The choice of using qualitative methods has been driven by the complexity of the concepts used in the analysis as mentioned above. Even more importantly, it has allowed for in-depth analyses, nuances and multiple perspectives of people using different sources of evidence under a "...real-world case which involves important contextual conditions" (Yin, 2014, p. 16) and for specific social protection programmes. In particular, interviews and focus group discussions have been relevant to explore social protection interventions with specific programme designs and methods of implementation and with different institutional dynamics such as the Block Grant in Nepal and the PSNP and IN-SCT programmes in Ethiopia. For example, qualitative methods in this research were key to understand how community members and social protection clients participate and interact with local administrations or how service providers could improve efficiency and affect the delivery of social protection interventions.

Because Nepal and Ethiopia are socio-economically very different with diverse social protection systems, there are limitations in terms of comparability of the findings among the two countries. The findings do not aim to be nationally or regionally representative but the two case studies should be considered as in-depth and localised studies within their respective regional contexts. The selection of the districts in both Nepal and Ethiopia was done by taking into account both programmatic and convenience considerations which necessarily introduce elements of bias. It is important to notice that while the limited number of district compromises the external validity of the findings, the decision of focusing on few districts was mainly driven by the desire to have an in-depth understanding and variation of people's views and of the different levels of institutional performance among VDCs and kebeles.

Specifically, in the case of Nepal, the district of Kaski was selected because it presented enough variations in terms of capacity of the VDCs within the district. Furthermore, the district was easy to access from the capital Kathmandu where the principle investigator was based at the time the field work. In the 
case of Ethiopia, the IN-SCT pilot covers four districts in two regions: namely Oromia and Southern Nations, Nationalities, and People Region (SNNPR). The region of Oromia was selected because it was easy to access from the capital Addis Ababa. The two districts, namely Adami Tulu and Arsi Negele were selected based on their proximity, access to main roads, availability of services and performance in IN-SCT and PSNP (as advised by district representatives). However, the selected kebeles within their respective districts were distant, therefore limiting the risk of programme contamination.

Future research can benefit from a broader study, involving for example a greater number of local administrations and a larger number of subjects to enhance the external validity of the results. Furthermore, this could be supplemented with quantitative analyses conducted on specific social protection programmes to complement and triangulate the findings obtained with the qualitative research.

\subsection{Concluding remarks}

This thesis builds on the existing literature that investigates the determinants of social protection and assesses the extent to which the quality of institutions and people's preferences influence the allocation, provision and quality of implementation of social protection programmes in developing countries. It acknowledges that the demographic, political and economic environment and the governance of countries are important factors, which can influence social protection, but it decides to focus on the quality of institutions and people's preferences as these aspects have not been sufficiently studied.

To answer the research question both quantitative and qualitative methods were used. Findings from the quantitative analysis confirm the positive contribution of institutional factors and people's preferences to the level of expenditure in social protection. The qualitative case studies conducted in Nepal and Ethiopia have served to explore at local levels how institutions and people's preferences affect the provision and quality of implementation of social protection interventions. The case studies show that better performing institutions, effective community structures, and better citizens' involvement are key factors in the delivery of social protection programmes. Furthermore, results have highlighted the importance of the planning and budgeting process in influencing the allocation and provision of social protection programmes.

Overall, the dissertation has confirmed that the determinants of social protection go beyond financial affordability and political commitment, although they remain key factors in determining the shape and size of social protection programmes. The functioning of institutions and people's preferences play an important role and should be carefully considered in any analytical framework of social protection, and during the inception of social protection policies and programmes. Findings and recommendations of this dissertation provide guidance to government, donors, international organisations and practitioners on the importance of a continuous focus on effective and efficient institutional quality and a better involvement of citizens in the choice of social protection programmes. 


\section{References}

Acemoglu, D., Gallego, F. A., \& Robinson, J. A. (2014). Institutions, Human Capital, and Development. Annual Review of Economics, Vol. 6(No. 1), 875-912.

Acemoglu, D., Johnson, S., \& Robinson, J. A. (2002). Reversal of Fortune: Geography and Institutions in the Making of the Modern World Income Distribution. Quarterly Journal of Economics, 1231-1294.

Acemoglu, D., \& Robinson, J. A. (2001). A Theory of Political Transitions. The American Economic Review, Vol. 91 (No. 4), 938-963.

Acemoglu, D., \& Robinson, J. A. (2012). Why nations fail: the origins of power, prosperity, and poverty (Vol. Vol. 4). New York: Crown Business.

Acemoglu, D., Robinson, J. A., \& Johnson, S. (2001). The Colonial Origins of Comparative Development: An Empirical Investigation. The American Economic Review, Vol. 91(No. 5), 1369-1401.

Adsera, A., Boix, C., \& Payne, M. (2003). Are You Being Served? Political Accountability and Quality of Government. Journal of Law, Economics, and Organization, Vol. 19(No. 2), 445-490.

Agarwal, B. (1997). Gender, environment, and poverty interlinks: Regional variations and temporal shifts in rural India, 1971-1991. World Development, 25(1), 23-52.

Alesina, A., \& Angeletos, G.-M. (2005). Fairness and Redistribution. American Economic Review, 95(4), 960980.

Alesina, A., \& Giuliano, P. (2009). Preferences for Redistribution. NBER Working Paper Series, (w14825).

Alesina, A., \& La Ferrara, E. (2005). Preferences for Redistribution in the Land of Opportunities. Journal of Public Economics, Vol. 89(No. 5-6), 897-931.

Alesina, A., \& Tabellini, G. (2004). Bureaucrats or politicians? National Bureau of Economic Research, 10241.

Allen, E. R., \& Tommasi, D. (2001). Managing Public Expenditure: A Reference Book for Transition Countries. OECD.

Atkinson, A. (2013). Reducing income inequality in Europe. IZA Journal of European Labor Studies, 2(1), 12.

Avramov, D. (2003). People, Demography and Social Exclusion (Population Studies, Vol. 37). Strasbourg: Council of Europe Publishing.

Ayliffe, T. (2018). Social Accountability in the Delivery of Social Protection. Ethiopia case study. Development Pathways. 
Babajanian, B. (2012). Social Protection and its Contribution to Social Cohesion and State-Building. Bonn: GIZ.

Baez, J. E., \& Camacho, A. (2011). Assessing the Long-Term Effects of Conditional Cash Transfers on Human Capital: Evidence from Colombia. World Bank Policy Research Working Paper Series.

Bailey, C. (2004). Extending Social Security Coverage in Africa. ESS Extension of Social Security. International Labour Office, Geneva, (20).

Banerjee, A., Duflo, E., Goldberg, N., Karlan, D., Osei, R., Pariente, W., ... Udry, C. (2015). A Multifaceted Program Causes Lasting Progress for the Very Poor: Evidence From Six Countries. Science, Vol. 348(No. 6236).

Barrientos, A. (2007). Financing Social Protection. Brooks World Poverty Institute Working Paper, (5).

Barrientos, A. (2010). Social Protection and Poverty. United Nations Research Institute for Social Development.

Barrientos, A. (2013). Social Assistance in Developing Countries. Cambridge University Press.

Barrientos, A., \& Hulme, D. (2005). Chronic Poverty and Social Protection: Introduction. The European Journal of Development Research, 17(1), 1-7.

Barrientos, A., \& Hulme, D. (2010). Social Protection for the Poor and Poorest. Concepts, Policies and Politics. Palgrave Studies in Development.

Barrientos, A., Hulme, D., \& Shepherd, A. (2005). Can Social Protection Tackle Chronic Poverty? The European Journal of Development Research, Vol. 17(No. 1), 8-23.

Bastagli, F. (2015). Bringing Taxation into Social Protection Analysis and Planning. Overseas Development Institute Working Papers, (421).

Bastagli, F., Hagen-Zanker, J., Harman, L., Barca, V., Sturge, G., Schmidt, T., \& Pellerano, L. (2016). Cash transfers: what does the evidence say. A Rigorous Review of Programme Impact and the Role of Design and Implementation Features. London: ODI.

Behrendt, C., Cichon, M., Hagemejer, K., Léger, F., \& Pal, K. (2005). Can Low Income Countries Afford Basic Social Protection? First Results of a Modelling Exercise. Issues in Social Protection, (13).

Behrman, J. R., \& Hoddinott, J. (2005). Programme Evaluation with Unobserved Heterogeneity and Selective Implementation: The Mexican PROGRESA Impact on Child Nutrition. Oxford Bulletin of Economics and Statistics, 67(4), 547-569. 
Bénabou, R., \& Ok, E. A. (2001). Social Mobility. The Quarterly Journal of Economics, Vol. 116(No. 2), 447487.

Bender, K. (2013). The political economy of social protection reforms in developing countries: What is to be explained and how? In: K. Bender, M. Kaltenborn, \& C. Pfleiderer (eds.). London: Routledge.

Berhane, G., Devereux, S., Hoddinott, J., Tegebu, F. N., Roelen, K., \& Schwab, B. (2012). Evaluation of the social cash transfers pilot programme, Tigray region, Ethiopia, Baseline Report. Addis Ababa: IFPRI.

Berhane, G., Hoddinott, J., Kumar, N., Taffesse, A. S., Diressie, M. T., Yohannes, Y., ... Sima, F. (2013). Evaluation of Ethiopia's Food Security Program: Documenting progress in the implementation of the Productive Safety Nets Programme and the Household Asset Building Programme (HABP). Addis Ababa: ESPPII/IFPRI/IDS/Dadimos.

Besley, T., \& Persson, T. (2013). Pillars of Prosperity The Political Economics of Development Clusters. Princeton New Jersey, USA: Princeton University Press.

Bhattachan, K. B., Sunar, T. B., \& Bhattachan, Y. K. (2009). Caste-based Discrimination in Nepal. Indian Institute of Dalit Studies, 3(8).

Bloomberg, B., Cooper, D. R., \& Schindler, P. S. (2008). Business Research Methods (2nd European). Berkshire: McGraw-Hill Education.

Bluhm, R., \& Szirmai, A. (2012). Institutions and Long-run Growth Performance: An Analytic Literature Review of the Institutional Determinants of Economic Growth. UNU-MERIT Working Paper Series, (033).

Brooks, C., \& Manza, J. (2007). Why Welfare States Persist. The Importance of Public Opinion in Democracies (Studies in Communication, Media, and Public). Chicago: IL: University of Chicago Press.

Caiden, N., \& Wildavsky, A. B. (1974). Planning and Budgeting in Poor Countries. New York.

Cameron, D. R. (1978). The Expansion of the Public Economy: A Comparative Analysis. American Political Science Review, 72(04), 1243-1261.

Carbone, G. (2011). Democratic demands and social policies: the politics of health reform in Ghana. The Journal of Modern African Studies, 49(03), 381-408.

Central Bureau of Statistics. (2011). Nepal Living Standards Survey 2010-2011, NLSS Third. Government of Nepal. 
Chan, K. S. (2002). Trade and Bureaucratic Efficiency. Economic Development and Cultural Change, Vol. 50(No. 3), $735-754$.

Chhetri, B. B. K., Johnsen, F. H., Konoshima, M., \& Yoshimoto, A. (2013). Community forestry in the hills of Nepal: Determinants of user participation in forest management. Forest Policy and Economics, 30, $6-13$.

CIAT, ECLAC, OECD, \& IDB. (2015). Revenue Statistics in Latin America and the Caribbean 2015. OECD Publishing.

Cichon, M., Hagemejer, K., \& Woodall, J. (2006). Changing the Paradigm in Social Security: From Fiscal Burden to Investing in People. Geneva: ILO.

Cichon, M., Scholz, W., van de Meerendonk, A., Hagemejer, K., Bertranou, F., \& Plamondon, P. (2004). Financing Social Protection. Geneva: International Labour Office/International Social Security Association.

Cingolani, L. (2013). The State of State Capacity: A Review of Concepts, Evidence and Measures. United Nations University, Maastricht Economic and Social Research and Training Centre on Innovation and Technology.

Coll-Black, S., Monchuk, V., \& Standford, J. (2018). Anchoring in Strong Institutions to Expand and Sustain Social Safety Nets in Kathleen Beegle, Aline Coudoule, Emma Monsalve (eds.) Realizing the Full Potential of Social Safety Nets in Africa. Washington, D.C.: World Bank.

Conway, T., de Haan, A., \& Norton, A. (2000). Social Protection: New Directions of Donor Agencies. Paper for the DFID-ODI Inter-Agency Seminar on Social Protection. Easthamstead Park.

Conway, T., Foster, M., \& Norton, A. (2001). Social protection concepts and approaches: implications for policy and practice in international development. Overseas Development Institute, 143.

Corneo, G., \& Grüner, H. P. (2002). Individual Preferences for Political Redistribution. Journal of Public Economics, Vol. 83(No. 1), 83-107.

Cornia, G. A. (2014). Falling Inequality in Latin America: Policy Changes and Lessons. Oxford: Oxford University Press and United Nations University. 
Crouch, L., \& Winkler, D. (2008). Governance, Management and Financing of Education for All: Basic Frameworks and Case Studies. Background paper for EFA Global Monitoring Report 2009 (through Research Triangle Institute). Paris: UNESCO.

d'Agostino, G., Dunne, J. P., \& Pieroni, L. (2016). Corruption and Growth in Africa. European Journal of Political Economy, 43, 71-88.

Daidone, S., Davis, B., Handa, S., \& Winters, P. (2017). The household and individual-level economic impacts of cash transfer programmes in sub-Saharan Africa. Rome: FAO.

de Waal, A. (1996). Social contract and deterring famine: first thoughts. Disasters, 20(3), 194-205.

de Waal, A. (1997). Famine crimes: politics and the disaster relief industry in Africa. Oxford: James Currey: International African Institute.

de Waal, A. (2000). Democratic political process and the fight against famine. Brighton, Institute of Development Studies, (107).

Debowicz, D., \& Golan, J. (2014). The Impact of Oportunidades on Human Capital and Income Distribution in Mexico: A Top-Down/Bottom-Up Approach. Journal of Policy Modeling, 36(1), 24 42.

Delavallade, C. (2006). Corruption and Distribution of Public Spending in Developing Countries. Journal of Economics and Finance, Vol. 30(No. 2), 222-239.

Dercon, S. (2002). Income Risk, Coping Strategies, and Safety Nets. The World Bank Research Observer, 17(2), 141-166.

Devereux, S. (2000). Food Insecurity in Ethiopia. A Discussion Paper for DFID. Brighton: IDS, Sussex.

Devereux, S., Roelen, K., Sabates, R., Stoelinga, D., \& Dyevre, A. (2015). Final Evaluation Report. Concern's Graduation Model Programme in Burundi. Dublin: Concern.

Devereux, S., \& Sabates-Wheeler, R. (2004). Transformative social protection. Institute of Development Studies, 232.

Devereux, S., Sabates-Wheeler, R., Taye, M. T., Sabates, R., Sima, F., \& others. (2014). Graduation from the Food Security Programme in Ethiopia: FAC Ethiopia Final Report. Working Paper-Future Agricultures, (80). 
Diamond, J., \& Potter, B. H. (1999). Guidelines for Public Expenditure Management. International Monetary Fund.

Dion, M. L., \& Birchfield, V. (2010). Economic Development, Income Inequality, and Preferences for Redistribution1: Development, Inequality, and Redistribution. International Studies Quarterly, 54(2), $315-334$.

Donder, P. D., \& Hindriks, J. (1998). The political economy of targeting. Public Choice, 95(1/2), 177-200.

Dreher, A. (2006). The influence of globalization on taxes and social policy: An empirical analysis for OECD countries. European Journal of Political Economy, 22, 179-201.

DSD, SASSA, \& UNICEF. (2012). The South African Child Support Grant Impact Assessment. Evidence From a Survey of Children, Adolescents and Their Households (p. 132). Pretoria: UNICEF South Africa.

Duman, A. (2013). Attitudes Towards Hard Work and Redistributive Preferences in Developing Countries, in Katia Bender, Markus Kaltenborn and Christian Pfleider (ed.) Social Protection in Developing Countries: Reforming Systems. Routledge.

Dupper, O. (2013). The Role of Law and Legal Institutions in the Reform of Social Protection Systems: Experiences from South Africa, in Katia Bender, Markus Kaltenborn and Christian Pfleider (ed.) Social Protection in Developing Countries: Reforming Systems. Routledge.

Durán-Valverde, F., \& Pacheco, J. F. (2012). Fiscal Space and the Extension of Social Protection: Lessons Learnt from Developing Countries. ESS Extension of Social Security. International Labour Office, Geneva, (33).

Easterly, W. (2001). The Elusive Quest for Growth: Economists' Adventures and Misadventures in the Tropics. Cambridge, MA: The MIT Press.

Easterly, W. (2013). The Tyranny of Experts: Economists, Dictators, and the Forgotten Rights of the Poor. New York: Basic Books.

Easterly, W., \& Rebelo, S. (1993). Fiscal Policy and Economic Growth: An Empirical Investigation. Journal of Monetary Economics, 32(2), 417-458.

Engelen, B. (2017). A new definition of and role for preferences in positive economics. Journal of Economic Methodology, 24(3), 254-273. 
ESAP. (2016). Ethiopia Protection of Basic Services Social Accountability Program. Internal Assessment. Addis Ababa: Government of Ethiopia.

Esping-Andersen, G. (1990). The Three Worlds of Welfare Capitalism. John Wiley \& Sons.

Evans, P., \& Rauch, J. E. (1999). Bureaucracy and Growth: A Cross-National Analysis of the Effects of "Weberian" State Structures on Economic Growth. American Sociological Review, Vol. 64(No. 5), $748-765$.

Faguet, J.-P. (2014). Decentralization and Governance. World Development, 53, 2-13.

Ferrera, M., Hemerijck, A., \& Rhodes, M. (2001). The future of the European "social model” in the global economy. Journal of Comparative Policy Analysis: Research and Practice, 3(2), 163-190.

Fisher, I. (2006). Mathematical Investigations in the Theory of V alue and Prices, and Appreciation and Interest. New York, NY: Cosimo.

Fong, C. (2001). Social Preferences, Self-Interest, and the Demand for Redistribution. Journal of Public Economics, Vol. 82(No. 2), 225-246.

Frankel, J. A. (2004). The World Trading System and Implications of External Opening. The Initiative for Policy Dialogue Series, 180.

Gallup, J. L., Sachs, J. D., \& Mellinger, A. D. (1999). Geography and Economic Development. International Regional Science Review, Vol. 22(No. 2), 179-232.

García, A. B., \& Gruat, J. V. (2003). Social Protection: A Life Cycle Continuum Investment for Social Justice, Poverty Reduction and Sustainable Development (p. 64). Geneva: International Labour Organization.

Garde, M., Mathers, N., \& Dhakal, T. (2017). The evolution of Nepal's child grant: from humble beginnings to a real driver of change for children? Global Social Policy, 17(3), 359-364.

Garrett, G. (1998). Global Markets and National Politics: Collision Course or Virtuous Circle? International Organization, 52(4), 787-824.

Gassmann, F., Mohnen, P., \& Vinci, V. (2016). Institutional Factors and People’s Preferences in Social Protection. UNU-MERIT Working Paper Series, (3).

Germann, S., Ngoma, F., Wamimbi, R., Claxton, A., \& Gaudrault, M. (2009). Mobilizing and strengthening community-led childcare through community care groups and coalitions: A study from Ethiopia, Mozambique, Uganda and Zambia. International NGO Journal, 4(1), 001-006. 
Gilligan, D. O., Devereux, S., Hoddinott, J., Jilani, A., Kebede, D., Ledlie, N., .. Taffesse, A. S. (2016). Impact Evaluation of the UNICEF Social Cash Transfer Pilot Program In Oromia and SNNP Regions, Ethiopia. Addis Ababa: IFPRI.

Giri, K., \& Darnhofer, I. (2010). Nepali Women Using Community Forestry as a Platform for Social Change. Society \& Natural Resources, 23(12), 1216-1229.

Glaeser, E. L., La Porta, R., Lopez-de-Silanes, F., \& Shleifer, A. (2004). Do Institutions Cause Growth? Journal of Economic Growth, Vol. 9(No. 3), 271-303.

Government of Nepal. (2008). Technical Note on Input to the Strategy for Topping-Up of Capital Grants to Local Bodies - the "Expanded Block Grants (EBGs)" in Nepal. Government of Nepal.

Graham, C. (2002). Public attitudes matter: A conceptual frame for accounting for political economy in safety nets and social assistance policies. Washington, DC: World Bank, (0233).

Greenhill, R., Carter, P., Hoy, C., \& Manuel, M. (2015). Financing the Future. How International Public Finance Should Fund a Global Social Compact to Eradicate Poverty. Overseas Development Institute.

Grindle, M. S. (2004). Good Enough Governance: Poverty Reduction and Reform in Developing Countries. Governance: An International Journal of Policy, Administration, and Institutions, 17(4), 525-548.

Guillaud, E. (2013). Preferences for Redistribution: An Empirical Analysis over 33 Countries. The Journal of Economic Inequality, 11(1), 57-78.

Gupta, S., Davoodi, H., \& Tiongson, E. (2000). Corruption and the Provision of Health Care and Education Services. International Monetary Fund Working Paper, (WP/00/116).

Hagen-Zanker, J., Mallett, R., \& Ghimire, A. (2015). How does Nepal's Child Grant work for Dalit children and their families? UNICEF and ODI.

Haggard, S., \& Birdsall, N. (2002). After the crisis: the social contract and the middle class in East Asia. In: E. Kapstein and B. Milanovic, eds. When markets fail: social policy and economic reform. New York: Russell Sage Foundation.

Haggard, S., \& Kaufman, R. (2004). Revising Social Contracts: Social Spending in Latin America, East Asia, and the Former Socialist Countries, 1980-2000. Revista de Ciencia Politica (Santiago), 24(1).

Haggard, S., \& Kaufman, R. R. (2008). Development, Democracy, and Welfare States. Princeton and Oxford: Princeton University Press. 
Hall, D. (2010). Why We Need Public Spending (Project Report). Greenwich, UK: University of Greenwich.

Handa, S., Huerta, M.-C., Perez, R., \& Straffon, B. (2000). Poverty, Inequality, and Spill Over in Mexico’s Education, Health, and Nutrition Program. International Food Policy Research Institute, Washington, DC. Handa, S., Natali, L., Seidenfeld, D., Tenbo, G., \& Davis, B. (2016). Can Unconditional Cash Transfers Lead to Sustainable Poverty Reduction? Evidence from two government-led programmes in Zambia. UNICEF Office of Research, Florence, 2016(21).

Hausman, D. M. (2005). Sympathy, commitment, and preference. Economics \& Philosophy, 21, 33-50.

Heller, M. P. S. (2005). Understanding Fiscal Space (EPub). International Monetary Fund.

Hendrix, C. S. (2010). Measuring State Capacity: Theoretical and Empirical Implications for the Study of Civil Conflict. Journal of Peace Research, 47(3), 273-285.

Hickey, S. (2007). Conceptualising the Politics of Social Protection in Africa. Brooks World Poverty Institute.

Hickey, S. (2009). The politics of protecting the poorest: Moving beyond the 'anti-politics machine'? Political Geography, 28(8), 473-483.

Hickey, S. (2011). The politics of social protection: what do we get from a 'social contract' approach? Canadian Journal of Development Studies/Revue Canadienne d'études Du Développement, 32(4), 426-438.

Hirvonen, K., Mascagni, G., \& Roelen, K. (2016). Linking taxation and social protection evidence on redistribution and poverty reduction in Ethiopia. Helsinki, Finland: United Nations University World Institute for Development Economics Research.

Holmes, R., \& Jones, N. (2010). How to Design and Implement Gender-Sensitive Social Protection Programmes. Overseas Development Institute.

Holzmann, R., Sherburne-Benz, L., Tesliuc, E., \& Unit, S. P. (2003). Social Risk Management: The World Bank's Approach to Social Protection in a Globalizing World. World Bank Washington, DC.

Huber, E., \& Stephens, J. D. (2005). State Economic and Social Policy in Global Capitalism in Thomas Janoski, Robert Alford, Alexander M. Hicks, and Mildred Schwartz (eds.), The Handbook of Political Sociology: States, Civil Societies, and Globalization. New York: Cambridge University Press.

ILO. (2001). Social Security: Issues, Challenges and Prospects: Sixth Item on the Agenda. Geneva.

ILO. (2008). Can Low-Income Countries Afford Basic Social Security? Social Security Policy Briefings, (3). 
ILO. (2012). 101st Session of the International Labour Conference, 30 May - 14 June 2012. International Labour Organization.

ILO. (2013). Employment and Social Protection in the New Demographic Context Fourth Item on the Agenda. International Labour Office.

ILO. (2014). World Social Protection Report 2014-15: Building economic recovery, inclusive development and social justice. Geneva ILO: International Labour Office.

ILO. (2017). World Social Protection Report 2017-19: Universal social protection to achieve the Sustainable Development Goals. Geneva ILO: International Labour Office.

ILO, \& World Bank. (2016). A Shared Mission for Universal Social Protection.

ISSA. (2013). Good Governance Guidelines for Social Security Institutions. International Social Security Association. Retrieved from http://socialprotection-humanrights.org

Jacobs, L. R. (1993). The Health of Nations: Public Opinion and the Making of American and British Health Policy. New York: Cornell University Press.

Jennings, C. (2013). Institutions and Prosperity. A review of Timothy Besley and Torsten Persson, Pillars of Prosperity: The Political Economics of Development Clusters, Princeton University Press, Princeton, 2011, pp. 375 and Daron Acemoglu and James A. Robinson, Why Nations Fail: The Origins of Power, Prosperity and Poverty, Profile Books, London 2012, pp. 529. European Journal of Political Economy, 29, 252-258.

Jones, N., \& Bhatta, B. (2009). Governance and Citizenship From Below Views of Poor and Excluded Groups and Their Vision for a New Nepal. Overseas Development Institute Working Papers, (301).

Jütting, J., Corsi, E., Kauffmann, C., McDonnel, I., Osterrieder, H., Pinaud, N., \& Wegner, L. (2005). What Makes Decentralisation in Developing Countries Pro-poor? The European Journal of Development Research, 17(4), 626-648.

Jutting, J., \& Prizzon, A. (2013). Social Cohesion, Does it Matter for Growth and Development, in Katia Bender, Markus Kaltenborn and Christian Pfleider (ed.) Social Protection in Developing Countries: Reforming Systems. Routledge.

Kaltenborn, M. (2017). Overcoming Extreme Poverty by Social Protection Floors - Approaches to Closing the Right to Social Security Gap. Law and Development Review, 10(2), 237-273. 
Kaltenborn, M., Abdulai, A.-G., Roelen, K., \& Hague, S. (2017). The Influence of Policy and Legal Frameworks on the Development of Social Protection Systems. IDS Working Paper, 2017(51).

Kardan, A., Wyatt, A., Quarles van Ufford, P., \& Attah, R. (2016). Assessing the Capacity of Local Administration and Community Structures to Deliver Social Protection Programmes. (Presented at the Symposium on Social Protection Systems - Tying the Knots, 5-6 September) 2017, Bonn, Germany.

Kaufmann, D., Kraay, A., \& Mastruzzi, M. (2007). Worldwide Governance Indicators Project: Answering the Critics. World Bank Policy Research Working Paper, (4149).

Kaufmann, D., Kraay, A., \& Mastruzzi, M. (2010). Response to 'What do the Worldwide Governance Indicators Measure?' European Journal of Development Research, Vol. 22(No. 1), 55-58.

Khanal, P. (2013). Community participation in schooling in Nepal: a disjunction between policy intention and policy implementation? Asia Pacific Journal of Education, 33(3), 235-248.

Kochar, A. (1999). Smoothing Consumption by Smoothing Income: Hours-of-Work Responses to Idiosyncratic Agricultural Shocks in Rural India. The Review of Economics and Statistics, Vol. 81(No. 1), 50-61.

Koehler, G. (2014). Social Protection in Nepal. How can social protection in Nepal become effective and genuinely transformative? in UNDP (ed.) Leveling the Playing Field... (Development Advocate Nepal No. Year 2; Issue 1). Nepal: UNDP.

Koster, F., \& Kaminska, M.-E. (2012). Welfare state values in the European Union, 2002-2008. A multilevel investigation of formal institutions and individual attitudes. Journal of European Public Policy, 19(6), 900-920.

La Porta, R., Lopez-de-Silanes, F., Shleifer, A., \& Vishny, R. (1998). The Quality of Government. NBER Working Paper Series, (w6727), 221-279.

Lachapelle, P., Smith, P. D., \& McCool, S. F. (2004). Access to power or genuine empowerment? An analysis of three community forest groups in Nepal. Human Ecology Review, 11(1), 1-12.

Lawoti, M. (2005). Towards a Democratic Nepal. Inclusive Political Institutions for a Multicultural Society. New Delhi: Sage Publications. 
Lehne, J., Mo, J., \& Plekhanov, A. (2014). What Determines the Quality of Economic Institutions? CrossCountry Evidence. SSRN Electronic Journal, (WP/171).

Lu, C., Chin, B., Lewandowski, J. L., Basinga, P., Hirschhorn, L. R., Hill, K., ... Binagwaho, A. (2012). Towards Universal Health Coverage: An Evaluation of Rwanda Mutuelles in Its First Eight Years. PLOS ONE, 7(6).

Machlup, F. (1958). Structure and Structural Change: Weaselwords and Jargon. Zeitschrift Für Nationalökonomie / Journal of Economics, 18(3), 280-298.

Manor, J. (2004). Appendix 3 in 'Politicking for the Poor. Final Report to the U.K. Department for International Development”. Institute of Development Studies, University of Sussex.

Marshall, Monty, J., \& Keith Jaggers. (2009). Polity IV Project: Political Regime Characteristics and Transitions, 1800-2008.

Mathema, P. (2012). National Social Security Policy: A Reality Need for Nepal. Administration and Management Review, 24(2), 56-64.

Mauro, P. (1995). Corruption and Growth. The Quarterly Journal of Economics, Vol. 110(No. 3), 681-712.

Mauro, P. (1997). The Effects of Corruption on Growth, Investment and Government Expenditure: A Cross-Country Analysis in Corruption and the World Economy, (ed.) by K.A. Elliot. Washington, DC: Institute for International Economics.

Mauro, P. (1998). Corruption and the Composition of Government Expenditure. Journal of Public Economics, $69(2), 263-279$.

McCord, A. (2012). The politics of social protection: why are public works programmes so popular with governments and donors? Overseas Development Institute, 9.

McNamara, C. (1999). Basic Definition of Organisation. Accessed from the internet on 9 October 2014. Retrieved from http://managementhelp.org/organizations/definition.htm

Mideros, A., Gassmann, F., \& Mohnen, P. (2015). Estimation of Rates of Return on Social Protection: Ex Ante Microsimulation of Social Transfers in Cambodia. Journal of Development Effectiveness.

Miles, M. B., \& Huberman, A. M. (1994). Qualitative Data Analysis: An Expanded Sourcebook. Sage Publications. 
Milgrom, P., \& Roberts, J. (1990). The Economics of Modern Manufacturing: Technology, Strategy, and Organization. The American Economic Review, Vol. 80(No. 3), 511-528.

Ministry of Finance. (2009). Budget Speech of Fiscal Year 2009/10. Government of Nepal.

Ministry of Finance. (2016). Budget Speech of Fiscal Year 2016/17. Government of Nepal.

Ministry of Labour and Social Affairs (MoLSA). (2012). National Social Protection Policy of Ethiopia. Addis Ababa: MOLSA.

MoARD. (2014). Productive Safety Net Programme Phase IV, Programme Implementation Manual. Addis Ababa: Ministry of Agriculture and Rural Development.

MoARD. (2016). Training Guide. Gender, Social Development and Nutrition Mainstreaming in PSNP. Addis Ababa: Ministry of Agriculture and Natural Resources, Food Security Coordination Directorate.

Moene, K. O., \& Wallerstein, M. (2003). Targeting and Political Support for Welfare Spending. In Conflict and Governance (pp. 33-54). Springer.

MoFALD. (2013). Local Governance and Community Development Programme (LGDP II). Programme Document FY 2013/2014 - 2016/2017. Singhadurbar: Ministry of Federal Affairs and Local Development, Government of Nepal.

MOLSA. (2017). Situation analysis of community care coalition structures in five regions of Ethiopia. Revised Report (Draft). Ministry of Labour and Social Affairs.

Morduch, J. (1995). Income Smoothing and Consumption Smoothing. The Journal of Economic Perspectives, Vol. 9(No. 3), 103-114.

Morel, N., Palier, B., \& Palme, J. (2012). Towards a Social Investment Welfare State? Ideas, Policies and Challenges. Bristol: Policy.

Murshed, S. M., Badiuzzaman, M., \& Pulok, M. H. (2017). Fiscal capacity and social protection expenditure in developing nations. United Nations University UNU-WIDER, (60).

Niño-Zarazúa, M., Barrientos, A., Hulme, D., \& Hickey, S. (2010). Social Protection in Sub-Saharan Africa. Will the Green Shoots Blossom? Brooks World Poverty Institute Working Paper, (116).

North, D. C. (1990). Institutions, Institutional Change and Economic Performance. Cambridge university press.

Norton, A., \& Elson, D. (2002). What's Behind the Budget?: Politics, Rights and Accountability in the Budget Process. London: Overseas Development Institute. 
NPC. (2017). Ethiopia's Progress Towards Eradicating Poverty: An Interim Report on 2015/2016 Poverty Analysis Study. Addis Ababa: National Planning Commission, Federal Democratic Republic of Ethiopia. Ocampo, J. A., \& Stiglitz, J. E. (2018). The Welfare State Revisited. New York: Columbia University Press. OECD. (2007). The Social Expenditure Database: An Interpretive Guide. SOCX 19800-2003. (Version 2007). OECD Publication Service.

OECD. (2009). Promoting Pro-Poor Growth. Social Protection. OECD Publishing.

Olivera, J. (2014). Preferences for Redistribution After the Economic Crisis. Economics and Business Letters, 3(3), 137.

Ortiz, I., Chai, J., \& Cummins, M. (2011). Austerity Measures Threaten Children And Poor Households. Recent Evidence in Public Expenditures from 128 Developing Countries. UNICEF, Social and Economic Policy Working Paper.

Ortiz, I., Cummins, M., Capaldo, J., \& Karunanethy, K. (2015). The Decade of Adjustment: A Review of Austerity Trends 2010-2020 in 187 Countries. ESS Extension of Social Security. International Labour Office, Geneva, (53).

Ortiz, I., Cummins, M., \& Karunanethy, K. (2015a). Fiscal Space for Social Protection and the SDGs: Options to Expand Social Investments in 187 Countries. SSRN Electronic Journal.

Ortiz, I., Cummins, M., \& Karunanethy, K. (2015b). Fiscal Space for Social Protection: Options to Expand Social Investments in 187 Countries. ESS Extension of Social Security. International Labour Office, Geneva, (48).

Parker, S. W., Saenz, J., \& Wong, R. (2018). Health Insurance and the Aging: Evidence From the Seguro Popular Program in Mexico. Demography, 55(1), 361-386.

Piachaud, D. (2013). Social Protection, Redistribution and Economic Growth. Development Southern Africa, Vol. 30(No. 1), 24-38.

Pritchett, L. (2005). A Lecture on the Political Economy of Targeted Safety Nets. World Bank. Social Protection Discussion Paper Series, (0501).

Rabobank. (2016). Institutional Quality and Economic Performance. RaboResearch Utrecht.

Ravallion, M. (2010). Do Poorer Countries Have Less Capacity for Redistribution? Journal of Globalization and Development, Vol. 1(No. 2), 1948-1837. 
Reeskens, T., \& van Oorschot, W. (2013). Equity, Equality, or Need? A Study of Popular Preferences for Welfare Redistribution Principles Across 24 European Aountries. Journal of European Public Policy, $20(8), 1174-1195$.

Rehm, P. (2009). Risks and Redistribution: An Individual-Level Analysis. Comparative Political Studies, 42(7), $855-881$.

Robinson, J. A., Acemoglu, D., \& Johnson, S. (2005). Institutions as a Fundamental Cause of Long-Run Growth in Philippe Aghion and Steven N. Durlauf (eds.) Handbook of Economic Growth Volume 1A. Amsterdam, Netherlands: Elsevier.

Rodrik, D. (1997). Has Globalization Gone Too Far? Washington, D.C.: Institute for International Economics. Roelen, K., Devereux, S., Abdulai, A.-G., Martorano, B., Palermo, T., \& Ragno, L. P. (2017). How to Make ‘Cash Plus’ Work: Linking Cash Transfers to Services and Sectors. UNICEF Office of Research, (WP2017-10).

Roelen, K., Devereux, S., Kebede, D., \& Ulrichs, M. (2017). Cash 'plus' - Integrated Nutrition and Social Cash Transfer (IN-SCT) Pilot in Ethiopia: perceptions and feedback from clients and service providers. ISD \& REBRET Business and Consultancy, PLC.

Ross, M. L. (2012). The Oil Curse: How Petroleum Wealth Shapes the Development of Nations. Princeton University Press.

Rueschemeyer, D., \& Evans, P. (1985). The State and Economic Transformation: Toward an Analysis of the Conditions Underlying Effective Intervention. In Evans, P. B., Rueschemayer, D., and Skocpol, T., editors, Bringing the State Back in. Cambridge University Press.

Sabates-Wheeler, R., \& Devereux, S. (2007). Social Protection for Transformation. IDS Bulletin, 38(3), 2328.

Samson, M. (2013). How are Countries Using Social Protection to Benefit the Poor? in Erik Solbeim Development Cooperation Report 2013. (ed.). Paris: OECD.

Scharpf, F. W. (2000). "Economic Changes, Vulnerabilities, and Institutional Capabilities." in Fritz. W. Scharpf and Vivien A. Schmidt, (eds.), Welfare and Work in the Open Economy. Volume I. From Vulnerability to Competitiveness. Oxford: Oxford University Press. 
Scheil-Adlung, X. (2015). Global Evidence on Inequities in Rural Health Protection. New Data on Rural Deficits in Health Coverage for 174 Countries. ESS Document No. 47. ESS Extension of Social Security. International Labour Office, Geneva, (47).

Schubert, B. (2015). Manual of Operations for the Social Cash Transfer Pilot Programs for Direct Support Clients. Addis Ababa: UNICEF.

Schüring, E., \& Gassmann, F. (2012). Whom to Target-An Obvious Choice? UNUMERIT Working Paper Series, (028).

Schwabish, J. A., Smeeding, T. M., \& Osberg, L. (2003). Income Distribution and Social Expenditures: A Cross-National Perspective. Luxembourg Income Study Working Paper, (350).

SDD. (2015). Time For Equality. The Role of Social Protection in Reducing Inequalities in Asia and the Pacific (No. ST/ESCAP/2735). Bangkok: UN ESCAP.

Seekings, J. (2017). 'Affordability' and the political economy of social protection in contemporary Africa, (43).

Sen, A. (1995). Public Spending and the Poor, Dominique van de Walle and Kimberly Nead (ed.). World Bank Publications.

Sen, A. (2007). Rational choice: discipline, brand name, and substance. In Fabienne Peter (ed.), Rationality and Commitment. USA: Oxford University Press.

Shepherd, A., Mitchell, T., Lewis, K., Lenhardt, A., Jones, L., Scott, L., \& Muir-Wood, R. (2013). The geography of poverty, disasters and climate extremes in 2030 (ODI Report). London: Overseas Development Institute.

Shimeles, A. (2010). Community Based Health Insurance Schemes in Africa: the Case of Rwanda. African Development Bank Group.

Slater, R., \& McCord, A. (2013). 'Learning from the PSNP: The Influence of Ethiopia's Social Protection Experience." In Food Security, Safety Nets and Social Protection in Ethiopia, edited by Dessalegn Rabmato, Alula Pankhurst and Jan-Gerrit van Uffelen, 39 (Forum for Social Studies). Addis Ababa.

Snyder, J. M., \& Yackovlev, I. (2000). Political and Economic Determinants of Changes in Government Spending on Social Protection Programs. Massachusetts Institute of Technology. 
Soares, F. V., Ribas, R. P., \& Osario, R. G. (2010). Evaluating the Impact of Brazil's Bolsa Família: Cash Transfer Programs in Comparative Perspective. Latin American Research Review, 45(2), 173-190.

Søndergård Madsen, T., \& Triantafillou, P. (2016). Making Good Citizens: Power and Empowerment in Community Development Programmes in Nepal in "Critical reflections on interactive governance. Participation and selforganization in public governance". Edited by Jurian Edelenbos and Ingmar van Meerkerk. Faculty of Social Sciences, Erasmus University, Rotterdam, The Netherlands: Edward Elgar Publishing.

Soroka, S. N., \& Wlezien, C. (2005). Opinion-Policy Dynamics: Public Preferences and Public Expenditure in the United Kingdom. British Journal of Political Science, 35(04), 665.

Stake, R. E. (1995). The Art of Case Study Research. London: Sage Publications.

Stefan, D., Holmberg, S., Rothstein, B., \& Hartmann, F. (2013). The Quality of Government Basic Dataset Made from The Quality of Government Dataset, version 15May13. University of Gothenburg: The Quality of Government Institute, http://www.qog.pol.gu.se.

Steven van de Walle. (2006). The State of the World's Bureaucracies. Journal of Comparative Policy Analysis: Research and Practice, Vol. 8(No. 4), 437-448.

Stimson, J. A., Mackuen, M. B., \& Erikson, R. S. (1995). Dynamic Representation. American Political Science Review, 89(03), 543-565.

Tanzi, V., \& Davoodi, H. (1997). Corruption, Public Investment and Growth. International Monetary Fund Working Paper, (WP/97/139).

Tanzi, V., \& Zee, H. (2001). Tax Policy for Developing Countries. IMF, Economic Issues No. 27.

The Kenya CT-OVC Evaluation Team. (2012). The Impact of Kenya's Cash Transfer for Orphans and Vulnerable Children on Human Capital. Journal of Development Effectiveness, 4(1), 38-49.

Thomas, M. A. (2010). What Do the Worldwide Governance Indicators Measure? European Journal of Development Research, Vol. 22(No. 1), 31-54.

Thome, K., Filipski, M., Kagin, J., Taylor, J. E., \& Davis, B. (2013). Agricultural Spillover Effects of Cash Transfers: What Does LEWIE Have to Say? American Journal of Agricultural Economics, Vol. 95(No. 5), 1338-1344.

Thome, Karen, Taylor, J. E., Mateusz, F., Davis, B., \& Handa, S. (2016). The Local Economy Impacts of Social Cash Transfers. A Comparative Analysis of Seven Sub-Saharan Countries. Rome: FAO. 
Thurmaier, K. (1995). Decisive Decision Making in the Executive Budget Process: Analyzing the Political and Economic Propensities of Central Budget Bureau Analysts. Public Administration Review, Vol. 55(No. 5), 448-460.

Trujillo, A. J., Portillo, J. E., \& Vernon, J. A. (2005). The Impact of Subsidized Health Insurance for the Poor: Evaluating the Colombian Experience Using Propensity Score Matching. International Journal of Health Care Finance and Economics, 5(3), 211-239.

UNDP. (2011). UNDP in Nepal, Results from 2011. Kathmandu: UNDP.

UNDP. (2013). UNDP in Nepal, Annual Report 2013. Kathmandu: UNDP.

UNDP. (2014). Leveling the Playing Field (Development Advocate Nepal No. Year 2; Issue 1). Nepal: UNDP. UNDP. (2015). Work for Human Development. New York, NY.

UNICEF. (2011). Social Protection Strategic Framework. Integrated Social Protection Systems: Enhancing equity for children. UNICEF.

UNICEF, \& ODI. (2009). Fiscal Space for Strengthened Social Protection in West and Central Africa.

UNICEF, \& UNAIDS. (2004). The Framework for the Protection, Care and Support of Orphans and Vulnerable Children Living in a World with HIV AIDS. New York, NY: UNICEF.

United Nations. (2015). Report of the Inter-Agency and Expert Group on Sustainable Development Goal Indicators. Economic and Social Council.

van de Walle, D. (1998). Targeting Revisited. The World Bank Research Observer, 13(2), 231-248.

van Oorschot, W. (2006). Making the difference in social Europe: deservingness perceptions among citizens of European welfare states. Journal of European Social Policy, 16(1), 23-42.

Veres, Z., Tarjan, T., \& Hamornik, B. P. (2014). Product attribute preferences-a multidisciplinary approach. European Scientific Journal, ESJ, 10(7).

Warlters, M., \& Auriol, E. (2005). The Marginal Cost of Public Funds in Africa. World Bank Policy Research Working Paper, (3679).

Weber, A. A. (Ed.). (2006). Social protection index for committed poverty reduction (Ed.). Mandaluyong City, Metro Manila, Philippines: Asian Development Bank.

Wildavsky, A. B. (1964). The Politics of the Budgetary Process (Second Edition). Boston: Little, Brown and Company. 
Wildavsky, A. B. (1986). Budgeting: A Comparative Theory of Budgetary Processes. Boston: Little, Brown and Company.

Wildavsky, A. B. (1992). "Political Implications of Budget Reform:" A Retrospective. Public Administration Review, Vol. 52(No. 6), 594-599.

Wilensky, H. L. (1975). The Welfare State and Equality: Structural and Ideological Roots of Public Expenditures. Berkeley, CA: University of California Press.

Williamson, O. E. (1975). Markets and Hierarchies: Analysis and Antitrust Implications. New York: Free Press.

Williamson, O. E. (1985). The Economic Institutions of Capitalism. New York: Free Press.

Willoughby, K. G. (1993a). Patterns of Behavior: Factors Influencing the Spending Judgments of Public Budgeters. In Thomas D. Lynch and Lawrence L. Martin (ed.), Handbook of Comparative Public Budgeting and Financial Management. New York: Marcel Dekker.

Wlezien, C. (1996). Dynamics of Representation: The Case of US Spending on Defence. British Journal of Political Science, 26(01), 81.

World Bank. (1998). Public Expenditure Management Handbook. Washington, D.C.: World Bank.

World Bank. (2001). Social Protection Sector Strategy: From Safety Net to Springboard. Washington, D.C.: World Bank.

World Bank. (2011a). Evidence and Lessons Learned from Impact Evaluations on Social Safety Nets. Washington, DC: Independent Evaluation Group - World Bank.

World Bank. (2011b). Worldwide Governance Indicators.

World Bank. (2012). Managing Risk, Promoting Growth: Developing Systems for Social Protection in Africa. Washington, D.C.: World Bank.

World Bank. (2014). Social Protection Study. Improving Social Protection for the Vulnerable in Nepal: A Review of Social Assistance Programs and Expenditures (No. ACS10594). Nepal: World Bank.

World Bank. (2015a). Ethiopia: Poverty Assessment 2014. Washington, D.C.: The World Bank.

World Bank. (2015b). The State of Social Safety Nets 2015. Washington, DC: World Bank.

World Bank. (2016). Ethiopia's great run: the growth acceleration and how to pace it. Washington, D.C.: The World Bank.

World Bank. (2018). The State of Social Safety Nets 2018 (p. 189). Washington, DC: World Bank. 
World Vision International. (2010). Community Care Coalitions: Guideline for integrated programming. Monrovia: WVI.

Yilmaz, S., \& Venugopal, V. (2008). Local government discretion and accountability in Ethiopia. Georgia State University, Andrew Young School of Plicy Studies.

Yin, R. K. (2014). Case Study Research: Design and Methods (5th Edition). Beverly Hills: Sage Publications. 


\section{Addendum on valorisation to the dissertation}

This addendum presents how this research creates value by making knowledge suitable and available for social and economic use. It focuses on the main implications, the relevance of the research, and the various forms in which its results have been and will be disseminated.

This study's findings are relevant to the current public and policy debate on social protection. Although over the last years evidence in social protection design, planning and policymaking has been increasing, the research findings expand the understanding on how and to what extent the quality of institutions and people's preferences affect the level of expenditure and the quality of implementation of social protection programmes. It provides practical recommendations on how to strengthen the quality of institutions and make more inclusive people's participation in the implementation of social protection programmes in developing countries.

This research provides evidence of interest to policy makers, development agencies and government authorities responsible for the design and implementation of social protection programmes. It is very relevant for developing countries in general and timely in the case of those countries which have been part of this study. This is because both Nepal and Ethiopia have been experiencing in the last years a rapid expansion of social protection policies, not necessarily accompanied by inclusiveness in the programming and improved governance, and therefore the study can contribute to the debate on the effectiveness of these social protection programmes.

The research shows that, after controlling for economic, demographic, legal, historical and geographical factors, proxies for the quality of institutions and people's preferences influence the level of expenditure in social protection in low- and middle-income countries. In addition, government revenue and maturity of social protection systems positively contribute to the overall level of social expenditure. This confirms the assumption that the level of social protection spending cannot be considered separately from tax policy considerations.

The research highlights how governments, donors, development organisations and civil society organisations should advocate and consider the quality of institutions and people's preferences in the design of social policy and social protection interventions. Furthermore, the research argues that the planning and budgeting process is a key step through which people's preferences are gathered, priorities identified and resources allocated.

This research has been developed building on discussions with policymakers and practitioners on the field. It allowed the research, especially the part implemented through case studies in Nepal and Ethiopia, to be of practical relevance. At the local level, the research findings confirm that strong collaboration among service providers, capacity of local institutions to effectively manage funds and the establishment and regular functioning of community structures are associated with better social protection interventions. Furthermore, the extent to which people are able to engage and manifest their preferences to local 
authorities and community structures may affect the type of social protection interventions implemented. The case studies conducted in selected villages highlight the challenges that lowest social classes in Nepal and female community members in Ethiopia face in engaging with local authorities, because they feel that their voice is not heard.

These findings are important and will be shared and discussed in debates related to the development of social protection interventions at national and international conferences. The time and the investment required for the dissemination will be available within the context of the author's current position as Social Policy Specialist at UNICEF Ethiopia.

Throughout the $\mathrm{PhD}$, at various occasions the author had the opportunity to share these important points with a larger and non-scientific audience. He was invited to the international conference on "Political Economy Aspects of Income (Re-Redistribution)" in Venice, organized by CESifo in collaboration with Venice International University, and with Prof. Franziska Gassmann to the International Symposium on "Social Protection Systems - Tying the Knots", organized by the Bonn-Rhein-Sieg University of Applied Sciences in Bonn.

Evidence from this research will provide an important contribution to the author's current work which supports, among others, the advocacy for inclusive social policy and social protection programme design. Some of the findings of this research have been shared with UNICEF Ethiopia's technical experts involved in the implementation of social protection interventions and have contributed to increase the quality of governance and the functioning of community structures. For example, increasing attention has been given during the design of IN-SCT programme evaluation to the quality of institutions at the village level, the establishment of community structures and the social protection's clients capacity to engage in the implementation of social protection interventions. 


\section{Research methods appendices}

\section{Appendix A.1 Study information sheet - Nepal}

\section{Maastricht University}

Study title: Institutional factors and people's preferences in social protection: the case of Nepal.

Dear Sir/Madam,

My name is Vincenzo Vinci and I am a research fellow in the Maastricht Graduate School of Governance at the University of Maastricht in the Netherlands. Before you decide whether or not to take part in the study, it will be important for you to understand why the research is being done and what it will involve. Please take time to read the following information.

The purpose of this study is to explore to what extent social protection programmes in Nepal have been influenced by factors related to the quality of the institutions and by the people's preferences for social protection programmes. The purpose of this study is therefore to 1) to examine capacity issues and challenges faced by the institutions at central and local level in the planning, budgeting process and implementation of selected social protection interventions; 2) to explore how people's preferences expressed towards government's decisions on social protection interventions influence the allocation of social protection programmes.

I plan to interview central and local officials, civil society orgns and I plan to conduct Focus Group Discussions with community members. During the interviews, I will ask you several questions to explore the factors which may have contributed to influence the provision of social protection programmes such as the capacity of the administration, how people communicate to their administration to express needs and how they engage in the planning and budgeting process.

Your contribution is of high value to this study and your participation is entirely voluntarily. Your participation is entirely voluntarily. If you decide to take part, you are free to end your participation at any time and without giving a reason. Your identity will be protected at all times and your participation in the study will hence be strictly anonymous, if you do not wish otherwise. If you agree, our interview will be audio recorded. The record will however be immediately deleted after the data is transcribed. All data will be carefully and securely stored and only used for research purposes.

Your contribution will help to get valuable insights into the debate around social protection in Nepal. In case you have any questions or concerns regarding your participation in this study, please do not hesitate to contact me directly at v.vinci@student.maastrichtuniversity.nl.

Yours sincerely, Vincenzo Vinci

Vincenzo Vinci, Executive Researcher

Maastricht Graduate School of Governance, Maastricht University

Boschstraat 24 | 6211 AX Maastricht | The Netherlands

v.vinci@student.maastrichtuniversity.nl. | Cell phone Nepal: +9779813757785 


\section{Appendix A.2 Consent form for local officials - Nepal}

\section{Maastricht University}

Please consider this information carefully before deciding whether to participate in this research.

My name is Vincenzo Vinci and I am a research fellow in the Maastricht Graduate School of Governance of Maastricht University. I am undertaking a Ph.D. and the purpose of this research is to explore to what extent social protection programmes in Nepal have been influenced by the quality of the institutions at both central and sub-national level and by people's preferences for social protection programmes.

If you decide to volunteer to this interview, you will be asked several questions which relates to the topic mentioned above. Some of them will be about the capacity of the institutions to provide social protection programmes, others will be related on how the institutions manage the planning and budgeting process and take into account people's preference when funds are allocated to social protection. This will give you the opportunity to share your experience in relation to this topic. I will tape record the interviews so I don't have to make so many notes. You will not be asked to state your name on the recording.

This interview will require about 1 hour of your time and there are no anticipated risks or discomforts related to this research. Your participation in this research is completely voluntary and there is no compensation for participating to this study.

Your responses to interview questions will be kept confidential. At no time will your actual identity be revealed. You will be assigned a random numerical code. Anyone who helps me transcribe responses will only know you by this code. The recording of this interview and the transcript, without your name, will be kept until my Ph.D. research is accepted. The key code linking your name with your number will be kept in a locked file cabinet in a locked office, and no one else will have access to it. The record will be immediately deleted after the data is transcribed. The data you give me will be used for a study I am currently writing and for future articles or presentations.

Your participation in this study is completely voluntary, and you may refuse to participate or withdraw from the study without penalty or loss of benefits to which you may otherwise be entitled. You may withdraw by informing me that you no longer wish to participate (no questions will be asked). You may skip any question during the interview, but continue to participate in the rest of the study.

To Contact the researcher: If you have questions or concerns about this research, please contact:

Vincenzo Vinci, Executive Researcher

Maastricht Graduate School of Governance, Maastricht University

Boschstraat 24 | 6211 AX Maastricht | The Netherlands

v.vinci@student.maastrichtuniversity.nl. | Cell phone Nepal: +9779813757785

Agreement:

The nature and purpose of this research have been sufficiently explained and I agree to participate in this study. I understand that I am free to withdraw at any time without incurring any penalty.

Signature:

Date:

Name (print): 


\section{Appendix A.3 Interview guide for central level officials- Nepal}

The interviews at central level will be conducted with selected government official in ministries and agencies who are knowledgeable about social protection programmes.

\section{Respondent's information}

Date of the interview: (date_/month__/year

ID Code:

District:

Municipality:

Name of the organisation:

Respondent's name:

Age:

Sex: $M \quad F$

Estimated time for the interview: (45-60 minutes total)

\section{Introduction}

(start at _

Thank you for agreeing to participate in this interview. My name is Vincenzo Vinci and I am a research fellow in the Maastricht Graduate School of Governance of Maastricht University. I'll be talking with you today. As you know, this study is part of a Ph.D. research on Governance and Policy with the title "Institutional factors and people's preferences in social protection".

The purpose of this interview today is to learn more about your experiences and insights on how institutional factors and people's preferences might have influenced the provisions of social protection programmes in Nepal. The interview will last about 45-60 minutes.

Did you read the consent form that was sent to you? Do you have any questions?

[Collect signed consent form]

\section{Ground rules}

Everything you tell us will be confidential. To protect your privacy, we won't connect your name with anything that you say. At any time during our conversation, please feel free to let me know if you have any questions or if you would rather not answer any specific question. You can also stop the interview at any time for any reason. Please remember that we want to know what you think and feel and that there are no right or wrong answers.

Is it $\mathrm{OK}$ if I audiotape this interview today?

[Turn on recording equipment.]

\section{Introductory questions}

(start at _ min end at

I'd like to begin by asking you some questions about your current job.
a. What is your position at [organisation]?
b. What are your major responsibilities in your current position?
c. Who did you report to and who reported to you (title)?
d. How long have you been with [organisation]?
e. How long have you been in this current job?
f. How has your present job changed while you've held it?

\section{Key questions}

In the below questions the term social protection refers to the following social protection programmes defined in the box 1 below. 


\section{Box 1 Definition for selected social protection programmes}

Old age allowance, widows and single women and disability pensions: The Old Age Allowance was introduced in Nepal during the Fiscal Year 1994/1995. Originally the programme started as a monthly cash transfer of NRs 100 to citizens of 75 years and above. Some years later, during the Fiscal Year 2008/2009, this amount was increased to NRs 500 per month and eligibility was extended: members of the Dalit community and those living in the Karnali region aged over 60 years are now able to claim the allowance, as are other Nepalese citizens over the age of 70 . The allowance for single women and widows introduced in 1996 targets single women 60 years or older and widows of all ages with a monthly transfer of NRs 500 per month distributed three times in a year. The disability allowance introduced in 1996 targets people with partial disabilities, who normally receive NRs.300 per month and people with full disability who receive NRs. 1,000 per month.

Child Grant: The Child Grant has been introduced in the Fiscal Year 2009/2010 for the objective of improving the nutrition of the children. Eligible children, up to two per family are entitled to a benefit of NRs 200 per month which would sum up as NRs 2,400 rupees per child per year, with a maximum of NRs 4,800 per family where there are 2 under- 5 children, to be paid in trimestral instalments. The Child Grant is geographically targeted to under 5 children in the five Karnali districts (Jumla, Humla, Dolpa, Kalikot and Mugu) and to under five children from poor Dalit families across the country.

Block Grants allocate to Village Development Committees (VDCs): VDC block grants are provided for the funding of capital development projects as well as for recurrent purposes. For each "categorical" grant level between Rs. 1.5 and 3.0 million a specific amount is set aside for recurrent activities. The amount is based on the following indicators/criteria: a) equal share (30\%) which is taken as a first charge, prior to distributing the remainder of the grant pool on the basis of the remaining allocation factors; b) population (60\%); c) Land area (10\%) and d) Cost Index. Each VDC, based on these criteria, belongs to one of the following six categories which is composed by a capital part and a recurrent component: Category I: Rs 1.50 million (Recurrent - Rs 350,000); Category II: Rs 1.76 million (Recurrent - Rs 393,000); Category III: Rs 1.95 million (Recurrent - Rs 400,000); Category IV: Rs 2.15 million (Recurrent - Rs 420,000); Category V: Rs 2.45 million (Recurrent - Rs 420,000); and Category VI: Rs 3.00 million (Recurrent - Rs 425,000). 35 percent of the capital part is allocated for social protection programmes in particular to support a) children $(10 \%)$; women $(10 \%)$ and disadvantaged groups $(15 \%)$. The remaining part of the capital part can also include a $10 \%$ of matching funds for developing programmes, and for social mobilisations activities. The recurrent part should be spent for salary and benefits of VDC staff members (technical and others); annual salary of chairman and vice chairman; meeting allowance and stationary; grant for the teachers' who are recruited at a predetermined ratio of teachers to students; grant for health workers and expenditures in human resource development.

Notes: In 2015, as consequence of the $25^{\text {th }}$ of April's earthquake in Nepal, in agreement with the Ministry of Finance (MoF) and the National Planning Commission (NPC), UNICEF provided technical and financial assistance to the Government of Nepal to deliver a payment of NRs. 3,000 as a top-up to the regular social assistance payments received by five vulnerable groups in the 19 districts most affected by the earthquakes, including: (1) Dalit children under five years of age, who normally receive NRs. 200 per month; (2) Widows, and single women over 60 years of age, who normally receive NRs. 500 per month; (3) People with disabilities, who normally receive NRs.300 per month if partially disabled and NRs. 1,000 per month if fully disabled; (4) Senior citizens over 70 years of age or over 60 if Dalit, who normally receive NRs. 500 per month; (5) Highly marginalised Janajati ethnic groups who normally receive NRs. 1,000 per month. This initiative have been implemented in 19 districts mostly affected by the earthquake.

I will start now with the key questions:

1. Information related to key factors which may have contributed to influence the establishment or the changes in social protection programmes. 
1.1 Please, tell me which critical factors in the past have led to the establishment or to changes in social protection programmes. For example, the establishment or changes of specific social protection programmes such as the increase or reduction in the benefits provided, the increase in the geographical scope of the project or the extension of the population targeted, etc.).

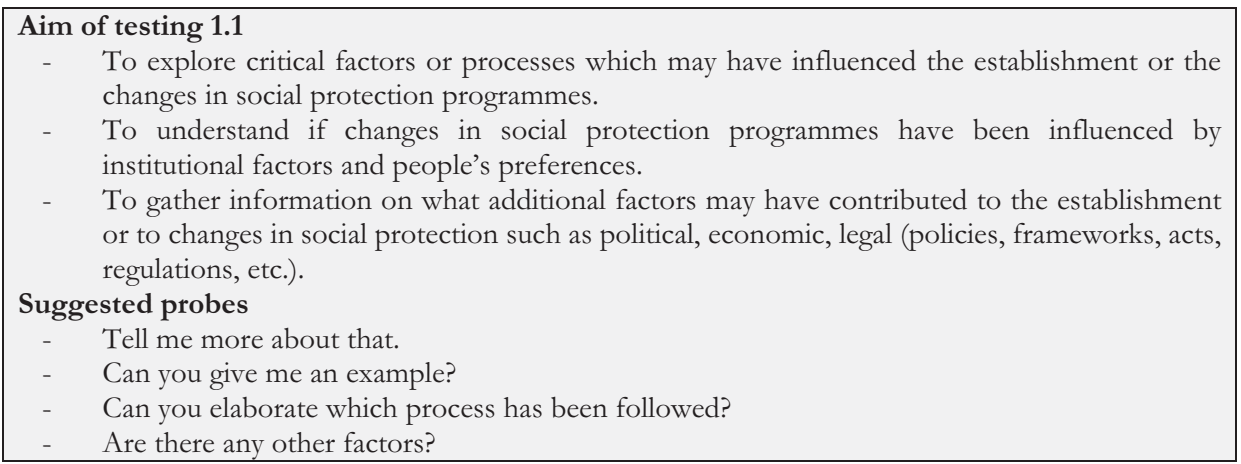

2. Key institutional factors (such as capacity or performance of the [organisation]) which may have contributed to influence the establishment or the changes in social protection programmes.

2.1 Please, tell me what are the critical factors of success and failure in the functioning or capacity your [organisation]. (For example, but not limited to the adequacy of buman and financial resources, the leadership in your [organisation] etc.)

\section{Aim of testing 2.1}

To explore the factors related to the capacity of the [organisation] such as 1) The context or operating environment; 2) Clarity of results, mandate, and purpose; 3) Adequacy of resources; 4) Organisation, management and infrastructure; 5) Organisational culture and values; 6) Vision and leadership; 7) Attitude to change; 8) Monitoring mechanisms.

\section{Follow up questions.}

- Please, tell me how your [organisation] ensures adequate resources to achieve the objectives. (Dimension: Adequacy of resources)

- $\quad$ Please, tell me how directions and guidance are given from leaders in your [organisation] to ensure involvement and consultation. (Dimension: Vision and leadership)

Please, tell me how your [organisation] uses information and data to provide monitoring and evaluation of social protection programmes. (Dimension: Monitoring mechanisms).

- Please, tell me to what extent your [organisation] has met the past programme targets. (Dimension: clarity of results, mandate, and purpose)

- Please, tell me how your [organisation] ensures transparency and keep the society informed about its activities. (Dimension: context or operating environment). [For example, by publishing annual reports to keep society informed, holding press conferences, public awareness campaigns, posting information on the internet, etc.]

Please, tell me how your [organisation] has processes in place to ensure communication with other units and ministries and information sharing. (Dimension: Organisation, management and infrastructure)

- Please, tell me how your [organisation] promotes a sense of efficiency and problem solving. (Dimension Organisational culture and values)

- Please, tell me how your [organisation] is able to adjust and manage change. (Dimension: Attitude to change)

\section{Dimensions of organisational capacity}

The context or operating environment: Effectiveness and adequacy of legal/regulatory/broader policy framework; Oversight and supervision, pressure for accountability; Pressure for performance 
from citizens/customers/ political leaders/competitors; Effectiveness of formal and informal networks and connections; Overall public sector incentives, reforms; Other.

Clarity of results, mandate, and purpose: Quality, quantity and relevance of services; Achievement of past targets; Contribution to desired outcomes and impact; Other.

Adequacy of resources: Match between objectives, mandate and resources; Predictability of resource envelope; Match between funds for salaries, operational costs and investments; Ability to recruit staff with adequate skills/ experience; Other.

Organisation, management and infrastructure: Clarity of and compliance with strategies; Structures ensuring balance between specialisation and coordination; Systems and processes adequately ensuring efficiency; Communication and information sharing flowing in and between units; Other.

Organisational culture and values: Correspondence between formal values and actual behaviour; Culture promoting efficiency and problem-solving; Positive atmosphere in daily relations; Team-spirit and identification with the vision/ mission; Other.

Vision and leadership: Clarity of directions and guidance from leaders; Adequate involvement and consultation of staff; Encouraging innovation; Role of self-review and critical reflection.

Attitude to change: Priority of change and resources for it; Previous experiences of change; Capacity to manage change.

Monitoring mechanisms: Availability of data on performance (outputs, client satisfaction, staff satisfaction); Monitoring data informing strategic and operational decisions; Monitoring data available to staff and key stakeholders.

3. To explore to what extent people's preferences may have contributed to influence the establishment or the changes in social protection programmes.

3.1. Please, tell me to what extent society (defined as a group of acting citizens) has influenced the discussion on social protection. (For example, to what extent society in general or particular groups of citizens have influenced in the past the decisions taken to introduce or to changes (increasing or reducing) the provisions of social protection programmes.)

\section{Aim of testing 3.1}

To explore people's influence on social protection programmes.

\section{Follow up questions}

- Please, tell me how the society has played a role in influencing the establishment or changes in social protection programmes?

- Please, tell me how your [organisation] takes into account the pressure coming from citizens /political leaders. (Dimension: context or operating environment).

\section{Suggested probes}

Tell me more about that.

Can you give me an example?

- Can you elaborate which process has been followed?

4. To explore to what extent, the planning and budgeting processes may have contributed to influence the establishment or the changes in social protection programmes.

4.1. Please, tell me how your [organisation] manages the planning and budgeting process.

\section{Aim of testing 4.1}

To explore and assess issues related to the overall management of the planning and budgeting process at central and local level. Horizontal interactions (between line ministries, National Planning Commission and the Ministry of Finance for example); and vertical interactions central level, District Development Committee and VDC for example.

To explore critical factors of success and failure in the planning and budgeting process.

To explore if the process of planning and budgeting is timely and participatory.

Follow up questions

Please, tell me what are the critical factors of success and failure in the planning and budgeting process. 


\section{Planning and budgeting}

- $\quad$ Please, tell me how people engages in the planning phase and budgeting process.

- $\quad$ For example, how women, Dalits, people with disability and marginalised communities, youth take part to the planning and budgeting process where needs are identified?]

- Please, tell me to what extent the participation of political leaders influences the planning phase and budgeting processes.

\section{Allocation and utilization of resources}

- Please, tell me to what extent the resources used by your [organisation] reflect the needs expressed by the population.

- Please, tell me how resources are allocated and used transparently in your [organisation].

- Please, tell me to what extent the resources allocated and used are just a reflection of historical expenditures.

\section{Suggested probes}

- Tell me more about that.

- Can you give me an example?

- Can you elaborate which process has been followed?

\section{Closing}

(start at min end at

- What is the most important message that you want us to take away from this interview?

- Is there anything else that you would like to add about any of the topics that we've discussed or other areas that we didn't discuss but you think are important?

- If you know of any documents, reports or resources that may be useful to complement this interview, please share or send them to me.

Thank you for your time and participation in this interview. The information you have provided will be analysed for the research. I will be happy to share with you the findings of this part of my research. 


\section{Appendix A.4 Interview guide for local level officials - Nepal}

The interview at local level will be conducted with the Village Development Committee's (VDCs) secretary.

\section{Respondent's information}

Date of the interview: (date__/month__/year

ID Code:

District:

VDC:

Respondent's name:

Age:

Sex: M F

Estimated time for the interview: (45-60 minutes total)

\section{Introduction}

(start at min end at

Thank you for agreeing to participate in this interview. My name is Vincenzo Vinci and I am a research fellow in the Maastricht Graduate School of Governance of Maastricht University. I'll be talking with you today. As you know, this study is part of a Ph.D. research on Governance and Policy with the title "Institutional factors and people's preferences in social protection".

The purpose of this interview today is to learn more about your experiences and insights on how institutional factors and people's preferences might have influenced the provisions of social protection programmes in Nepal. The interview will last about 45-60 minutes.

Did you read the consent form that was sent to you? Do you have any questions?

[Collect signed consent form]

\section{Ground rules}

Everything you tell us will be confidential. To protect your privacy, we won't connect your name with anything that you say. At any time during our conversation, please feel free to let me know if you have any questions or if you would rather not answer any specific question. You can also stop the interview at any time for any reason. Please remember that we want to know what you think and feel and that there are no right or wrong answers.

Is it $\mathrm{OK}$ if I audiotape this interview today?

[Turn on recording equipment.]

\section{Introductory questions}

(start at min end at

I'd like to begin by asking you some questions about your current job.
a. What is your position at [organisation]?
b. What are your major responsibilities in your current position?
c. Who did you report to and who reported to you (title)?
d. How long have you been with [organisation]?
e. How long have you been in this current job?
f. How has your present job changed while you've held it?

\section{Key questions}

In the below questions the term social protection refers to the Block Grant (portion of capital fund allocated for social protection interventions) defined in box 1 below.

Box 1 Definition of Village Development Committee's Block Grants 
Block Grants allocate to Village Development Committees (VDCs): VDC block grants are provided for the funding of capital development projects as well as for recurrent purposes. For each "categorical" grant level between Rs. 1.5 and 3.0 million a specific amount is set aside for recurrent activities. The amount is based on the following indicators/criteria: a) equal share $(30 \%)$ which is taken as a first charge, prior to distributing the remainder of the grant pool on the basis of the remaining allocation factors; b) population (60\%); c) Land area (10\%) and d) Cost Index. Each VDC, based on these criteria, belongs to one of the following six categories which is composed by a capital part and a recurrent component: Category I: Rs 1.50 million (Recurrent - Rs 350,000); Category II: Rs 1.76 million (Recurrent - Rs 393,000); Category III: Rs 1.95 million (Recurrent - Rs 400,000); Category IV: Rs 2.15 million (Recurrent - Rs 420,000); Category V: Rs 2.45 million (Recurrent - Rs 420,000); and Category VI: Rs 3.00 million (Recurrent - Rs 425,000). 35 percent of the capital part is allocated for social protection programmes in particular to support a) children $(10 \%)$; women $(10 \%)$ and disadvantaged groups (15\%). The remaining part of the capital part can also include a $10 \%$ of matching funds for developing programmes, and for social mobilisations activities. The recurrent part should be spent for salary and benefits of VDC staff members (technical and others); annual salary of chairman and vice chairman; meeting allowance and stationary; grant for the teachers' who are recruited at a predetermined ratio of teachers to students; grant for health workers and expenditures in human resource development.

I will start now with the key questions:

1. Information related to key factors and processes followed to allocate and use Block Grants to support social protection programmes at VDC level.

3.1. Please, tell me how the Block Grants received by your VDC have been used.

\section{Aim of testing 1.1}

To assess the level of utilization of the Block Grants at VDC level.

To explore the process followed by the VDC to identify social protection programmes to be supported through the Block Grants.

\section{Follow up questions}

- Please, tell me the amount of the Block Grant that was allocated to social protection programmes.

- Please, tell me how much of the Block Grant was spent in social protection programmes.

\section{Suggested probes}

Can you give me an example?

- Can you elaborate which process your VDC followed to identify the specific programmes to be supported by the Block Grants?

2. Key institutional factors which might have contributed to influence the provision of social protection programmes.

2.1 Please, tell me what are the critical factors of success and failure in the functioning or capacity of your VDC. (For example, but not limited to the adequacy of human and financial resources, etc.)

\section{Aim of testing 2.1}

To explore the factors related to the capacity of the VDC such as 1) The context or operating environment; 2) Clarity of results, mandate, and purpose; 3) Adequacy of resources; 4) Organisation, management and infrastructure; 5) Organisational culture and values; 6) Vision and leadership; 7) Attitude to change; 8) Monitoring mechanisms.

Follow up questions.

Please, tell me how your VDC ensures adequate resources to achieve the objectives. (Dimension: Adequacy of resources)

Please, tell me how directions and guidance are given in your VDC to ensure involvement and consultation. (Dimension: Vision and leadership)

Please, tell me how your VDC uses information and data to provide monitoring and evaluation of the Block Grants. (Dimension: Monitoring mechanisms). 
Please, tell me to what extent your VDC has met the past programme targets. (Dimension: clarity of results, mandate, and purpose)

Please, tell me how your VDC ensures transparency and keep the society informed about its activities. (Dimension: context or operating environment). [For example, by publishing annual reports to keep society informed, holding press conferences, public awareness campaigns, posting information on the internet, etc.]

- Please, tell me how your VDC has processes in place to ensure communication with other units, DDCs and Ministries and information sharing. (Dimension: Organisation, management and infrastructure)

- $\quad$ Please, tell me how your VDC promotes a sense of efficiency and problem solving. (Dimension Organisational culture and values)

Please, tell me how your VDC is able to adjust and manage change. (Dimension: Attitude to change)

\section{Dimensions of organisational capacity}

The context or operating environment: Effectiveness and adequacy of legal/regulatory/broader policy framework; Oversight and supervision, pressure for accountability; Pressure for performance from citizens/customers/ political leaders/competitors; Effectiveness of formal and informal networks and connections; Overall public sector incentives, reforms; Other.

Clarity of results, mandate, and purpose: Quality, quantity and relevance of services; Achievement of past targets; Contribution to desired outcomes and impact; Other.

Adequacy of resources: Match between objectives, mandate and resources; Predictability of resource envelope; Match between funds for salaries, operational costs and investments; Ability to recruit staff with adequate skills/ experience; Other.

Organisation, management and infrastructure: Clarity of and compliance with strategies; Structures ensuring balance between specialisation and coordination; Systems and processes adequately ensuring efficiency; Communication and information sharing flowing in and between units; Other.

Organisational culture and values: Correspondence between formal values and actual behaviour; Culture promoting efficiency and problem-solving; Positive atmosphere in daily relations; Team-spirit and identification with the vision/ mission; Other.

Vision and leadership: Clarity of directions and guidance from leaders; Adequate involvement and consultation of staff; Encouraging innovation; Role of self-review and critical reflection.

Attitude to change: Priority of change and resources for it; Previous experiences of change; Capacity to manage change.

Monitoring mechanisms: Availability of data on performance (outputs, client satisfaction, staff satisfaction); Monitoring data informing strategic and operational decisions; Monitoring data available to staff and key stakeholders.

3. To explore to what extent people's preferences may have contributed to influence the changes in the provisions of social protection programmes in relation to the use of the Block Grants.

4.1. Please, tell me to what extent the community has influenced the discussion on the allocation and utilization of the Block Grants?

\section{Aim of testing Q2.3}

To explore people's influence on social protection programmes.

\section{Follow up questions}

- Please, tell me to what extent your VDC is influenced by pressure coming from citizens or political leaders.

- Please, tell me how your VDC takes into account the pressure coming from citizens or political leaders. (Dimension: context or operating environment).

\section{Suggested probes}

Tell me more about that.

Can you give me an example?

- Can you elaborate which process has been followed? 


\section{To explore to what extent, the planning and budgeting processes may have contributed to}

influence the establishment or the changes in social protection programmes.

4.1. Please, tell me how your VDC manages the planning and budgeting process.

\section{Aim of testing 4.1}

To explore and assess issues related to the overall management of the planning and budgeting process. Horizontal interactions (between Wards Committees, Civil Society Organisations, etc.). Vertical interactions with District Development Committees, Ministries and Department for example.

- To explore critical factors of success and failure in the planning and budgeting process.

- To explore if the process of planning and budgeting is timely and participatory.

\section{Follow up questions}

- Please, tell me what are the critical factors of success and failure in the planning and budgeting process.

\section{Planning and budgeting}

- $\quad$ Please, tell me how people engages in the planning phase and budgeting process. [For example, how women, Dalits, people with disability and marginalised communities, youth take part to the planning and budgeting process where needs are identified?]

- Please, tell me to what extent the participation of political leaders influences the planning phase and budgeting processes.

\section{Allocation and utilization of resources}

- $\quad$ Please, tell me to what extent the resources used by your VDC reflect the needs expressed by all the population.

Please, tell me how resources are allocated and used transparently in your VDC.

Please, tell me to what extent the resources allocated and used are just a reflection of historical expenditures.

\section{Suggested probes}

Tell me more about that.

Can you give me an example?

Can you elaborate which process has been followed?

Notes on timely execution of the planning process for VDCs: VDC timely receive the guidance (including any new directives on national development policies) and prior estimation of the resources and means from the District Development Committee (DDC) and other concerned agencies for the forth coming fiscal year during the period mid-November to mid-December (the month of Marg); VDCs invites assembly of Village/Town council to discuss and prepare the sector wise development programs and projects through ward offices, NGOs and consumer committee for the forth-coming fiscal year and submit them to district.

\section{Closing}

(start at min end at

- What is the most important message that you want us to take away from this interview?

- Is there anything else that you would like to add about any of the topics that we've discussed or other areas that we didn't discuss but you think are important?

- If you know of any documents, reports or resources that may be useful to complement this interview, please share or send them to me.

Thank you for your time and participation in this interview. The information you have provided will be analysed for the research. I will be happy to share with you the findings of this part of my research. 


\section{Appendix A.5 Interview guide for civil society organisations - Nepal}

The interview will be conducted with selected Civil Society Organisations' representatives.

\section{Respondent's information}

Date of the interview: (date_/month__/year

ID Code:

District:

VDC:

Name of the organisation:

Respondent's name:

Age:

Sex: $\quad M \quad F$

Estimated time for the interview: (45-60 minutes total)

\section{Introduction}

(start at _ min end at

Thank you for agreeing to participate in this interview. My name is Vincenzo Vinci and I am a research fellow in the Maastricht Graduate School of Governance of Maastricht University. I'll be talking with you today. As you know, this study is part of a Ph.D. research on Governance and Policy with the title "Institutional factors and people's preferences in social protection".

The purpose of this interview today is to learn more about your experiences and insights on how institutional factors and people's preferences might have influenced the provisions of social protection programmes in Nepal. The interview will last about 45-60 minutes.

Did you read the consent form that was sent to you? Do you have any questions?

[Collect signed consent form]

\section{Ground rules}

Everything you tell us will be confidential. To protect your privacy, we won't connect your name with anything that you say. At any time during our conversation, please feel free to let me know if you have any questions or if you would rather not answer any specific question. You can also stop the interview at any time for any reason. Please remember that we want to know what you think and feel and that there are no right or wrong answers.

Is it $\mathrm{OK}$ if I audiotape this interview today?

[Turn on recording equipment.]

\section{Introductory questions}

(start at min end at

I'd like to begin by asking you some questions about your current job.
a. What is your position at [organisation]?
b. What are your major responsibilities in your current position?
c. Who did you report to and who reported to you (title)?
d. How long have you been with [organisation]?
e. How long have you been in this current job?

\section{Key questions}

In the below questions the term social protection refers to the following social protection programmes defined in the box 1 below.

Box 1 Definition for selected social protection programmes 
Old age allowance, widows and single women and disability pensions: The Old Age Allowance was introduced in Nepal during the Fiscal Year 1994/1995. Originally the programme started as a monthly cash transfer of NRs 100 to citizens of 75 years and above. Some years later, during the Fiscal Year 2008/2009, this amount was increased to NRs 500 per month and eligibility was extended: members of the Dalit community and those living in the Karnali region aged over 60 years are now able to claim the allowance, as are other Nepalese citizens over the age of 70 . The allowance for single women and widows introduced in 1996 targets single women 60 years or older and widows of all ages with a monthly transfer of NRs 500 per month distributed three times in a year. The disability allowance introduced in 1996 targets people with partial disabilities, who normally receive NRs.300 per month and people with full disability who receive NRs. 1,000 per month.

Child Grant: The Child Grant has been introduced in the Fiscal Year 2009/2010 for the objective of improving the nutrition of the children. Eligible children, up to two per family are entitled to a benefit of NRs 200 per month which would sum up as NRs 2,400 rupees per child per year, with a maximum of NRs 4,800 per family where there are 2 under- 5 children, to be paid in trimestral instalments. The Child Grant is geographically targeted to under 5 children in the five Karnali districts (Jumla, Humla, Dolpa, Kalikot and Mugu) and to under five children from poor Dalit families across the country.

Block Grants allocate to Village Development Committees (VDCs): VDC block grants are provided for the funding of capital development projects as well as for recurrent purposes. For each "categorical" grant level between Rs. 1.5 and 3.0 million a specific amount is set aside for recurrent activities. The amount is based on the following indicators/criteria: a) equal share $(30 \%)$ which is taken as a first charge, prior to distributing the remainder of the grant pool on the basis of the remaining allocation factors; b) population (60\%); c) Land area (10\%) and d) Cost Index. Each VDC, based on these criteria, belongs to one of the following six categories which is composed by a capital part and a recurrent component: Category I: Rs 1.50 million (Recurrent - Rs 350,000); Category II: Rs 1.76 million (Recurrent - Rs 393,000); Category III: Rs 1.95 million (Recurrent - Rs 400,000); Category IV: Rs 2.15 million (Recurrent - Rs 420,000); Category V: Rs 2.45 million (Recurrent - Rs 420,000); and Category VI: Rs 3.00 million (Recurrent - Rs 425,000). 35 percent of the capital part is allocated for social protection programmes in particular to support a) children $(10 \%)$; women $(10 \%)$ and disadvantaged groups (15\%). The remaining part of the capital part can also include a $10 \%$ of matching funds for developing programmes, and for social mobilisations activities. The recurrent part should be spent for salary and benefits of VDC staff members (technical and others); annual salary of chairman and vice chairman; meeting allowance and stationary; grant for the teachers' who are recruited at a predetermined ratio of teachers to students; grant for health workers and expenditures in human resource development.

Notes: In 2015, as consequence of the $25^{\text {th }}$ of April's earthquake in Nepal, in agreement with the Ministry of Finance (MoF) and the National Planning Commission (NPC), UNICEF provided technical and financial assistance to the Government of Nepal to deliver a payment of NRs. 3,000 as a top-up to the regular social assistance payments received by five vulnerable groups in the 19 districts most affected by the earthquakes, including: (1) Dalit children under five years of age, who normally receive NRs. 200 per month; (2) Widows, and single women over 60 years of age, who normally receive NRs. 500 per month; (3) People with disabilities, who normally receive NRs.300 per month if partially disabled and NRs. 1,000 per month if fully disabled; (4) Senior citizens over 70 years of age or over 60 if Dalit, who normally receive NRs. 500 per month; (5) Highly marginalised Janajati ethnic groups who normally receive NRs. 1,000 per month. This initiative have been implemented in 19 districts mostly affected by the earthquake.

I will start now with the key questions:

1. Information related to key factors which may have contributed to influence the establishment or the changes in social protection programmes.

1.1 Please, tell me which critical factors in the past have led to the establishment or to changes in social protection programmes. (For example, the establishment or changes of specific social protection 
programmes such as the increase or reduction in the benefits provided, the increase in the geographical scope of the project or the extension of the population targeted, etc.).

\section{Aim of testing 1.1}

To explore critical factors or processes which may have influenced the establishment or the changes in social protection programmes.

- To understand if changes in social protection programmes have been influenced by institutional factors and people's preferences.

- To gather information on what additional factors may have contributed to the establishment or to changes in social protection such as political, economic, legal (policies, frameworks, acts, regulations, etc.).

\section{Suggested probes}

Tell me more about that.

Can you give me an example?

Can you elaborate which process has been followed?

- Are there any other factors?

2. Key institutional factors (such as capacity or performance of the [organisation]) which may have contributed to influence the establishment or the changes in social protection programmes.

3.1. Please, tell me what are the critical factors of success and failure in the functioning or capacity of public institutions in relation to the provisions of social protection programmes. (For example, but not limited to the adequacy of human and financial resources, etc.)

\section{Aim of testing 2.1}

To explore the factors related to the capacity of the institutions at central and local level

\section{Suggested probes}

Please, tell me what are the key strategic issues or critical success factors in the functioning of the institutions at central and local level

Please, tell me what are the key strategic issues or critical factors of failure in the functioning of the institutions at central and local level

3. To explore to what extent people's preferences may have contributed to influence the establishment or the changes in social protection programmes.

3.1. Please, tell me to what extent society (defined as a group of acting citizens) has influenced the discussion on social protection. (For example, to what extent society in general or particular groups of citizens have influenced in the past the decisions taken to introduce or to changes (increasing or reducing) the provisions of social protection programmes.)

\section{Aim of testing 3.1}

To explore how people influences social protection programmes.

Follow up questions

- Please, tell me how the society has played a role in influencing the establishment or changes in social protection programmes?

- Please, tell me how Ministries and Planning Agencies at central level and VDC at local level take into account the pressure coming from citizens / political leaders. (Dimension: context or operating environment).

\section{Suggested probes}

Tell me more about that.

Can you give me an example?

- Can you elaborate which process has been followed?

4. To explore to what extent, the planning and budgeting processes may have contributed to influence the establishment or the changes in social protection programmes.

4.1. Please, tell me what are the critical factors of success and failure in the planning and budgeting process managed by the Government. 


\section{Aim of testing 4.1}

To explore and assess issues related to the overall management of the planning and budgeting process at central and local level. Horizontal interactions (between line ministries, National Planning Commission and the Ministry of Finance for example); and vertical interactions central level, DDC and VDC.

- To explore critical factors of success and failure in the planning and budgeting process.

- To explore if the process of planning and budgeting is timely and participatory.

\section{Suggested probes}

\section{Planning and budgeting}

- $\quad$ Please, tell me how people engages in the planning phase and budgeting process.

- $\quad$ For example, how women, Dalits, people with disability and marginalised communities, youth take part to the planning and budgeting process where needs are identified?]

- $\quad$ Please, tell me to what extent the participation of political leaders influences the planning phase and budgeting processes.

\section{Allocation and utilization of resources}

- Please, tell me to what extent the resources allocated by the Government reflect the needs expressed by the population.

- Please, tell me if resources are allocated and used transparently.

- Please, tell me to what extent the resources allocated and used are just a reflection of historical expenditures.

\section{Suggested probes}

- Tell me more about that.

- Can you give me an example?

- Can you elaborate which process has been followed?

- Can you please tell me how your organisation contribute to the planning and budgeting process at central and local level?

\section{Closing}

(start at min end at

- What is the most important message that you want us to take away from this interview?

- Is there anything else that you would like to add about any of the topics that we've discussed or other areas that we didn't discuss but you think are important?

- If you know of any documents, reports or resources that may be useful to complement this interview, please share or send them to me.

Thank you for your time and participation in this interview. The information you have provided will be analysed for the research. I will be happy to share with you the findings of this part of my research. 


\section{Appendix A.6 Consent form to be signed before the focus group discussions}

\section{- Nepal}

\section{Maastricht University}

Your consent in writing is needed to confirm your involvement in this research on "Institutional factors and people's preferences in social protection: the case of Nepal". Signing this form means that you have agreed to be a part of the research but does not stop you from changing your mind at a later time. You can withdraw from the research at any time and doing so will not affect your public or community standing. To withdraw from the research please contact the Principal Researcher at the address shown on the Information Sheet.

Your participation in the study will hence be strictly anonymous, the discussion will be audio recorded. The record will be immediately deleted after the data is transcribed. All data will be carefully and securely stored and only used for research purposes. No reports will link what you say to your name, department, or institution. In this way, we will maintain your confidentiality.

- I confirm that I have read and understand the information sheet for the above study.

- I understand that my participation is voluntary and that I am free to withdraw at any time, without giving reason.

- I agree to take part in the above study.

- I agree to the focus group discussion being audio recorded

- I agree to the use of anonymised quotes in publications

Signature:

Date:

Name (print):

Finger print (optional) 


\section{Appendix A.7 Interview guide for focus group discussions with community members - Nepal}

The Focus Group Discussions (FGDs) will be conducted with community members representing different segments of the society in the selected VDCs with a maximum of 10 participants in each FGD.

\section{Categories of participants for each Focus Group Discussion conducted at VDC level} Category Definition

Senior citizens

Single woman/Widow

People with disability

Representative of indigenous and disadvantaged communities.

Dalits' representatives
All citizens over 70; over 60 in Karnali region or if identified as Dalits in all of Nepal.

Allowance for single women 60 years or older; widows of all ages.

Belong to one of the 22 Dalit Castes in $\mathrm{Nepal}^{64}$.

In order to plan the FGD, a pool of names of potential participants will be generated for each of the main categories defined. Then names will be randomized and selected to reduce bias. Invitation will be sent to the selected participants indicating date, place and time of the FGD and a reminder phone call will be made to remind participant to attend the session. For each category 1-2 representatives will be selected with the objective to have a balanced representation of men and women in the FGD and of the selected segments. Because of the language a moderator and a translator will be hired to facilitate and translate the FGDs. The KIIs at VDC level will be also conducted with the support of a translator.

\begin{tabular}{|c|c|c|c|c|}
\hline \multicolumn{2}{|c|}{ Date of the interview: (date/ month/ year) } & \multicolumn{3}{|c|}{ Time started: } \\
\hline \multicolumn{2}{|l|}{ District: } & \multicolumn{3}{|c|}{ Time ended: } \\
\hline \multicolumn{2}{|l|}{ VDC: } & \multirow{3}{*}{\multicolumn{3}{|c|}{ Number of Participants: }} \\
\hline Interviev & & & & \\
\hline \multicolumn{2}{|c|}{ List of Participants: } & & & \\
\hline No./ID. & Name & Age & $\operatorname{Sex}(M / F)$ & Remarks \\
\hline \multicolumn{5}{|l|}{1} \\
\hline \multicolumn{5}{|l|}{2} \\
\hline \multicolumn{5}{|l|}{3} \\
\hline \multicolumn{5}{|l|}{4} \\
\hline \multicolumn{5}{|l|}{5} \\
\hline .. & & & & \\
\hline
\end{tabular}

Estimated time for the interview: (90-120 minutes total)

\section{Introduction}

(start at _ min end at

Thank you for agreeing to join this discussion institutional factors and people's preferences in social protection in Nepal. My name is Vincenzo Vinci and I am a research fellow in the Maastricht Graduate School of Governance of Maastricht University and this are [Moderator's name] and [Translator's name].

64 (A) Hill Origin: Gandarva (Gaine), Pariyar (Damai, Darji, Suchikar, Nagarchi, Dholi, Hoodke), Badi, Viswakarma (Kami, Lohar, Sunar, Wod, Chunara, Parki, Tamata), and Sarki (Mijar, Charmakar, Bhool). (B) Madhesi Origin: Kalar, Kakaihiya, Kori, Khatik, Khatbe (Mandal, Khanka), Chamar (Ram, Mochee, Harijan, Rabidas), Chidimar, Dom(Marik), Tatma (Tanti, Das), Dusadh (Paswan, Hajara), Dhobi (Hindu Rajak), Pattharkatta, Pasi, Bantar, Mushar, Mestar (Halkhor), and Sarvanga (Sarbaraiya) (Bhattachan, Sunar, \& Bhattachan, 2009). 
[Moderator's name] will be talking with you today. The purpose of this interview today is to learn more about how the capacity of the institutions and how the preferences expressed by the people could influence the provisions of social protection programmes in Nepal. The discussion will last about 90120 minutes.

Did you read the consent form that was sent to you? Do you have any questions?

[Collect signed consent form]

\section{Ground rules}

[Moderator speaking]. Before we begin, let me suggest some things to make our discussion more productive. Because we'll be recording for an accurate record, it is important that you speak up and that you only speak one at a time. We don't want to miss any of your comments. We'll only use first names here. No reports will link what you say to your name, department, or institution. In this way, we will maintain your confidentiality. Audio records will be deleted after transcribing them. In addition, we ask that you also respect the confidentiality of everyone here. Please don't repeat who said what when you leave this room. During our discussion we'll be here, I will ask you questions, and I will listen to what you have to say. I will not participate in the discussion. So please, feel free to respond to each other and to speak directly to others in the group. We want to hear from all of you. We're interested in both majority and minority viewpoints, common and uncommon experiences. So, I may sometimes intervene to encourage someone who has been quiet to talk, or by asking someone to hold off for a few minutes. When we write about our findings we might use direct quotes from this focus group but we will not identify you individually and any quotes that we do use are will be attributable to an individual or to a role. You should all have an information sheet that describes the research, if after today you have any questions about what we are doing, this information sheet contains our contact details and we welcome you to get in touch.

If it is OK with you, we will turn on the recorder and start now.

[Turn on recording equipment.]

\section{Engagement questions}

(start at min end at

\section{Explanation and introduction}

Our first question relates to those services provided by the VDC which relate to social protection. By social protection we mean those services which includes cash or in-kind transfers to the eligible population such as civil servants who receive pensions or other benefits, old age allowance, single woman/widow allowance, Dalits' 65 representatives and Block Grants which are transferred through projects that directly benefit women of poor and deprived communities, children of poor and deprived communities, and indigenous and disadvantaged communities.

1. Please, discuss about what kind of benefits does the VDC provides to the eligible community members as part of the social protection/social assistance programmes?

\section{Key questions}

In the below questions the term social protection refers to the following social protection programmes with are defined in the box 1 below.

\section{Box 1 Definition for selected social protection programmes}

Block Grants allocate to Village Development Committees (VDCs): VDC block grants are provided for the funding of capital development projects as well as for recurrent purposes. For each "categorical" grant level between Rs. 1.5 and 3.0 million a specific amount is set aside for recurrent activities. The amount is based on the following indicators/criteria: a) equal share $(30 \%)$ which is taken as a first charge, prior to distributing the remainder of the grant pool on the basis of the 
remaining allocation factors; b) population (60\%); c) Land area (10\%) and d) Cost Index. Each VDC, based on these criteria, belongs to one of the following six categories which is composed by a capital part and a recurrent component: Category I: Rs 1.50 million (Recurrent - Rs 350,000); Category II: Rs 1.76 million (Recurrent - Rs 393,000); Category III: Rs 1.95 million (Recurrent - Rs 400,000); Category IV: Rs 2.15 million (Recurrent - Rs 420,000); Category V: Rs 2.45 million (Recurrent - Rs 420,000); and Category VI: Rs 3.00 million (Recurrent - Rs 425,000). 35 percent of the capital part is allocated for social protection programmes in particular to support a) children $(10 \%)$; women $(10 \%)$ and disadvantaged groups $(15 \%)$. The remaining part of the capital part can also include a $10 \%$ of matching funds for developing programmes, and for social mobilisations activities. The recurrent part should be spent for salary and benefits of VDC staff members (technical and others); annual salary of chairman and vice chairman; meeting allowance and stationary; grant for the teachers' who are recruited at a predetermined ratio of teachers to students; grant for health workers and expenditures in human resource development.

I will start now with the key questions:

\section{Information related to the Block Grants (social protection programmes) provided at VDC level.}

\section{Explanation and introduction}

We have been looking at some of the social protection programmes provided by the VDC. We would now like to narrow the discussion on the Block Grants also known as Development Grants which is a lump sum transferred by the central level to each VDC. As you know a portion of these funds should be allocated for social protection interventions which may target one or more than one categories of population among Women of poor and deprived communities; children from poor family or deprived communities; Indigenous and disadvantaged communities.

\subsection{Please, discuss about the Block Grants / Development Grants?}

\section{Aim of testing 2.1}

To explore the knowledge of the community of the Block Grants (social protection) provided by the VDC.

\section{Follow up questions}

- Please, discuss how the Block Grants / Development Grants are delivered to people in the community.

- Please, discuss what you think about the transparency of the process followed by the VDC to assign the Block Grants for social protection programmes to people in the community.

- Please, what is the process followed by the VDC to consult the community for the allocation of the Block Grants for social protection interventions.

\section{Suggested probes}

- Tell me more about that.

- Can you give me an example?

- Can you elaborate which process has been followed?

\section{Key institutional factors which might have contributed to influence the provision of social protection programmes.}

\section{Explanation and introduction}

We will now want to broaden our discussion to understand about the capacity of the VDC in delivering social protection services to the community. Aspects that might be considered: waiting time at the VDC for collecting money; distance to the facility; information received about the day to collect the benefit; others?

3.1. Please, discuss what aspects would allow you to say that the service provided by the VDC in delivering social protection programmes was a good service.

3.2. Please, discuss what aspects would make you say that the service provided by the VDC in delivering social protection programmes was less than good. 
3.3. Please, discuss how good your VDC is delivering social protection programmes in your community.

3.4. Please, discuss what things can be improved in the VDC to better deliver the services to the community in social protection.

3.5. If you had to choose the most important aspect that affects quality of your VDC in delivering social protection programmes what would it be?

Prompt: Why do you choose this one?

\section{Aim of testing 3.2 and 3.3}

- To explore the factors related to the capacity of the institutions at local level.

\section{Follow up questions}

- Please, discuss if the services in your VDC are delivered on time.

- Please, discuss how your VDC ask the community for consultations.

- Please, discuss how your VDC keeps the community informed about its activities. (Dimension: context or operating environment). [For example, by publishing annual reports to keep society informed, public awareness campaigns, etc.]

- Please, discuss if your VDC keeps the promises about the services to be provided to the community.

- Please, discuss if the resources available are used in a fair way.

Prompt: Please explain and give examples of fair or unfair treatment.

\section{Suggested probes}

- Tell me more about that.

- Can you give me an example?

- Can you elaborate which process has been followed?

\section{People's preferences which might have contributed to the provision of social protection} programmes.

\section{Explanation and introduction}

We will now want to know to what extent the community is able to communicate its needs and its preferences on social protection to the VDC. Aspect that might be considered: participation of the community to Ward Citizens' Forums (WCFs); interactions with the Citizen Awareness Centre (CAC); direct interaction with local officials, others?

4.1. Please, discuss on how you communicate your needs to the VDC.

\section{Aim of testing 4.1}

- To explore how people influences social protection programmes.

\section{Follow up questions}

- Please, discuss what needs to be done to improve the communication and dialogue between VDC and community?

- Please, discuss how you interact with Citizen Awareness Centre (CAC) and the Ward Citizens' Forums (WCFs)?

- Can you please tell me which process is followed?

\section{Suggested probes}

- Tell me more about that.

- Can you give me an example?

- Can you elaborate which process has been followed?

5. Planning and budgeting processes which might have contributed to the provision of social protection programmes.

\section{Explanation and introduction}

We will now want to know about the planning process and the budgeting process at VDC level. In particular, we would like to know to what extent the community is able to engage in the planning and 
budgeting process with the VDC. Aspect that might be considered: current involvement of the community in the planning and budgeting process through different mechanisms and processes.

5.1 Please, discuss how the community engages with the VDC during the planning and budgeting process.

\section{Aim of testing 5.1}

- To explore and assess issues related to the overall management of the planning and budgeting process at local level.

- To explore critical factors of success and failure in the planning and budgeting process.

- To explore if the process of planning and budgeting is timely and participatory.

\section{Follow up questions}

\section{Planning and budgeting}

- Please, discuss what needs to be done to improve the participation of the community with the VDC during the planning and budgeting process.

- Please, discuss to what extent the participation of political leaders influences the planning phase and budgeting processes at VDC level.

\section{Allocation and utilization of resources}

- Please, discuss to what extent the resources allocated and used by VDC benefit the right people.

- Please, discuss to what extent the resources allocated and used by the VDC reflect the needs expressed by the community.

- Please, tell me if resources are allocated and used transparently.

\section{Suggested probes}

- Tell me more about that.

- Can you give me an example?

- Can you elaborate which process has been followed?

\section{Closing}

(start at min end at

- Is there anything else that you would like to add about any of the topics that we've discussed or other areas that we didn't discuss but you think are important?

- Do you have any question for me?

Thank you for your time and participation in this focus group discussion. The information you have provided will be analysed for the research. 
Appendix A.8 Timeframe of the interviews - Nepal

\begin{tabular}{|c|c|c|c|c|}
\hline Date & Place & $\begin{array}{l}\text { Interview } \\
\text { methodology }\end{array}$ & Gender & Respondent/Ward \\
\hline \multicolumn{5}{|l|}{ Central level } \\
\hline 27-May-16 & Kathmandu & KII-1 (Face-to-face) & $\mathrm{M}$ & MoFALD \\
\hline 02-Jun-16 & Kathmandu & KII-2 (Face-to-face) & M & $\mathrm{MoF}$ \\
\hline 06-Jun-16 & Kathmandu & KII-3 (Face-to-face) & M & Nepan \\
\hline 16-Jun-16 & Kathmandu & KII-4 (Face-to-face) & M & HelpApge \\
\hline 29-Jun-16 & Kathmandu & KII-5 (Face-to-face) & M & MoPR \\
\hline 07-Jul-16 & Kathmandu & KII-6 (Face-to-face) & $\mathrm{F}$ & $\begin{array}{l}\text { Women for Human } \\
\text { Rights }\end{array}$ \\
\hline 12-Jul-16 & Kathmandu & KII-7 (Face-to-face) & $\mathrm{F}$ & The World Bank \\
\hline 13-Jul-16 & Kathmandu & KII-8 (Face-to-face) & $\mathrm{F}$ & Save the Children \\
\hline 03-Dec-16 & Kathmandu & KII-9 (e-mail) & M & NPC \\
\hline \multicolumn{5}{|l|}{ Local level } \\
\hline 31-May-16 Pre-test & VDC 1 & KII & $\mathrm{M}$ & VDC Secretary \\
\hline 31-May-16 Pre-test & VDC 1 & FGD & $4 \mathrm{M}, 6 \mathrm{~F}$ & Ward $3(10)$ \\
\hline 01-Jun-16 Pre-test & VDC 1 & FGD & $1 \mathrm{M}, 9 \mathrm{~F}$ & Ward 1 (10) \\
\hline 01-Jun-16 Pre-test & VDC 1 & FGD & $12 \mathrm{~F}$ & Ward 1 (12) \\
\hline 11-July-16 & VDC 4 & FGD-1 & $6 \mathrm{M}, 6 \mathrm{~F}$ & Ward 2 (12) \\
\hline 11-July-16 & VDC 4 & FGD-2* & $2 \mathrm{M}, 7 \mathrm{~F}$ & Ward $2(9)$ \\
\hline 12-July-16 & VDC 4 & FGD-3 & $1 \mathrm{M}, 6 \mathrm{~F}$ & Ward $5(7)$ \\
\hline 12-July-16 & VDC 4 & KII-1 & M & VDC Secretary \\
\hline 12-July-16 & VDC 4 & FGD-4* & $5 \mathrm{M}, 5 \mathrm{~F}$ & Ward $5(10)$ \\
\hline 14-July-16 & VDC 3 & FGD-5* & $4 \mathrm{M}, 6 \mathrm{~F}$ & Ward 3 (10) \\
\hline 15-July-16 & VDC 3 & FGD-6 & $4 \mathrm{M}, 3 \mathrm{~F}$ & Ward 6 (7) \\
\hline 15-July-16 & VDC 3 & FGD-7 & $4 \mathrm{M}, 3 \mathrm{~F}$ & Ward $6(7)$ \\
\hline 16-July-16 & VDC 3 & KII-2 & M & VDC Secretary \\
\hline 17-July-16 & VDC 6 & FGD-8* & $4 \mathrm{M}, 4 \mathrm{~F}$ & Ward $6(8)$ \\
\hline 17-July-16 & VDC 6 & FGD-9* & $6 \mathrm{M}, 5 \mathrm{~F}$ & Ward 5 (11) \\
\hline 18-July-16 & VDC 6 & KII-3 & M & VDC Secretary \\
\hline 18-July-16 & VDC 6 & FGD-10 & $6 \mathrm{M}, 4 \mathrm{~F}$ & Ward $1(10)$ \\
\hline 19-July-16 & VDC 6 & FGD-11 & $3 \mathrm{M}, 4 \mathrm{~F}$ & Ward $1(7)$ \\
\hline 21-July-16 & VDC 2 & KII-4 & $\mathrm{M}$ & VDC Secretary \\
\hline 22-July-16 & VDC 2 & FGD-12 & $2 \mathrm{M}, 8 \mathrm{~F}$ & Ward 7 (10) \\
\hline 22-July-16 & VDC 2 & FGD-13 & $7 \mathrm{M}, 4 \mathrm{~F}$ & Ward 7 (11) \\
\hline 23-July-16 & VDC 2 & FGD-14 & $4 \mathrm{M}, 6 \mathrm{~F}$ & Ward 1 (10) \\
\hline 25-July-16 & VDC 5 & FGD-15* & $1 \mathrm{M}, 14 \mathrm{~F}$ & Ward 1 (15) \\
\hline 25-July-16 & VDC 5 & FGD-16 & $6 \mathrm{M}, 2 \mathrm{~F}$ & Ward $1(8)$ \\
\hline 26-July-16 & VDC 5 & FGD-17 & $7 \mathrm{M}, 2 \mathrm{~F}$ & Ward $9(9)$ \\
\hline 26-July-16 & VDC 5 & FGD-18 & $2 \mathrm{M}, 6 \mathrm{~F}$ & Ward 9 (8) \\
\hline 27-July-16 & VDC 5 & FGD-19* & $5 \mathrm{M}, 3 \mathrm{~F}$ & Ward 8 (8) \\
\hline 29-July-16 & VDC 5 & KII-5 & M & VDC Secretary \\
\hline
\end{tabular}




\section{Appendix B.1 Study information sheet - Ethiopia}

\section{Maastricht University}

Study title: Institutional factors and people's preferences in social protection: the case of Ethiopia.

Dear Sir/Madam,

My name is Vincenzo Vinci and I am a research fellow at the Maastricht Graduate School of Governance at the University of Maastricht in the Netherlands. Before you decide whether or not to take part in the study, it will be important for you to understand why the research is being done and what it will involve. Please take some time to read the following information.

The purpose of this study is to understand how the quality of institutions (for example how the woreda/kebele delivery services to community, availability of skilled staff, coordination among social protection providers etc..) and the way people express their preferences (for example how people communicate their needs to kebele/woreda focal persons or grievance mechanisms in relation to social protection services) influence the delivery of the Productive Safety Net Programme (PSNP) in Ethiopia. I plan to conduct interviews with key informants and have focus group discussions. I will discuss issues such as: What are the critical factors of success and failure in the provision of social services in the kebele? What is the process followed to deliver/collect PSNP payments to beneficiaries? How does the community decide on the type of public works implemented in the community? I plan to interview local officials and additional key informants at kebele and woreda level. In addition, I plan to conduct Focus Group Discussions with PSNP beneficiaries.

Your contribution is of high value to this study and your participation is entirely voluntarily. If you decide to take part, you are free to end your participation at any time and without giving a reason.

[For KII informants: Your identity will be protected at all times and your participation in the study will hence be strictly anonymous, if you do not wish otherwise.]

[For FGD participants: I kindly request you to keep the content of this discussion confidential. I will pursue to the extent possible to keep information gather anonymous and confidential. However, I acknowledge that it cannot be completely guaranteed.]

If you agree, our interview will be audio recorded. The record will however be immediately deleted after the data is transcribed. All data will be carefully and securely stored and only used for research purposes. Your contribution will help to get valuable insights into the debate around social protection in Ethiopia. In case you have any questions or concerns regarding your participation in this study, please do not hesitate to contact me directly at v.vinci@student.maastrichtuniversity.nl.

Yours sincerely, Vincenzo Vinci

Vincenzo Vinci, Executive Researcher

Maastricht Graduate School of Governance, Maastricht University

Boschstraat 24 | 6211 AX Maastricht | The Netherlands

v.vinci@student.maastrichtuniversity.nl. | Cell phone Ethiopia: +251909541805 


\section{Appendix B.2 Consent form for local officials - Ethiopia}

\section{Maastricht University}

Please consider this information carefully before deciding whether to participate in this research.

My name is Vincenzo Vinci and I am a research fellow in the Mastricht Graduate School of Governance of Maastricht University. I am undertaking a Ph.D. and the purpose of this research is to explore to what extent the provisions of social protection programmes (PSNP) in Ethiopia have been influenced by the quality of the institutions at sub-national level and by people's preferences for social protection programmes.

If you decide to volunteer to this interview, you will be asked several questions which relates to the topic mentioned above. Some of them will be about the capacity of the institutions to provide social protection programmes, others will be related on how the institutions manage the planning and budgeting process and take into account people's preference when social protection interventions are provided. This will give you the opportunity to share your experience in relation to this topic. I will tape record the interviews so I don't have to make so many notes. You will not be asked to state your name on the recording. This interview will require about 1 hour of your time and there are no anticipated risks or discomforts related to this research. Your participation in this research is completely voluntary and there is no compensation for participating to this study.

Your responses to interview questions will be kept confidential. At no time will your actual identity be revealed. You will be assigned a random numerical code. Anyone who helps me transcribe responses will only know you by this code. The recording of this interview and the transcript, without your name, will be kept until my Ph.D. research is accepted. The key code linking your name with your number will be kept in a locked file cabinet in a locked office, and no one else will have access to it. The record will be immediately deleted after the data is transcribed. The data you give me will be used for a study I am currently writing and for future articles or presentations.

Your participation in this study is completely voluntary, and you may refuse to participate or withdraw from the study without penalty or loss of benefits to which you may otherwise be entitled. You may withdraw by informing me that you no longer wish to participate (no questions will be asked). You may skip any question during the interview, but continue to participate in the rest of the study.

Vincenzo Vinci, Executive Researcher

Maastricht Graduate School of Governance, Maastricht University

Boschstraat 24 | 6211 AX Maastricht | The Netherlands

v.vinci@student.maastrichtuniversity.nl. | Cell phone Ethiopia: +251909541805

\section{Agreement:}

The nature and purpose of this research have been sufficiently explained and I agree to participate in this study. I understand that I am free to withdraw at any time without incurring any penalty.

Signature:

Date:

Name (print): 


\section{Appendix B.3 Interview guide for district representatives - Ethiopia}

Note: This interview guide is used for two types of kebeles/woredas: those ones where PSNP is implemented and those ones where IN-SCT approach is integrated. Therefore, when the questions mention "PSNP/IN-SCT" we will need to refer to "TN-SCT" only in the IN-SCT selected kebeles/woredas.

\section{Interviewee information}

- Date

- Respondent category

- Location [woreda and kebele]

- Name of interviewee(s) [male/ female, age, qualifications]

\section{Understanding institutions}

5.1. What are your main activities and responsibilities in coordinating the PSNP/IN-SCT in this woreda?

5.2. What are the challenges you face in performing your role?

5.3. Do you feel that your roles (division of tasks and responsibilities) are clear? If, not why? Can you please provide some examples?

5.4. Do you feel overloaded in the roles you perform? If yes, could you please provide an example?

6. Quality of implementation: co-responsibilities

6.1. How are co-responsibilities being implemented in this kebele/woreda? Please explain the process?

6.2. What challenges are encountered in implementing co-responsibilities in this kebele/woreda?

6.3. What changes can you recommend for improving the implementation of co-responsibilities?

6.4. What is the process followed to monitor co-responsibilities in this kebele/ woreda?

6.5. What challenges are encountered in monitoring co-responsibilities in this kebele/woreda?

6.6. What changes can you recommend to improve the monitoring of co-responsibilities?

6.7. Overall, do you think co-responsibilities in the PSNP Direct Support are a good idea? If yes, why? If not, why not?

7. Quality of implementation: TDS [pregnant women, lactating women, caregivers of malnourished children]

7.1. How is the transition into TDS being implemented in this kebele/woreda?

7.2. How well do you think the transition into TDS is being implemented in this kebele/woreda?

7.3. What challenges are being encountered with respect to implementing the transition into TDS?

7.4. What changes can you recommend to improve the implementation of the transition into TDS?

7.5. How is the transition into TDS being monitored in this kebele/woreda?

7.6. What changes can you recommend to improve the monitoring of the transition into TDS in this kebele/ woreda?

7.7. Overall, do you think transition to TDS is a good addition to the PSNP? If yes, why? If not, why not?

8. Quality of implementation: PW [Public Works]

8.1. How do you decide the type of PW (i.e. construction of roads, bridges, pipelines etc.) implemented in this kebele/ woreda?

8.2. How do people in the community influence the type of PW implemented in this woreda?

8.3. Do you know about children being enrolled in PW in this woreda?

8.4. Do you know about children working for PW in this woreda?

9. Quality of implementation: Payments

9.1. What is the process followed to delivery PSNP payments to beneficiaries?

9.2. Are PSNP payments delivered on time to beneficiaries? If no, why? Can you provide some examples? 
9.3. What challenges are you encountering in the delivery of the payments? What changes can you recommend to improve the implementation of delivery of payments?

\section{People's preferences: Grievance mechanisms}

10.1. How does the grievance mechanism for PSNP work in this kebele/ woreda? How can people make complaints and how are these complaints processed?

10.2. How well do you think the grievance mechanism is being implemented in this kebele/ woreda?

10.3. Do you think that the grievance mechanism is helpful for including people's preferences or voices in the programme? If so, how? If not, why not?

\section{Community Care Coalitions (CCCs)}

11.1. Are CCCs established and functional in all kebeles in this woreda? And in this kebele? If not, why not?

11.2. What is the role of the CCCs? How do they operate?

11.3. Do you think that the CCCs help to represent people's preferences and voices? If so, how?

11.4. Overall, do you think the CCCs are a good idea? If yes, why? If not, why not?

\section{Quality of institutions and people's preferences}

12.1. How does the collaboration work between different PSNP service providers at kebele/ woreda level? How do the main stakeholders interact with each other? (e.g. Woreda Health Office, Agriculture Office, Women and Children Affairs, Education Office, Woreda Administration Office? etc.)

12.2. What are the most important collaborations at woreda level for ensuring the PSNP/IN-SCT project functions well? (e.g. between the Woreda Health Office and the WoLSA Office, etc.)

12.3. Do you think these collaborations between the most important service providers are working well? Please explain.

12.4. What are the critical factors of success and failure in the functioning or capacity in this Woreda? (For example, the adequacy of human and financial resources, the leadership, etc.)

12.5. How does the woreda ensure transparency and keep the society informed about its activities? (For example, by publishing annual reports to keep society informed, by holding press conferences, public awareness campaigns, posting information on the internet, etc.)

12.6. How does the Woreda take into account people's voice and preferences? Can you please provide some examples?

12.7. How does the Woreda take into account the pressure coming from citizens / political leaders? 12.8. Please, tell me how do people engage in the planning phase and budgeting process? 


\title{
Appendix B.4 Interview guide for social workers - Ethiopia
}

\author{
Note: This interview guide is used for two type of kebeles/woredas: those ones where PSNP is implemented and those \\ ones where IN-SCT approach is integrated. Therefore, when the questions mention "PSNP/IN-SCT" we will need to \\ refer to "IN-SCT" only in the IN-SCT selected kebeles/woredas.

\section{Interviewee information} \\ - Date \\ - Respondent category \\ - Location [woreda and kebele] \\ - Name of interviewee(s) [male/ female, age, qualifications, years of experience]
}

\section{Understanding institutions}

1.1. What are your main activities and responsibilities in implementing the PSNP/IN-SCT in this kebele/woreda?

1.2. What are the challenges you face in performing your role?

1.3. Do you feel that your roles (division of tasks and responsibilities) are clear? If, not why? Can you please provide some examples?

1.4. Do you feel overloaded in the roles you perform? If yes, could you please provide an example?

\section{Quality of implementation: co-responsibilities}

2.1. How are co-responsibilities being implemented in this kebele/woreda? Please, explain the process.

2.2. What role do you play in implementing the co-responsibilities?

2.3. What challenges are being encountered with respect to implementing the co-responsibilities?

2.4. What changes can you recommend to improve the implementation of co-responsibilities?

2.5. What is the process followed to monitor co-responsibilities in this kebele/woreda?

2.6. Who is responsible for monitoring the co-responsibilities?

2.7. What challenges are encountered in monitoring co-responsibilities in this kebele/woreda?

2.8. What changes can you recommend to improve the monitoring of co-responsibilities?

2.9. Have you been personally involved with managing cases of SCT clients who are not complying with their co-responsibilities? If yes, what were the issues involved? Can you give us examples of actual cases?

2.10. Overall, do you think co-responsibilities in the PSNP Direct Support are a good idea? If yes, why? If not, why not?

3. Quality of implementation: TDS [pregnant women, lactating women, caregivers of malnourished children]

3.1. How is the transition into TDS being implemented in this kebele/woreda?

3.2. How well do you think the transition into TDS is being implemented in this kebele/woreda?

3.3. What challenges are being encountered with respect to implementing the transition into TDS?

3.4. What changes can you recommend to improve the implementation of the transition into TDS?

3.5. How is the transition into TDS being monitored in this kebele/woreda?

3.6. What role do you play in monitoring TDS, at kebele/woreda level? What changes can you recommend to improve the monitoring of the transition into TDS in this kebele/woreda?

3.7. Overall, do you think TDS is a good addition to the PSNP? If yes, why? If not, why not?

\section{Quality of implementation: PW [ Public Works]}

4.1. How do you decide the type of PW (i.e. construction of roads, bridges, pipelines etc.) implemented in this kebele/woreda?

4.2. How do people in the community influence the type of PW implemented in this kebele/woreda?

4.3. Do you know about children being enrolled in PW in this kebele/woreda?

4.4. Do you know about children working for PW in this kebele/woreda? 


\section{Quality of implementation: Payments}

5.1. What is the process followed to delivery PSNP payments to beneficiaries?

5.2. Are PSNP payments delivered on time to beneficiaries? If no, why? Can you provide some examples?

5.3. What challenges are you encountering in the delivery of the payments?

5.4. What changes can you recommend to improve the implementation of delivery of payments?

\section{People's preferences: Grievance mechanisms}

6.1. How does the grievance mechanism for this PSNP work in this kebele/woreda? How can people make complaints and how are these complaints processed?

6.2. How well do you think the grievance mechanism is being implemented in this kebele/woreda?

6.3. Do you think that the grievance mechanism is helpful for including people's preferences or voices in the programme? If so, how? If not, why not?

\section{Community Care Coalitions (CCCs)}

7.1. Are CCCs established and functional in all kebeles in this woreda? And in this kebele? If not, why not?

7.2. What is the role of the CCCs? How do they operate?

7.3. Do you think that the CCCs help to represent people's preferences and voices? If so, how?

7.4. Overall, do you think the CCCs are a good idea? If yes, why? If not, why not?

\section{Quality of institutions and people's preferences}

8.1. How does the collaboration work between different PSNP service providers at kebele/ woreda level? How do the main stakeholders interact with each other? (e.g. Woreda Health Office, Agriculture Office, Women and Children Affairs, Education Office, Woreda Administration Office? etc.)

8.2. What are the most important collaborations at woreda level for ensuring the PSNP/IN-SCT project functions well? (e.g. between the Woreda Health Office and the WoLSA Office, etc.)

8.3. Do you think these collaborations between the most important service providers are working well? Please explain.

8.4. What are the critical factors of success and failure in the functioning or capacity in the kebele/woreda? (For example, the adequacy of human and financial resources, the leadership, etc.)

8.5. How does the kebele/woreda ensure transparency and keep the society informed about its activities? (For example, by publishing annual reports to keep society informed, by holding press conferences, public awareness campaigns, posting information on the internet, etc.)

8.6. How does the kebele/woreda take into account people's voice and preferences? Can you please provide some examples?

8.7. How does the kebele/woreda take into account the pressure coming from citizens / political leaders?

8.8. Please, tell me how do people engage in the planning phase and budgeting process in the kebele/woreda? 


\section{Appendix B.5 Interview guide for development agents - Ethiopia}

Note: This interview guide is used for two type of kebeles/woredas: those ones where PSNP is implemented and those ones where IN-SCT approach is integrated. Therefore, when the questions mention "PSNP/IN-SCT" we will need to refer to "IN-SCT" only in the IN-SCT selected kebeles/woredas.

\section{Interviewee information}

- Date

- Respondent category

- Location [woreda and kebele]

- Name of interviewee(s) [male/ female, age, qualifications, years of experience]

1. Understanding institutions:

1.1. What are your main activities and responsibilities in implementing the PSNP/IN-SCT in this kebele?

1.2. What are the challenges you face in performing your role?

1.3. Do you feel that your roles (division of tasks and responsibilities) are clear? If, not why? Can you please provide some examples?

1.4. Do you feel overloaded in the roles you perform? If yes, could you please provide an example?

\section{Quality of implementation: co-responsibilities}

2.1. How are co-responsibilities being implemented in this kebele/woreda? Please, explain the process.

2.2. What role do you play in implementing the co-responsibilities?

2.3. What challenges are being encountered with respect to implementing the co-responsibilities?

2.4. What changes can you recommend to improve the implementation of co-responsibilities?

2.5. What is the process followed to monitor co-responsibilities in this kebele/woreda?

2.6. Who is responsible for monitoring the co-responsibilities?

2.7. What challenges are encountered in monitoring co-responsibilities in this kebele/woreda?

2.8. What changes can you recommend to improve the monitoring of co-responsibilities?

2.9. Have you been personally involved with managing cases of SCT clients who are not complying with their co-responsibilities? If yes, what were the issues involved? Can you give us examples of actual cases?

2.10. Overall, do you think co-responsibilities in the PSNP Direct Support are a good idea? If yes, why? If not, why not?

3. Quality of implementation: TDS [pregnant women, lactating women, caregivers of malnourished children]

3.1. How is the transition into TDS being implemented in this kebele?

3.2. How well do you think the transition into TDS is being implemented in this kebele?

3.3. What challenges are being encountered with respect to implementing the transition into TDS?

3.4. What changes can you recommend to improve the implementation of the transition into TDS?

3.5. How is the transition into TDS being monitored in this kebele?

3.6. What role do you play in monitoring TDS, at kebele level?

3.7. What changes can you recommend to improve the monitoring of the transition into TDS in this kebele?

3.8. Overall, do you think TDS is a good addition to the PSNP? If yes, why? If not, why not?

\section{Quality of implementation: PW [ Public Works]}

4.1. How do you decide the type of PW (i.e. construction of roads, bridges, pipelines etc.) implemented in this kebele?

4.2. How do people in the community influence the type of PW implemented in this kebele?

4.3. Do you know about children being enrolled in PW in this kebele?

4.4. Do you know about children working for PW in this kebele? 


\section{Quality of implementation: Payments}

5.1. What is the process followed to delivery PSNP payments to beneficiaries?

5.2. Are PSNP payments delivered on time to beneficiaries? If no, why? Can you provide some examples?

5.3. What challenges are you encountering in the delivery of the payments?

5.4. What changes can you recommend to improve the implementation of delivery of payments?

\section{People's preferences: grievance mechanisms}

6.1. How does the grievance mechanism for this PSNP work in this kebele? How can people make complaints and how are these complaints processed?

6.2. How well do you think the grievance mechanism is being implemented in this kebele?

6.3. Do you think that the grievance mechanism is helpful for including people's preferences or voices in the programme? If so, how? If not, why not?

\section{Community Care Coalitions (CCCs)}

7.1. Are CCCs established and functional in all kebeles in this in this kebele? And in this kebele? If not, why not?

7.2. What is the role of the CCCs? How do they operate?

7.3. Do you think that the CCCs help to represent people's preferences and voices? If so, how?

7.4. Overall, do you think the CCCs are a good idea? If yes, why? If not, why not?

\section{Quality of institutions and people's preferences}

8.1. How does the collaboration work between different PSNP service providers at kebele level? How do the main stakeholders interact with each other? (e.g. Health Office, Agriculture Office, Women and Children Affairs, Education Office, Administration Office? etc.)

8.2. What are the most important collaborations at kebele level for ensuring the PSNP/IN-SCT project functions well? (e.g. between the Woreda Health Office and the WoLSA Office, etc.)

8.3. Do you think these collaborations between the most important service providers are working well? Please explain.

8.4. What are the critical factors of success and failure in the functioning or capacity in the kebele/woreda? (For example, the adequacy of human and financial resources, the leadership, etc.)

8.5. How does the kebele/woreda ensure transparency and keep the society informed about its activities? (For example, by publishing annual reports to keep society informed, by holding press conferences, public awareness campaigns, posting information on the internet, etc.)

8.6. How does the kebele/woreda take into account people's voice and preferences? Can you please provide some examples?

8.7. How does the kebele/woreda take into account the pressure coming from citizens / political leaders?

8.8. Please, tell me how do people engage in the planning phase and budgeting process in the kebele/woreda? 


\section{Appendix B.6 Interview guide for health extension workers - Ethiopia}

Note: This interview guide is used for two type of kebeles/woredas: those ones where PSNP is implemented and those ones where IN-SCT approach is integrated. Therefore, when the questions mention "PSNP/IN-SCT" we will need to refer to "IN-SCT" only in the IN-SCT selected kebeles/woredas.

\section{Interviewee information}

- Date

- Respondent category

- Location [woreda and kebele]

- Name of interviewee(s) [male/ female, age, qualifications, years of experience]

1. Understanding institutions:

1.1. What are your main activities and responsibilities in implementing the PSNP/IN-SCT in this kebele?

1.2. What are the challenges you face in performing your role?

1.3. Do you feel that your roles (division of tasks and responsibilities) are clear? If, not why? Can you please provide some examples?

1.4. Do you feel overloaded in the roles you perform? If yes, could you please provide an example?

\section{Quality of implementation: co-responsibilities}

2.1. How are co-responsibilities being implemented in this kebele/woreda? Please, explain the process.

2.2. What role do you play in implementing the co-responsibilities?

2.3. What challenges are being encountered with respect to implementing the co-responsibilities?

2.4. What changes can you recommend to improve the implementation of co-responsibilities?

2.5. What is the process followed to monitor co-responsibilities in this kebele/woreda?

2.6. Who is responsible for monitoring the co-responsibilities?

2.7. What challenges have you encountered in monitoring co-responsibilities in this kebele/woreda?

2.8. What changes can you recommend to improve the monitoring of co-responsibilities?

2.9. Have you been personally involved with managing cases of SCT clients who are not complying with their co-responsibilities? If yes, what were the issues involved? Can you give us examples of actual cases?

2.10. Overall, do you think co-responsibilities in the PSNP Direct Support are a good idea? If yes, why? If not, why not?

3. Quality of implementation: TDS [pregnant women, lactating women, caregivers of malnourished children]

3.1. How is the transition into TDS being implemented in this kebele?

3.2. How well do you think the transition into TDS is being implemented in this kebele?

3.3. What challenges are being encountered with respect to implementing the transition into TDS?

3.4. What changes can you recommend to improve the implementation of the transition into TDS?

3.5. How is the transition into TDS being monitored in this kebele?

3.6. What role do you play in monitoring TDS, at kebele level?

3.7. What changes can you recommend to improve the monitoring of the transition into TDS in this kebele?

3.8. Overall, do you think TDS is a good addition to the PSNP? If yes, why? If not, why not?

\section{Quality of implementation: PW [ Public Works]}

4.1. How do you decide the type of PW (i.e. construction of roads, bridges, pipelines etc.) implemented in this kebele?

4.2. How do people in the community influence the type of PW implemented in this kebele?

4.3. Do you know about children being enrolled in PW in this kebele?

4.4. Do you know about children working for PW in this kebele? 


\section{Quality of implementation: Payments}

5.1. What is the process followed to delivery PSNP payments to beneficiaries?

5.2. Are PSNP payments delivered on time to beneficiaries? If no, why? Can you provide some examples?

5.3. What challenges are you encountering in the delivery of the payments?

5.4. What changes can you recommend to improve the implementation of delivery of payments?

\section{Grievance mechanisms}

6.1. How does the grievance mechanism for this PSNP work in this kebele? How can people make complaints and how are these complaints processed?

6.2. How well do you think the grievance mechanism is being implemented in this kebele?

6.3. Do you think that the grievance mechanism is helpful for including people's preferences or voices in the programme? If so, how? If not, why not?

\section{Community Care Coalitions (CCCs)}

7.1. Are CCCs established and functional in all kebeles in this in this kebele? And in this kebele? If not, why not?

7.2. What is the role of the CCCs? How do they operate?

7.3. Do you think that the CCCs help to represent people's preferences and voices? If so, how?

7.4. Overall, do you think the CCCs are a good idea? If yes, why? If not, why not?

\section{Quality of institutions and people's preferences}

8.1. How does the collaboration work between different PSNP service providers at kebele level? How do the main stakeholders interact with each other? (e.g. Health Office, Agriculture Office, Women and Children Affairs, Education Office, Administration Office? etc.)

8.2. What are the most important collaborations at kebele level for ensuring the PSNP/IN-SCT project functions well? (e.g. between the Woreda Health Office and the WoLSA Office, etc.)

8.3. Do you think these collaborations between the most important service providers are working well? Please explain.

8.4. What are the critical factors of success and failure in the functioning or capacity in the kebele/woreda? (For example, the adequacy of human and financial resources, the leadership, etc.)

8.5. How does the kebele/woreda ensure transparency and keep the society informed about its activities? (For example, by publishing annual reports to keep society informed, by holding press conferences, public awareness campaigns, posting information on the internet, etc.)

8.6. How does the kebele/woreda take into account people's voice and preferences? Can you please provide some examples?

8.7. How does the kebele/woreda take into account the pressure coming from citizens / political leaders?

8.8. Please, tell me how do people engage in the planning phase and budgeting process in the kebele/woreda? 


\title{
Appendix B.7 Interview guide for focus group discussion with community care coalitions - Ethiopia
}

\author{
Note: This interview guide is used for two type of kebeles/woredas: those ones where PSNP is implemented and those \\ ones where IN-SCT approach is integrated. Therefore, when the questions mention "PSNP/IN-SCT" we will need to \\ refer to "IN-SCT" only in the IN-SCT selected kebeles/woredas.

\section{Interviewee information} \\ - Date \\ - Respondent category \\ - Location [woreda and kebele] \\ - Name of interviewee(s) [male/ female, age, position in CCC, representative of which \\ organisation]
}

\section{Understanding CCC}

1.1. When was this CCC established? (month and year)

1.2. What is the CCC's role in the implementation of the PSNP4 and IN-SCT?

1.3. What kind of support do you provide to PSNP clients?

1.4. How do you decide who to support?

1.5. Do you also provide assistance to non-PSNP clients? If so, how?

1.6. How often do you meet? What kinds of issues do you usually discuss?

1.7. How much time do you spend on your activities as a CCC member per month (or quarter) on average?

1.8. Do you feel that you have enough time to undertake all your activities as CCC member? If not, why?

1.9. How important do you think that the CCC is in achieving positive change for PSNP clients (e.g. school enrolment, education outcomes, nutrition, health, birth registration)? Can you explain?

1.10. Can you provide an example of how the CCC has played a strong role in improving the situation of a PSNP client?

1.11. What are the challenges in performing your role? Please explain.

1.12. How could the role of the CCC in the implementation of the PSNP4 be improved? Please explain.

1.13. What do you think will be the role of the CCC in the future? Will it remain the same or change, and why?

1.14. Do you feel that your roles (division of tasks and responsibilities) are clear? If, not why? Can you please provide some examples?

1.15. Do you feel overloaded in the roles you perform? If yes, could you please provide an example?

\section{Quality of implementation: co-responsibilities}

2.1. What is your role in the implementation of co-responsibilities for PSNP?

2.2. How do you collaborate with the SWs on the implementation of co-responsibilities?

2.3. How do you collaborate with the HEWs on the implementation of co-responsibilities?

2.4. How do you collaborate with the DA on the implementation of co-responsibilities?

2.5. How well do you think the co-responsibilities are being implemented in this kebele?

2.6. What challenges are being encountered with respect to implementing co-responsibilities?

2.7. What changes can you recommend to improve the implementation of co-responsibilities?

2.8. What is the process followed to monitor co-responsibilities in this kebele?

2.9. What challenges have you encountered in monitoring co-responsibilities in this kebele/woreda?

2.10. What changes can you recommend to improve the monitoring of co-responsibilities?

2.11. Overall, do you think co-responsibilities in the PSNP4 and IN-SCT are a good idea? Why? 
3. Quality of implementation: TDS [pregnant women, lactating women, caregivers of malnourished children]

3.1. How is the transition into TDS being implemented in this kebele?

3.2. How well do you think the transition into TDS is being implemented in this kebele?

3.3. What challenges are being encountered with respect to implementing the transition into TDS?

3.4. What changes can you recommend to improve the implementation of the transition into TDS?

3.5. How is the transition into TDS being monitored in this kebele?

3.6. What role do you play in monitoring TDS, at kebele level?

3.7. What changes can you recommend to improve the monitoring of the transition into TDS in this kebele?

3.8. Overall, do you think TDS is a good addition to the PSNP? If yes, why? If not, why not?

\section{Quality of implementation: PW [Public Works]}

4.1. How do you decide the type of PW (i.e. construction of roads, bridges, pipelines etc.) implemented in this kebele?

4.2. How do people in the community influence the type of PW implemented in this kebele?

4.3. Do you know about children being enrolled in PW in this kebele?

4.4. Do you know about children working for PW in this kebele?

\section{Quality of implementation: Payments}

5.1. What is the process followed to delivery PSNP payments to beneficiaries?

5.2. Are PSNP payments delivered on time to beneficiaries? If no, why? Can you provide some examples?

5.3. What challenges are you encountering in the delivery of the payments?

5.4. What changes can you recommend to improve the implementation of delivery of payments?

\section{Quality of institutions and people's preferences}

6.1. How does the collaboration work between different PSNP service providers at kebele level? How do the main stakeholders interact with each other? (e.g. Health Office, Agriculture Office, Women and Children Affairs, Education Office, Administration Office? etc.)

6.2. What are the most important collaborations at kebele level for ensuring the PSNP/IN-SCT project functions well? (e.g. between the Woreda Health Office and the WoLSA Office, etc.)

6.3. Do you think these collaborations between the most important service providers are working well? Please explain.

6.4. What are the critical factors of success and failure in the functioning or capacity in the kebele/woreda? (For example, the adequacy of human and financial resources, the leadership, etc.)

6.5. How does the kebele/woreda ensure transparency and keep the society informed about its activities? (For example, by publishing annual reports to keep society informed, by holding press conferences, public awareness campaigns, posting information on the internet, etc.)

6.6. How does the kebele/woreda take into account people's voice and preferences? Can you please provide some examples?

6.7. How does the kebele/woreda take into account the pressure coming from citizens /political leaders?

6.8. Please, tell me how do people engage in the planning phase and budgeting process in the kebele/woreda? 


\section{Appendix B.8 Interview guide for focus group discussions with permanent direct support clients - Ethiopia}

\begin{tabular}{|c|c|c|c|c|c|}
\hline \multicolumn{6}{|c|}{$\begin{array}{l}\text { Note: This interview guide is used for two typ } \\
\text { ones where IN-SCT approach is integrated. Th } \\
\text { refer to "IN-SCT" only in the IN-SCT selected } \\
\text { Interviewee information } \\
\text { - Date } \\
\text { - Respondent category } \\
\text { - Location [woreda and kebele] }\end{array}$} \\
\hline Respondent & Name & Sex & Age & $\begin{array}{l}\text { Number } \\
\text { of } \\
\text { children }\end{array}$ & $\begin{array}{l}\text { How many years } \\
\text { are you on PSNP? }\end{array}$ \\
\hline \multicolumn{6}{|l|}{1} \\
\hline \multicolumn{6}{|l|}{2} \\
\hline \multicolumn{6}{|l|}{3} \\
\hline \multicolumn{6}{|l|}{4} \\
\hline \multicolumn{6}{|l|}{5} \\
\hline \multicolumn{6}{|l|}{6} \\
\hline \multicolumn{6}{|l|}{7} \\
\hline 8 & & & & & \\
\hline
\end{tabular}

1. Quality of implementation: co-responsibilities

1.1. Can you explain the co-responsibilities that are part of the IN-SCT/PSNP TDS support? What kind of co-responsibilities do you have to meet?

1.2. Have you been given a form explaining your co-responsibilities? How have you been informed about the co-responsibilities?

1.3. How are the co-responsibilities monitored? Who checks up on them?

1.4. Who is responsible for monitoring the co-responsibilities?

1.5. What challenges are encountered in monitoring co-responsibilities in this kebele/woreda?

1.6. What changes can you recommend to improve the monitoring of co-responsibilities?

1.7. What happens if you don't meet your co-responsibilities? [Probe for actual cases - what happened?]

1.8. Do you think co-responsibilities are a good thing? Why?

1.9. Are there any problems with the implementation of co-responsibilities? If so, what are they?

1.10. How can the implementation of co-responsibilities be improved?

2. Quality of implantation: Social services and CCC

2.1. What services and support do you receive from local Social Workers?

2.2. How has the support from Social Workers helped you?

2.3. Are there any challenges or problems with the support that you receive from Social Workers? If so, what are they?

2.4. How can the support from Social Workers be improved?

2.5. What services and support do you receive from Health Extension Workers?

2.6. How has the support from Health Extension Workers helped you?

2.7. Are there any challenges or problems with the support that you receive from Health Extension Workers? If so, what are they?

2.8. How can the support from Health Extension Workers be improved?

2.9. What services and support do you receive from Development Agents?

2.10. How has the support from Development Agents helped you?

2.11. Are there any challenges or problems with the support that you receive from Development Agents? If so, what are they?

2.12. How can the support from Development Agents be improved? 
2.13. What services and support do you receive from the Community Care Coalitions (CCC)?

2.14. How has the support from the CCC helped you?

2.15. Are there any challenges or problems with the support that you receive from the CCC? If so, what are they?

2.16. How can the support from the CCC be improved?

3. People's preferences: grievance mechanisms

3.1. Is it possible to make a complaint about PSNP or IN-SCT? If so, to whom?

3.2. Have any of you ever made a complaint about PSNP or IN-SCT? If so, what was the complaint?

3.3. What was the response? Do you think it was adequate?

3.4. How can the process for making complaints be improved?

4. Quality of implementation: PW [ Public Works]

4.1. How is it decided the type of PW (i.e. construction of roads, bridges, pipelines etc.) implemented in this kebele?

4.2. How do people in the community influence the type of PW implemented in this kebele?

4.3. Do you know about children being enrolled in PW in this kebele?

4.4. Do you know about children working for PW in this kebele?

5. Quality of implementation: payments

5.1. What is the process followed to delivery/collect PSNP payments to beneficiaries?

5.2. Are PSNP payments delivered on time to beneficiaries? If no, why? Can you provide some examples?

5.3. What challenges are you encountering in the delivery of the payments?

5.4. What changes can you recommend to improve the implementation of delivery of payments?

\section{Quality of institutions and people's preferences}

6.1. How does the collaboration work between different PSNP service providers at kebele level? How do the main stakeholders interact with each other? (e.g. Health Office, Agriculture Office, Women and Children Affairs, Education Office, Administration Office? etc.)

6.2. What are the most important collaborations at kebele level for ensuring the PSNP/IN-SCT project functions well? (e.g. between the Woreda Health Office and the WoLSA Office, etc.)

6.3. Do you think these collaborations between the most important service providers are working well? Please explain.

6.4. What are the critical factors of success and failure in the functioning or capacity in the kebele/woreda? (For example, the adequacy of human and financial resources, the leadership, etc.)

6.5. How does the kebele/woreda ensure transparency and keep the society informed about its activities? (For example, by publishing annual reports to keep society informed, by holding press conferences, public awareness campaigns, posting information on the internet, etc.) 


\section{Appendix B.9 Interview guide for focus group discussions with temporary direct support clients - Ethiopia}

Note: This interview guide is used for two type of kebeles/woredas: those ones where PSNP is implemented and those ones where IN-SCT approach is integrated. Therefore, when the questions mention "PSNP/IN-SCT" we will need to refer to "IN-SCT" only in the IN-SCT selected kebeles/woredas.

\section{Interviewee information}

- Date

- Respondent category

- Location [woreda and kebele]

$\begin{array}{llll}\text { Respondent Name } \quad \text { Sex } \quad \text { Age } & \begin{array}{l}\text { Number } \\ \text { of } \\ \text { children }\end{array} & \begin{array}{l}\text { How many years } \\ \text { are you on PSNP? }\end{array} \\ 1 & & & \\ 3 & & & \\ 4 & & \\ 5 & & \\ 6 & & \\ 7 & \end{array}$

1. Understanding TDS and transition from PW to TDS

1.1. Can you explain your transition into TDS? Who was involved in the process? What kind of information were you provided and by whom? How long did the process take?

1.2. How well do you think the transition into TDS is being implemented in this kebele?

1.3. What challenges are being encountered with respect to implementing the transition into TDS?

1.4. What changes can you recommend to improve the implementation of the transition into TDS?

1.5. Who is monitoring the process of transition from PW to TDS?

1.6. What changes can you suggest to improve the monitoring of the transition from PW to TDS?

1.7. Overall, do you think TDS is a good addition to the PSNP? If yes, why? If not, why not?

2. Quality of implementation: co-responsibilities

2.1. Can you explain the co-responsibilities that are part of the IN-SCT/PSNP TDS support? What kind of co-responsibilities do you have to meet?

2.2. Have you been given a form explaining your co-responsibilities? How have you been informed about the co-responsibilities?

2.3. How are the co-responsibilities monitored? Who checks up on them?

2.4. Who is responsible for monitoring the co-responsibilities?

2.5. What challenges are encountered in monitoring co-responsibilities in this kebele/woreda?

2.6. What changes can you recommend to improve the monitoring of co-responsibilities?

2.7. What happens if you don't meet your co-responsibilities? [Probe for actual cases - what happened?]

2.8. Do you think co-responsibilities are a good thing? Why?

2.9. Are there any problems with the implementation of co-responsibilities? If so, what are they?

2.10. How can the implementation of co-responsibilities be improved?

3. Quality of implantation: Social services and CCC

3.1. What services and support do you receive from local Social Workers?

3.2. How has the support from Social Workers helped you?

3.3. Are there any challenges or problems with the support that you receive from Social Workers? If so, what are they?

3.4. How can the support from Social Workers be improved?

3.5. What services and support do you receive from Health Extension Workers?

3.6. How has the support from Health Extension Workers helped you? 
3.7. Are there any challenges or problems with the support that you receive from Health Extension Workers? If so, what are they?

3.8. How can the support from Health Extension Workers be improved?

3.9. What services and support do you receive from Development Agents?

3.10. How has the support from Development Agents helped you?

3.11. Are there any challenges or problems with the support that you receive from Development Agents? If so, what are they?

3.12. How can the support from Development Agents be improved?

3.13. What services and support do you receive from the Community Care Coalitions (CCC)?

3.14. How has the support from the CCC helped you?

3.15. Are there any challenges or problems with the support that you receive from the CCC? If so, what are they?

3.16. How can the support from the CCC be improved?

4. People's preferences: grievance mechanisms

4.1. Is it possible to make a complaint about PSNP or IN-SCT? If so, to whom?

4.2. Have any of you ever made a complaint about PSNP or IN-SCT? If so, what was the complaint?

4.3. What was the response? Do you think it was adequate?

4.4. How can the process for making complaints be improved?

5. Quality of implementation: PW [ Public Works]

5.1. How is it decided the type of PW (i.e. construction of roads, bridges, pipelines etc.) implemented in this kebele?

5.2. How do people in the community influence the type of PW implemented in this kebele?

5.3. Do you know about children being enrolled in PW in this kebele?

5.4. Do you know about children working for PW in this kebele?

6. Quality of implementation: payments

6.1. What is the process followed to delivery/collect PSNP payments to beneficiaries?

6.2. Are PSNP payments delivered on time to beneficiaries? If no, why? Can you provide some examples?

6.3. What challenges are you encountering in the delivery of the payments?

6.4. What changes can you recommend to improve the implementation of delivery of payments?

7. Quality of institutions and people's preferences

7.1. How does the collaboration work between different PSNP service providers at kebele level? How do the main stakeholders interact with each other? (e.g. Health Office, Agriculture Office, Women and Children Affairs, Education Office, Administration Office? etc.)

7.2. What are the most important collaborations at kebele level for ensuring the PSNP/IN-SCT project functions well? (e.g. between the Woreda Health Office and the WoLSA Office, etc.)

7.3. Do you think these collaborations between the most important service providers are working well? Please explain.

7.4. What are the critical factors of success and failure in the functioning or capacity in the kebele/woreda? (For example, the adequacy of human and financial resources, the leadership, etc.)

7.5. How does the kebele/woreda ensure transparency and keep the society informed about its activities? (For example, by publishing annual reports to keep society informed, by holding press conferences, public awareness campaigns, posting information on the internet, etc.) 


\section{Appendix B.10 Interview guide for focus group discussions with PSNP Public Works clients - Ethiopia}

Note: This interview guide is used for two type of kebeles/woredas: those ones where PSNP is implemented and those ones where IN-SCT approach is integrated. Therefore, when the questions mention "PSNP/IN-SCT" we will need to refer to "IN-SCT" only in the IN-SCT selected kebeles/woredas.

\section{Interviewee information}

- Date

- Respondent category

- Location [woreda and kebele]

\begin{tabular}{|llll} 
Respondent $\quad$ Name & Sex $\quad$ Age $\begin{array}{l}\text { Number } \\
\text { of } \\
\text { children }\end{array}$ & $\begin{array}{l}\text { How many years } \\
\text { are you on PSNP? }\end{array}$ \\
1 & & & \\
2 & & & \\
3 & & & \\
4 & & \\
5 & & \\
6 & & \\
7 & & \\
8 & & \\
\end{tabular}

1. Quality of implementation: co-responsibilities/BCC sessions

1.1. When did you last attend a BCC activity? How often are they undertaken?

1.2. What happens during the BCC activities? What is discussed and who provides them?

1.3. What happens if you do not attend the BCC session? Can you provide an example of nonattendance and tell us what happened?

1.4. Do you think that participation in BCC activities is a good thing? If so, why?

1.5. What have you learned from participation in BCC activities?

1.6. Have you changed anything in your behaviour since participation in activities? If so, what? Why did you make those changes?

2. Quality of implementation: Social services and CCC

2.1. What services and support do you receive from local Social Workers?

2.2. How has the support from Social Workers helped you?

2.3. Are there any challenges or problems with the support that you receive from Social Workers? If so, what are they?

2.4. How can the support from Social Workers be improved?

2.5. What services and support do you receive from Health Extension Workers?

2.6. How has the support from Health Extension Workers helped you?

2.7. Are there any challenges or problems with the support that you receive from Health Extension Workers? If so, what are they?

2.8. How can the support from Health Extension Workers be improved?

2.9. What services and support do you receive from Development Agents?

2.10. How has the support from Development Agents helped you?

2.11. Are there any challenges or problems with the support that you receive from Development Agents? If so, what are they?

2.12. How can the support from Development Agents be improved?

2.13. What services and support do you receive from the Community Care Coalition (CCC)?

2.14. How has the support from the CCC helped you?

2.15. Are there any challenges or problems with the support that you receive from the CCC? If so, what are they?

2.16. How can the support from the CCC be improved? 


\section{People's preferences: grievance mechanisms}

3.1. Is it possible to make a complaint about PSNP or IN-SCT? If so, to whom?

3.2. Have any of you ever made a complaint about PSNP or IN-SCT? If so, what was the complaint?

3.3. What was the response? Do you think it was adequate?

3.4. How can the process for making complaints be improved?

\section{Quality if implementation: PW [ Public Works]}

4.1. How is it decided the type of PW (i.e. construction of roads, bridges, pipelines etc.) implemented in this kebele?

4.2. How do people in the community influence the type of PW implemented in this kebele?

4.3. Do you know about children being enrolled in PW in this kebele?

4.4. Do you know about children working for PW in this kebele?

\section{Quality of implementation: payments}

5.1. What is the process followed to delivery/collect PSNP payments to beneficiaries?

5.2. Are PSNP payments delivered on time to beneficiaries? If no, why? Can you provide some examples?

5.3. What challenges are you encountering in the delivery of the payments?

5.4. What changes can you recommend to improve the implementation of delivery of payment?

\section{Quality of institutions and people's preferences}

6.1. How does the collaboration work between different PSNP service providers at kebele level? How do the main stakeholders interact with each other? (e.g. Health Office, Agriculture Office, Women and Children Affairs, Education Office, Administration Office? etc.)

6.2. What are the most important collaborations at kebele level for ensuring the PSNP/IN-SCT project functions well? (e.g. between the Woreda Health Office and the WoLSA Office, etc.)

6.3. Do you think these collaborations between the most important service providers are working well? Please explain.

6.4. What are the critical factors of success and failure in the functioning or capacity in the kebele/woreda? (For example, the adequacy of human and financial resources, the leadership, etc.)

6.5. How does the kebele/woreda ensure transparency and keep the society informed about its activities? (For example, by publishing annual reports to keep society informed, by holding press conferences, public awareness campaigns, posting information on the internet, etc.) 


\section{Appendix B.11 Consent form to be signed before focus group discussions -}

\section{Ethiopia}

\section{Maastricht University}

Your consent in writing is needed to confirm your involvement in this research on "Institutional factors and people's preferences in social protection: the case of Ethiopia". Signing this form means that you have agreed to be a part of the research but does not stop you from changing your mind at a later time. You can withdraw from the research at any time and doing so will not affect your public or community standing. To withdraw from the research please contact the Principal Researcher at the address shown on the Information Sheet.

Your participation in the study will hence be strictly anonymous, the discussion will be audio recorded. The record will be immediately deleted after the data is transcribed. All data will be carefully and securely stored and only used for research purposes. No reports will link what you say to your name, department, or institution. In this way, we will maintain your confidentiality.

- I confirm that I have read and understand the information sheet for the above study.

- I understand that my participation is voluntary and that I am free to withdraw at any time, without giving reason.

- I agree to take part in the above study.

- I agree to the focus group discussion being audio recorded

- I agree to the use of anonymised quotes in publications

Signature:

Date:

Name (print):

Finger print (optional)

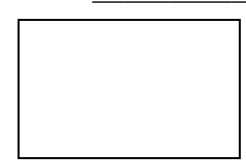




\section{Appendix B.12 Debriefing form for participation in the research study - Ethiopia}

\section{Maastricht University}

Thank you for your participation in our study! Your participation is greatly appreciated.

The purpose of this study is to explore to what extent social protection programmes in Ethiopia have been influenced by factors related to the quality of the institutions and by the people's preferences for social protection programmes. The purpose of this study is therefore to 1) to examine capacity issues and challenges faced by the institutions at central and local level in the planning, budgeting process and implementation of selected social protection interventions; 2) to explore how people's preferences expressed towards government's decisions on social protection interventions influence the quality of social protection programmes.

You may decide that you do not want your data used in this research. If you would like your data removed from the study and permanently deleted, please contact the moderator.

If you would like to receive a copy of the final report of this study (or a summary of the findings) when it is completed, please feel free to contact us.

If you have any questions or concerns regarding this study, its purpose or procedures, or if you have a research-related problem, please feel free to contact the researchers,

Vincenzo Vinci, Executive Researcher

Maastricht Graduate School of Governance, Maastricht University

Boschstraat 24 | 6211 AX Maastricht | The Netherlands

v.vinci@student.maastrichtuniversity.nl. | Cell phone Ethiopia: +251909541805

If you would like to learn more about "Institutional factors, people's preferences in social protection" please see the following references:

2016, Gassmann, Franziska, Pierre Mohnen, and Vincenzo Vinci. "Institutional factors and people's preferences in social protection.".

*** Please keep a copy of this form for your future reference. Once again, thank you for your participation in this study! *** 


\section{Appendix B.13 Timeframe of the interviews - Ethiopia}

\begin{tabular}{|c|c|c|c|c|}
\hline Date & Place & $\begin{array}{l}\text { Interview } \\
\text { methodology }\end{array}$ & Gender & Respondent/Ward \\
\hline 23-Apr-17 & Warja Washgula & FGDs and KII & - & Adami Tulu \\
\hline 24-Apr-17 & Kebele 2 (IN-SCT) & $\mathrm{KII}(\mathrm{DA})$ & $\mathrm{F}$ & Adami Tulu (1) \\
\hline 24-Apr-17 & Kebele 2 (IN-SCT) & KII (HEW) & $\mathrm{F}$ & Adami Tulu (1) \\
\hline 25-Apr-17 & Kebele 2 (IN-SCT) & KII (KM) & M & Adami Tulu (1) \\
\hline 26-Apr-17 & Kebele 2 (IN-SCT) & KII (SW) & M & Adami Tulu (1) \\
\hline 24-Apr-17 & Kebele 2 (IN-SCT) & FGD (CCC) & $5 \mathrm{M}$ & Adami Tulu (5) \\
\hline 24-Apr-17 & Kebele 2 (IN-SCT) & FGD (FPW) & $10 \mathrm{~F}$ & Adami Tulu (10) \\
\hline 24-Apr-17 & Kebele 2 (IN-SCT) & FGD (MPW) & $10 \mathrm{M}$ & Adami Tulu (10) \\
\hline 24-Apr-17 & Kebele 2 (IN-SCT) & FGD (PDS) & $10 \mathrm{~F}$ & Adami Tulu (10) \\
\hline 24-Apr-17 & Kebele 2 (IN-SCT) & FGD (TDS) & $8 \mathrm{~F}$ & Adami Tulu (8) \\
\hline 26-Apr-17 & - & KII (WFSTF) & $2 \mathrm{M}$ & Adami Tulu (2) \\
\hline 25-Apr-17 & Kebele 1 (IN-SCT) & $\mathrm{KII}(\mathrm{DA})$ & M & Adami Tulu (1) \\
\hline 26-Apr-17 & Kebele 1 (IN-SCT) & KII (HEW) & $\mathrm{F}$ & Adami Tulu (1) \\
\hline 29-Apr-17 & Kebele 1 (IN-SCT) & $\mathrm{KII}(\mathrm{KM})$ & M & Adami Tulu (1) \\
\hline 26-Apr-17 & Kebele 1 (IN-SCT) & KII (SW) & M & Adami Tulu (1) \\
\hline 25-Apr-17 & Kebele 1 (IN-SCT) & FGD (CCC) & $5 \mathrm{M}, 1 \mathrm{~F}$ & Adami Tulu (6) \\
\hline 25-Apr-17 & Kebele 1 (IN-SCT) & FGD (FPW) & $7 \mathrm{~F}$ & Adami Tulu (7) \\
\hline 25-Apr-17 & Kebele 1 (IN-SCT) & FGD (MPW) & $9 \mathrm{M}$ & Adami Tulu (9) \\
\hline 25-Apr-17 & Kebele 1 (IN-SCT) & FGD (PDS) & $8 \mathrm{~F}$ & Adami Tulu (8) \\
\hline 25-Apr-17 & Kebele 1 (IN-SCT) & FGD (TDS) & $7 \mathrm{~F}$ & Adami Tulu (7) \\
\hline 27-Apr-17 & Kebele 1 (PSNP) & KII (DA) & M & Arsi Negele (1) \\
\hline 27-Apr-17 & Kebele 1 (PSNP) & KII (HEW) & $\mathrm{F}$ & Arsi Negele (1) \\
\hline 28-Apr-17 & Kebele 1 (PSNP) & $\mathrm{KII}(\mathrm{KM})$ & M & Arsi Negele (1) \\
\hline 28-Apr-17 & Kebele 1 (PSNP) & FGD (KFSTF) & $2 \mathrm{M}, 1 \mathrm{~F}$ & Arsi Negele (3) \\
\hline 27-Apr-17 & Kebele 1 (PSNP) & FGD (FPW) & $10 \mathrm{~F}$ & Arsi Negele (10) \\
\hline 27-Apr-17 & Kebele 1 (PSNP) & FGD (MPW) & $8 \mathrm{M}$ & Arsi Negele (8) \\
\hline 27-Apr-17 & Kebele 1 (PSNP) & FGD (PDS) & $12 \mathrm{~F}$ & Arsi Negele (12) \\
\hline 27-Apr-17 & Kebele 1 (PSNP) & FGD (TDS) & $10 \mathrm{~F}$ & Arsi Negele (10) \\
\hline 29-Apr-17 & - & KII (WFSTF) & $2 \mathrm{M}$ & Arsi Negele (2) \\
\hline 28-Apr-17 & Kebele 2 (PSNP) & $\mathrm{KII}(\mathrm{DA})$ & $1 \mathrm{M}$ & Arsi Negele (1) \\
\hline 29-Apr-17 & Kebele 2 (PSNP) & KII (HEW) & $1 \mathrm{~F}$ & Arsi Negele (1) \\
\hline 26-Apr-17 & Kebele 2 (PSNP) & $\mathrm{KII}(\mathrm{KM})$ & $1 \mathrm{M}$ & Arsi Negele (1) \\
\hline 29-Apr-17 & Kebele 2 (PSNP) & $\mathrm{KII}(\mathrm{SW})$ & $1 \mathrm{M}, 1 \mathrm{~F}$ & Arsi Negele (2) \\
\hline 28-Apr-17 & Kebele 2 (PSNP) & FGD (KFSTF) & $1 \mathrm{M}, 1 \mathrm{~F}$ & Arsi Negele (1) \\
\hline 28-Apr-17 & Kebele 2 (PSNP) & FGD (FPW) & $11 \mathrm{~F}$ & Arsi Negele (11) \\
\hline 28-Apr-17 & Kebele 2 (PSNP) & FGD (MPW) & $9 \mathrm{M}$ & Arsi Negele (9) \\
\hline 28-Apr-17 & Kebele 2 (PSNP) & FGD (PDS) & $8 \mathrm{~F}$ & Arsi Negele (8) \\
\hline 28-Apr-17 & Kebele 2 (PSNP) & FGD (TDS) & $12 \mathrm{~F}$ & Arsi Negele (12) \\
\hline
\end{tabular}




\section{Curriculum Vitae}

Vincenzo was born on 15 February 1980 in Sant Agata Militello, Italy. Prior to university (1999-2003), he earned a high school diploma from Lice Scientifico Enrico Fermi (Sant Agata Militello, Italy). He holds bachelor in Economics and Management of Public Administration and International Institutions and a Master in Economics from Bocconi University, Italy. During his bachelor, Vincenzo attended a campus abroad in Havana, Cuba and he conducted an internship as analyst at the European Commission in Bruxelles, at Health \& Consumer Protection directorate.

He decided to engage in humanitarian and development work. Since 2004 he has been serving for UNICEF in emergency and development contexts in the areas of social policy, programme planning, monitoring and evaluation in regional and county offices in Indonesia, Angola, Kenya, Mali, Central Africa Republic, Malawi, Nepal. Parallel to his work, he committed to the dual career training programme to obtain a $\mathrm{PhD}$ in Governance and Policy Analysis (GPAC2) at the Maastricht Graduate School of Governance. Vincenzo is currently Social Policy Specialist at UNICEF Ethiopia. He is married to Roselyn and they have two children. 


\section{UNU-MERIT/MGSoG Dissertation Series}

2018

\section{Silke Heuser}

The Effectiveness of Environmental

Policies on Reducing Deforestation in the Brazilian Amazon

UNU-MERIT/MGSoG Dissertation Series № 212

\section{Jennifer Waidler}

Social Assistance and Remittances and Their Role in the Fight Against

Poverty

UNU-MERIT/MGSoG Dissertation Series № 211

\section{Choolwe Muzyamba}

The role of community mobilization in the promotion of maternal health of women living with HIV in Zambia UNU-MERIT/MGSoG Dissertation Series № 210

\section{Juan Carlos A. Castillo Sánchez}

Assessing the Role of the Export Sector in Mexican Economic

Development,1965-2014

UNU-MERIT/MGSoG Dissertation Series № 209

\section{Tareq Abuelhaj}

Food Security Policy Impact Analysis:

The Econometrics of Cash and Food Assistance Cost Effectiveness UNU-MERIT/MGSoG Dissertation Series № 208

\section{Marta Férnandez de Arroyabe}

Arranz

Essays on MEAS and Innovation

UNU-MERIT/MGSoG Dissertation

Series № 207

\section{Clotilde Mahé}

Essays on Migration and Occupational Choice

UNU-MERIT/MGSoG Dissertation Series № 206

\section{Simone Sasso}

Talent on the move. Essays on Human Capital, Graduate Mobility and Economic Development

UNU-MERIT/MGSoG Dissertation Series № 205

\section{Khaled Walid Rajab}

Strategic Planning under Fragility UNU-MERIT/MGSoG Dissertation Series № 204

\section{Mutinta Hambayi Nseluke}

A Tall Order: Improving Child Linear Growth

UNU-MERIT/MGSoG Dissertation Series № 203

\section{Elvis Korku Avenyo}

Innovations and Firm Performance in sub-Saharan Africa: Empirical Analyses UNU-MERIT/MGSoG Dissertation Series № 202 


\section{Ni Zhen}

Employment Dynamics, Firm

Performance and Innovation

Persistence in the Context of

Differentiated Innovation Types:

Evidence from Luxembourg

UNU-MERIT/MGSoG Dissertation

Series № 201

\section{Caroline Wehner}

Too Scared to Achieve: The Relation

Between Neuroticism,

Conscientiousness

and Socioeconomic Outcomes

UNU-MERIT/MGSoG Dissertation

Series № 200

\section{Stefania Innocenti}

On Institutional Persistence

UNU-MERIT/MGSoG Dissertation

Series № 199

\section{Hassen Abda Wako}

Economic Globalization, Institutions

and Development: Essays on Aid,

Foreign Direct Investment and Trade

UNU-MERIT/MGSoG Dissertation

Series № 198

2017

\section{Hans-Erik Edsand}

Winds of Change

UNU-MERIT/MGSoG Dissertation

Series № 197

\section{Ana Patricia Silva Vara}

Redressing the Gender Gap

UNU-MERIT/MGSoG Dissertation

Series № 196

\section{Andrés Iván Mideros Mora}

Essays on the Economic Effects of Noncontributory Social Protection

UNU-MERIT/MGSoG Dissertation

Series № 195

\section{Tobias Broich}

New Actors in the Global Economy

UNU-MERIT/MGSoG Dissertation

Series № 194

\section{Bernard Nikaj}

From No-government to E-government UNU-MERIT/MGSoG Dissertation

Series № 193

\section{Ali Safarnejad}

Prioritizing the HIV Response

UNU-MERIT/MGSoG Dissertation

Series № 192

\section{Clovis Freire}

Diversification and Structural

Economic Dynamics

UNU-MERIT/MGSoG Dissertation

Series № 191

\section{Michael Verba}

Innovation and Knowledge Dynamics:

Essays on the Knowledge Economy

UNU-MERIT/MGSoG Dissertation

Series № 190

\section{Pui Hang Wong}

The Hearts and Minds in Conflict and Peace: The Economics of

Counterinsurgency and the Psychology of Reconstruction

UNU-MERIT/MGSoG Dissertation

Series № 189 


\section{Brenda Yamba}

Schooling Despite All Odds: Evidence from Lesotho on Female Child Carers who Stayed in School

UNU-MERIT/MGSoG Dissertation Series № 188

\section{Sheng Zhong}

Moving towards An Energy Efficient

Future: Essays on Energy Efficiency,

Technology and Development

UNU-MERIT/MGSoG Dissertation

Series № 187

\section{Julieta Marotta}

Access to Justice and Legal

Empowerment of Victims of Domestic

Violence through Legal Organizations

in the City of Buenos Aires: A

Qualitative Empirical Legal Study

UNU-MERIT/MGSoG Dissertation

Series, № 186

\section{Andrea Franco-Correa}

On the Measurement of

Multidimensional Poverty as a Policy

Tool: Empirical Applications to Chile,

Colombia, Ecuador and Peru

UNU-MERIT/MGSoG Dissertation

Series, № 185

2016

\section{Yesuf Awel}

Insurance for Growth: Empirical

Essays on Insurance Demand and

Impacts in Africa

UNU-MERIT Dissertation Series, № 108

\section{Tigist Mekonnen Melesse}

Grow More Food using Fewer

Resources: Agricultural Technology

Adoption and Innovation Practices for

Inclusive and Sustainable

Development

UNU-MERIT Dissertation Series,

№ 107

\section{Eleni Yitbarek}

Getting Ahead or left Behind? Essays

on Poverty Dynamics and Social

Mobility in Africa

UNU-MERIT Dissertation Series,

№ 106

\section{Thuy Dieu Nguyen}

Firm-Level Theory and Evidence of

Corruption

UNU-MERIT Dissertation Series, № 105

\section{Raquel Tsukada Lehman}

Essays on Household Production with

Labor-Saving Technology

UNU-MERIT Dissertation Series, № 104

\section{Eva Barteková}

Multi-Problem Challenges for a Renewable Future: Empirical Studies on Competitive Disadvantages from Electricity Price Differentials and Mineral Supply Risk in an Open

Economy

UNU-MERIT Dissertation Series, № 103 


\section{Jocelyn Olivari}

Entrepreneurial Traits and Innovation:

Evidence from Chile

UNU-MERIT Dissertation Series, № 102

\section{Muhammad Shafique}

Essays on the role of knowledge, RED, and Technology-based Firms in the Evolution of Socio-techno-economic System

UNU-MERIT Dissertation Series, № 101

\section{Serdar Türkeli}

Governance of Innovation Policy:

Empirical Studies on Applied Political Economy by Multi-Methods Analysis UNU-MERIT Dissertation Series, № 100

\section{Ayokunu Adedokun}

Pathways to Sustainable Peace building in Divided Societies: Lessons and Experiences from Mozambique MGSoG Dissertation Series, № 75

\section{Luiz Rothier Bautzer}

Organizing Concurrent Engineering through ICT Platforms Blueprinting Product Lifecycle Management Platforms across Disciplinary Agencies MGSoG Dissertation Series, № 74

\section{Natalia Popova}

Migration in the Periphery of the

European Union:

Determinants of Successful and

Sustainable Labour Market Integration of Return Migrants in Albania, Egypt, Moldova and Tunisia

MGSoG Dissertations Series, № 73

\section{Richard A. Martina}

Uncertainty and Resource Constraint in the Small Island Developing States: Essays in Entrepreneurial Cognition MGSoG Dissertations Series, № 72

\section{Cécile Cherrier}

The Expansion of Basic Social Protection in Low-income Countries: An Analysis of Foreign Aid Actors' Role in the Emergence of Social Transfers in Sub-Saharan Africa MGSoG Dissertations series, № 71

\section{Paul Caldron}

The Tacit Bargain in Short-Term Medical Missions: Why U.S. physicians go and what it costs MGSoG Dissertation Series, № 70

\section{Mahmut Kobal}

Customs \& Excellence: A Comparative Approach on Administrative and Regulatory Compliance Perspectives of the EU-Turkey Customs Union MGSoG Dissertation Series, № 69

\section{Craig Loschmann}

Essays on Conflict-related Migration and Development in the Case of Afghanistan MGSoG Dissertations Series, № 68 


\section{Andrea Milan}

Rural Livelihoods, Location and

Vulnerable Environments: Approaches to Migration in Mountain areas of

Latin America

MGSoG Dissertation Series, № 67

\section{Farida Lada}

On Guarding the Welfare of Clinical

Trial Subjects While Promoting Novel

Drug Innovation

A Game Theoretical Approach

MGSoG Dissertation Series, № 66

\section{5}

\section{Hibret Belete Maemir}

Dissecting Aggregate Productivity:

International Integration and Growth

with Heterogeneous Firms

UNU-MERIT Dissertation Series, № 96

\section{Giorgio Triulzi}

Looking for the Right Path: Technology

Dynamics, Inventive Strategies and

Catching-up in the Semiconductor

Industry

UNU-MERIT Dissertation Series, № 95

\section{Abdul Baseer Qazi}

Knowledge flows and networks in the

ICT sector: The case of Pakistan

UNU-MERIT Dissertation Series, № 94

\section{Ajay Thutupalli}

Technology Paradigm Shifts in

Agriculture: Drivers of Sustainability and Catch up

UNU-MERIT Dissertation Series, № 93

\section{Eduardo Urias}

Improving access to HIVIAIDS

treatment in Brazil: When are

Compulsory Licenses effective in Price

Negotiations?

UNU-MERIT Dissertation Series, № 92

\section{Francesca Guadagno}

Why have so few Countries

Industrialised?

UNU-MERIT Dissertation Series, № 91

\section{Daniel Opolot}

The Evolution of Beliefs and Strategic Behaviour

UNU-MERIT Dissertation Series, № 90

\section{Alejandro Lavopa}

Structural Transformation and

Economic Development: Can

Development Traps be Avoided

UNU-MERIT Dissertation Series, № 89

\section{Jinjin Zhao}

Urban water management reform: The Case of China

UNU-MERIT Dissertation Series, № 88 


\section{Simona Vezzoli}

Borders, Independence and Postcolonial Ties: the Role of the State in Caribbean Migration

MGSoG Dissertation Series, № 65

\section{Silvia Consuelo Gómez Soler}

Civil Conflict and Education: How

Does Exposure to Civil Conflict Affect

Human Capital Accumulation?

Evidence from Standardized Exit

Exams in Colombia

MGSoG Dissertation Series, № 64

\section{Paula Nagler}

Occupational Choice in the Developing

World

MGSoG Dissertation Series, № 63

\section{Jasmin Kientzel}

Determinants of Professional

Commitment to Environmental

Sustainability

MGSoG Dissertation Series, № 62

\section{Mehmet Güney Celbiş}

Regional Policies: Convergence, Trade, and the Allocation of Public Capital MGSoG Dissertation Series, № 61

\section{Florian Henning}

Living Up to Standard:

Interoperability Governance and

Standards Adoption in Government

Information Networks

MGSoG Dissertation Series, № 60

\section{Niels P. Groen}

The Never-Ending Project

Understanding E-Government Project

Escalation

MGSoG Dissertation Series, № 59

\section{Derek Copp}

Teacher-Based Reactivity to Provincial

Large-scale Assessment in Canada

MGSoG Dissertation Series, № 58

\section{Michaella Vanore}

Family-Member Migration and the

Psychosocial Health Outcomes of

Children in Moldova and Georgia

MGSoG Dissertation Series, № 57

\section{Sonja Fransen}

The Economic and Social Effects of

Remittances and Return Migration in

Conflict-Affected Areas: The Case of

Burundi

MGSoG Dissertation Series, № 56

\section{Ibrahim Khalil Conteh}

The Impact of Floods on Primary

School Education in Zambia

MGSoG Dissertation Series, № 55

\section{Richard Bluhm}

Growth Dynamics and Development

Essays in Applied Econometrics and

Political Economy

MGSoG Dissertation Series, № 54

\section{Nevena P. Zhelyazkova}

Work-Family Reconciliation and Use of Parental Leave in Luxembourg:

Empirical Analysis of Administrative Records

MGSoG Dissertation Series, № 53 
2014

\section{Dirk Crass}

The Impact of Brands on Innovation and Firm Performance: Empirical

Evidence from Germany

UNU-MERIT Dissertation Series, № 87

\section{Samyukta Bhupatiraju}

The Geographic Dimensions of Growth and Development

UNU-MERIT Dissertation Series, № 86

\section{François Lafond}

TheEvolution of Knowledge Systems UNU-MERIT Dissertation Series, № 85

\section{Annalisa Primi}

Promoting Innovation in Latin

America: What Countries Have

Learned (and What They Have Not) in

Designing and Implementing

Innovation and Intellectual Property

Policies

UNU-MERIT Dissertation Series, № 84

\section{Fatoumata Lamarana Diallo}

Evaluation of Meal and Deworming Programs for Primary Schools in Rural Senegal

UNU-MERIT Dissertation Series, № 83

\section{Sachin Kumar Badkas}

Metachoice and Metadata: Innovating with Environmental Policy Analysis in Europe

MGSoG Dissertation Series, № 52

\section{Irina S. Burlacu}

An Evaluation of Tax-Benefit Systems Impact on the Welfare of Frontier

Worker:

The Case of Luxembourg and Belgium MGSoG Dissertation Series, № 51

\section{Özge Bilgili}

Simultaneity in Transnational Migration Research: Links Between Migrants' Host and Home Country Orientation

MGSoG Dissertation Series, № 50

\section{Yulia Privalova Krieger}

Reshaping the Big Agenda:

Transnational Politics and Domestic ResistanceFinancial crisis and social protection reform in Bosnia and Herzegovina MGSoG Dissertation Series, № 49

\section{Marieke van Houte}

Moving Back or Moving Forward?

Return migration after Conflict

MGSoG Dissertation Series, № 48

\section{Oxana Slobozhan}

Global Governance in the Management of Natural Resources: The Case of the Extractive Industries Transparency Initiative (EITI)

MGSoG Dissertation Series, № 47 


\section{Luis Bernardo Mejia Guinand}

The Changing Role of the Central

Planning Offices in Latin America: A

Comparative Historical Analysis

Perspective (1950-2013)

MGSoG Dissertation Series, № 46

\section{Cheng Boon Ong}

Ethnic Segregation in Housing,

Schools and Neighbourhoods in the

Netherlands

MGSoG Dissertation Series, № 45

\section{Luciana V. Cingolani}

Bureaucracies for Development:

Oxymoron or Reality? Studies on State

Capacity in Challenging Governance

Contexts

MGSoG Dissertation Series, № 44

\section{Carlos Cadena Gaitán}

Green Politics in Latin American

Cities - Sustainable Transport Agendas

MGSoG Dissertation Series, № 43

\section{Katie Kuschminder}

Female Return Migration and

Reintegration Strategies in Ethiopia

MGSoG Dissertation Series, № 42

\section{Metka Hercog}

Highly-Skilled Migration and New

Destination Countries

MGSoG Dissertation Series, № 41

\section{Margaret Agaba Rugadya}

Can Remittances Influence the Tenure and Quality of Housing in Uganda? MGSoG Dissertation Series, № 40

\section{Ilire Agimi}

New Governance Under Limited

Statehood: The Case of Local

Government Reform in Kosovo

MGSoG Dissertation Series, № 39

\section{3}

\section{Anant Kamath}

Information Sharing through Informal Interaction in Low-Tech Clusters

UNU-MERIT Dissertation Series, № 82

\section{Flavia Pereira de Carvalho}

What we talk about when we talk about Brazilian Multinationals: An Investigation on Brazilian FDI, Economic Structure, Innovation and the Relationship between them UNU-MERIT Dissertation Series, № 81

\section{Jun Hou}

Complementarity in Innovation and Development: A Cross-country

Comparison

UNU-MERIT Dissertation Series, № 80

\section{Rufin Baghana}

Impacts of Government Incentives to $R \mathcal{E D}$, Innovation and Productivity: A Microeconometric Analysis of the Québec Case UNU-MERIT Dissertation Series, № 79 


\section{Lilia I. Stubrin}

High-Tech Activities in Emerging

Countries: A Network perspective on

the Argentinean Biotech Activity

UNU-MERIT/MGSoG Dissertation

Series, № 78

\section{Kristine Farla}

Empirical Studies on Institutions,

Policies and Economic Development

MGSoG Dissertation Series, № 38

\section{Marina Petrovic}

Social Assistance and Activation in the

Pursuit of Happiness: Shedding New

Light on Old Policy Solutions to Social

Exclusion

MGSoG Dissertation Series, № 37

\section{Laura Torvinen}

Assessing Governance Assessments:

The Case of Mozambique: Governance

Assessments in the Context of Aid

Effectiveness Discourse

MGSoG Dissertation Series, № 36

\section{Biniam Egu Bedasso}

Institutional Change in the Long

Shadow of Elite: Essays on

Institutions, Human Capital and

Ethnicity in Developing Countries

MGSoG Dissertation Series, № 35

\section{Sepideh Yousefzadeh Faal}

\section{Deghati}

Childhoods Embargoed: Constructing

and Reconstructing Multidimensional

Child Poverty in Iran 1984-2009

MGSoG Dissertation Series, № 34

\section{Robert Bauchmüller}

Investing in Early Childhood Care and

Education: The Impact of Quality on

Inequality

MGSoG Dissertation Series, № 33

\section{Martin Rehm}

Unified Yet Separated: Empirical

Study on the Impact of Hierarchical

Positions within Communities of

Learning

MGSoG Dissertation Series, № 32

2012

\author{
Abdul Waheed \\ Innovation Determinants and \\ Innovation as a Determinant: Evidence \\ from Developing Countries \\ UNU-MERIT Dissertation Series, \\ № 77
}

\section{Bilal Mirza}

Energy Poverty and Rural Energy

Markets in Pakistan

UNU-MERIT Dissertation Series, № 76

\section{Benjamin Engelstätter}

Enterprise Software and Video Games:

An Empirical Analysis

UNU-MERIT Dissertation Series, № 75

\section{Fulvia Farinelli}

Natural Resources, Innovation and Export Growth: The Wine Industry in Chili and Argentina

UNU-MERIT Dissertation Series 


\section{Rodolfo Lauterbach}

Innovation in Manufacturing: From

Product Variety and Labor

Productivity Growth to Economic

Development in Chile

UNU-MERIT Dissertation Series

\section{Kirsten Wiebe}

Quantitative Assessment of

Sustainable Development and Growth

in Sub-Saharan Africa

UNU-MERIT Dissertation Series, № 74

\section{Julio Miguel Rosa}

Organizational Strategies, Firms'

Performance and Spatial Spillovers:

The Canadian Case in Research and

Development.

UNU-MERIT Dissertation Series,

№ 73

Johannes Wilhelmus Marie Boels

Joseph Schumpeter, Honderd Jaar

Economische Ontwikkeling: Een

Historisch-theoretische Beschouwing.

UNU-MERIT Dissertation Series

\section{Dorcas Mbuvi}

Utility Reforms and Performance of the

Urban Water Sector in Africa

MGSoG Dissertation Series, № 31

\section{Lina Salanauskaite}

Distributional Impacts of Public

Policies: Essays in Ex-Ante and Ex-

Post Evaluation

MGSoG Dissertation Series, № 30

\section{Esther Schüring}

To Condition or not - is that the

Question?

An Analysis of the Effectiveness of Ex-

Ante and Ex-Post Conditionality in

Social Cash Transfer Programs

MGSoG Dissertation Series, № 29

\section{Joe Abah}

Strong Organisations in Weak States: Atypical Public Sector Performance in Dysfunctional Environments

MGSoG Dissertation Series, № 28

\section{Zina Samih Nimeh}

Social Citizenship Rights: Inequality and Exclusion

MGSoG Dissertation Series, № 27

2011

\section{Daniel Vertesy}

Interrupted Innovation: Emerging

Economies in the Structure of the

Global Aerospace Industry

UNU-MERIT Dissertation Series,

№ 72

\section{Tina Saebi}

Successfully Managing Alliance

Portfolios: AnAlliance Capability View

UNU-MERIT Dissertation Series, № 71

\section{Nora Engel}

Tuberculosis in India: A Case of

Innovation and Control

UNU-MERIT/MGSoG Dissertation

Series, № 70 


\section{Evans Mupela}

Connectivity and growth in Sub-

Saharan Africa: The Role of

Communication Satellites

UNU-MERIT Dissertation Series, № 69

\section{Nantawan Kwanjai}

Cross Cultural Intelligence amid

Intricate Cultural Webs: A Tale of the

UnDutchables in the Land of 1002

Smiles

UNU-MERIT Dissertation Series, № 68

\section{Lina Sonne}

Innovation in Finance to Finance

Innovation: Supporting Pro-poor

Entrepreneur-based Innovation

UNU-MERIT Dissertation Series, № 67

\section{Lenka Eisenhamerová}

Legitimacy of 'Humanitarian Military

Intervention'

MGSoG Dissertation Series, № 26

\section{Sonila Tomini}

Informal Payments for Health Care

Services in Albania

MGSoG Dissertation Series, № 25

\section{Jinjing Li}

Dynamic Microsimulation in Public

Policy Evaluation

MGSoG Dissertation Series, № 24

\section{Aziz Atamanov}

Rural Nonfarm Employment and

International Migration as

Alternatives to Agricultural

Employment: The Case of Kyrgyzstan

MGSoG Dissertation Series, № 23

\section{Frieda Vandeninden}

Poverty Alleviation: Aid and Social

Pensions

MGSoG Dissertation Series, № 22

\section{Juliana Nyasha Tirivayi}

The Welfare Effects of Integrating

AIDS Treatment with Food Transfers:

Evidence from Zambia

MGSoG Dissertation Series, № 21

\section{Agnieska Ewa Sowa}

Who's Left Behind? Social Dimensions of Health Transition and Utilization of Medical Care in Poland

MGSoG Dissertation Series, № 20

\section{Emmanaouil Sfakianakis}

The Role of Private Actors in the

Provision of Public Goods with

Applications to Infrastructure and

Financial Stability

MGSoG Dissertation Series, № 19

\section{Siu Hing Lo}

White Collars Green Sleeves: An Interorganizational Comparison of Determinants of Energy-Related Behaviors among Office Workers MGSoG Dissertation Series, № 18 


\section{Treena Wu}

Constraints to Human Capital

Investment in Developing Countries:

Using the Asian Financial Crisis in

Indonesia as a Natural Experiment

MGSoG Dissertation Series, № 17

\section{Henry Espinoza Peña}

Impact Evaluation of a Job-Training

Programme for Disadvantaged Youths:

The Case of Projoven

MGSoG Dissertation Series, № 16

2010

Fernando Santiago

Human Resources Management

Practices and Learning for Innovation

in Developing Countries:

Pharmaceutical Firms in Mexico

UNU-MERIT Dissertation Series,

№ 66

\section{Zakaria Babutsidze}

Essays on Economies with

Heterogeneous Interacting Consumers

UNU-MERIT Dissertation Series,

№ 65

\section{Bertha Vallejo}

Learning and Innovation Under

Changing Market Conditions: The

Auto Parts Industry in Mexico

UNU-MERIT Dissertation Series, № 64
Donatus Ayitey

Technical Change, Competitiveness

and Poverty Reduction: A Study of the

Ghanaian Apparel Industry

UNU-MERIT Dissertation Series, № 63

\section{Sergey Filippov}

Multinational Subsidiary Evolution:

Corporate Change in New EU Member

States

UNU-MERIT Dissertation Series,

№ 62

\section{Asel Doranova}

Technology Transfer and Learning under the Kyoto Regime: Exploring the Technological Impact of CDM Projects in Developing Countries

UNU-MERIT Dissertation Series, № 61

\section{Florian Tomini}

Between Family and Friend:

Understanding the Interdependency of Private Transfers

MGSoG Dissertation Series, № 15

\section{Michał Polalowski}

The Institutional Transformation of Social Policy in East Central Europe: Poland and Hungary in Comparative and Historical Perspective MGSoG Dissertation Series, № 14

\section{Maha Ahmed}

Defining, Measuring and Addressing

Vulnerability: The Case of Post

Conflict Environments

MGSoG Dissertation Series, № 13 


\section{Pascal Beckers}

Local Space and Economic Success:

The Role of Spatial Segregation of

Migrants in the Netherlands

MGSoG Dissertation Series, № 12

\section{Victor Cebotari}

Conflicting Demands in Ethnically

Diverse Societies: Ethno political

Contention and Identity Values in

Europe

MGSoG Dissertation Series, № 11

\section{Dennis Gyllensporre}

Competing and Complementary

Perspectives on the EU as a Crisis

Management Actor:

An Examination of the Common

Security and Defence Policy through

the Lenses of Idealism and Realism

MGSoG Dissertation Series, № 10

\section{Judit Vall Castello}

Business Cycle and Policy Effects on Labour Market Transitions of Older and Disabled Workers in Spain

MGSoG Dissertation Series, № 9

\section{Keetie Roelen}

False Positives or Hidden Dimensions:

The Definition and Measurement of

Child Poverty

MGSoG Dissertation Series, № 8

\section{Denisa Maria Sologon}

Earning Dynamics in Europe

MGSoG Dissertation Series, № 7

\section{Melissa Siegel}

Money and Mobility: Migration and

Remittances

MGSoG Dissertation Series, № 6

\section{Jessica S. Hagen-Zanker}

Modest Expectations: Causes and

Effects of Migration on Migrant

Households inSource Countries

MGSoG Dissertation Series, № 5

2009

\begin{abstract}
Alexis Habiyaremye
From Primary Commodity Dependence to Diversification and Growth:

Absorptive Capacity and Technological Catch Up in Botswana and Mauritius. UNU-MERIT Dissertation Series, № 60
\end{abstract}

\section{Yoseph Getachew}

The Role of Public Capital in Economic Development

UNU-MERIT Dissertation Series, № 59

\section{Sandra Leitner}

Embodied Technological Change and Patterns of Investment in Austrian Manufacturing

UNU-MERIT Dissertation Series, № 58

\section{Semih Akçomak}

The Impact of Social Capital on Economic and Social Outcomes UNU-MERIT Dissertation Series, № 57 


\section{Abraham Garcia}

The Role of Demand in Technical

Change

UNU-MERIT Dissertation Series, № 56

\section{Saurabh Arora}

Coherence in Socio-technical Systems:

A Network Perspective on the

Innovation Process

UNU-MERIT Dissertation Series, № 55

\section{Mirtha R. Muniz Castillo}

Human Development and Autonomy in Project Aid: Experiences from four bilateral projects in Nicaragua and $\mathrm{El}$ Salvador

MGSoG Dissertation Series, № 4

\section{Christiane Arndt}

Governance Indicators

MGSoG Dissertation Series, № 3

\section{Britta Augsburg}

Microfinance: Greater Good or Lesser

Evil?

MGSoG Dissertation Series, № 2

\section{8}

\section{Rutger Daems}

Medicines for the Developing World UNU-MERIT Dissertation Series, № 54

\section{Johannes Hanel}

Assessing Induced Technology:

Sombart's Understanding of Technical

Change in the History of Economics

UNU-MERIT Dissertation Series,

№ 53

\section{Rifka Weehuizen}

Mental Capital: the Economic

Significance of Mental Health

UNU-MERIT Dissertation Series, № 52

\section{Danielle Cloodt}

The Relationship between RED

Partnership Formation, Social

Embeddedness and Innovative

Performance

UNU-MERIT Dissertation Series, № 51

\section{Sabine Fuss}

Sustainable Energy Development under Uncertainty

UNU-MERIT Dissertation Series, № 50

\section{Geranda Notten}

Measuring and Managing Poverty

Risks

MGSoG Dissertation Series, № 1

2007

\section{Tobias Kronenberg}

Reconciling Environmental

Conservation with Economic

Prosperity: The Feasibility of Double

Dividends in the Short and Long Run

UNU-MERIT Dissertation Series, № 49 


\section{Viktoria Kravtsova}

Assessing the Impact of Foreign Direct Investment in Transition Economies UNU-MERIT Dissertation Series, № 48

\section{Suhail Sultan}

The Competitive Advantage of Small and Medium Sized Enterprises: The Case of Jordan's Natural Stone

Industry

UNU-MERIT Dissertation Series, № 47

2006

\section{Bulat Sanditov}

Essays on Social Learning and Imitation

UNU-MERIT Dissertation Series, № 46

\section{Mamata Parhi}

Dynamics of New Technology Diffusion: A Study of the Indian Automotive Industry UNU-MERIT Dissertation Series, № 45

\section{Andreas Reinstaller}

Social Structures and the Innovation Process: Their Role in the Demand of Firms and Consumers

UNU-MERIT Dissertation Series, № 44

\section{Rose Kiggundu}

Innovation systems and Development: The Journey of a Beleaguered Nile Perch Fishery in Uganda UNU-MERIT Dissertation Series, № 43

\section{Thomas Pogue}

The Evolution of Research Collaboration in South African Gold Mining: 1886-1933

UNU-MERIT Dissertation Series, № 42

\section{Geoffrey Gachino}

Foreign Direct Investment, Spillovers and Innovation: The Case of Kenyan Manufacturing Industry UNU-MERIT Dissertation Series, № 41

\section{Önder Nomaler}

Technological Change, International Trade and Growth: An Evolutionary, Multi-Agents-Based Modeling Approach UNU-MERIT Dissertation Series, № 40

\section{5}

\section{Samia Satti Osman Mohamed- Nour \\ Change and Skill Development in the Arab Gulf Countries \\ UNU-MERIT Dissertation Series, № 39}




\section{Elad Harison}

Intellectual Property Rights:

Economics and Policy Analysis

UNU-MERIT Dissertation Series, № 38

\section{Daniel Dalohoun}

The Relationship between RED

Partnership Formation, Social

Embeddedness and Innovative

Performance: a Multi-level Approach of Social Embeddedness

UNU-MERIT Dissertation Series, № 37

\section{Müge Ozman}

Networks, Organizations and

Knowledge

UNU-MERIT Dissertation Series, № 36

\section{Bas Straathof}

Product Variety and Economic

Growth: The Counteracting Effects of

Scale and Idiosyncrasy

UNU-MERIT Dissertation Series, № 35

\section{Wilfred Schoenmakers}

Knowledge Flows between

Multinational Companies: A Patent

Data Analysis

UNU-MERIT Dissertation Series, № 34

\section{Myriam Cloodt}

Mergers and Acquisitions ( $M$ and As) in High-Tech Industries: Measuring the Post-M and A Innovative Performance of Companies UNU-MERIT Dissertation Series, № 33

\section{4}

\section{Paola Criscuolo}

$R \mathcal{E D}$ Internationalisation and Knowledge Transfer: Impact on MNEs and their Home Countries

UNU-MERIT Dissertation Series, № 32

\section{Maarten Verkerk}

Trust and Power on the Shop Floor UNU-MERIT Dissertation Series, № 31

\section{Gottfried Leibbrandt}

Adoption, Harmonization and Succession of Network Technologies across Countries

UNU-MERIT Dissertation Series, № 30

\section{Mark Sanders}

Skill Biased Technical change: Its Origins, the Interaction with the Labour Market and Policy Implications UNU-MERIT Dissertation Series, № 29 


\section{Bastiaan Johan terWeel}

The Computerization of the Labour Market

Inter-firm Cooperation in High-tech

Industries: a Study of RED

Partnerships in Pharmaceutical

Biotechnology

UNU-MERIT Dissertation Series, № 28

\section{Viki Sonntag}

Speed, Scale and Sustainability

UNU-MERIT Dissertation Series, № 27

\section{Masaru Yarime}

From End-of-Pipe Technology to Clean Technology

UNU-MERIT Dissertation Series, № 26

\section{Stéphane Malo}

The Combinatorial Chemistry

Revolution: Sustaining a Superior

Performance Position through

Technological Learning

UNU-MERIT Dissertation Series,

№ 25

2002

\section{Annelies Hogenbirk}

Determinants of Inward Foreign

Direct Investment: the Case of the

Netherlands

UNU-MERIT Dissertation Series, № 24
UNU-MERIT Dissertation Series

2001

\section{John Adeoti}

Technology Investment in Pollution Control in Sub-Saharan Africa: The Case of the Nigerian Manufacturing Industry

UNU-MERIT Dissertation Series, № 23

\section{Edward Huizenga}

Innovation Management: How

Frontrunners Stay Ahead: An

Empirical Study on Key Success

Factors in the ICT sector

UNU-MERIT Dissertation Series, № 22

2000

\section{Machiel van Dijk}

Technological Change and the Dynamics of Industries: Theoretical Issues and Empirical evidence from Dutch Manufacturing UNU-MERIT Dissertation Series, № 21

1999

\section{Jan Cobbenhagen}

Managing Innovation at the Company Level: A Study on Non-Sector-Specific Success Factors UNU-MERIT Dissertation Series, № 20 
Marjolein Caniëls

Regional Growth Differentials: The

Impact of Locally Bounded Knowledge

Spillovers

UNU-MERIT Dissertation Series, № 19

1998

\begin{abstract}
Aldo Geuna
Resource Allocation and Knowledge production: Studies in the Economics of University Research UNU-MERIT Dissertation Series, № 18
\end{abstract}

1996

\section{Reinoud Joosten}

Dynamics, Equilibria, and Values UNU-MERIT Dissertation Series, № 17

\section{Hugo Kruiniger}

Investment, $R \mathcal{E} D$, and the Financing

Decisions of the Firm

UNU-MERIT Dissertation Series, № 16

\section{5}

\section{Hans van Meij1}

Endogenous Technological Change:

The Case of Information Technology,

Theoretical Considerations and

Empirical Results

UNU-MERIT Dissertation Series, № 15

\section{René Kemp}

Environmental Policy and Technical

Change: A Comparison of the

Technological Impact of Policy

Instruments

UNU-MERIT Dissertation Series, № 14

\section{Rohini Acharya}

The Impact of New Technologies on Economic Growth and Trade: A Case Study of Biotechnology

UNU-MERIT Dissertation Series, № 13

\section{Geert Duysters}

The Evolution of Complex Industrial Systems: The Dynamics of Major IT Sectors

UNU-MERIT Dissertation Series, № 12

\section{Marjan Groen}

Technology, Work and Organisation: A Study of the Nursing Process in Intensive Care Units

UNU-MERIT Dissertation Series, № 11

\section{4}

\section{Huub Meijers}

On the Diffusion of Technologies in a Vintage Framework: Theoretical Considerations and Empirical Results UNU-MERIT Dissertation Series, № 10 
Theon van Dijk

The Limits of Patent Protection: Essays on the Economics of Intellectual

Property Rights

UNU-MERIT Dissertation Series, № 9

\section{Hans Voordijk}

Naar Integrale Logistiek in

Bedrijfsketens: Ontwikkelingen in de Bouw

UNU-MERIT Dissertation Series, № 8

1993

\section{Paul Diederen}

Technological Progress in Enterprises and Diffusion of Innovation:

Theoretical Reflections and Empirical

Evidence

UNU-MERIT Dissertation Series, № 7

\section{Ben Dankbaar}

Economic Crisis and Institutional Change: The Crisis of Fordism from the Perspective of the Automobile Industry UNU-MERIT Dissertation Series, № 6

\section{Hanno Roberts}

Accountability and Responsibility: The Influence of Organisation Design on Management Accounting UNU-MERIT Dissertation Series, № 5
1992

\section{Bart Verspagen}

Uneven Growth between

Interdependent Economies: An

Evolutionary View on Technology

Gaps, Trade and Growth

UNU-MERIT Dissertation Series,

№ 4

\section{Sjoerd Romme}

A Self-organization Perspective on

Strategy Formation

UNU-MERIT Dissertation Series, № 3

\section{9}

\section{John Spangenberg}

Economies of Scale, and Atmosphere in Research Organisations UNU-MERIT Dissertation Series, № 2

1988

\section{John Hagedoorn}

Evolutionary and Heterodox Innovation Analysis: A Study of Industrial and Technological Development in Process Control and Information Technology UNU-MERIT Dissertation Series, № 1 



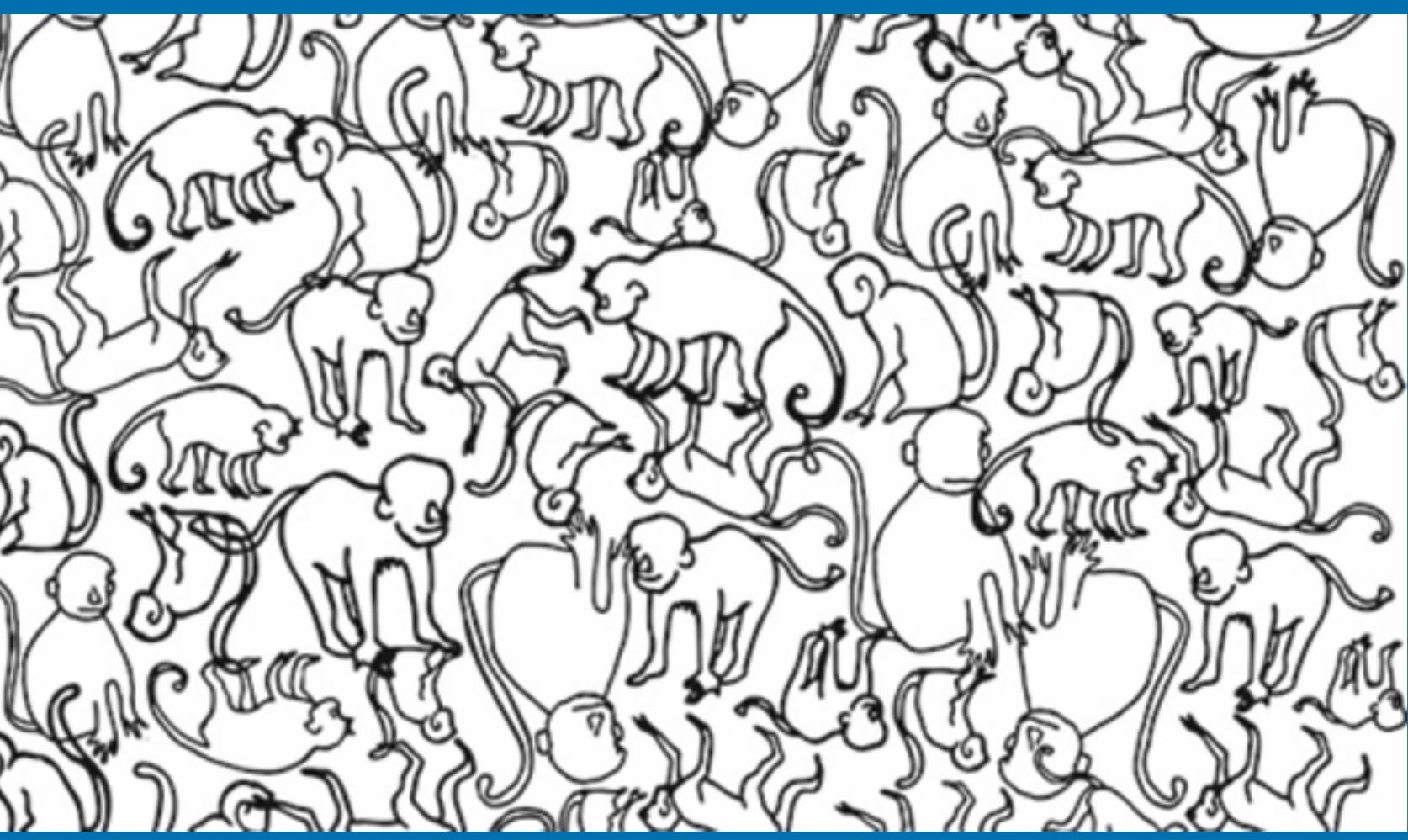

